Universidad de Lima

Facultad de Ciencias Empresariales y Económicas

Carrera de Administración

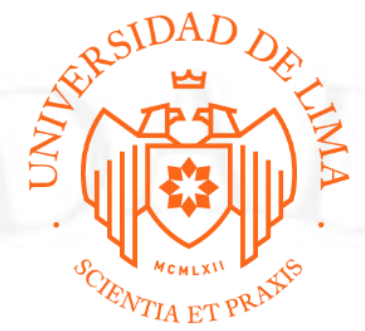

\title{
PLAN DE NEGOCIOS PARA IMPLEMENTAR UNA EMPRESA DE SERVICIOS DE MINDFULNESS
}

Trabajo de investigación para optar el Título Profesional de Licenciado en

Administración

Consuelo Chauny Schirmer

Código 20102288

Marcié Paloma Vigil Gasco

Código 20113144

\section{Asesor}

Alberto Enrique Matto Cáceres

$$
\text { Lima - Perú }
$$

Febrero de 2019 


\section{PLAN DE NEGOCIOS PARA IMPLEMENTAR UNA EMPRESA DE SERVICIOS DE MINDFULNESS}




\section{TABLA DE CONTENIDO}

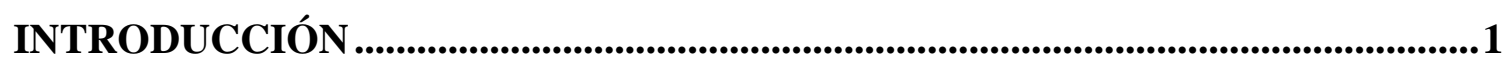

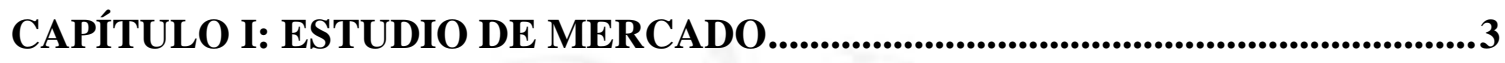

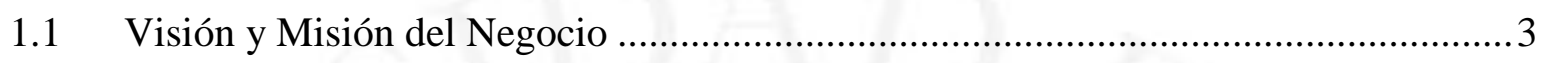

1.2 El producto, definición y posicionamiento .........................................................

1.3 Evaluación y determinación del mercado objetivo ...............................................

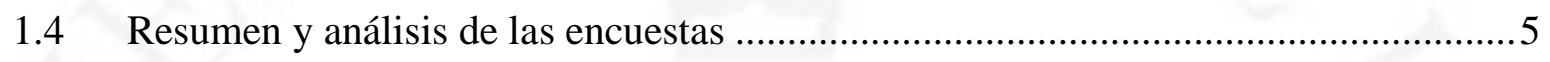

1.5 Resumen y análisis de las entrevistas........................................................ 20

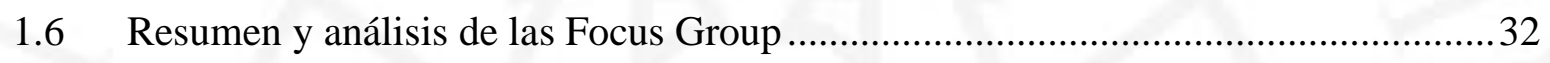

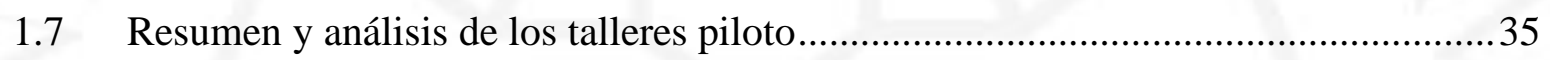

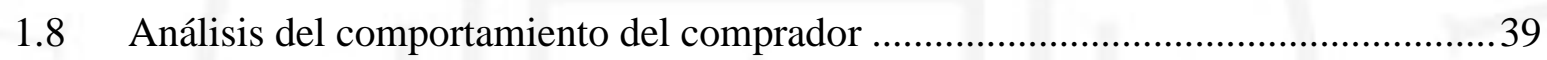

$1.9 \quad$ Análisis de los competidores (oferta) ......................................................... 41

1.10 Estrategias de distribución que se usan actualmente en la competencia...................41

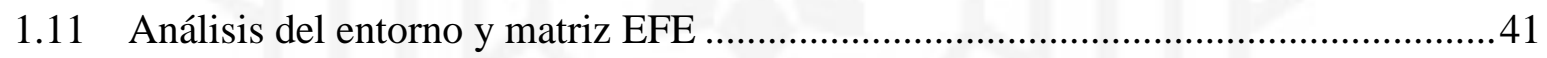

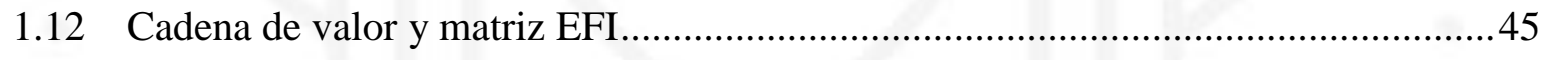

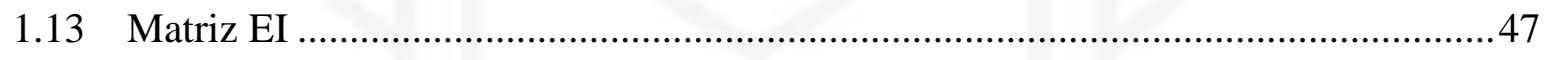

1.14 Determinación de la estrategia genérica.........................................................50

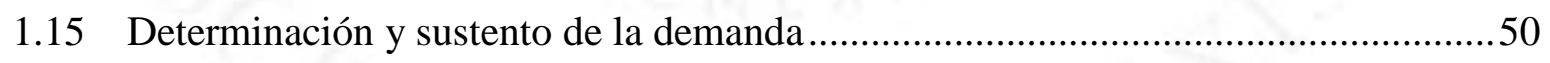

1.16 Determinación de la participación y sustento de la demanda ..................................52

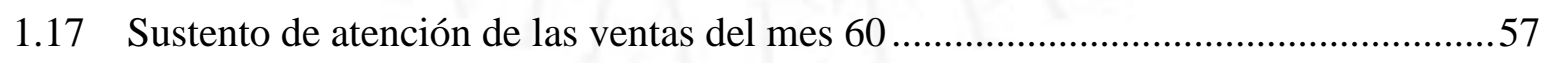

1.18 Análisis de la intensidad de y calidad de la publicidad y promoción ......................57

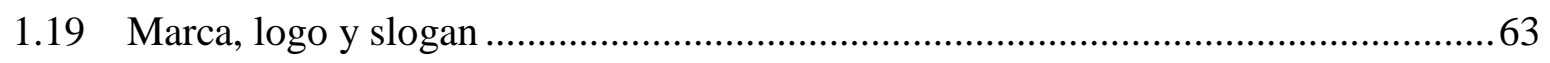

CAPÍTULO II: INGENIERIA DEL PROYECTO .................................................6

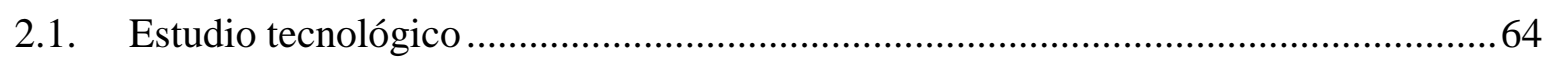


2.1.1. El producto, Visión técnica y logística

2.1.2. El proceso de producción y selección de la tecnología.......................................65

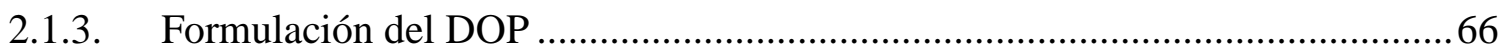

2.1.4. Formulación del programa de producción ........................................................6 68

2.1.5. Requerimientos productivos: equipos, materia prima, insumos y otros recursos

2.2. Tamaño de planta

2.2.1. Determinación de la capacidad de planta necesaria

2.2.2. Determinación del área de producción necesaria

2.3. Evaluación del impacto ambiental

2.3.1. Normas técnicas a ser aplicadas

2.3.2. Evaluación del proyecto dentro del impacto ambiental .70

2.4. Localización de planta. .71

2.4.1. Factores y análisis de éstos .71

2.4.2. Búsqueda y Evaluación de las ubicaciones candidatas.....................................72

2.4.3. Determinación de la localización de planta ........................................................ 73

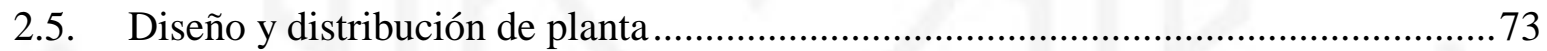

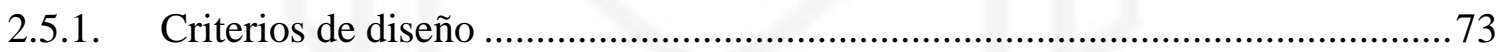

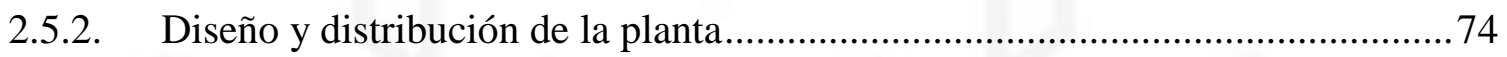

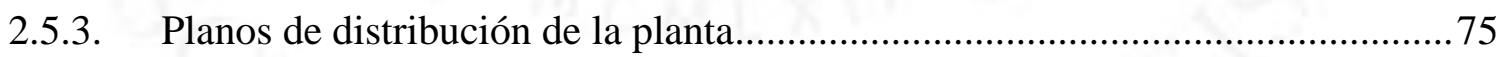

\section{CAPÍTULO III: ASPECTOS ADMINISTRATIVOS, ORGANIZATIVOS Y}

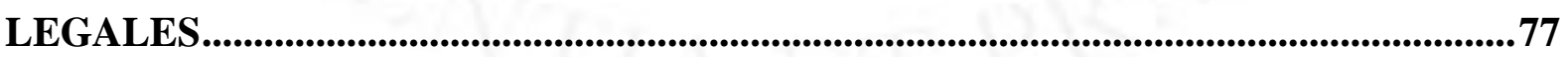

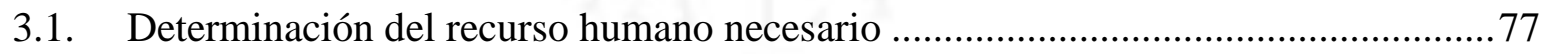

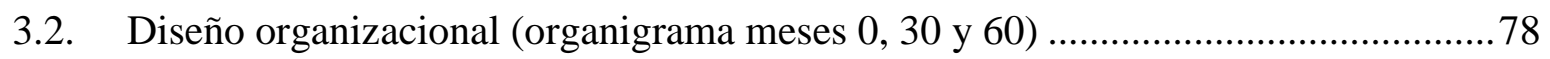

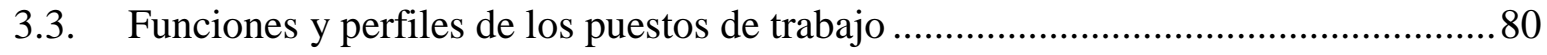

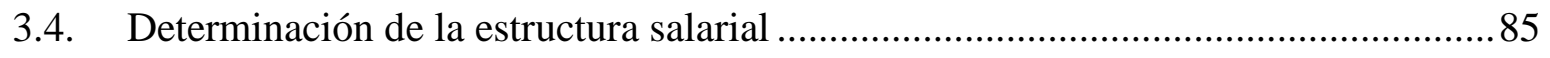

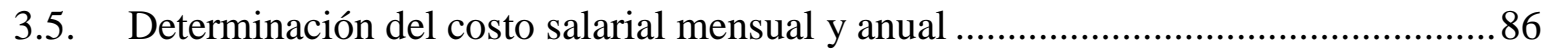


3.6. Políticas administrativas.

3.7. Minuta de Constitución de la empresa y marco legal ...............................................89

CAPÍTULO IV: PLANEAMIENTO ........................................................................97

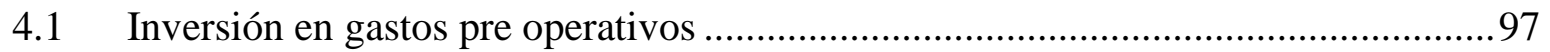

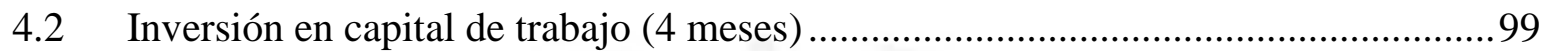

4.3 Inversión en activos fijos e intangibles en el periodo pre operativo ........................ 100

4.4 Resumen de las inversiones totales iniciales .................................................... 102

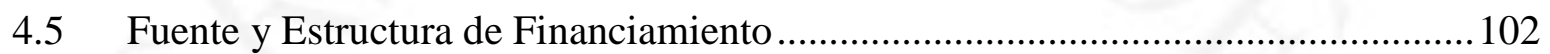

4.6 Cronograma de nuevas inversiones en activos fijos e intangibles (3er año)........... 103

4.6.1 Criterios y ppto. anual de depreciación de activos fijos e intangibles .............. 107

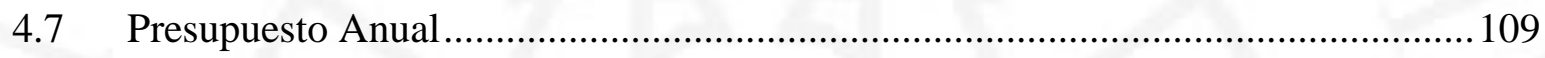

4.7.1 Pptos. de ventas en unidades y en soles .......................................................... 109

4.7.2 Ppto. de producción en unidades ............................................................... 110

4.7.3 Pptos. de consumo de materiales, insumos, etc. en unidades y soles ..............112

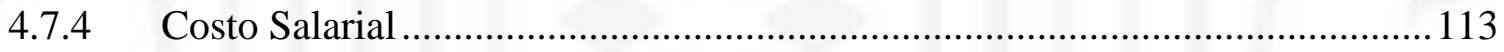

4.7.5 Pptos. de gastos de luz, agua, teléfono, limpieza, seguridad, impuesto predial, etc 115

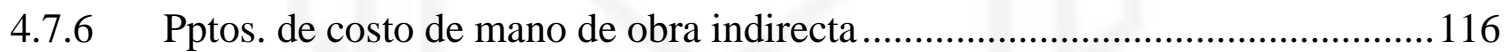

4.7.7 Pptos. de gastos indirectos de producción ........................................................116

4.7.8 Pptos. de costos indirectos de producción ........................................................ 117

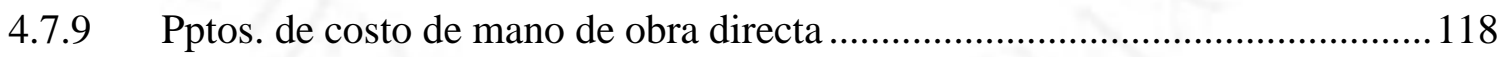

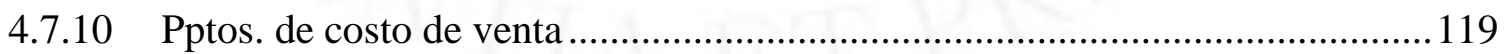

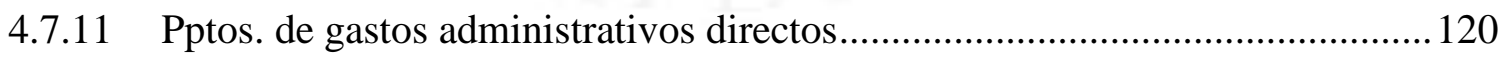

4.7.12 Pptos. de gastos de mano de obra administrativa ........................................ 121

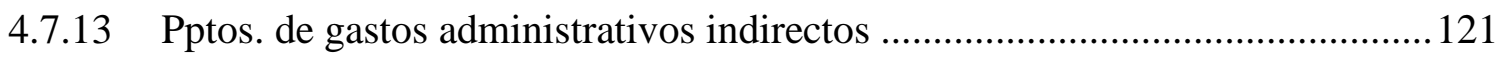

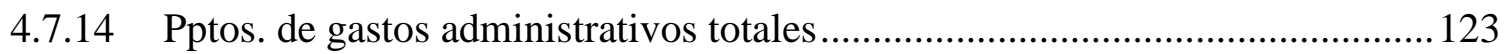




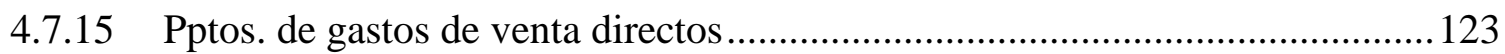

4.7.16 Pptos. de gastos para personal de ventas ..................................................... 124

4.7.17 Pptos. de gastos de venta indirectos............................................................... 125

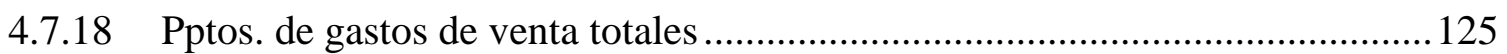

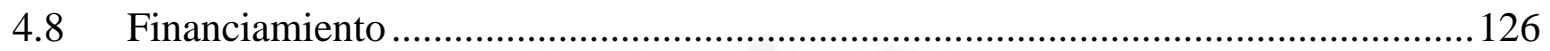

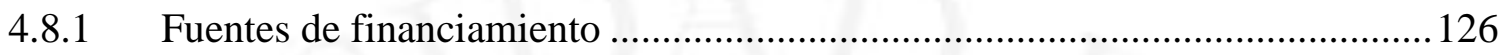

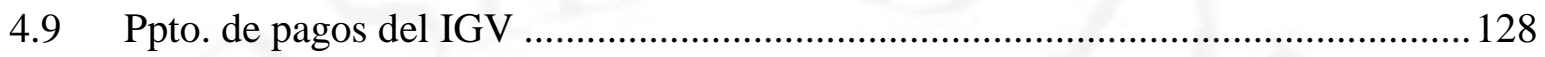

CAPÍTULO V: ESTADOS FINANCIEROS ....................................................129

5.1. Ppto. de Estado de Resultados o Ganancias y Pérdidas .......................................... 129

5.2 Ppto. anual de las utilidades retenidas, capitalizadas, pasadas a reserva técnica y

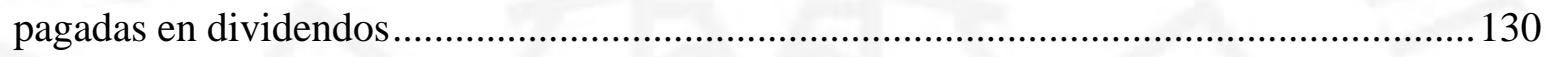

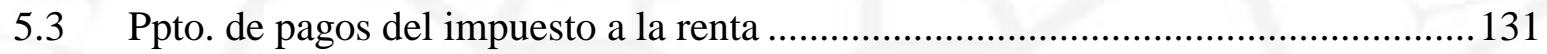

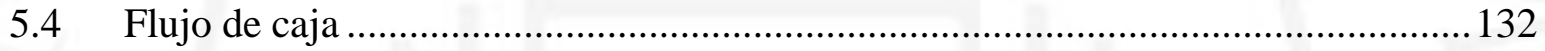

5.5 Ppto. de Situación Financiera o Balance General .................................................. 134

CAPÍTULO VI: ANALISIS Y EVALUACION DEL PROYECTO ........................137

6.1. Cálculo de las tasas para evaluación del proyecto ............................................... 137

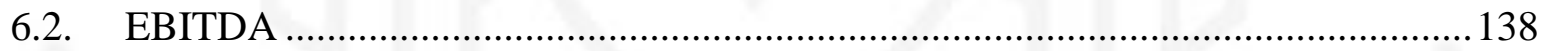

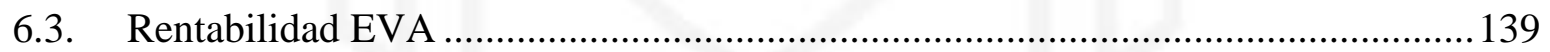

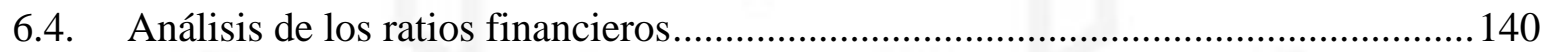

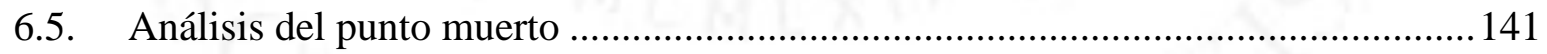

6.6. Flujo de la caja económica (desde la UN, UO y Vtas) ......................................... 142

6.7. Evaluación del VAN y TIR Económico........................................................... 142

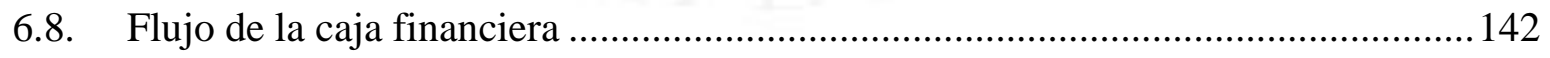

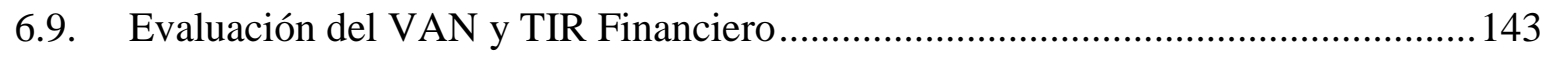

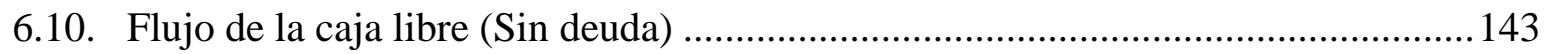

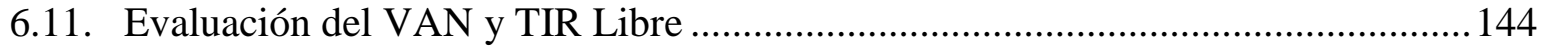




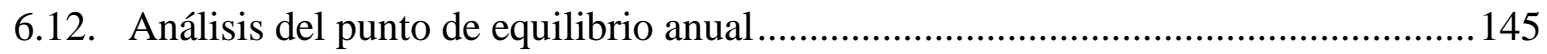

CAPÍTULO VII: SIMULACION Y SENSIBILIDAD................................................146

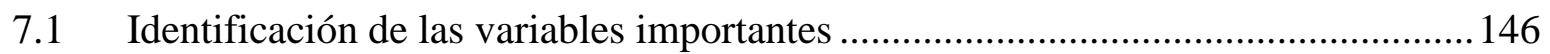

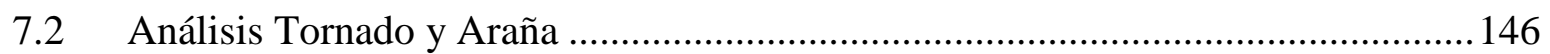

7.3 Determinación de las variaciones porcentuales de las variables importantes en cada

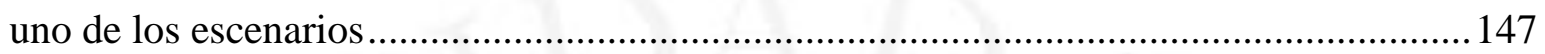

7.4 Evaluación económica y financiera de cada escenario ........................................ 148

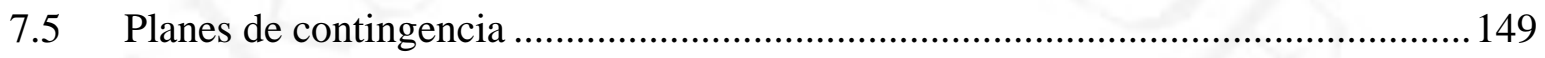

CONCLUSIONES .................................................................................................................. 150

RECOMENDACIONES ................................................................................................ 151

REFERENCIAS BIBLIOGRAFICAS ...................................................................152 


\section{ÍNDICE DE TABLAS}

Tabla 1.1 Medidas para el cálculo del tamaño muestral .................................................. 6

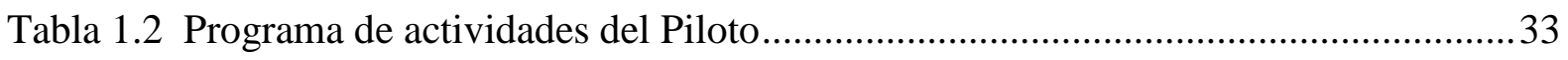

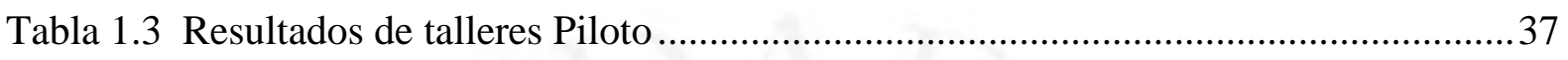

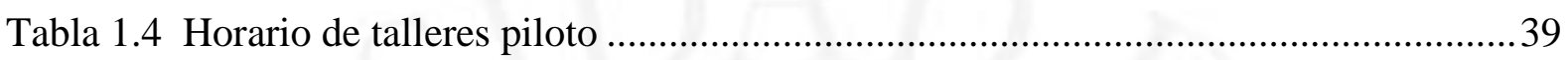

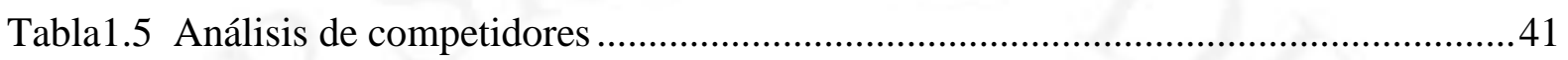

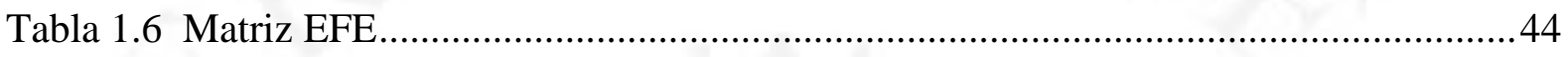

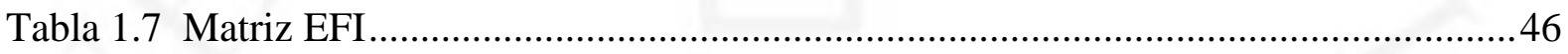

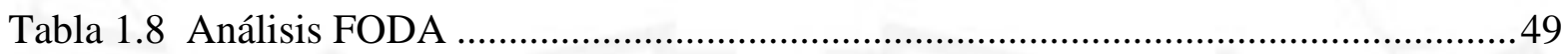

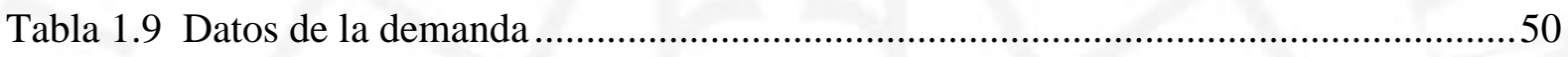

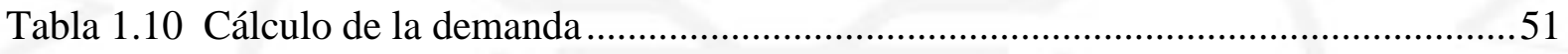

Tabla 1.11 Participación y sustento de la demanda .............................................................52

Tabla 1.12 Participación y crecimiento por año ……........................................................53

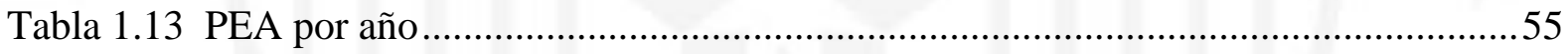

Tabla 1.14 Demanda valorizada en unidades y soles ......................................................56

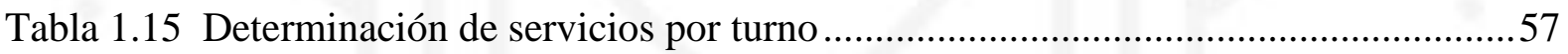

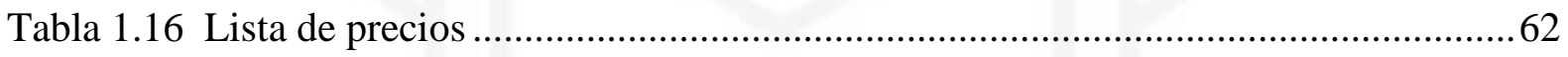

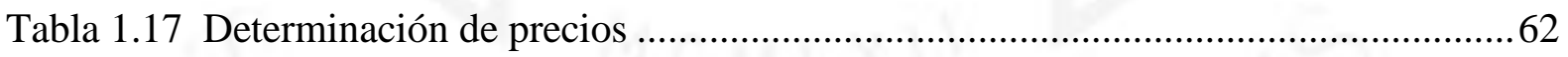

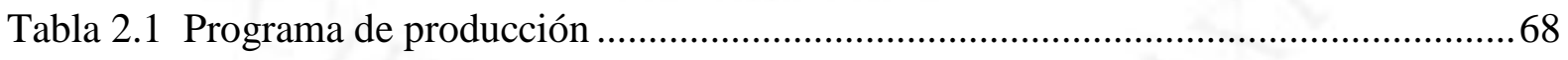

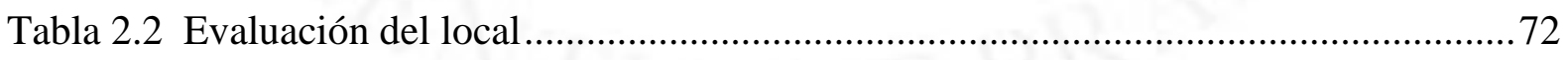

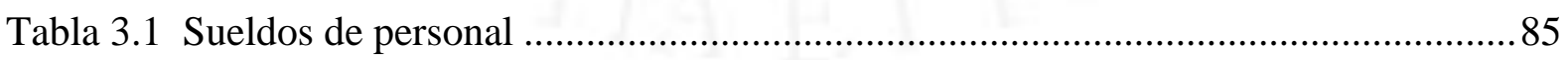

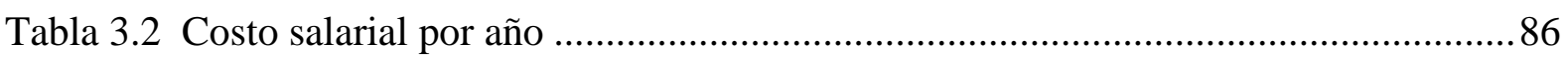

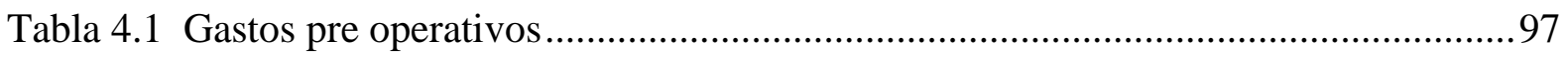

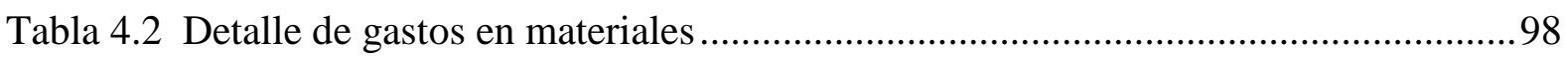

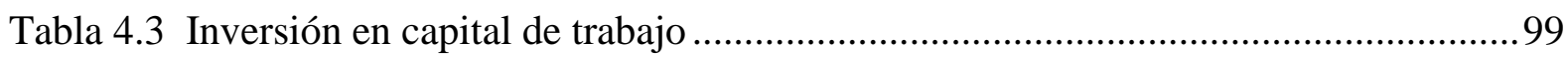


Tabla 4.4 Inversión en equipos de producción 100

Tabla 4.5 Inversión en activos fijos e intangibles 101

Tabla 4.6 Resumen de inversiones totales 102

Tabla 4.7 Estructura de financiamiento 102

Tabla 4.8 Nuevas inversiones de activos fijos 103

Tabla 4.9 Renovación de activos fijos tangibles (3er año) 104

Tabla 4.10 Renovación de activos fijos intangibles (3er año) 105

Tabla 4.11 Ampliación de capacidad de producción y venta 105

Tabla 4.13 Criterios y ppto anual de depreciación de activos fijos 107

Tabla 4.14 Criterios y ppto. anual de activos intangibles 108

Tabla 4.15 Proporción de ventas y precio del servicio 109

Tabla 4.16 Cantidad de servicios vendidos por año 109

Tabla 4.17 Cantidad de servicios valorizado en soles 110

Tabla 4.18 Proporción de servicios y costo de materiales 110

Tabla 4.19 Cantidad de servicios producidos por año 111

Tabla 4.20 Presupuesto de materiales utilizados por año

Tabla 4.21 Presupuesto de materiales operativos

Tabla 4.22 Detalle de costos de planilla total

Tabla 4.23 Cantidad de especialistas por año

Tabla 4.24 Presupuesto de gastos en servicios públicos. 115

Tabla 4.25 Proporción de gastos en servicios públicos 115

Tabla 4.26 Sueldos de mano de obra indirecta 116

Tabla 4.27 Gastos indirectos de producción 116

Tabla 4.28 Costos indirectos de producción 118

Tabla 4.29 Sueldos de mano de obra directa 118

Tabla 4.30 Costo de producción valorizado en soles 
Tabla 4.31 Servicios producidos y vendidos

Tabla 4.32 Costo de venta.

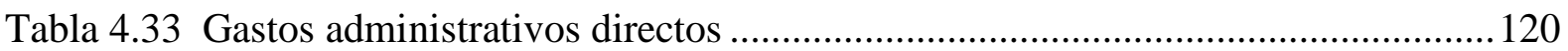

Tabla 4.34 Gastos de mano de obra administrativa ........................................................ 121

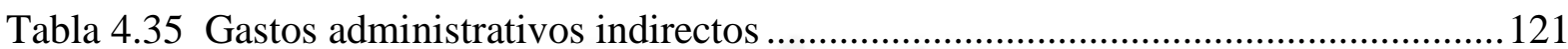

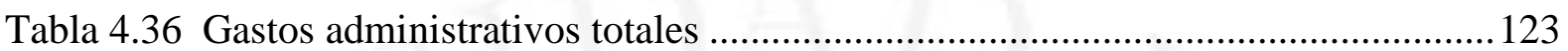

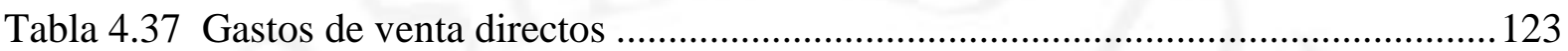

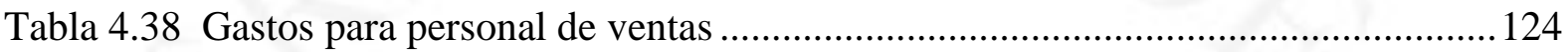

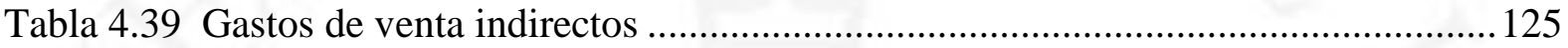

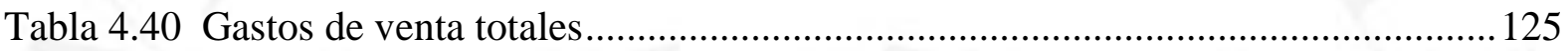

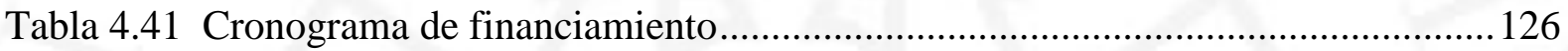

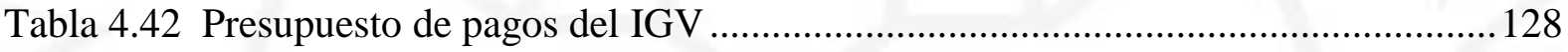

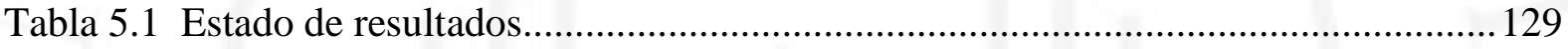

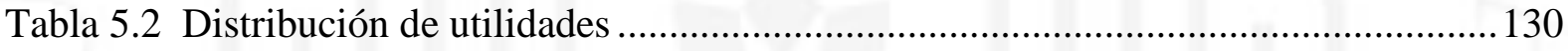

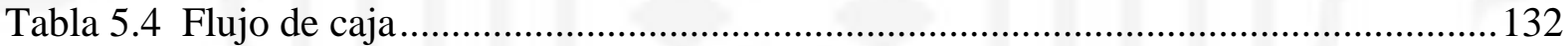

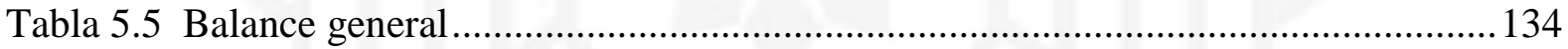

Tabla 6.1 Cálculo de tasas para evaluación de proyecto ................................................... 137

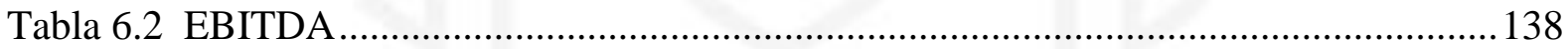

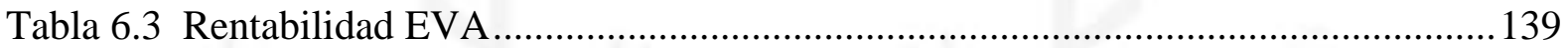

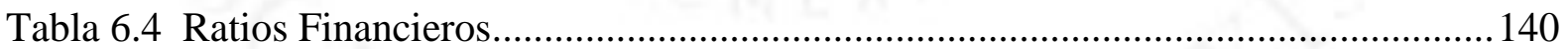

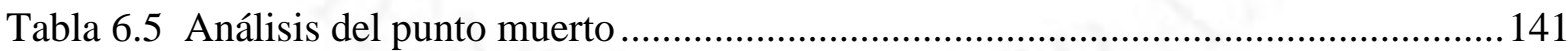

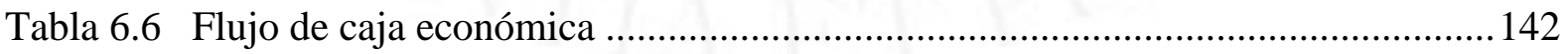

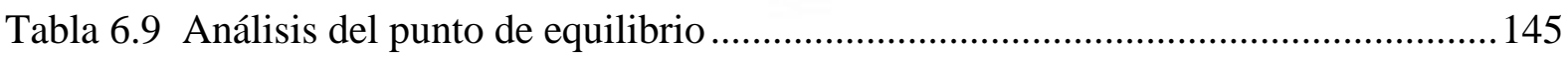

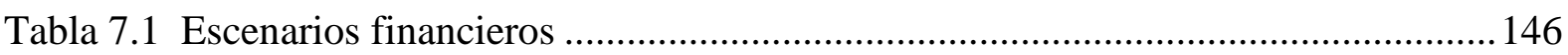

Tabla 7.2 Variaciones porcentuales en cada escenario ...................................................... 147 


\section{INDICE DE FIGURAS}

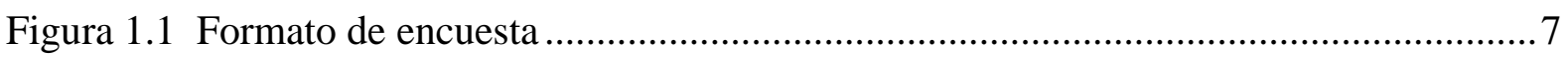

Figura 1.2 ¿Ha asistido alguna vez a un taller de bienestar? ............................................. 12

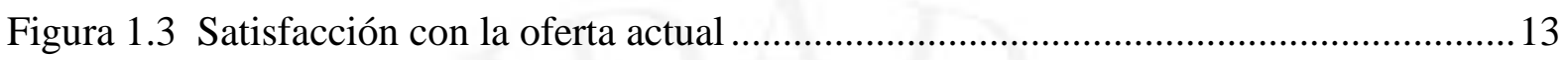

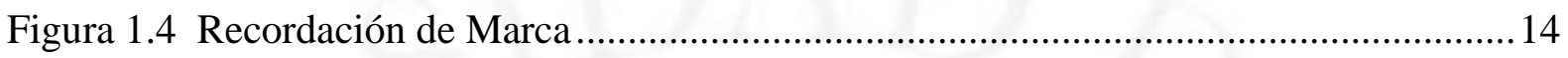

Figura 1.5 Precio que están dispuestos a invertir en su bienestar ...................................... 15

Figura 1.6 Valoraciones más relevantes del servicio..................................................... 15

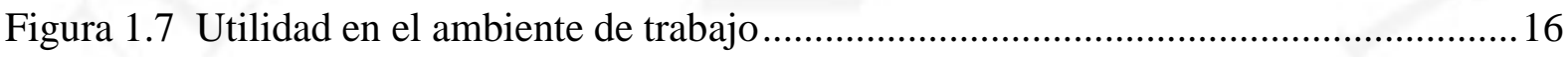

Figura 1.8 Percepcion de beneficio del servicio ........................................................... 16

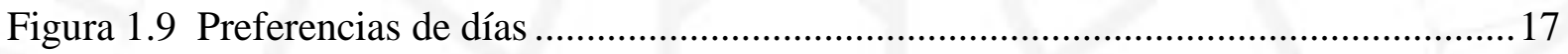

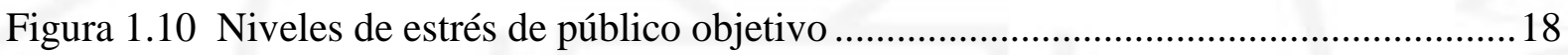

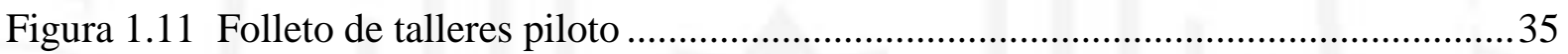

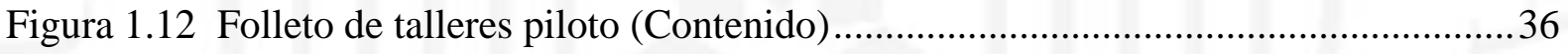

Figura 1.13 Resultados de satisfacción de talleres piloto ....................................................38

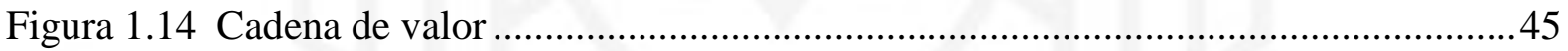

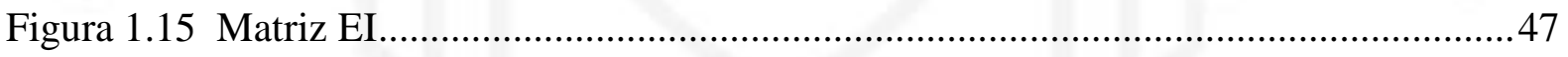

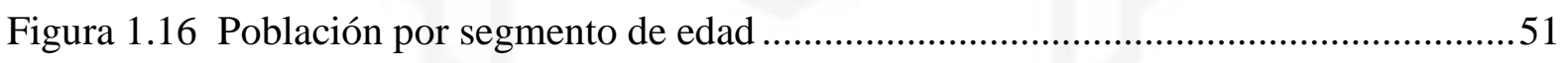

Figura 1.17 Evolución de la participación de mercado.......................................................53

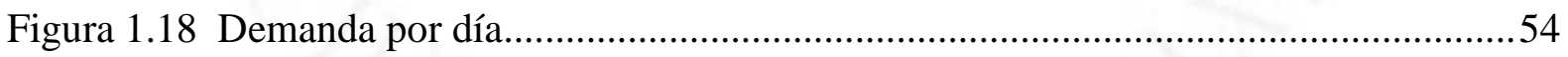

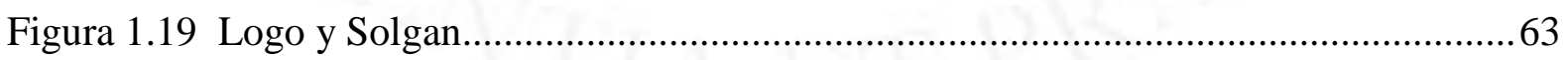

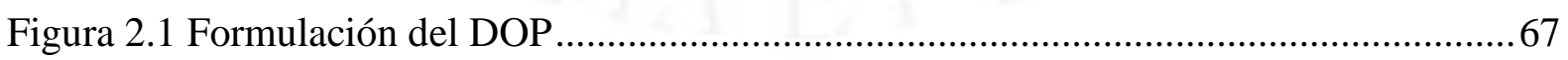

Figura 2.2 Ubicación geográfica del local …................................................................. 73

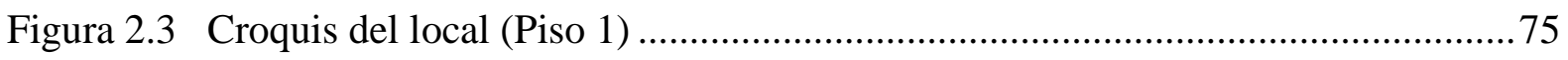

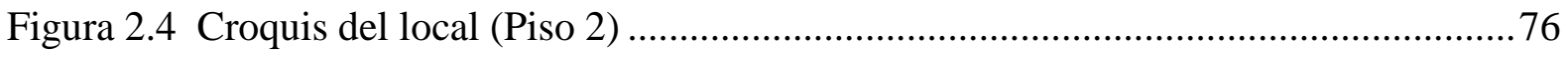

Figura 3.1 Diseño Organizacional (Mes 0) .............................................................. 78 


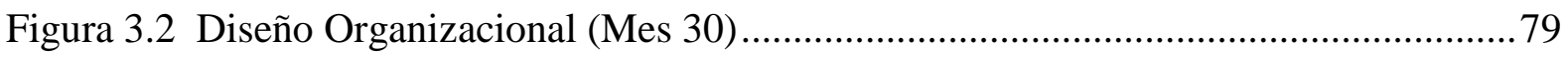

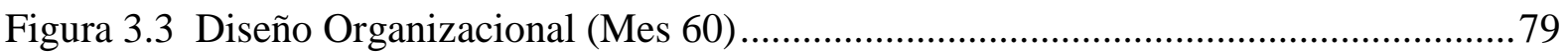

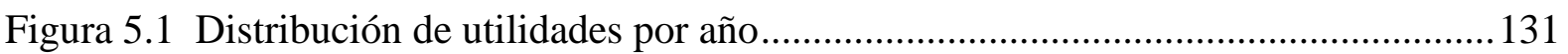

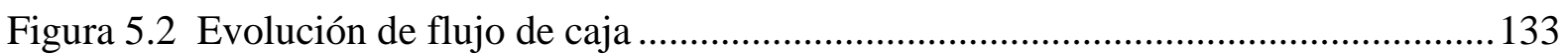

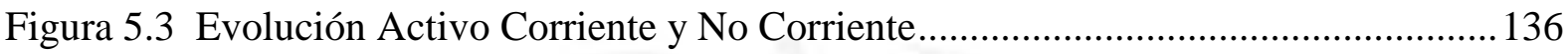

Figura 5.4 Evolución de Patrimonio y Pasivos ...................................................................... 136

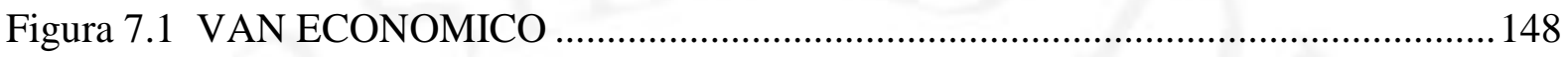

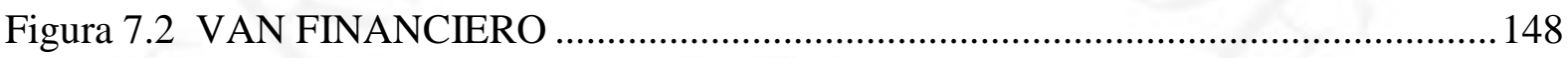

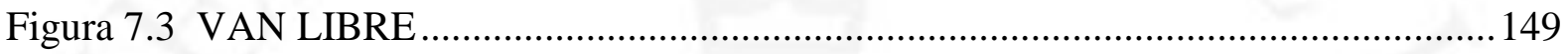




\section{ÍNDICE DE ANEXOS}

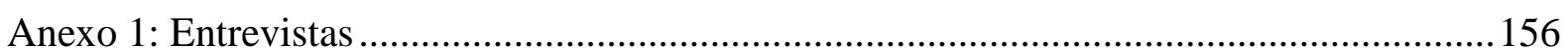

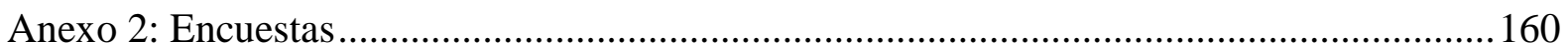

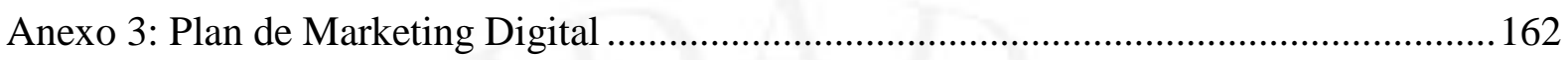

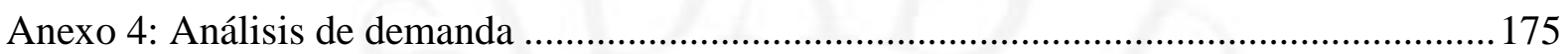




\section{INTRODUCCIÓN}

El siguiente plan de negocio busca evaluar:

"Evaluar la viabilidad y la rentabilidad de un negocio que mejore la salud física y mental de un público objetivo conformado por ejecutivos y profesionales dependientes e independientes de 20 a 60 años de NSE A - B en Lima Metropolitana en los distritos de Miraflores, San Isidro, San Borja, Surco y La Molina”.

La tesis responderá las siguientes preguntas:

1. ¿Cuál es el nivel de aceptación del servicio propuesto?

2. ¿Qué adaptaciones requiere el servicio propuesto?

3. ¿Existe una demanda para nuestro producto o servicio?

4. ¿Cuáles son nuestros competidores?

5. ¿Con qué estrategias nos acercaremos a nuestro público?

6. ¿Cómo comunicaremos nuestro producto o servicio?

7. ¿Cuál es nuestra estructura de costos e ingresos?

8. ¿El Negocio es viable y rentable?

A continuación, se detallan algunas definiciones básicas para el entendimiento de esta tesis:

- "El aquí y el ahora" como principio en la psicología Gestalt: consiste en cómo la persona se define en el ahora o en el presente mediante un estado de conciencia sin distracciones generadas por experiencias pasadas o pensamientos futuros.

- El Mindfulness es una prática que ayuda a controlar la mente, reconectar las emociones y circuitos cerebrales con el fin de estar enfocado plenamente en el presente, en el aquí y ahora.

- Bienestar: estado de satisfacción personal que considera aspectos positivos como la salud o el bienestar psico-biológico, el placer personal, el sentirse realizado por haber logrado alguna meta, etc. 
- Salud mental: estado de bienestar en el cual una persona es consciente de sus propias capacidades. Lo cual permite resolver cualquier problema que se pueda presentar, trabajar de forma productiva y ser capaz de aportar y contribuir a su comunidad.

- Autoconocimiento: es el conocimiento de uno mismo y del entorno para poder lograr una armonía y llegar al máximo de las capacidades. 


\section{CAPÍTULO I: ESTUDIO DE MERCADO}

\subsection{Visión y Misión del Negocio}

Visión: "Ser un referente en salud física y mental para la población que busca desarrollar sus habilidades en diferentes ámbitos profesionales".

Misión: "Ayudar a nuestros clientes a vivir una vida saludable creando un espacio donde encuentren bienestar".

\subsection{El producto, definición y posicionamiento}

\section{- El producto}

Según un estudio de Arellano Marketing (2017), la tendencia de la población peruana por preocuparse más por su salud y bienestar es creciente. Por esta razón, buscan productos y servicios que permitan mejorar la calidad de vida y disminuir el nivel de estrés. Esto se pudo ver reflejado en el presente estudio de mercado. El plan de negocio gira en torno a una propuesta que busca lograr un mejor estilo de vida, respondiendo a la necesidad actual del mercado. Esta propuesta es "Agora".

Agora es la marca que ofrece un servicio con dinámicas personalizadas. Estas dinámicas buscan mejorar en los clientes ciertas habilidades a través de herramientas y técnicas con las que se logre bienestar físico y mental. Por consiguiente, se busca mejorar el rendimiento de los clientes en diferentes aspectos de sus vidas.

El negocio depende de los siguientes tipos de especialistas: Psicólogo, Psiquiatra, Nutricionista, Sociólogo, Entrenador físico y Coach.

Para un primer acercamiento con el cliente, el grupo de especialistas debe:

1. Realizar un primer diagnóstico del cliente.

2. Realizar charlas con material didáctico.

3. Contar con el respaldo de investigaciones científicas que tangibilicen los beneficios y propuestas para desarrollar nuevas investigaciones con el equipo de Agora. 
Los temas a tratar son los siguientes:

$>$ Relaciones sociales (Sociólogo).

$>$ Relaciones Intrapersonales (Psicólogo / Psiquiatra).

$>$ Relación con lo global (Sociólogo).

$>$ Relación con el cuerpo (Nutricionista, Entrenador físico).

$>$ Relación con las emociones (Psicólogo, Psiquiatra).

Nuestra propuesta de valor se centra en hacer cursos vivenciales para el cliente, a través de dinámicas creadas con el objetivo de que experimenten, de forma individual y grupal, momentos cotidianos con un enfoque o percepción distinta. De esta forma, el servicio propuesto logra que el cliente tome una postura flexible y encuentre mecanismos que le permitan desarrollar sus capacidades. Esto permite que ellos estén dispuestos a recibir herramientas para iniciar el proceso de autoconomiento, siendo más conscientes de su entorno, lo cual genera que estén dispuestos a adoptar un estilo de vida que mejore su calidad de vida en lo laboral e interpersonal.

Es importante proyectar profesionalismo y cercanía para que el público objetivo se interese en asistir a talleres/cursos que representen un beneficio en su estilo de vida. Además, la connotación de ser un servicio intangible, es un reto en la comunicación y descripción del servicio, por esa razón, la marca debe contar con el respaldo de profesionales de la salud que reflejen un estilo de vida aspiracional para los clientes.

\section{- Posicionamiento}

Agora busca posicionarse en la mente de los consumidores peruanos como un espacio que desarrolla el autoconocimiento y habilidades personales. Un servicio personalizado que se adecua a los objetivos profesionales de los clientes.

\subsection{Evaluación y determinación del mercado objetivo}

En los últimos años la cantidad de personas que se preocupan por su salud física y mental es cada vez mayor. Esto se asocia a la tendencia de estilo de "Vida Sana" que busca equilibrar mente, cuerpo y alma, elevando los estados de conciencia. De esta manera, se espera que el incremento de esta población sea aún mayor en los próximos años. 
El perfil del peruano saludable según investigaciones de Arellano Marketing es:

- 25-44 años.

- $60 \%$ son hombres.

- Vida formal: ejecutivos y profesionales.

- Buena alimentación.

- Hacen deporte de manera regular.

- Buscan equilibrar trabajo y calidad de vida.

El público objetivo de nuestro servicio está conformado por hombres y mujeres de 2060 años, dándole énfasis a las mujeres, se postula esta idea como resultado de las entrevistas realizadas a especialistas en el rubro. Consideramos que tanto hombres como mujeres están interesados de manera proporcional al cuidado de su bienestar, ya que se toma en cuenta lo mencionado por Arellano (importante referente de estudios de mercado en el Perú) y el presente estudio de mercado mediante las encuestas.

Por otro lado, los niveles socioeconómicos objetivos serían los niveles A y B, debido a que la población en estos segmentos, a parte de tener un mayor poder adquisitivo, tiende a tener una mayor educación y por ello comprenden la necesidad de seguir desarrollándose. Entendemos que el público de NSE A y B tiene cubiertos las necesidades básicas de la pirámide de Maslow resueltas, y por ello puede y está dispuesto a invertir en necesidades menos básicas como la Autorrealización.

\subsection{Resumen y análisis de las encuestas}

Para determinar el tamaño de la muestra para la encuesta, se realizó el cálculo en base a una población infinita debido a que la población de Lima es mayor con respecto a las demás provincias del país. Para ello se utilizó la siguiente fórmula:

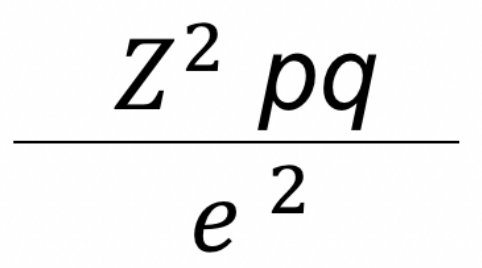


Con los datos de la Tabla 1.1, se pudo calcular un tamaño de muestra de 129 personas a las cuales se debía encuestar.

Tabla 1.1

Medidas para el cálculo del tamaño muestral

\begin{tabular}{c|c}
\hline Medida & Valor \\
\hline Probabilidad a favor (p) & $73.4 \%^{*}$ \\
Probabilidad en contra (q) & $26.6 \%^{*}$ \\
Error de muestreo (e) & $5.0 \%$ \\
Nivel de confianza o riesgo (Z) & $90 \%$ \\
Tamaño muestral (n) & $\mathbf{1 2 9}$ \\
\hline
\end{tabular}

Nota: Resultado de una encuesta tomada a 20 personas Elaboración propia

La encuesta constó de 35 preguntas que abarcaron como principales temas:

- Datos básicos.

- Niveles de estrés.

- Asistencia a un servicio similar al propuesta.

- Satisfacción de demanda con respecto a la oferta existente.

- Aceptación del servicio de nuestro proyecto.

- Precio que está dispuesto a pagar el cliente.

- Valoraciones del servicio más relevante.

- Utilidad del servicio.

- Redes sociales más utilizadas.

- Conocimiento de conceptos de bienestar.

Se realizaron un total de 131 encuestas. Esto significó un cumplimiento del 100\% de la cantidad de encuestas necesitadas para poder realizar el análisis del mercado objetivo.

El formato de encuesta fue el siguiente: 


\section{Figura 1.1}

Formato de encuesta

\section{Interés en el bienestar personal}

¡Hola! Nos encontramos investigando para un proyecto de la universidad. Ayúdanos con esta simple encuesta. Tu opinión nos importa. ¡Gracias!

*Obligatorio

1. Sexo*

Marca solo un óvalo.

Femenino

Masculino

2. Edad *

Marca solo un óvalo.

$\square$ Entre 18 y 25 años

Entre 26 y 30 años

Cntre 31-40 años

Entre 40-50 años

Mayores de 50 años

3. ¿En qué distrito vives? * Marca solo un óvalo.
Miraflores
Surco
San Isidro
La Molina
San Borja
Barranco
Otro

4. ¿Cuál es su situación actual? *

Marca solo un óvalo.

Estudiante de universidad

Trabajador independiente (horarios flexibles)

Trabajador dependiente (horario fijo)

Ama de casa

$\longrightarrow$ Jubilado

5. ¿Has asistido alguna vez a algún taller/curso/charla de meditación o de bienestar personal? * Marca solo un óvalo.

Sí, sólo una vez

$\bigcirc$ Nunca

Sí, más de una vez

Sí, con alta frecuencia

6. Si elegiste la opción "Nunca", ¿por qué?

Selecciona todas las opciones que correspondan.

No tengo tiempo

No me interesa

Me parecen muy caros

No creo que necesite nada relacionado a bienestar personal

No lo había considerado 
7. Si elegiste "Si", ¿cumplió tus expectativas? Marca solo un óvalo.

Sí, más de lo que esperaba

Sí, fue lo que esperaba

No

8. ¿Conoces alguna empresa que enseñe Mindfulness? ¿Cuál es el nombre de la

empresa? Si no conoces ninguna, pasa a la

siguiente sección.

9. ¿Cuál es el precio de los servicios de Mindfulness de la empresa que mencionas?

Te contamos un poco de qué trata nuestro proyecto:

Mindfulness es una filosofía de vida que incluye la práctica de la meditación, técnicas de relajación y el enfoque en la atención plena. Busca reducir el estrés y aprender a vivir en el "aquí y ahora". Consigue separar a la persona de sus pensamientos para poder reconocerlos y poner en duda los patrones mentales.

Nuestro negocio consta de un servicio que entrega herramientas y momentos experienciales que invitan a descubrir nuevas herramientas, a todo aquel que esté dispuesto, para vivir una vida con Mindfulness.

Ofrecemos este servicio tanto a los más pequeños como hasta adultos mayores.

Algunos de los beneficios de practicar Mindfulness son: reducción y prevención del estrés y la ansiedad, mejora el sistema inmunológico, ayuda a dormir mejor, a superar hábitos muy arraigados, desarrolla de inteligencia emocional, mejora las relaciones interpersonales, fomenta la creatividad y la innovación y mejora la calidad del liderazgo.

10. ¿Conocias que es el mindfulness? *

Marca solo un óvalo.

Sí

No

11. ¿Te interesaria participar en un taller Mindfulness? Puede consistir en un día o varios dias. * Marca solo un óvalo.

Sí

No

No sé

12. Si respondió "Si", valore las siguientes características de un taller al cual le gustaria participar (siendo 1: menos importante y 4 : muy importante)

Marca solo un óvalo por fila.

1- Menos importante
Precio
Teoría científica
Ubicación
Cararios
Experión del taller del servicio


13. ¿Cuánto estarias dispuesto a invertir en su bienestar personal por mes? * Marca solo un óvalo.

No estaria dispuesto a invertir
Hasta S/ 200
Entre S/ 201 - S/ 350
Entre S/ 351 - S/ 400
Entre S/ 401 - S/ 500
Más de S/ 500

Cuéntanos un poco sobre cómo te sientes en general:

14. ¿Duermes mal o de manera irregular? * Marca solo un óvalo.

$\begin{array}{lllll}1 & 2 & 3 & 4 & \\ \text { Nunca } & \square & & \\ & \square & & \end{array}$

15. ¿Te sientes irritable? * Marca solo un óvalo.

$\begin{array}{lllll}1 & 2 & 3 & \\ \text { Nunca } \square & \square & \end{array}$

16. ¿Tienes dificultades para poder concentrarte? * Marca solo un óvalo.

$\begin{array}{lllll}1 & 2 & 3 & \\ \text { Nunca } & \square & & \\ & \square & \end{array}$

17. ¿Sientes exceso o falta de apetito? Marca solo un óvalo.

$\begin{array}{lllll}1 & 2 & 3 & 4 & \\ \text { Nunca } & \square & & \end{array}$

Tenemos el interés de dar talleres de Mindfulness a través de unas clases virtuales. Cuéntanos un poco sobre lo siguiente:

18. ¿Cuáles de las siguientes redes sociales utilizas? (por lo menos 1 vez a la semana) * Selecciona todas las opciones que correspondan.
Facebook
Whatsapp
Youtube
Linkedin
Instagram
7 Twitter
Correo electrónico

$\square$ Otros:

19. ¿Te gustaría poder tener clases virtuales? * Marca solo un óvalo.

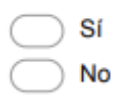

20. Si respondiste "Si", ¿Cuánto estarias dispuesto a pagar? (3-4 horas a la semana) \$=dólares Marca solo un óvalo.
Hasta $\$ 50$ mensuales
Entre \$ 100 - \$ 200 mensuales
Más de $\$ 200$ 
21. ¿Cuánto tiempo le podrías dedicar a este curso virtual por semana? Marca solo un óvalo.

Hasta 4 horas

Entre 5 y 7 horas

Más de 8

En este momento nos encontramos realizando talleres vivenciales de Mindfulness. Entregamos

herramientas que permiten disfrutar de beneficios como la reducción y prevención del estrés y la ansiedad, mejorar el sistema inmunológico, desarrollar la inteligencia emocional y todos aquellos que hemos mencionado anteriormente.

Contamos con un staff compuesto de psicólogos y coaches con amplia experiencia no sólo en Mindfulness sino en otros ámbitos que vuelven el curso una experiencia completa.

Nos gustaría saber si:

22. ¿Te interesaria meterte a un curso de Mindfulness con nosotros? Si respondiste "No", puedes finalizar la encuesta.

Marca solo un óvalo.

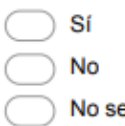

23. Si te encuentras interesado puedes dejar un correo o teléfono de contacto para que te enviemos información

24. ¿En qué horarios te gustaria asistir?

Marca solo un óvalo.

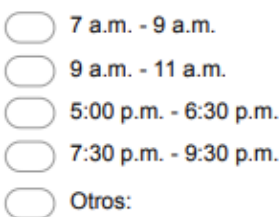

25. ¿Qué días te gustaria poder asistir?

Selecciona todas las opciones que correspondan.
$\square$ Lunes y Miércoles
Martes y Jueves
Fin de semana
Miércoles y Sábados
Otros:

26. ¿En qué sede preferirias asistir?

Marca solo un óvalo.

San Isidro

Miraflores

27. ¿Te gustaria que tu equipo de trabajo realizara este taller? Marca solo un óvalo.

$\longrightarrow \mathrm{Si}$

No 
28. ¿Crees que seria útil para el desempeño de tu trabajo?

Marca solo un óvalo.

No es útil

Útil

Bastante util

Muy útil

Imprescindible

29. ¿Crees que este taller sería valioso para tu vida personal?

Marca solo un óvalo.

No es valioso

Valioso

Bastante valioso

Muy valioso

Imprescindible

30. ¿Consideras que este tipo de taller podria ayudarte a ser más feliz? Marca solo un óvalo.

$\begin{array}{lll}1 & 2 & 3 \\ \text { En desacuerdo } & \longrightarrow & \\ & & \\ & & \end{array}$

Elaboración propia

A continuación, se realiza un análisis de las respuestas dadas por los encuestados.

El 76\% de los participantes fue de género femenino y el $24 \%$ masculino. La mayoría tenía entre 18 y 25 años de edad (30\%), seguido de personas mayores de 50 años (27\%), entre 26 y 30 años (16\%) y 31 y 40 años (16\%), y 40 a 50 años (11\%).

Específicamente sobre el rango de edad de las mujeres y hombres, se obtuvo la siguiente información respectivamente: $26 \%$ y $32 \%$ tenían entre 18 y 25 años de edad; el $6 \%$ y $23 \%$ entre 26 y 30 años; $8 \%$ y $23 \%$ entre 31 y 40 años; $14 \%$ y $6 \%$ entre 40 y 50 años; y, $26 \%$ y $16 \%$ tenía más de 50 años. Se puede visualizar un público jóven de 18 a 25 años con un $22 \%$ y mayores de 50 años con un 23\%. Sin embargo, si tenemos en cuenta a ejecutivos y profesionales, tenemos un total de $73 \%$ por contar con los encuestados de las edades de entre 18 y 50 años. Decidimos tomar en cuenta los encuestados de 18 a 25 años ya que el $59 \%$ de ese perfil es trabajador dependiente o independiente. 
Asimismo, el 76\% de los encuestados se encuentran laborando, de los cuales el $48 \%$ fueron trabajadores dependientes y el 28\% independientes. Los demás participantes son estudiantes (13\%), amas de casa $(8 \%)$ y jubilados $(2 \%)$.

En cuanto al distrito de residencia, la mayoría de encuestados residen en Miraflores (23\%), Surco (19\%), San Isidro (11\%), San Borja (9\%) y La Molina (7\%), sumando 69\%. La encuesta determinó entonces las preferencias de estos distritos. La descripción "Otro" (31\%) abarca todos los demás distritos con una participación que no consideramos relevante.

Respecto al perfil del cliente consumidor de servicios de bienestar, el 55\% de los encuestados han asistido al menos $1 \mathrm{vez}$ a un taller de bienestar personal (figura 1.2).

Figura 1.2

¿Ha asistido alguna vez a un taller de bienestar?

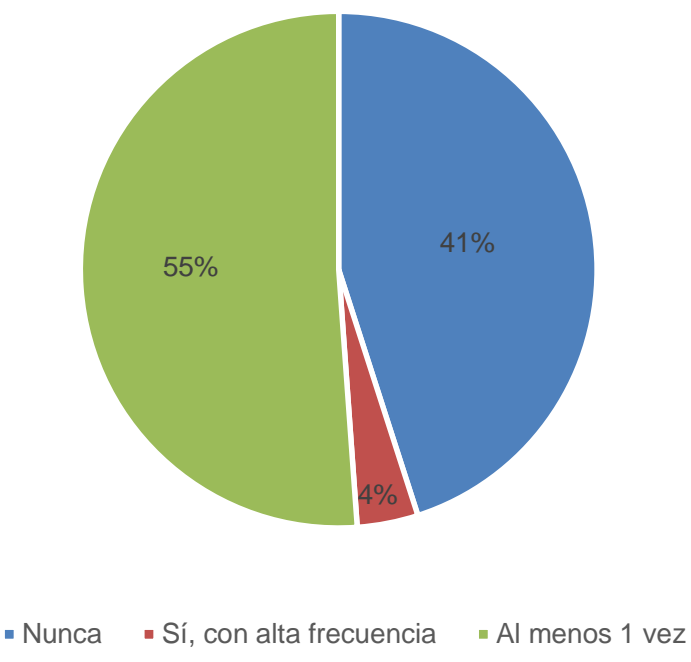

Elaboración propia en base a resultados de las encuestas

El 63\% considera se siente satisfecho con la oferta del mercado. Sólo el $27 \%$ considera que el servicio que tomó fue más de lo que esperaba (figura 1.3). 
Figura 1.3

Satisfacción con la oferta actual

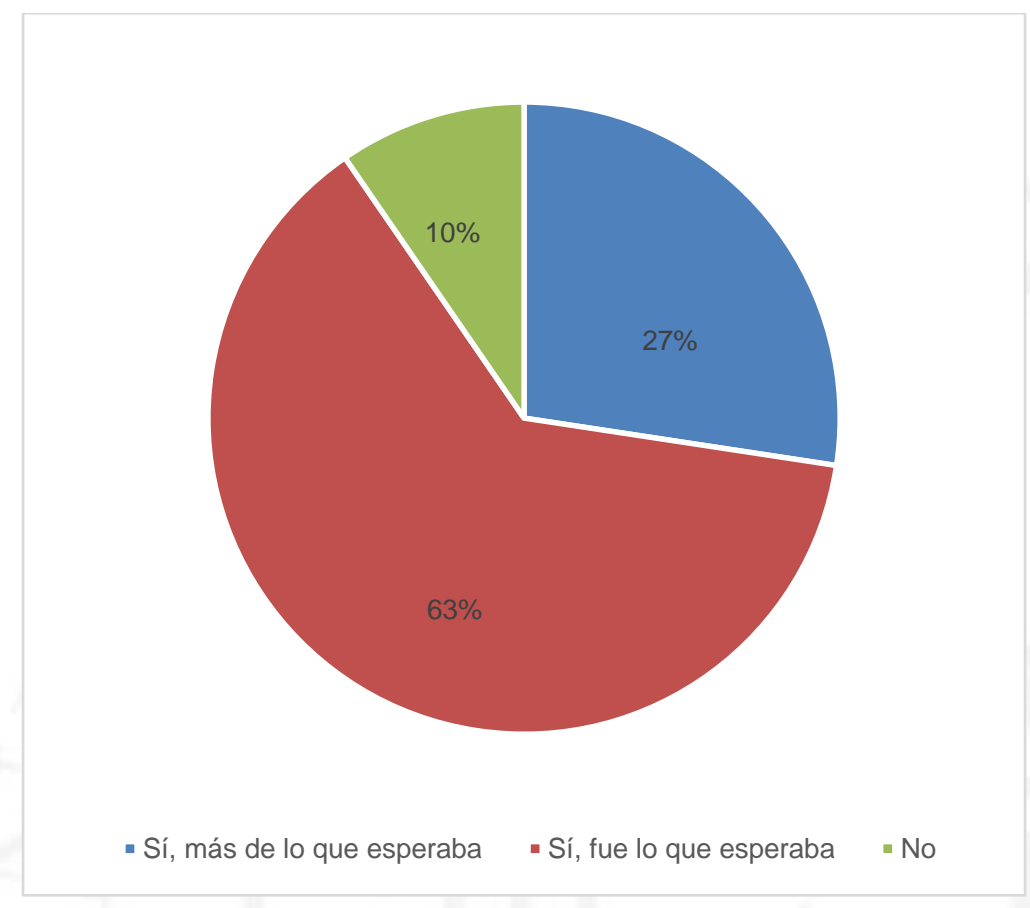

Elaboración propia en base a resultados de las encuestas

Como lo demuestra la figura 1.4, la recordación de marca sólo la respondieron el 18\% de encuestados (24 personas). 
Figura 1.4

Recordación de Marca

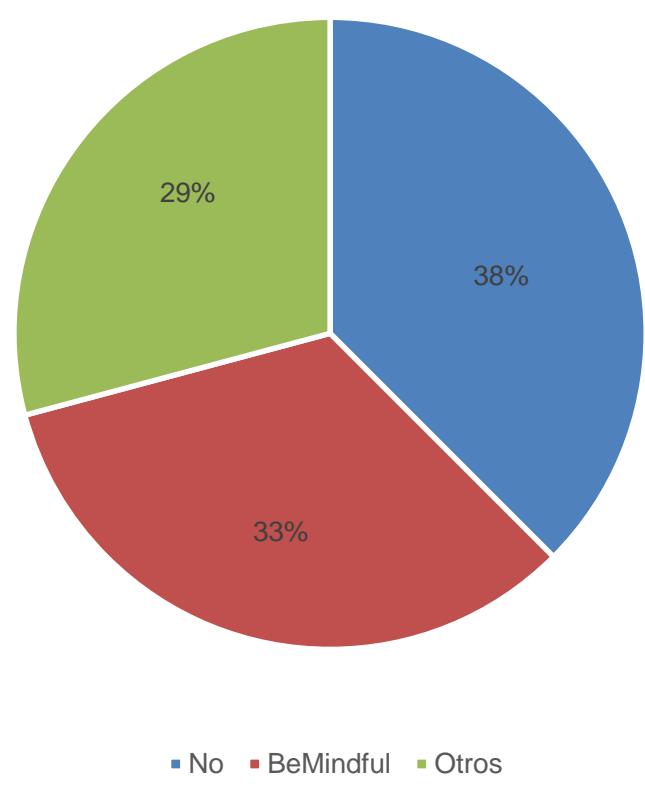

Elaboración propia en base a resultados de las encuestas

Además, se encontró que el 38\% de clientes que asistieron a un servicio de bienestar no recuerdan el nombre de la empresa. El 33\% recuerda el nombre de BeMindful, nombre de la empresa con la cual se hizo los talleres piloto. Casi el $29 \%$ recuerda el nombre de otras empresas en la que asistió. Esto último representa 6 empresas reconocidas.

Un dato crucial para determinar la demanda de los servicios de bienestar es que el $88 \%$ de encuestados estarían dispuestos a invertir en su bienestar mientras que el $12 \%$ no lo haría. Un $78 \%$ personas encuestadas no asisten a un taller de bienestar porque "No lo habían considerado". Los demás motivos detallados representan solo el 9\% de los encuestados, y son "No me interesa" y "No tengo tiempo" y el 4\% que opina "Me parece muy caro" .

Por otro lado, las redes sociales más usadas son Facebook, Whatsapp y correo eletrónico con un $93 \%, 89 \%$ y $77 \%$, respectivamente. Con un uso menor pero representativo encontramos Instagram (48\%) y Youtube (47\%). 
Como se puede observar en la Figura 1.5, la mayoría de encuestados estarían dispuestos a pagar entre S/ 200 y S/ 350. Casi el 50\% de encuestados pagaría "Hasta S/200” y el 25\% "Entre S/ 201 - S/ 350", sumando 74\% de aceptación por el precio mencionado anteriormente.

\section{Figura 1.5}

Precio que están dispuestos a invertir en su bienestar

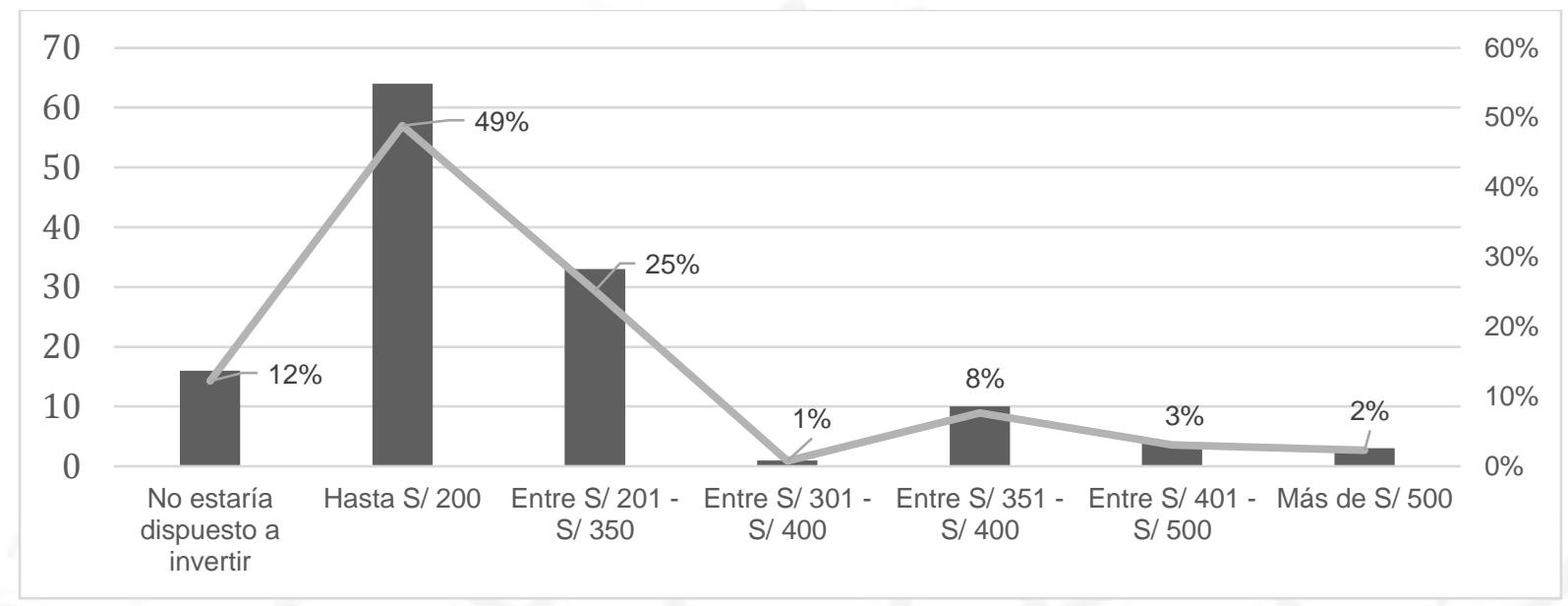

Elaboración propia en base a las encuestas.

Como se puede observar en la Figura 1.6, el atributo más apreciado por los encuestados es la calidad del servicio con un 54\%. Casi igual de importante es la experiencia del expositor y los horarios de los talleres con un $48 \%$ y $46 \%$, respectivamente.

\section{Figura 1.6}

Valoraciones más relevantes del servicio

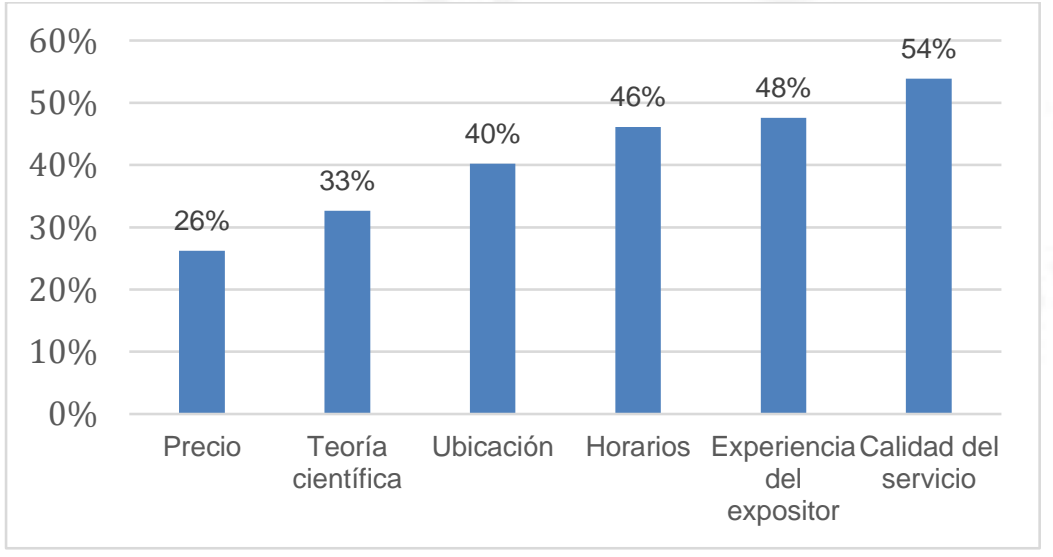

Elaboración propia en base a las encuestas. 
En la Figura 1.7, encontramos que el cliente encuentra en su mayoría utilidad el ambiente de trabajo y, además, lo califica como un servicio valioso en un 99\%. La percepción de los encuestados como aporte del servicio a su felicidad es del 60\% como calificación 3 y 33\% como calificación 2 (se puede marcar del 1 al 3, siendo "De acuerdo").

\section{Figura 1.7}

Utilidad en el ambiente de trabajo

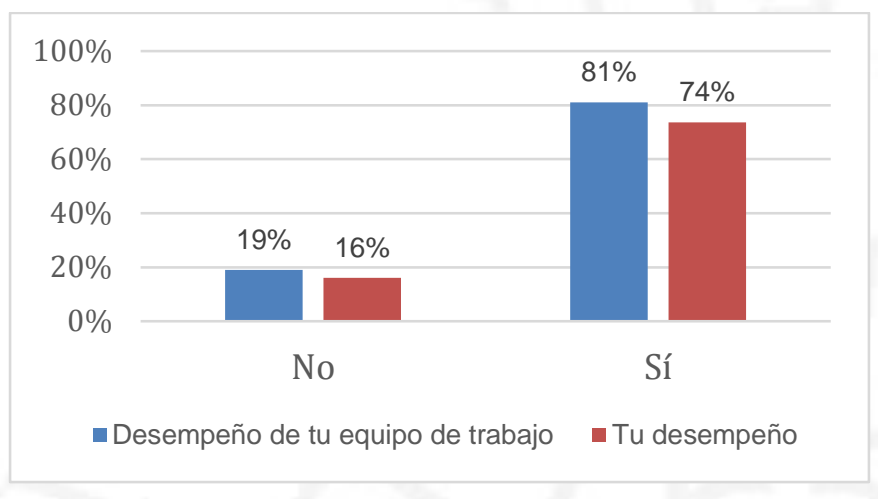

Elaboración propia en base a resultados de las encuestas

\section{Figura 1.8}

Percepcion de beneficio del servicio

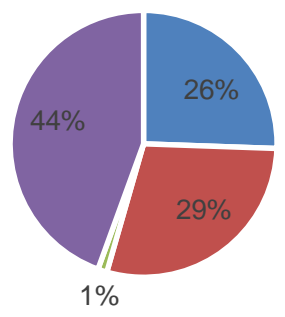

- Bastante valioso - Muy valioso - No es valioso - Valioso

Elaboración propia en base a resultados de las encuestas

La Figura 1.9 detalla las preferencias sobre el servicio de bienestar. En cuanto a los días que se prefieren, no se encuentra ningún día muy diferenciado. Los días martes, miércoles y jueves tuvieron una mayor aceptación. El horario con mayor aceptación fue el de las 7:30 - 
9:30 p.m (41\%), seguido de 9:00 - 11:00 p.m (24\%), 5:00 - 6:30 p.m (19\%) y 7:00 - 9:00 p.m (16\%). La preferencia de ubicación de local es Miraflores (60\%) y San Isidro (40\%).

\section{Figura 1.9}

Preferencias de días

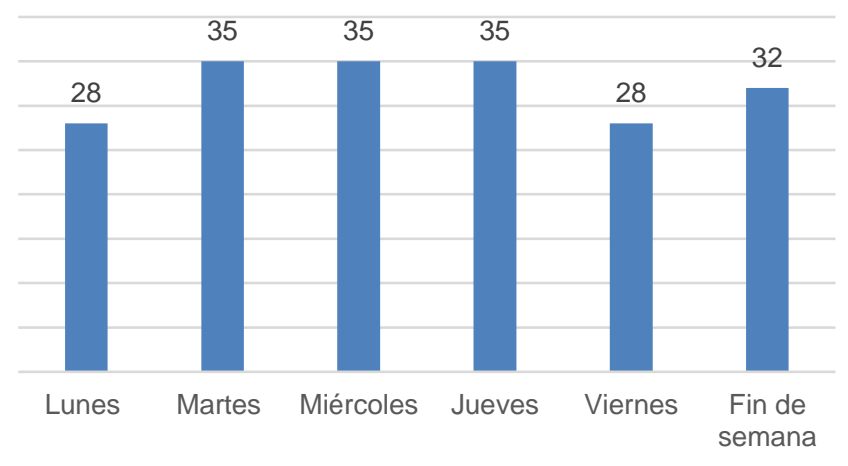

Elaboración propia en base a resultados de las encuestas

Como se puede observar en la Figura 1.10 encontramos a un grupo de encuestados con ciertos niveles de estrés. Para poder determinar si una persona está estresada, consideramos tener al menos 2 características con percepción de 3 o más. Lo consideramos como personas estresada ya que esta percepción se da en las situaciones de: alteración del sueño, menor concentración, desórdenes en la alimentación, irritabilidad. El público más estresado es el de estudiantes y jubilados. En trabajadores dependientes e independientes tenemos un nivel de estrés de $38 \%$ y $27 \%$, respectivamente. 
Figura 1.10

Niveles de estrés de público objetivo

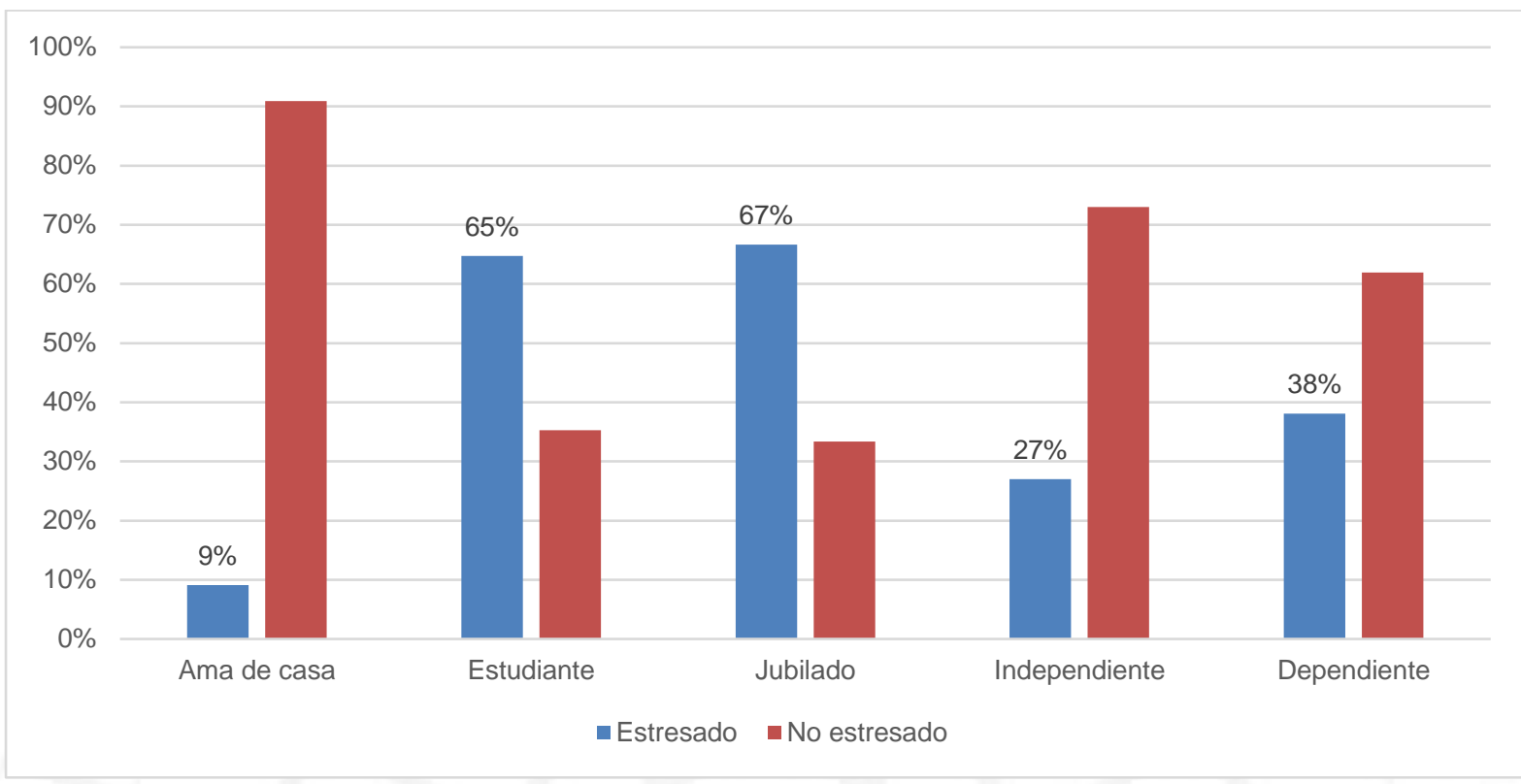

Elaboración propia en base a las encuestas

\section{Conclusiones de las encuestas:}

- En las encuestas predominó el público de trabajadores dependientes e independientes (76\%) y de mujeres (76\%). La encuesta determinó entonces las preferencias de este público.

- La encuesta determinó entonces las preferencias de los distritos de Miraflores, Surco, San Isidro, San Borja y La Molina, sumando 69\%.

- Dividimos la encuesta por género para diferenciar qué edades tienen mayor preferencia por el bienestar. Recordemos que los talleres los podemos adaptar según edades, sexo o cualquier otro factor que se considere relevante.

- Decidimos tomar a ejecutivos y profesionales por contar con un total de $73 \%$ de encuestados con las edades de entre 18 y 50 años. Debemos considerar que el 63\% de los encuestados se siente satisfecho con la oferta del mercado. Sólo el $27 \%$ considera que el servicio que tomó fue más de lo que esperaba. Nuestra estrategia es diferenciarnos del mercado con un servicio que supere las expectativas del cliente consumidor de este tipo de servicios.

- Solo el 33\% de los que al menos 1 vez asistieron a un taller de bienestar respondieron la pregunta de Recordación de marca. Dentro de ese contexto, se 
encontró que el 38\% de clientes no recuerdan el nombre de la empresa. El 33\% recuerda el nombre de BeMindful, nombre de la empresa con la cual hicimos los talleres piloto. Casi el 30\% recuerda el nombre de otra empresa a la que asistió. Esto último representa 6 empresas reconocidas. Deducimos que no existe una alta recordación de marca, lo cual nos da una ventaja para posicionarnos como marca.

- Según las encuestas, el 78\% personas no asisten a un taller de bienestar porque "No lo habían considerado". Los demás motivos detallados representan solo el $9 \%$ de los encuestados, y son "No me interesa" y "No tengo tiempo" y el 4\% que opina "Me parece muy caro" por lo que es crucial tener en cuenta un eficiente plan de comunicación de nuestro servicio para generar una demanda del mismo.

- El 74\% de encuestados estarían dispuestos a pagar entre S/ 200 y S/ 350. El precio se comparará con la oferta de mercado para una correcta definición.

- Los atributos más apreciado por los encuestados es la calidad del servicio, la experiencia del expositor y los horarios de los talleres.

- Consideramos que sí hay un potencial de un servicio de bienestar por la percepción de niveles de estrés que marcan los encuestados. En trabajadores independientes y dependientes tenemos un nivel de estrés de $27 \%$ y $38 \%$, respectivamente.

- Las redes sociales más usadas son Facebook, Whatsapp y correo eletrónico, y con un uso menor pero representativo encontramos Instagram y Youtube. Se recomienda incluir estas redes sociales en el plan de comunicación. Además, tomar en cuenta Linkedin, ya que el $36 \%$ de los trabajadores dependientes e independientes la usan.

- Los días que se prefieren por el encuestado son los martes, miércoles y jueves, sin embargo, no encontramos ningún día muy diferenciado.

- $\quad$ El horario con mayor aceptación fue el de las 7:30 - 9:30 p.m.

- El 57\% de personas encuestadas conocen el Mindfulness. El cliente no conoce sobre nuestra competencia en el mercado (ventaja de ser los primeros referentes).

- El $49 \%$ del total de personas encuestadas sí les interesaría participar en un taller de Mindfulness (alta aceptación del servicio). Las edades de mayor aceptación para mujeres son entre 18 y 25 años y mayores de 50 años. En el caso de hombres, el interés está en las edades de entre 18 y 40 años. El nivel de aceptación según sexo es similar siendo $55 \%$ y $58 \%$ para mujeres y hombres, respectivamente.

- $\mathrm{Al} 56 \%$ le interesaría poder tener clases virtuales. 


\subsection{Resumen y análisis de las entrevistas}

\section{Entrevista a Ana Loret de Mola - Co Fundadora y Directora de Mindfulness Perú}

"Dos de los centros más importantes donde se dictan talleres, seminarios y cursos de Mindfulness se llaman "Conciencia Plena Perú" y "Mindfulness Perú". La Sra. Brisa Deneumostier, chef holística y coach, y La Sra. Ana Loret de Mola, psicóloga especialista en mindfulness, son las directoras y co-fundadoras de este último".

Mindfulness Perú ofrece talleres, conferencias, viajes, retiros y terapias basados en mindfulness. Estos son dictados a todo público con los enfoques de salud, familia, educación y empresa. Ana es psicóloga clínica especialista en mindfulness, graduada de la Pontificia Universidad Católica del Perú. En el 2009 se convirtió en pionera de la investigación y difusión del Mindfulness en el Perú con su tesis para licenciarse. En el 2017, finalizó la maestría en Terapia Cognitiva Basada en Mindfulness en la Universidad de Oxford, Inglaterra.

Su acercamiento al mindfulness empieza hace más de 15 años por su práctica en la meditación, artes marciales e interés por la naturaleza. Trabajó durante 10 años en centros educativos como La Asociación para la Niñez y su Ambiente, el Nido la Casa Amarilla y el Colegio San Silvestre.

A continuación, se resume la entrevista:

- La Sra. Ana Loret de Mola recomienda la formación continua en Mindfulness y complementarios como parte de una ventaja competitiva.

- Ella no tiene noción sobre cómo llevar un negocio ni cómo liderarlo.

- La razón de ser de Mindfulness Perú es dar a conocer que es el Mindfulness por los resultados de bienestar personal. Se empezó dando clases gratuitas y poco a poco el interés de la gente por conocer el Mindfulness aumentaba. Hoy en día se ha vuelto un negocio, pero su motivación nunca fue hacer negocio.

- La fijación de precio se dio teniendo en cuenta la formación de ambas socias. Los talleres que dictan tienen un precio que se basa en la calidad de la formación que han recibido. Por otro lado, comentó que, hoy en día, hay empresas que estafan respecto a este tipo de servicios por la calidad de formación que dan.

- Actualmente, solo se dedican al Mindfulness. Vive de eso y asegura que es un negocio realmente rentable. 
- La forma de promocionarse no tiene una estrategia definida. Se apoyaron y confiaron del "boca a boca" de sus clientes satisfechos. Comentan que no tienen página web desde el 2015 porque no se dan abasto.

- Respecto a la competencia, señalan que no tienen competencia directa porque no hay otra empresa con el mismo nivel de formación que ellas han recibido.

Con referencia a los talleres que dan se resume que:

- El número promedio de talleres a la semana son 2 por semana.

- Máximo de 12 personas por taller.

- Su objetivo no es tener mayor cantidad de gente por taller sino brindar mayor calidad.

- Cuando se preguntó sobre el perfil de la persona que busca Mindfulness nos comentó que en sí no hay un perfil exacto, no hay un rango de edades tampoco. Dictan talleres a niños como también a adultos, lo que sí nos dijeron es que son más mujeres que hombres las que buscan Mindfulness.

- Recomienda medir el nivel de estrés de una persona, señaló que lo hacen a través de evaluaciones psicométricas y evaluaciones personales. En una conversación de máximo 45 minutos indican que se puede saber cómo es y qué es lo que realmente necesita.

- Respecto al tema de horarios contó que al principio hacían sus horarios pensando en los clientes, pero ahora ya no, primero piensan en sus horarios y luego en el de ellos.

Beneficios del Mindfulness:

- Existe una Terapia Cognitiva basada en Mindfulness muy efectiva para enfermedades psicológicas. Cuenta Ana que la visitan escépticos que no conocen el Mindfulness, pero las buscan como recomendación de sus mismos psicólogos.

- Por último, comentó que el Mindfulness no hará que cambies tu forma de ser de un día a otro; por ejemplo una persona que normalmente es impulsiva no significa que practicando el Mindfulness deje de serlo al $100 \%$ en un día, sino que puede ayudar mucho, de tal manera que la persona aprenda a ser consciente de cómo se está sintiendo en ese momento, sepa controlarte y tome otra actitud menos impulsiva. 
Mucho va a depender de lo que quiera trabajar, uno se puede ayudar del Mindfulness de diferentes maneras. Te conoces de una manera distinta, aprendes a reconocerte como seres duales.

\section{Entrevista a Punkie Hermoza - Influencer de Bienestar}

Punkie es blogger de yoga, comida saludable y thai massage. Realiza talleres y retiros. Da clases de yoga en LimaYoga (uno de los centros más conocidos de clases de yoga) y en Ashtanga yoga. El taller más reciente que dicta es "Herramientas para potenciar tu vida cotidiana".

- Siempre ha escuchado del Mindfulness desde pequeña en casa por sus papás.

- Se le hizo muy complicado ver el tema de los talleres como negocio, ve más el beneficio de propagarlo porque es algo que vale la pena practicarlo y es realmente bueno para el bienestar personal.

- Se le complica mucho valorizar su trabajo. Nos cuenta que ella ofrecería los servicios de manera gratuita, pero necesita vivir en esta sociedad y para ello necesita dinero. Vive de eso.

- Se le preguntó si sabía de empresas que dicten talleres de Mindfulness en Perú y mencionó que no sabe quiénes hacen pero sí sabe que hay.

- Para ella el Yoga es un estilo de vida y una ciencia. Es la unión de todo: cuerpo, espíritu, mente, energía y universo. Somos lo que comemos, decimos y hacemos.

- Lo que se logra con una buena práctica del yoga es calmar las fluctuaciones de la mente.

- Comentó que la felicidad para ella es estar presente y consciente, agradecido por ese momento.

- “Todas las personas necesitamos meditar, incluso los niños". Señaló que hay muchas formas de meditar pero cada uno tiene que encontrar su estilo de meditar.

- Cuando se le preguntó sobre cómo podría saber si una persona está estresada o no, nos mencionó 3 aspectos: Postura, forma de hablar y gestos de la cara.

- Considera que algunos de los principales beneficios del Yoga son: calmar los pensamientos, reducir el estrés, mantener una vida tranquila y consciente. 
- Ella cree que este tipo de negocios es rentable, la gente hoy en día está dispuesto a pagar por este tipo de talleres de salud y bienestar personal. Cada vez la gente se preocupa más por la salud física y mental.

- El perfil del público objetivo del yoga: dentro del perfil de personas que buscan un taller de Yoga están las personas que son muy alteradas y que no pueden lidiar más con la situación por la que están viviendo; y también las personas que ya hacen yoga y quieren seguir con la práctica. Son más mujeres de todas las edades. Normalmente de rangos de 19-25 y 40-50 años. A los 30 años están más enfocados en el trabajo, los hijos, etc.

- Comentó un poco sobre algunos de sus proyectos y mencionó que quiere abrir un blogg y canal de youtube donde pueda colgar videos e información sobre el yoga, talleres, retiros, dar a conocer las diferentes formas de meditación, nutrición saludable, alimentación basada en plantas, etc. Otro punto que nos comentó es que quisiera ser coach nutricional.

- Señaló que ella no era tan fan de las redes sociales, pero al empezar con su negocio se dio cuenta que era necesario para llegar a más gente y tener un mayor alcance.

Se puede concluir que Punkie es una joven que desde pequeña tuvo gran influencia por parte de sus padres en el tema de la meditación y bienestar personal, que poco a poco fue incrementando esas ganas de seguir aprendiendo en este caso, sobre el yoga; es por ello que decidió llevar un profesorado para luego ser captada por los profesionales que le ofrecieron enseñar en Lima Yoga y lo aceptó. Al igual que Ana Loret se le complica un montón ponerle precio a los diferentes actividades que realiza (talleres, clases, retiros y charlas). Lo hacen porque realmente les interesa que la gente viva saludable, no solo tenga un cuerpo sano sino también una menta sana, estar enfocadas en el presente sin preocuparse de lo que ya pasó ni de lo que podría pasar en un futuro; es decir ser conscientes del hoy. Para ella la felicidad es estar presente y consciente. Siempre ser agradecido por ese momento: Otro punto que nos recalca Punkie es que "Somos lo que comemos, decimos y hacemos". Todo guarda relación.

\section{Entrevista a Alex Canales - Gerente General de LimaYoga}

"Mi experiencia profesional por años han sido las finanzas, la banca hasta hace unos meses (Agosto 2017) ya que se me ofreció la oportunidad de entrar a la línea del yoga, a través de LimaYoga (...) y yo feliz porque internamente tenía una vida con una disciplina orientada 
hacia un camino espiritual, pero también una práctica energética, digamos, práctica de meditación, de yoga ... esta oportunidad se convirtió, en otras palabras, a hacer aquello en donde tú quieres contribuir a la sociedad y que además sea tu fuente de ingreso, es la combinación ideal”.

Como resumen de la entrevista se tiene:

- Para que un negocio sea rentable o sostenible en el tiempo debe tener un criterio empresarial y objetivos comerciales puros y, también puede tener un objetivo definido diferente (ejemplo: social, de bienestar hacia las personas).

- Como creencia personal, Alex mencionó que se debe tener un criterio empresarial con énfasis en el "Dar", ya que el "Recibir viene solo", y debe estar instrumentalizado a través de una organización. El “dar" está relacionado al Dharma (propósito de vida), es decir; cuál es tu esencia, lo que tú quieres dar en la sociedad vinculado a tu talento (ejemplo: personas nacidas para ser médicos y sanar).

- Recomendaciones para formar objetivos empresariales y definir estrategias:

- Determinar si existe una demanda. Se investiga el mercado para entender si en el mercado existen empresas que están en ese rubro, ya que si están presentes hay una demanda. Determinar qué se ofrece en el mercado. Es evidente que hay una necesidad de tranquilidad interior, relajamiento, capacidad de enfoque, concentración y energía. Las personas están estresadas, inquietas, agitadas mentalmente, cansadas, distraídas y desenfocadas. "Demanda hay, no me cabe duda."

- Determinar la presentación del producto (cómo). Definir claramente el producto, que en este caso es un servicio. En Mindfulness hablamos de meditación y hay muchas líneas o formas de meditar (meditación guiada, Raja Yoga, Vipassana, Cristiana, entre otras). Dejar claro qué es la meditación.

- Determinar la exposición del producto. No generar un problema de expectativas. Mostrar el producto de manera explícita, pero sin mostrarle o evidenciarle toda la experiencia. No puedes mostrarle la experiencia completa ya que el ser humano tiende a mentalizar y anticipar. "No engañarte, es esto pero no te puedo decir el método. No puedo ser muy específico porque sino te pierdes la oportunidad de la experiencia”. 
- Las personas mentalizamos y somos emocionales. No debemos adelantar conceptos que vayan a ser mentalizados por la experiencia. "Yo quiero impactar en tu vida y puedo ocasionarlo con la experiencia (...) Con lo que te hable te voy a interesar". Hay que sorprender, la experiencia es lo que transforma. Es todo un arte no poder contar y atraer.

- El arte está en lograr atraer teniendo en cuenta el perfil cortoplacista y poco tangible del peruano.

- "Nosotros vivimos con una inercia. Todo lo que hemos pensado, hecho, nos ha llevado a lo que somos hoy. Somos un conjunto de decisiones tomadas, tendencias. Pero si yo de pronto nunca he meditado y quiero hacerlo, la fuerza más grande con la que voy a luchar es interna y no externa."

- Uno de los retos está en enganchar a la persona en la disciplina. Convencerla de que si no tiene disciplina (práctica constante) no se verán los cambios esperados. El problema de romper con la inercia no solo es peruano, sino universal. El reto es que se enamore de la disciplina y la implemente en su vida.

- Una forma de atacar ese reto es "asegurar una buena calidad de la experiencia" con un ambiente adecuado, música, instructor idóneo y palabras atractivas para que la persona quiera regresar. El beneficio se siente con la buena experiencia.

- No es tan importante diferenciarte de la competencia sino tener "personalidad". Esto último te da fuerza y hace que gane la esencia para luego sumarle el marketing. La personalidad de una empresa la compone la visión y la forma en que armas el producto. Luego incorporas el marketing.

- Alex considera que el perfil del público que busca bienestar es aquel que se acerca por problemas de salud, también por tranquilidad de la mente y por verse bien físicamente.

- Se debe pensar en redes sociales, pero más en contactos en empresas, pues es diferente hablarle a uno por uno que acercarte al gerente de RRHH de una empresa para ofrecerle bienestar (paquetes) que mejore los indicadores de productividad.

- Un inversionista toma en cuenta lo siguiente:

○ Ciclo económico del negocio.

○ Escala del negocio:

- 1 solo local propio: muchas ventajas, siendo el gasto fijo más importante al comienzo y vas abriendo más locales según el crecimiento. 
- Salarios variables al principio desde el punto de equilibrio.

- 1 solo local y alquilado: menos ventajas, debes promocionarte a través de red de contactos, redes sociales ó página web con oferta bien definida.

- LimaYoga creció 1 a 1 y ahora tiene 7 locales.

- Tener en cuenta la demanda: "hay lugares en donde pones una licorería y no están listos para el vino sino para la cerveza". La Lima moderna está para estos servicios (más sutiles).

- Reto: concepto de yoga más definido en el Perú, sin tantos prejuicios.

- Beneficios del yoga:

- Apertura del cuerpo

- Propicias que salga la tensión del cuerpo (energía negativa y acumulada).

- Respiración adecuada

- El sistema nervioso se recarga de energía vital que equilibra el sistema nervioso.

- Estado de presencia

- Estás en el presente.

- Según Alex Canales:

- Se acercarán aquellos que experimenten estrés, con 28 - 45 años (la media es 35 años). Este perfil se describe como aquellos que empiezan a ser jefes, tener familias con desafíos cada vez más grandes. Alex comenta que considera que hay mujeres que demandan más este tipo de servicio por ser más abiertas al cambio.

○ Horarios: Si son personas que trabajan, a partir de las $7 \mathrm{pm}$. Los horarios punta en LimaYoga son en la mañana.

- Cantidad de alumnos por salón: tomar en cuenta la demanda y el tamaño del salón.

- Se debe desarrollar una buena estrategia de redes sociales.

\section{Entrevista a Marco Pizarro - Estratega y comunicador creativo de marca}

Comunicador, especializado en desarrollo de marcas, procesos creativos y básicamente en crear productos comunicacionales, ya sea desde videos de algún tema específico o identidad de marca. 
- El Mindfulness si lo vemos como negocio es un negocio intangible y al ser intangible tienes que pensar en que la persona quiere saber qué va a recibir a cambio del dinero que está invirtiendo. Se necesita convertir el concepto del Mindful en una experiencia que va a comprender el cliente cuando reciba este servicio.

- Lo tangible sería el espacio donde las personas van a desestresarse, manejar el tema de la ansiedad, distraerse conociéndose a sí mismo y un espacio para el autoconocimiento.

- Ahorita no podríamos vender el Mindfulness como "Mindfulness" porque hay mucha gente que no lo conoce. Primero tenemos que educar al público, llevarlos al autoconocimiento con las técnicas que usa el Mindful y al ver que les va bien se va a dar el "boca a boca" mediante recomendaciones. Enseñarles a las personas cómo llegar a la paz y felicidad; es decir, enseñarles el camino, las técnicas para llegar a eso. Ahí es donde los estamos educando.

- Este espacio es más que todo un centro donde encontrarán la calma y tranquilidad para afrontar todos sus problemas, donde la persona va a poder desarrollar sus capacidades al máximo. Una ventaja competitiva de nuestro negocio es el contar con psicólogos y expertos en el tema. El psicólogo te da un diagnóstico inicial y de acuerdo a ello se trabaja el Mindfulness según lo que necesite desarrollar cada persona. El Mindful con la psicología se complementa.

- La marca es muy moderna y minimalista. La marca tiene que ser como si te conectaras a algo que está fuera de la realidad.

- La página web tiene que ser de transiciones, publicar un contenido suave, conciso, ver qué elementos son los que transmiten calma, los colores (blanco, celeste, azul).

- La comunicación tiene que ser dirigida a las necesidades de las personas. Podríamos empezar contando casos y experiencias de personas que han hecho Mindfulness y han podido ver como resultado cambios positivos en su vida. Manejar notas de prensa, videos con los mismos psicólogos y especialistas donde cuentan en qué consiste el Mindfulness. También se puede empezar con campañas, visitar a diferentes empresas, y reunirse con el área de RR.HH y proponerles descuentos a sus empleados. Es algo interesante tanto para los empleados como para la compañía. 


\section{Entrevista a Maite Schirmer - Psicóloga Clínica}

Maite Schirmer, Psicóloga clínica con formación en terapia Gestalt y Mindfulness con 30 años de experiencia en meditación. Con esto último, ha podido disfrutar de los beneficios de apaciguar la mente y las emociones, como poder tomar decisiones fuera del piloto automático. Encontró el Mindfulness luego de terminar la carrera (2016) y pudo relacionarla perfectamente a la psicología Gestalt.

Su experiencia profesional se dio parte en la Universidad Católica del Perú y en Familia Saludable, con las intervenciones que tenían mucho que ver con dejar un espacio antes de la reacción (propio de Mindfulness). Ha trabajado con niños en Aldeas Infantiles y en el Puericultorio Pérez Araníbar, y el Mindfulness ayudó a generar un espacio antes de las acciones impulsivas de los niños con pausas de respiraciones.

- El autoconocimiento mejora la salud física y mental. Lo que te da el autoconocimiento es un tiempo para pensar en soluciones diferente a las que fluyen de manera espontánea (normales, actuales) desde cerebros más primitivos (impulsivos). El autoconocimiento te permite conocer tus emociones y dar una respuesta más racional con un espacio de observación. Permite también que tus reacciones físicas sean más lentas, menos apresuradas y más conscientes, y con ello entregar mejores respuestas al entorno (círculo virtuoso). Para entender lo mencionado explicamos los 3 "cerebros" que nos componen:

- Reptiliano: altamente reactivo. Es el cerebro que primero se forma en el ser humano hace 300 millones de años. Es un cerebro muy básico en dónde vemos acción y reacción. "Es el cerebro que hace pasar a la persona por procesos de "fight, flight or freeze", es decir, te congelas porque sientes que te supera la situación, o la peleas porque sientes que tienes los recursos o huyes porque consideras que no los tienes (los recursos)".

- Evolución del Sistema límbico: la parte de la memoria y los procesos más integrados, la experiencia, la integración de las diferentes áreas.

○ Córtex prefrontal: importante para procesos ejecutivos y superiores. Es la parte del cerebro más desarrollado, en donde trabajamos. "Es la parte del cerebro que nos ayuda a pasar de aquello que es instintivo para pasar a aquello "meditado", pensado o que ha tenido un tiempo para integrar experiencias previas y procesos superiores en la respuesta. El Mindfulness ayuda a incrementar la cantidad de neuronas y sus conexiones. Si nos encontramos en una situación de estrés vamos 
a tender a utilizar las conexiones neuronales existentes. Las conexiones neuronales hacen, a su vez, que tu amígdala cerebral (parte del sistema límbico y reptiliano) disminuya la cantidad de energía que involucra por utilizar los caminos neuronales existentes. Con esto se refiere a que te vuelves menos reactivo o impulsivo por generar un espacio para entender qué emoción te embarga y no dar una respuesta impulsiva y más racional. "Aquí es donde empiezas a conocerte..."

- Existen muchas técnicas para traer aspectos al presente tratando de vivenciarlos a través de los 5 sentidos. El autoconocimiento en el cuerpo te permite valorar aquellas acciones que uno hace. En el deporte, puedes ser más consciente de aquellos músculos que se necesitan para realizarlo de manera más adecuada y así trabajarlos. En la alimentación, con los 5 sentidos puedes sentir lo físico y así placer, felicidad, entre otros. Puedes valorar más y así agradecer en mayor proporción lo evidente y cotidiano. Con lo anteriormente mencionado, podemos segregar mayores hormonas positivas (serotonina, melatonina, oxitocina, entre otras) y disminuir las negativas (adrenalina, cortisol, entre otras).

- Si uno conoce más o es más consciente en su alimentación puede percibir y entender mejor qué alimentos le favorecen más y cuáles no tanto. Las emociones influyen en el proceso digestivo. Se ha descubierto en estudios en Estados Unidos que "la experiencia que tú tienes sobre aquello que ingieres, le das una connotación negativa "no me gusta" o una connotación creativa "esto es interesante" también influye en el resto de tu cuerpo".

- Para percibir y para pensar hacemos conjeturas de situaciones pasadas. Y a esas conjeturas se le suman las hormonas generadas por las connotaciones negativas o positivas que le das. Con todo lo anterior, podemos generar círculos virtuosos en nuestras vidas. Con las connotaciones positivas generamos mayores hormonas positivas y menos negativas, y con las connotaciones negativas sucede a la inversa.

- ¿Hasta qué punto tenemos injerencia sobre las hormonas que producimos? La acción consciente que se toma por una decisión y autoconocimiento para generar una hormona hace que evidencie ese efecto. Hay acciones inconscientes que también te las generan. La diferencia está en hacer aquello que conscientemente sabes que te generará hormonas positivas. Si pensamos en lo que viene, nos causamos ansiedad. Si pensamos en lo que pasó, nos causamos depresión. Con 
estas emociones fluyen con mayor facilidad las hormonas negativas. Y el fluir de las hormonas influyen en tu estado emocional y físico.

- Para lograr el autoconocimiento necesitamos hacer introspección. Eso significa observar la cantidad y calidad de pensamiento que se tienen. Se puede anclar los pensamientos en técnicas definidas y percepciones corporales. Esto se apoya en la idea de la aceptación que se tiene del espacio y no a la invasión causando malestar.

- El Mindfulness "es una manera de estar en la vida, enfocada, sin juicio y ojalá también creativamente". Hay muchas definiciones del Mindfulness pero todas llegan a una misma idea: el enfoque de llevar tu consciencia de lo que quieres lograr (ya sea apaciguar tu mente, conectarte con tus emociones, entre otros beneficios). El Mindfulness viene del oriente, del budismo pero se buscó secularizar hacia el occidente por Jon Kabat-Zinn y su equipo.

- Se pueden controlar las acciones que se devuelven al mundo externo y con ello algunas reacciones del mismo. "Si alguien me grita y yo no le devuelvo el grito sino trato de acogerlo y comprenderlo en su situación, es bastante obvio que su respuesta va a ser más positiva".

- Cuando nos encontramos en situaciones de estrés, podemos decir que se da una competencia en nuestro cerebro por ocupar aquello que menos energía nos demande. Esto se relaciona con las conexiones neuronales, mientras más conexiones desarrollemos, mejor podremos responder al entorno por contar con mayores opciones.

- Los beneficios se detallan en la descripción del producto detallado anteriormente.

- La toma de consciencia hace que eleves tu consciencia para re-pensar y re-sentir para poder dar mejores respuestas al medio.

- El autoconocimiento puede ayudar en todo aspecto de tu vida, en el cual por tu conocimiento interno y externo puedes dar una respuesta más positiva. Desde lo laboral, intrapersonal, interpersonal, dolores físicos, entre tantos otros.

- Logramos tangibilizar los beneficios del autoconocimiento a través de la evidencia científica, experiencia y práctica. "Si tú ves que hay cientos de estudios que se han hecho con el Mindfulness, cuyos resultados han sido positivos significativamente, y la persona ha cambiado para bien, puedes tangibilizarlo". La experiencia corta y con beneficio inmediato puede lograr pequeñas convicciones. Al principio se debe 
enfocar en esas pequeñas experiencias para que la persona genere curiosidad. Se empieza con la evidencia científica y luego la experiencia.

- Se ha descubierto que los seres humanos traemos una línea base de felicidad. Después de 8 semanas de realizar meditaciones de Mindfulness se puede incrementar la línea base, reestructurando tu cerebro. La reestructuración se refiere a darle mayor energía a tu córtex prefrontal.

- El espacio para el autoconocimiento debe permitirle percibir mayor tranquilidad y conexión: horarios libres y fuera de estímulos distractores. Debe existir canalizadores de autoconocimiento como personas guías.

- Hay muchas técnicas de diferentes corrientes. La idea es aquietar tu cuerpo y luego pensar sobre aquello que te está acongojando. La psicología siempre busca el autoconocimiento. Algunas técnicas a mencionar son:

○ Preguntarte siempre "Me doy cuenta de..." - Psicología Gestalt

- Encontrar tu sentido de vida - Viktor Frankl (logoterapia)

- Tomar consciencia de las acciones - Psicología Cognitivo - conductual

- Bienestar es lidiar con las situaciones que se te presentan de la mejor manera posible. No es estar siempre feliz, sino que puedas reconocerlo, validarlo y manejarlo de la manera en que te produce tranquilidad y crecimiento.

- Salud mental es poder tomar consciencia interna del entorno para responder de manera más adecuada.

- "El aquí y el ahora" lo menciona tanto la psicología Gestalt como el Mindfulness. Tomar consciencia de que lo único y real que tenemos es el momento presente. Se aprecia a través de los sentidos. Solo en el momento presente se puede actuar. En el pasado o futuro se generan los trastornos ya sea de depresión o ansiedad. Frases emblemáticas: "Vivir en el aquí y en el ahora" y la toma de consciencia "Me doy cuenta de ..."

- Para vivir realmente en el presente es importante no juzgar. La realidad es subjetiva y única, ya que existen percepciones de por medio para tener un círculo virtuoso. El dolor es parte del proceso y de la vida, y hay que aceptarlo. No debemos buscar salir rápidamente de las emociones, sino procesarlas y darles un tiempo. 


\subsection{Resumen y análisis de las Focus Group}

El Domingo 29 de Abril del año xxx se realizó el Focus Group en Catapalla, un pueblo que se encuentra en Lunahuaná en la provincia de Cañete en la región de Lima, mismo lugar donde se llevó a cabo el retiro de Bienestar el día Sábado 28 de Abril a las 8.30 am hasta la tarde del Domingo 29 de abril. A este retiro asistieron seis participantes, hombres y mujeres de un rango de edades de 25 a 30 años y de 45 a 55 años más las otras tres personas que se encargaron de dirigir las actividades del retiro: una coach, una psicóloga y una profesora de yoga. Las mismas personas que asistieron al retiro fueron partícipes del Focus Group que se realizó al término de éste.

En la siguiente Tabla se detalla el programa con las actividades que se realizaron: 
Tabla 1.2

Programa de actividades del Piloto

\begin{tabular}{|c|c|c|c|}
\hline \multirow{2}{*}{\multicolumn{2}{|c|}{$\begin{array}{l}\text { Simple } \\
\text { Feliz }\end{array}$}} & \multirow{3}{*}{ Neente } & \\
\hline & & & \\
\hline \multicolumn{2}{|c|}{ Intensa } & & \\
\hline \multicolumn{4}{|c|}{ Programa ( 2 dias) } \\
\hline & & & \\
\hline \multirow[t]{17}{*}{ Sábado } & \multirow[t]{17}{*}{ DIA 1} & SALIDA DE LIMA & $8.30 \mathrm{AM}$ \\
\hline & & LLEGADA A CATAPALLA & $12.30 \mathrm{PM}$ \\
\hline & & Tiempo libre & 12.30 .12 .50 \\
\hline & & Preparación Almuerzo & $12.50-1.35 \mathrm{PM}$ \\
\hline & & Almuerzo & $1.35-2.15 \mathrm{PM}$ \\
\hline & & Descanso & $2.15-3.15 \mathrm{PM}$ \\
\hline & & INICIO DE ACTIVIDADES & \\
\hline & & Charla DE BIENVENIDA & $3.15-3.45 \mathrm{PM}$ \\
\hline & & Yoga Mindful & $3.45-4.15 \mathrm{PM}$ \\
\hline & & Meditación M & $4.20-4,50 \mathrm{PM}$ \\
\hline & & Snack para comer y tomar & \\
\hline & & Charla & $5.00-5.30 \mathrm{PM}$ \\
\hline & & Caminata M & 5.30- 7.00 PM \\
\hline & & Preparación Cena Parrilla & $7.00-7.40 \mathrm{PM}$ \\
\hline & & Cena & $7.40-8.25$ PM \\
\hline & & Fogata y contemplación & 8.30 - en adelante \\
\hline & & Comienza el silencio (se entrega libretita y lapiz) & \\
\hline \multirow[t]{12}{*}{ Domingo } & \multirow[t]{12}{*}{ DIA 2} & Tai Chi & $7.00-7.30 \mathrm{AM}$ \\
\hline & & Meditación M & $7.30-8.00 \mathrm{AM}$ \\
\hline & & Aseo personal & $8.00-8.45 \mathrm{AM}$ \\
\hline & & Desayuno & $8.45-9.30 \mathrm{AM}$ \\
\hline & & Final del Silencio & \\
\hline & & Experiencia (artistica) & $10.00-11.00 \mathrm{AM}$ \\
\hline & & Piscinazo & $11.00-12.00 \mathrm{PM}$ \\
\hline & & Almuerzo & $1230.1 .15 \mathrm{PM}$ \\
\hline & & Pausa (hacer maletas) & $1.15-1.45 \mathrm{PM}$ \\
\hline & & Focus & $1.45-3.10 \mathrm{PM}$ \\
\hline & & SALIDA DE CATAPALLA & $3.30 \mathrm{PM}$ \\
\hline & & LLEGADA A LIMA & $6.30 \mathrm{PM}$ \\
\hline
\end{tabular}

Elaboración propia 
Recomendaciones destacadas del Focus Group:

- Hacer mayor énfasis en la parte teórica de Mindfulness, explicar un poco más sobre lo que es Mindfulness, no sólo basarnos en la experiencia sino también entender lo que es el Mindfulness.

- Una buena idea es plantearles una pregunta una semana antes del retiro con el fin de que se cuestionen y tengan tiempo de reflexionar sobre ello.

- Previo a la fogata que se realiza en el retiro creemos que se podría realizar una charla con el fin de crear una buena atmósfera en el ambiente.

- Llevar un orden de todas las actividades que se van a realizar durante el retiro.

- Con la información brindada el objetivo del retiro debería ser descubrir y experimentar los beneficios del Mindfulness.

- Los tiempos se manejaron bastante bien, se pudieron realizar varias actividades (tai chi, yoga, parrilla, caminata, fogata, actividades Mindful) en un tiempo adecuado y de forma dinámica.

- Es importante saber cuál es el objetivo de cada persona que va al retiro para enfocar en eso la teoría.

- Sería una buena idea de que al terminar la actividad de la caminata cada participante pueda encontrar un mensaje agradable que describa los beneficios de esa actividad.

- Se propone que para la siguiente actividad los participantes no sepan en qué lugar exactamente será el retiro y sea sorpresa, pero sí tengan conocimiento del tiempo que tardan de Lima al lugar donde se realizará el retiro.

- Podríamos ofrecer una bolsita de tela con el logo de "Agora" que contenga el detalle de actividades y temas a tratar (itinerario), un block de notas con la marca y una fruta para el camino.

- Otras de las ideas que surgieron era que al momento que el participante se inscriba se le pregunte si es alérgico a algún tipo de comida para tenerlo en cuenta a la hora de determinar el menú para los días de retiro. Esto es muy importante ya que es un mensaje para el cliente de que estará muy bien cuidado. Será tratado con respeto y cariño.

- Surgió una idea de no solo enfocarnos en un público nacional sino también incluir a los extranjeros y vender este servicio a través de las agencias de viaje/ ferias a modo de Turismo Vivencial. Tenemos la opción de realizarlo en Cusco, debido a 
que existe la posibilidad de que el turista prefiera Cusco en vez de Lima para realizar este tipo de talleres vivenciales.

\subsection{Resumen y análisis de los talleres piloto}

Se realizaron talleres piloto que consistían de 06 módulos desarrollados en 03 semanas. Cada clase duraba 1.5 horas y habían 02 clases por semana. Se eligió un horario de día (9 a.m.) y uno de noche (6 p.m). A continuación, se detalla la descripción de los brouchures repartidos para la captación de clientes y algunos ejemplos de los materiales entregados.

Figura 1.11

Folleto de talleres piloto

\section{Taller de \\ Mindfulness \\ Tomar consciencia: \\ existir en el aqui y ahora}

Nuestros talleres han sido diseñados para regalarnos una experiencia de vida única y trascendente. Nos embarcaremos en ese viaje siempre anhelado, un viaje sin retorno, hacia la toma de consciencia de aquello que nos conforma y circunda.

Del 3 al 22 de agosto

- Club Suizo, Genaro Castro Iglesias 550, Mir.

(ㄷ) Martes y jueves de 10.00 a 11.00 am

Agosto 3, 8, 10, 15, 17, 22 de agosto

\section{Inversión}

380 soles (por las 6 sesiones, incluido materiales)

Depósito en banco BCP cta. n 19325376993024

Contacto y reserva de cupos: 996318870 - 987936555

raspillagamar@gmail.commaiteschirmer2@gmail.com

Elaboración propia 
Figura 1.12

Folleto de talleres piloto (Contenido)

\section{Contenido}
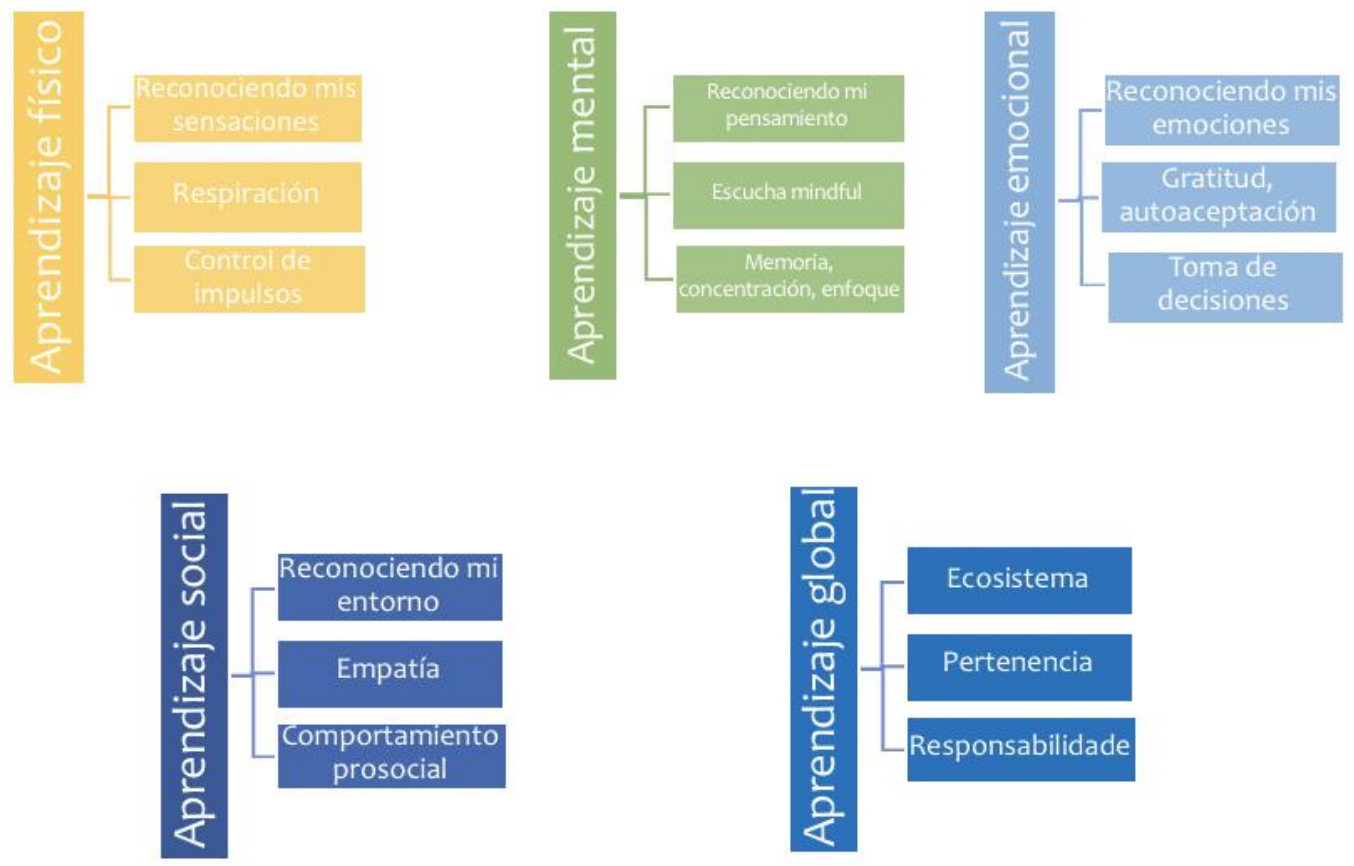

Reconociendo $\mathrm{mi}$

entorno

Empatía

Comportamiento

\section{Objetivos}

- Enfocarte en el aquí y ahora

- Tomar conciencia de tus emociones, sensaciones, pensamientos y relaciones

- Afianzar la relación contigo/a mismo/a

- Aprender a controlar tus impulsos

- Motivar tu ecuanimidad y empatía

- Incrementar tu autoestima y auto valía

- Promover tu iniciativa y creatividad

- Incrementar tu concentración para mejorar tu desempeño académico y general

Elaboración propia 
Los resultados de satisfacción se detallan a continuación:

Tabla 1.3

Resultados de talleres Piloto

\begin{tabular}{lcc}
\hline Factor & Taller San Isidro & Taller Miraflores \\
\hline$\%$ de satisfacción general & $74.30 \%$ & $84 \%$ \\
Actividades & $75 \%$ & $86 \%$ \\
Meditación & $80 \%$ & $82 \%$ \\
Teoría & $63 \%$ & $76 \%$ \\
Información complementaria & $76 \%$ & $75 \%$ \\
Desempeño de instructoras & $78 \%$ & $96 \%$ \\
\hline
\end{tabular}

Elaboración propia

Apreciaciones:

- Podemos identificar una satisfacción mayor en el taller de Miraflores con una diferencia de casi 10 puntos porcentuales.

- Un aspecto evidente a mejorar por ser la puntuación más baja es la de "Teoría" e "Información complementaria".

- El aspecto que genera gran diferencia en la satisfacción es el desempeño de las instructoras. Esto puede significar que el público de San Isidro es más exigente o la calidad de los instructores puede verse afectado por la cantidad de personas por taller.

- En ambos talleres se sugirió desarrollar más los aspectos de: emociones, estrés y relaciones.

- Sobre lo calificado como “¿Qué fue lo que menos te gustó?” se encuentra: horarios (43\%) y poca disposición de algunos integrantes del grupo (13\%). Cabe resaltar que en horarios encontramos descripciones como cansancio y estrés (San Isidro). La Encuesta de Satisfacción de Piloto de Talleres, se detalla a continuación. 
Figura 1.13

Resultados de satisfacción de talleres piloto

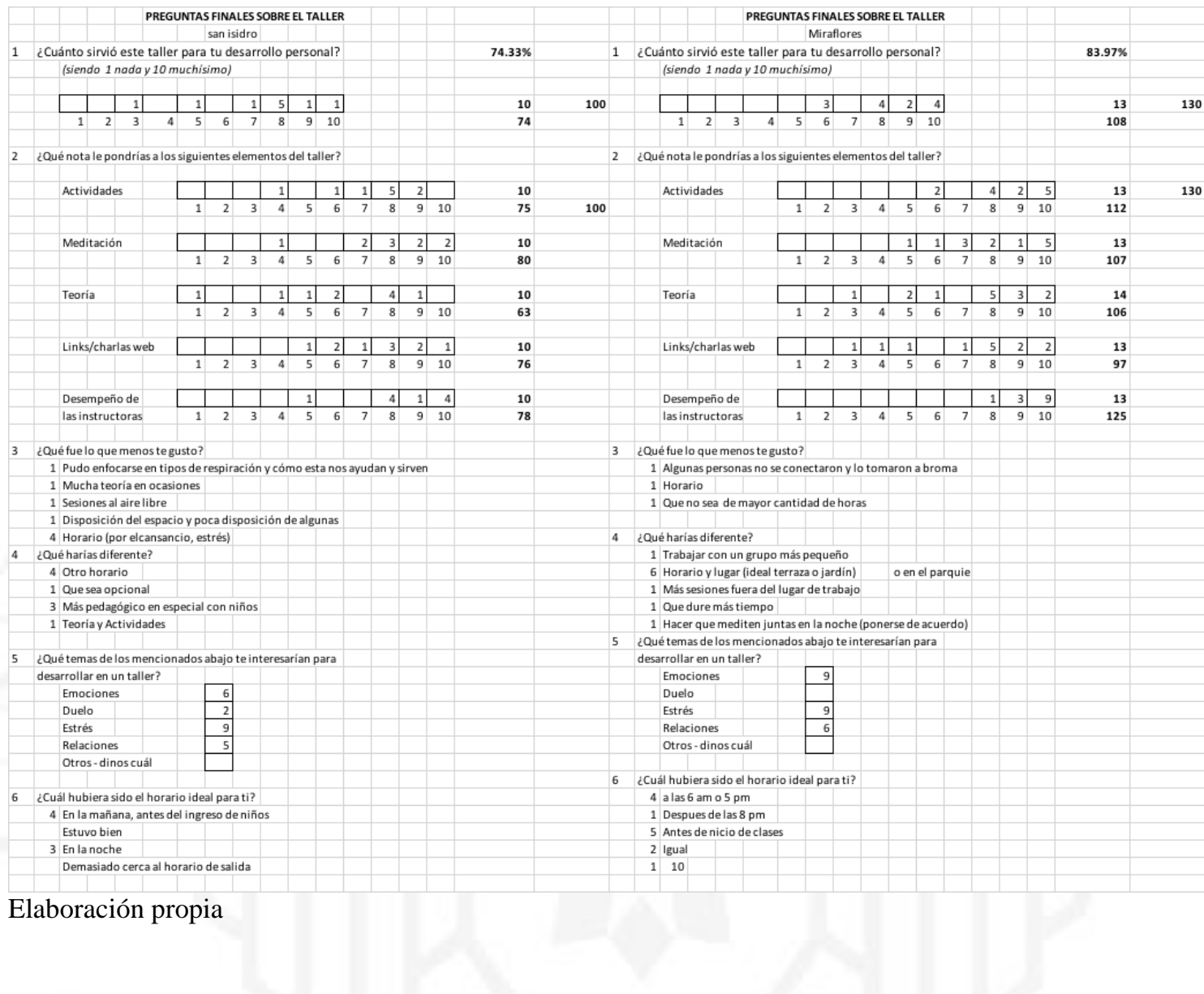

- Queda evidenciado que dependerá del perfil al que nos dirigiremos en cada taller para definir horarios. Algunos horarios elegidos fueron:

- Personas con horario de trabajo fijo: antes o después del trabajo (6 a.m. o 7:30 p.m.)

- Personas padres de familia: antes del ingreso de niños al colegio o en las noches.

Los horarios de los Pilotos de Talleres fueron los siguientes: 
Tabla 1.4

Horario de talleres piloto

\begin{tabular}{cc}
\hline MIRAFLORES & SAN ISIDRO \\
\hline Martes y & Lunes y Miércoles \\
Jueves & $7.00 \mathrm{pm}-8.30 \mathrm{pm}$ \\
$10.30 \mathrm{am}-12 \mathrm{pm}$ & \\
$7.00 \mathrm{pm}-8.30 \mathrm{pm}$ & \\
\hline
\end{tabular}

Elaboración propia

El precio piloto de cada taller que consistió en 6 sesiones de $1.5 \mathrm{hrs}$ cada uno durante 3 semanas fue de S/. 360.00 por persona. Cada grupo estuvo conformado por 8 personas.

\subsection{Análisis del comportamiento del comprador}

Luego de la investigación de mercado, podemos tomar a nuestro consumidor con la descripción detallada a continuación.

Nuestro público objetivo está interesado en el bienestar mental y físico, con el fin de desarrollar habilidades a través del autoconocimiento. La mayoría de personas que buscan este servicio tienden a estar estresadas, enfermas y/o preocupadas por su físico. Son personas que buscan la felicidad, y muchas veces no la alcanzan porque necesitan un espacio y tiempo para poder relajarse y, así conocerse.

Lo primero que inferimos con la ayuda de las personas entrevistadas fue que la mayoría eran del público femenino, siendo ejecutivos y profesionales (independientes y dependientes). Nuestro público es del nivel socioeconómico A y B de los distritos de Miraflores, Surco, San Isidro, San Borja y La Molina. Por las entrevistas, podemos concluir que este perfil se debe a que, muy aparte de tener poder adquisitivo, tienen eduación. Por ello, representan personas más conscientes del beneficio de lograr la autorrealización a través de desarrollar habilidades. Estas habilidades se desarrollan por el autoconocimiento.

Según las encuestas, el nivel de aceptación por un servicio de bienestar es alto (49\%) y es similar para mujeres y hombres. Las edades de mayor aceptación para mujeres son entre 18 y 25 años y mayores de 50 años. En el caso de hombres, el interés está en las edades de entre 
18 y 40 años. También se encontró a un público que en su mayoría se siente satisfecho con la oferta del mercado. Sin embargo, solo la tercera parte considera que el servicio que tomó fue más de lo que esperaba. Nuestra estrategia es diferenciarnos del mercado con un servicio que supere las expectativas del cliente consumidor de este tipo de servicios.

Estos compradores desean encontrar un servicio de calidad, alta experiencia del expositor y horarios de los talleres accesibles. Prefieren asistir a estos talleres los días martes, miércoles y jueves, sin embargo, no encontramos ningún día muy diferenciado. El horario con mayor aceptación fue el de las 7:30 - 9:30 p.m. Existe una demanda potencial para clases virtuales.

La recordación de marca es baja, se encontró que casi la mitad de encuestados no recuerdan el nombre de la empresa en la cual asistieron a un servicio de bienestar. Se encontró que un motivo de la mayoría de encuestados para no asistir a un taller de bienestar es "No lo habían considerado". Por ello, sabemos que es crucial tener en cuenta un eficiente plan de comunicación del presente servicio para generar una demanda del mismo.

Nuestro público objetivo utiliza, en mayor proporción las redes sociales de Facebook, Whatsapp y correo eletrónico. También podemos, encontrarlos pero en menor proproción, en Instagram, Youtube y Linkedin.

En conclusión, la decisión del consumidor por optar por nuestros servicios considera fundamental los siguientes puntos:

- Contar con talleres dinámicos, sustento teórico y científico.

- Tener un equipo de especialistas que lideren los talleres.

- Brindar un espacio para desarrollar actividades que promuevan el autoconocimiento.

- Tener en cuenta evaluaciones personales, para volver el presente servicio especializado y adaptado a la persona.

- Comunicarle al público los beneficios del servicio antes de nombrar las características del mismo.

- Tener aliados de especialistas que recomienden el servicio para incrementar el bienestar de sus pacientes/clientes.

- Nuestra estrategia para diferenciarnos del mercado es con un servicio que supere las expectativas del cliente consumidor de este tipo de servicios. 
- Posicionarnos como marca por no existir una alta recordación de marca.

- Tener un eficiente plan de comunicación que incluya un aspecto informativo sobre beneficios de nuestro servicio para generar una demanda.

- Incluir en el plan de comunicación Facebook, Whatsapp, Correo electrónico, Instagram, Youtube y Linkedin como redes sociales.

\subsection{Análisis de los competidores (oferta)}

Tabla1.5

Análisis de competidores

\begin{tabular}{|l|c|c|c|c|c|c|c}
\hline \multicolumn{2}{l}{} & Mindfulness Perú & \multicolumn{2}{c|}{ Conciencia Plena } & \multicolumn{2}{c}{ Inside Up } \\
\hline Factores de éxito & Ponderación & Nota & Puntaje & Nota & Puntaje & Nota & Puntaje \\
\hline Recordación de marca & $5 \%$ & 4 & 0.2 & 2 & 0.1 & 4 & 0.2 \\
\hline Lealtar de los clientes & $12 \%$ & 2 & 0.24 & 2 & 0.24 & 4 & 0.48 \\
\hline Participación en el mercado & $8 \%$ & 2 & 0.16 & 1 & 0.08 & 3 & 0.24 \\
\hline Posición financiera & $12 \%$ & 1 & 0.12 & 1 & 0.12 & 4 & 0.48 \\
\hline Competitividad de precios & $15 \%$ & 3 & 0.45 & 4 & 0.6 & 2 & 0.3 \\
\hline Calidad del servicio & $18 \%$ & 2 & 0.36 & 2 & 0.36 & 4 & 0.72 \\
\hline Expansión global & $5 \%$ & 1 & 0.05 & 1 & 0.05 & 4 & 0.2 \\
\hline Innovación constante & $5 \%$ & 1 & 0.05 & 1 & 0.05 & 4 & 0.2 \\
\hline Experiencia en el sector & $10 \%$ & 4 & 0.4 & 4 & 0.4 & 4 & 0.4 \\
\hline Publicidad & $10 \%$ & 2 & 0.2 & 1 & 0.1 & 4 & 0.4 \\
\hline RESULTADO & $100 \%$ & & 2.23 & & 2 & & 3.62 \\
\hline
\end{tabular}

Elaboración propia

Luego de analizar la oferta de competidores, se puede decir que Inside Up es el mayor competidor.

\subsection{Estrategias de distribución que se usan actualmente en la competencia}

\section{Estrategias de Distribución:}

El tipo de distribución es directo, ya que es un servicio que brinda dos coach a los participantes en casa sesión en el salón designado, según cada taller. En este caso, el tipo de canal a utilizar es el canal corto, ya que es un servicio que se entrega directamente del instructor al participante en las sesiones. No pasa por ningún intermediario.

\subsection{Análisis del entorno y matriz EFE}




\section{Análisis del entorno}

\section{- Factor Político/ Legal:}

El 2018 es un año con un entorno político inestable debido a las elecciones municipales y regionales así como por todos los problemas políticos y legales que vemos día a día. Sin embargo, el Perú posee una tendencia positiva a promover la inversión privada, por lo que no existen indicios de riesgo para el negocio de bienestar personal.

\section{- Factor Económico:}

Si bien en el 2017, el Producto Bruto Interno del Perú anotó un crecimiento de $2.5 \%$, un resultado por debajo de la meta de $2.8 \%$ que proyectaba el gobierno, el Banco Central de Reserva estima crecimientos de $4.2 \%$ para los años 2018 y 2019. Las favorables perspectivas económicas para el Perú se sustentan en el impulso del consumo privado y en los anuncios de ejecución de proyectos de inversión tanto privados como públicos. Por tal motivo, los consumidores tendrán un gran poder adquisitivo que les permita adquirir los servicios de bienestar personal que ofrecemos.

\section{- Factor Social/Cultural y Demográfico:}

Las personas se están preocupando más por el cuidado de su salud física y mental, lo cual ha generado un hábito e incremento en el consumo de productos y servicios de bienestar personal.

\section{- Factores Tecnológicos:}

Al tratarse de un servicio de bienestar personal que consiste básicamente en talleres y retiros, no existen factores tecnológicos que afecten de manera considerable este negocio.

\section{ANALISIS DEL MICROENTORNO (5 FUERZAS)}

\section{- Rivalidad de la industria}

Se considera que la rivalidad es BAJA debido a los siguientes factores: la estructura de la industria no está consolidada, porque no existen competidores con alta participación de mercado o posicionados en el sector de manera relevante. Los costos de elegir entre una empresa y otra son bajos, lo cual eleva la rivalidad. El crecimiento del mercado es alto y eso baja la rivalidad. El mercado es amplio y se encuentra desatendido o insatisfecho.

\section{- Amenaza de competidores potenciales}


ALTA, debido a que para poder ser asesor de este estilo de vida solo se debe realizar un curso Online de 6 semanas y se obtiene un certificado de coach. Además, para poder capacitar a alguien en Mindfulness solo deberá tomar un curso adicional Online. La inversión es baja ya que se incurren en gastos de alquiler y personal capacitado en Mindfulness como prioritarios. Esto no representa un monto alto. Sin embargo, se puede enfocar en que si se obtiene un coach y psicólogo especializado en el tema puede resultar un servicio que no se encuentra fácilmente en el mercado hoy en día.

\section{- Amenaza de ingreso de productos sustitutos}

ALTA, debido a que hay muchos talleres, seminarios y cursos que buscan cubrir estas necesidades de bienestar en las personas.

\section{- Poder de negociación de los proveedores}

ALTA. Como proveedores uno se refiere a especialistas psicólogos y coaches. Por lo tanto, se considera que es alta porque son pocos los especialistas en Mindfulness y esto hace que ellos tengan el poder a la hora de negociar el precio de contratación.

\section{- Poder de negociación de los clientes}

BAJA. Al no existir todavía gran oferta de terapias Mindfulness, el cliente no puede decidir ni tiene gran noción de precios referenciales. 


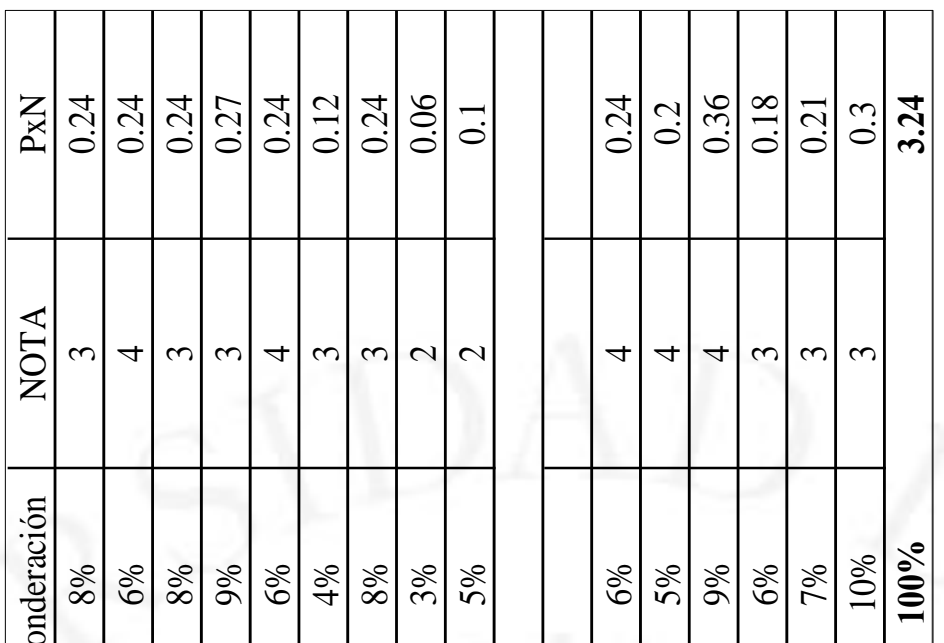
คำ

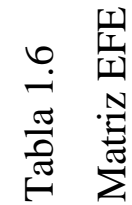

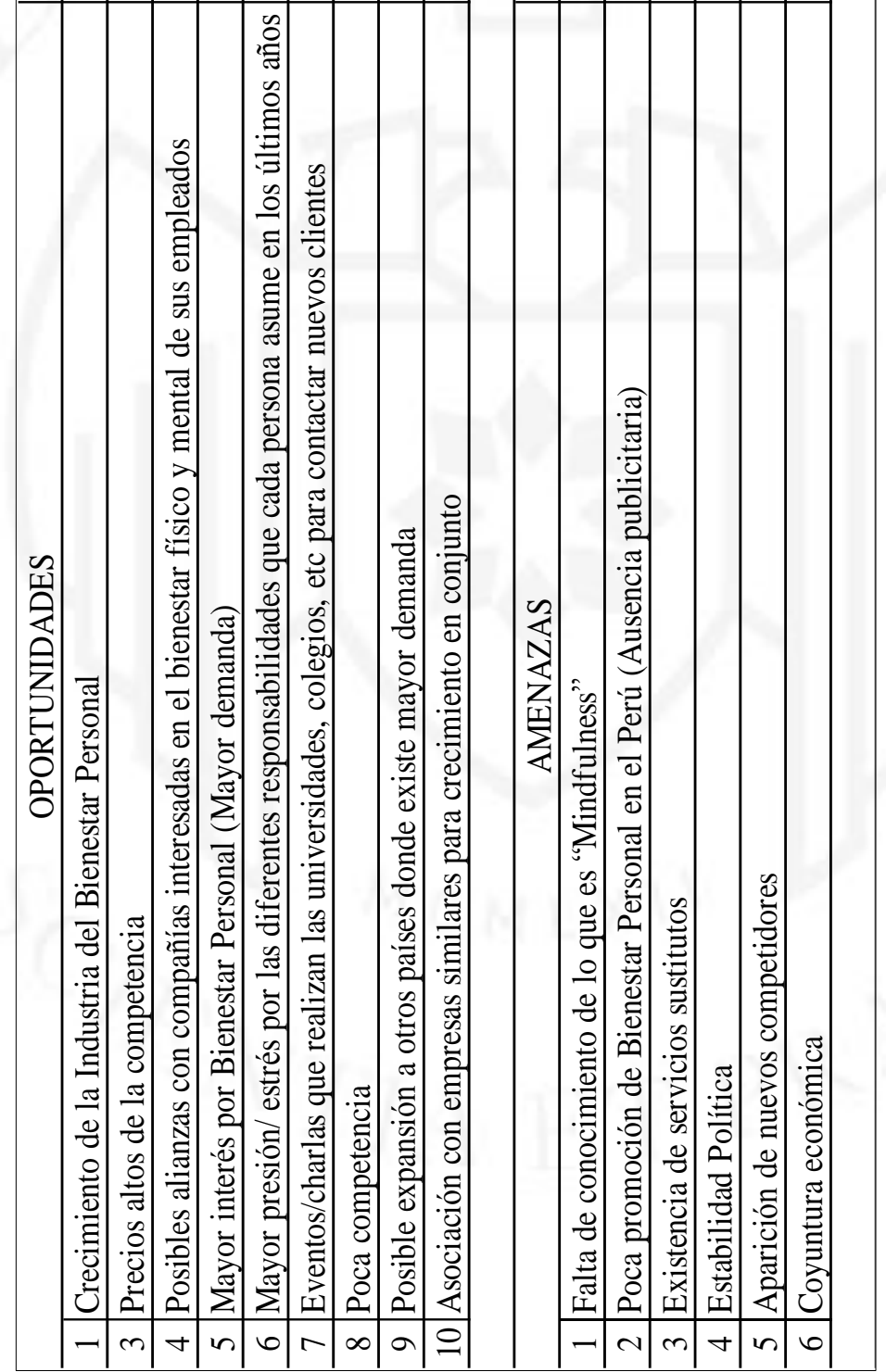

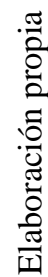


Podemos ver en esta matriz de qué manera respondería Agora con respecto al entorno externo. Tenemos un resultados de 3.24 lo cual está bien debido a que estamos por encima de la media, lo cual indica que hay oportunidades que favorecen al proyecto.

A pesar de la falta de conocimiento de lo que es "Mindfulness" en nuestro país, vamos a dirigir nuestro esfuerzo a ello con el fin de difundir el concepto y que llegue cada día a más personas, aprovechando que hoy en día hay mayor interés por el Bienestar Personal; es decir, hay mayor demanda lo cual es una gran oportunidad a trabajar.

\subsection{Cadena de valor y matriz EFI}

Figura 1.14

Cadena de valor

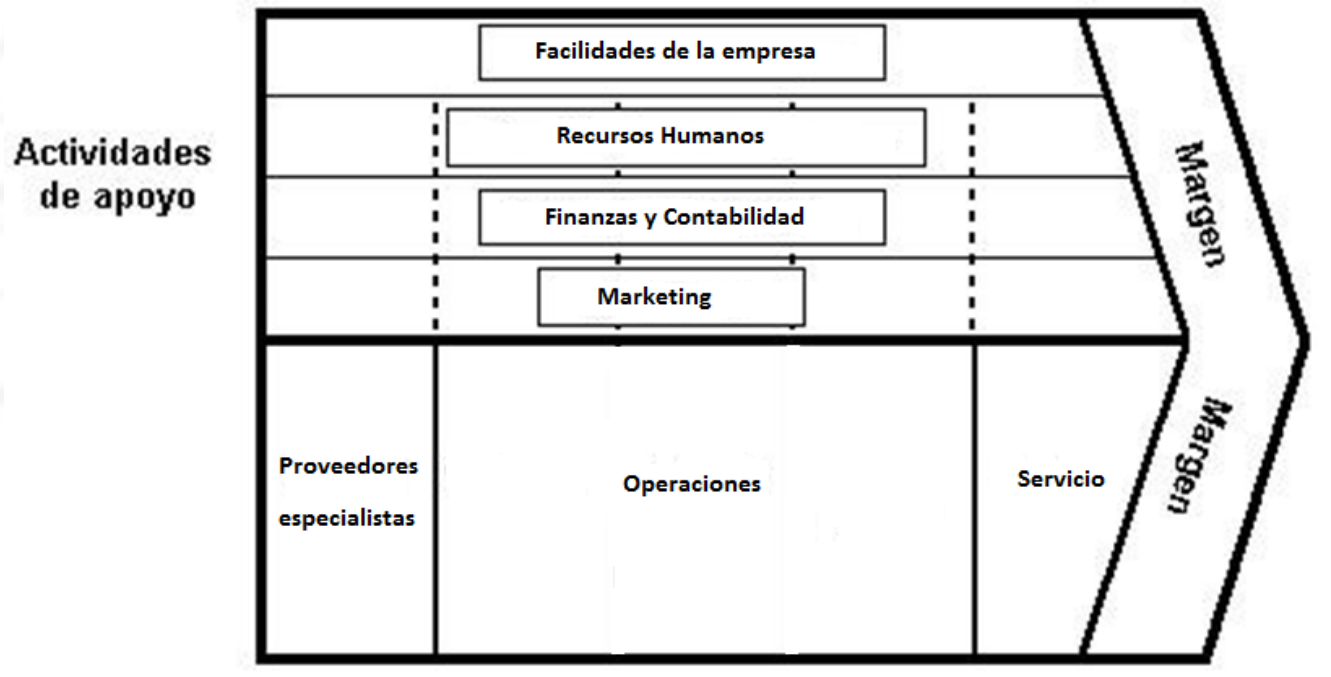

Actividades primarias

Elaboración propia

Podemos ver en la cadena de valor que las principales actividades de apoyo son las facilidades de la empresa pues contaremos con las siguientes áreas: Recursos Humanos ya que nuestro negocio se basa principalmente en las personas; Finanzas y Contabilidad, para poder estar informados de la inversión y la rentabilidad que iremos generando con el transcurso del tiempo; y por último el área de marketing, una de las áreas más importantes ya que gracias a esta área podremos desarrollar acciones estratégicas con el fin de hacernos más conocidos. Inicialmente no contaremos con un presupuesto tan elevado para campañas publicitarias 
masivas pero para empezar nos enfocaremos en hacer un buen trabajo en las redes sociales y el "boca a boca".

Con respecto a las actividades primarias de la empresa, el activo más importante serán nuestros especialistas, los profesionales que se encargarán de brindar el mejor servicios a nuestros clientes. Ellos serán responsables de la calidad de servicio que brindaremos día a día. Operaciones comprende desde temas administrativos como la inscripción de un nuevo cliente hasta temas internos como la planificación de las actividades, cursos, talleres y los horarios para los diferentes grupos. Finalmente, con respecto al servicio, nuestro objetivo es brindar un servicio diferenciado con el fin de lograr bienestar físico y mental de nuestros clientes; así como ayudarlos a conocerse un poco más, y puedan desarrollar diferentes habilidades mediante las técnicas y herramientas que le ofreceremos.

Tabla 1.7

Matriz EFI

\begin{tabular}{|c|c|c|c|c|}
\hline \multicolumn{2}{|r|}{ FORTALEZAS } & Ponderación & NOTA & PxN \\
\hline 1 & $\begin{array}{l}\text { Se cuenta con profesionales altamente capacitados y con previa experiencia en el } \\
\text { rubro }\end{array}$ & $9 \%$ & 3 & 0.30 \\
\hline 2 & Buena infraestructura del local y ambiente adecuado donde se dictarán los talleres & $6 \%$ & 4 & 0.28 \\
\hline 3 & Buena ubicación del local & $5 \%$ & 3 & 0.18 \\
\hline 4 & Servicio adaptado a cada segmento del mercado & $6 \%$ & 4 & 0.28 \\
\hline 5 & Producto/ Servicio saludable y novedoso & $9 \%$ & 4 & 0.4 \\
\hline 6 & Estabilidad y liderazgo del personal directivo en la empresa & $4 \%$ & 4 & 0.2 \\
\hline 7 & Actitud abierta al cambio, flexibilidad y adaptación a nuevas situaciones & $6 \%$ & 4 & 0.28 \\
\hline 8 & Los objetivos estratégicos están alineados a la misión y visión de la empresa & $6 \%$ & 4 & 0.28 \\
\hline \multicolumn{5}{|c|}{ DEBILIDADES } \\
\hline 1 & No contar con infraestructura propia. Costos altos & $7 \%$ & 1 & 0.08 \\
\hline 2 & Falta de reconocimiento en el mercado por ser una empresa nueva & $7 \%$ & 1 & 0.08 \\
\hline 3 & Elevada dependencia de los Recursos Humanos especilizados & $8 \%$ & 1 & 0.09 \\
\hline 4 & Tamaño empresarial reducido & $6 \%$ & 2 & 0.14 \\
\hline 5 & Al ser una empresa nueva la participación del mercado inicialmente podría ser baja & $8 \%$ & 2 & 0.18 \\
\hline 6 & Presupuesto limitado para esfuerzos de marketing & $7 \%$ & 1 & 0.07 \\
\hline \multirow[t]{2}{*}{7} & Presupuesto limitado para fuerza de ventas & $6 \%$ & 1 & 0.06 \\
\hline & & $100 \%$ & & 2.9 \\
\hline
\end{tabular}

Elaboración propia

Se puede ver en la tabla 1.7 las diferentes fortalezas y debilidades de la empresa, y ver qué estamos preparados para enfrentar los diferentes retos del mercado. Esto nos servirá para 
la formulación de diversas estrategias a desarrollar. Nuestro resultado fue de 2.9 lo cual significa que Agora está por encima del promedio (2.5) y está en capacidad de aprovechar las oportunidades y minimizar las amenazas del mercado.

A pesar que inicialmente se tendrá un presupuesto limitado para las ventas y marketing, se cuenta con profesionales altamente capacitados y con previa experiencia en el mercado, otro punto muy importante es la muy buena infraestructura del local y el ambiente adecuado donde se realizarán los talleres, los cuales son aspectos de gran importancia para el cliente.

\subsection{Matriz EI}

Después de realizar las matrices EFE y EFI los resultados son los siguientes:

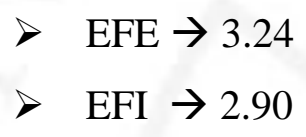

Figura 1.15

Matriz EI

Resultados ponderados totales de matriz de evaluación de factor interno

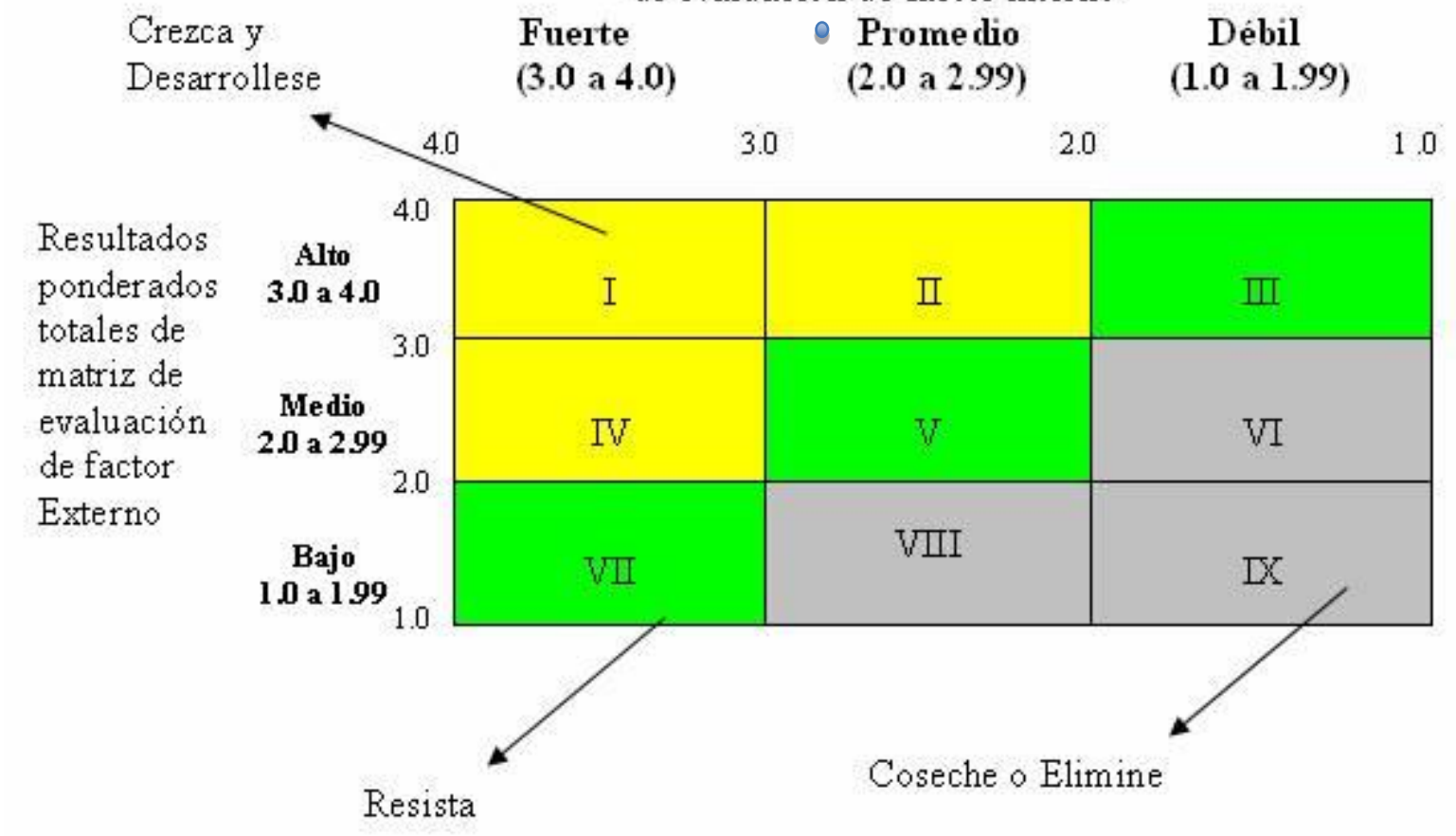

Elaboración propia 
Al colocar esos puntajes en la matriz, se puede ver que el resultado se ubica en el II cuadrante, lo cual quiere decir que se tiene que desarrollar una estrategia de CRECIMIENTO Y DESARROLLO. Se debe hacer conocido el servicio que se ofrece mediante las diferentes redes sociales, dar a conocer la ventaja competitiva, demostrar que se tiene profesionales altamente capacitados en lo que se ofrece y sobretodo brindar confianza al cliente. Hacer saber las fortalezas del servicio y desarrollar la publicidad necesaria, lanzar promociones ya que es un servicio prácticamente nuevo en el Perú pero con mucho potencial. 


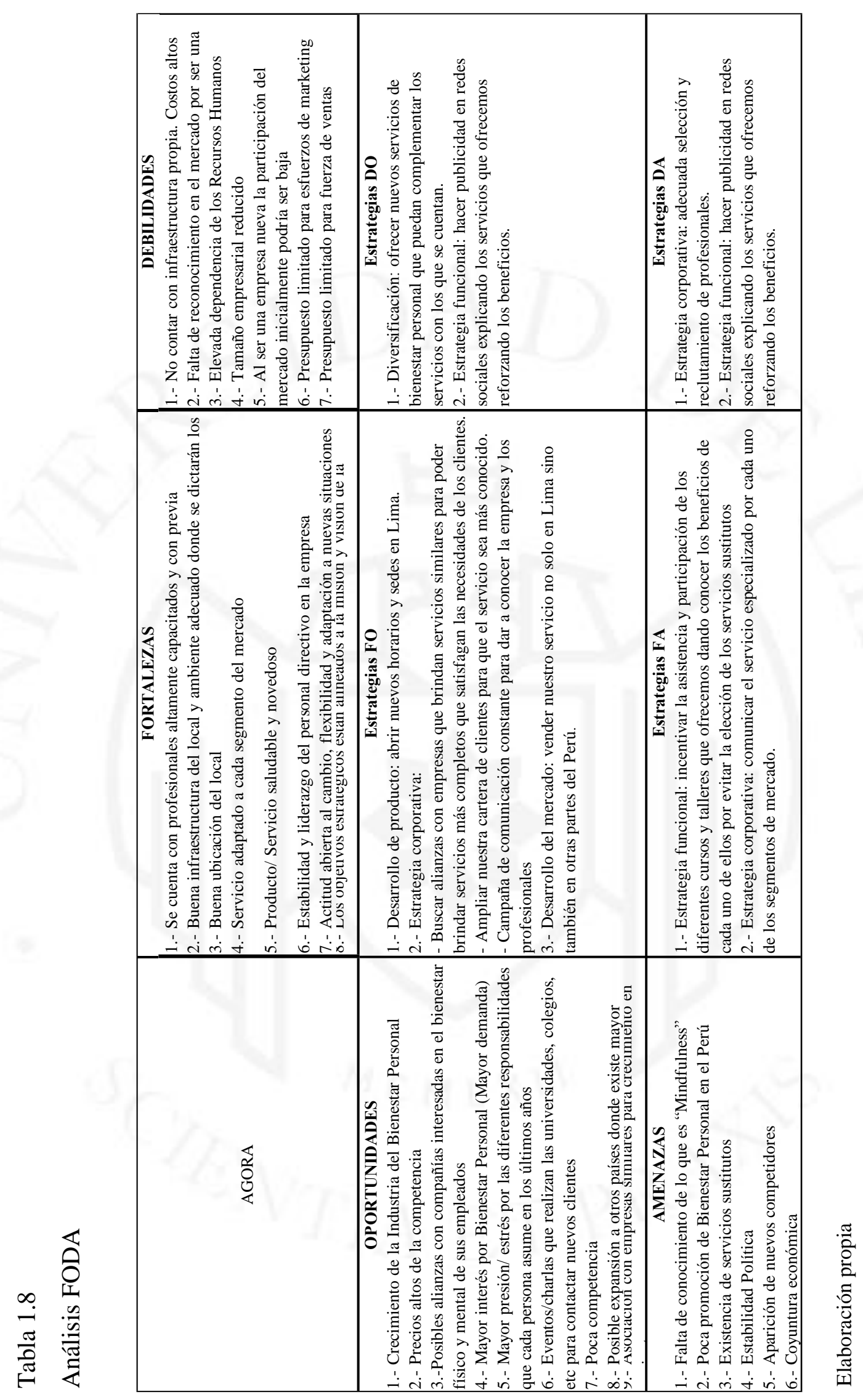




\subsection{Determinación de la estrategia genérica}

La estrategia que se va a implementar en el mercado objetivo al que se está apuntando es la Estrategia de Diferenciación de Michael Porter enfocada en el valor, ya que al ser un servicio de muy alta calidad, innovador y que ofrece muchas experiencias al consumidor, la idea es diferenciarnos de la competencia, entregándole un servicio con alto valor para el cliente, superando sus expectativas. De esta forma, se busca que el cliente viva una experiencia única desde que entra al curso, diferenciándonos de los demás.

\subsection{Determinación y sustento de la demanda}

Tabla 1.9

Datos de la demanda

\begin{tabular}{|c|c|c|}
\hline \multicolumn{2}{|l|}{ HOMBRES Y MUJERES } & MISION Y VISION \\
\hline $\begin{array}{l}\text { HOMBRES Y MUJERES } \\
20 \text { - } 60 \text { AÑOS }\end{array}$ & & MISION Y VISION \\
\hline \multicolumn{2}{|l|}{ NSE A Y B } & MISION Y VISION \\
\hline \multicolumn{2}{|l|}{ DISTRITOS MIRA, SI, SB, S, LM } & MISION Y VISION \\
\hline \multicolumn{2}{|l|}{ EJECUTIVOS Y PROFESIONALES } & MISION Y VISION \\
\hline DIJERON SI EJ / PROF & $54 \%$ & ENCUESTA \\
\hline FRECUENCIA & 6 SERVICIO / MES & ENCUESTA \\
\hline CANTIDAD & 1 & ENCUESTA \\
\hline PRECIO & 230 & ENCUESTA \\
\hline
\end{tabular}

Elaboración propia

Se tomó la decisión, luego de la investigación de mercado, de tener un público objetivo de hombres y mujeres profesionales y ejecutivos, de NSE A y B, entre 20 a 60 años y que viven en Miraflores, San Isidro, San Borja, Surco y La Molina.

El nivel de aceptación de nuestro producto en las encuestas es del 54\% para los ejecutivos y profesionales. Los recién mencionados, requieren de un paquete que comprende 6 clases al mes con un precio de S/ 230.00 mensual. 
Figura 1.16

Población por segmento de edad

\section{Gráfico $\mathbb{N}^{\circ} 7$}

\section{Lima Metropolitana:}

Población Por Segmento de Edad 2017

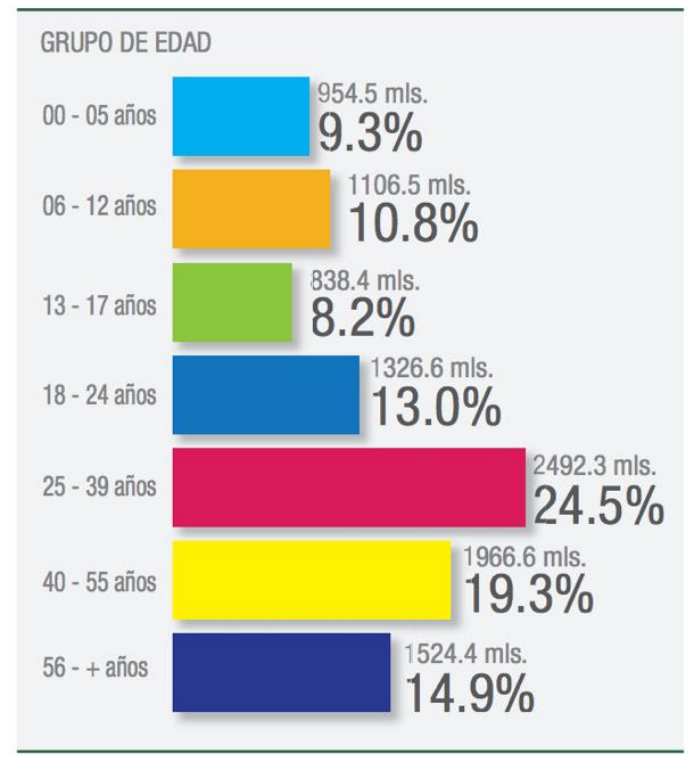

Fuente: INEI (año)

Tabla 1.10

Cálculo de la demanda

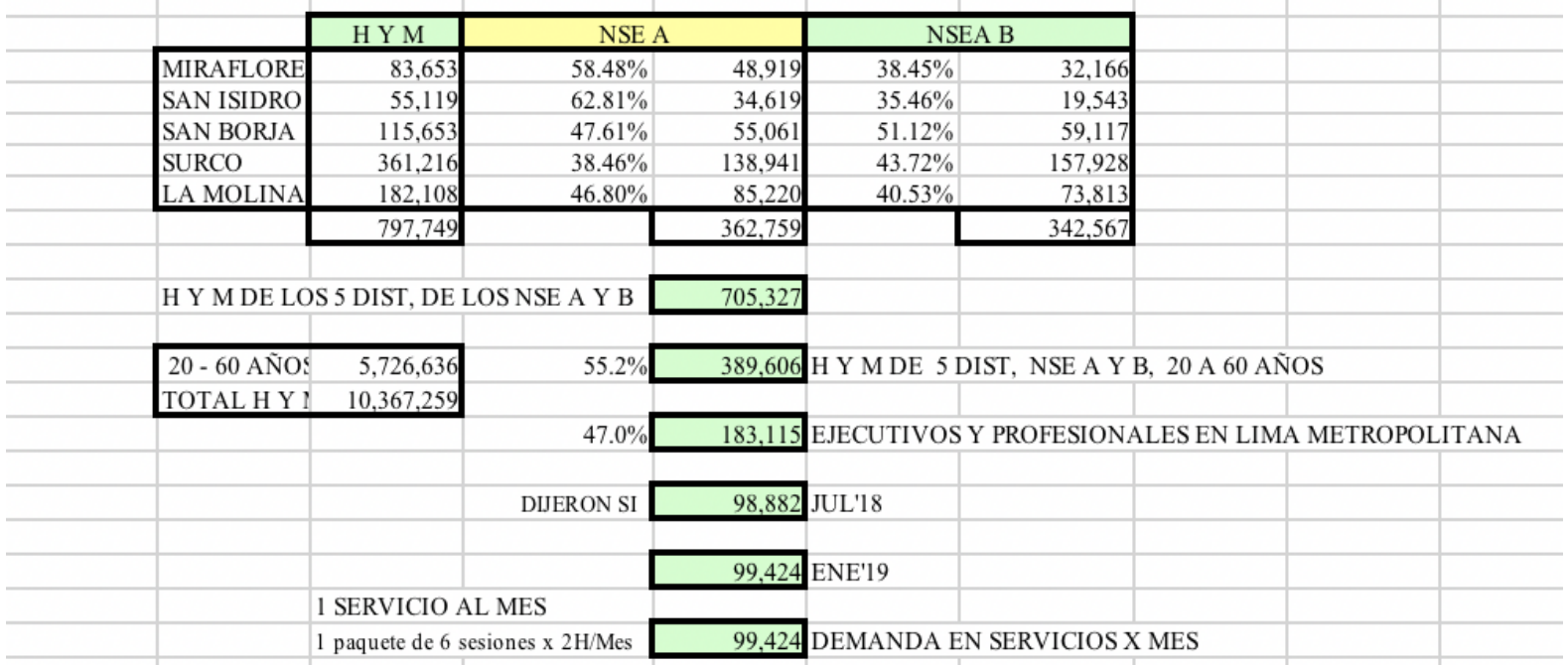

Elaboración propia 
Al calcular la demanda, consideramos 389,606 personas con el perfil que se busca atacar. Del total de la PEA, el $47 \%$ de la población son ejecutivos y profesionales (basado en el estudio del INEI 2016). Nuestra demanda, entonces, es de 99,424 paquetes de servicios en un mes que corresponden a la cantidad de personas que adquieren un servicio de 6 sesiones de 2 horas, cada una de ellas en un mes.

Nuestros días picos son los miércoles y habrá una caída de las ventas los lunes y viernes. Esto se desarrollará de esa manera por apuntar a un público más ocupado un día en el que empieza la semana y un viernes en el que prefiere salir a socializar.

\subsection{Determinación de la participación y sustento de la demanda}

Tabla 1.11

Participación y sustento de la demanda

\begin{tabular}{|c|c|c|c|c|c|c|c|c|}
\hline \multirow{2}{*}{\multicolumn{2}{|c|}{$\begin{array}{l}\text { HOMBRES Y MUJERES } \\
20-60 \text { AÑOS }\end{array}$}} & & MISION Y VISION & & & & & \\
\hline & & & MISION Y VISION & & & & & \\
\hline NSE A Y B & & & MISION Y VISION & & & & & \\
\hline DISTRITOS & \multicolumn{2}{|c|}{ MIRA, SI, SB, S, LM } & MISION Y VISION & & & & & \\
\hline \multicolumn{3}{|c|}{ EJECUTIVOS Y PROFESIONALES } & MISION Y VISION & & & & & \\
\hline \multicolumn{2}{|c|}{ DIJERON SI EJ / PROF } & $54 \%$ & ENCUESTA & & & & & \\
\hline \multicolumn{2}{|c|}{ FRECUENCIA } & $6 / \mathrm{MES}$ & ENCUESTA & & & & & \\
\hline CANTIDAD & & 1 & ENCUESTA & & & & & \\
\hline \multirow[t]{20}{*}{ PRECIO } & & 230 & ENCUESTA & & & & & \\
\hline & & HYM & NSE A & & NSE & $\mathrm{EA} \mathrm{B}$ & & \\
\hline & MIRAFLORE & 83,653 & $58.48 \%$ & 48,919 & $38.45 \%$ & 32,166 & & \\
\hline & SAN ISIDRO & 55,119 & $62.81 \%$ & 34,619 & $35.46 \%$ & 19,543 & & \\
\hline & SAN BORJA & 115,653 & $47.61 \%$ & 55,061 & $51.12 \%$ & 59,117 & & \\
\hline & SURCO & 361,216 & $38.46 \%$ & 138,941 & $43.72 \%$ & 157,928 & & \\
\hline & LA MOLINA & 182,108 & $46.80 \%$ & 85,220 & $40.53 \%$ & 73,813 & & \\
\hline & & 797,749 & & 362,759 & & 342,567 & & \\
\hline & & & & & & & & \\
\hline & \multicolumn{3}{|c|}{ HY M DE LOS 5 DIST, DE LOS NSE A Y B } & 705,327 & & & & \\
\hline & & & & & & & & \\
\hline & $20-60$ AÑO & $5,726,636$ & $55.2 \%$ & 389,606 & ]HYMDE $5 \mathrm{D}$ & DIST, NSE A Y & $B, 20$ A 60 AÑOS & \\
\hline & TOTAL HYN & $10,367,259$ & & & & & & \\
\hline & & & $47.0 \%$ & 183,115 & EJECUTIVOS & Y PROFESION & IALES EN LIMA ME & ETROPOLITANA \\
\hline & & & & & & & & \\
\hline & & & DIJERON SI & 98,882 & JUL'18 & & & \\
\hline & & & & & & & & \\
\hline & & & & 99,424 & ENE'19 & & & \\
\hline & & 1 SERVICIO & AL MES & & & & & \\
\hline & & 1 paquete de 6 & sesiones $\times 2 \mathrm{H} / \mathrm{Mes}$ & 99,424 & DEMANDA EN & N SERVICIOS $X$ & MES & \\
\hline
\end{tabular}

Elaboración propia

La participación de mercado que se desea llegar en el quinto año es de $0.31 \%$. El período más importante de ventas es el primer año debido a que se buscará asociar rápidamente bienestar con nuestra marca a los consumidores. El crecimiento luego será más lento y con 
esfuerzos constantes. La idea es buscar la diferenciación de nuestro servicio a través de la experiencia.

Tabla 1.12

Participación y crecimiento por año

\begin{tabular}{l|ll}
\hline & \multicolumn{2}{|c}{ \% partic } \\
\hline Año 0 & $0.00 \%$ & $0.10 \%$ \\
Año 1 & $0.10 \%$ & $0.08 \%$ \\
Año 2 & $0.18 \%$ & $0.06 \%$ \\
Año 3 & $0.24 \%$ & $0.04 \%$ \\
Año 4 & $0.28 \%$ & $0.02 \%$ \\
Año 5 & $0.31 \%$ & \\
\hline
\end{tabular}

Elaboración propia

Figura 1.17

Evolución de la participación de mercado

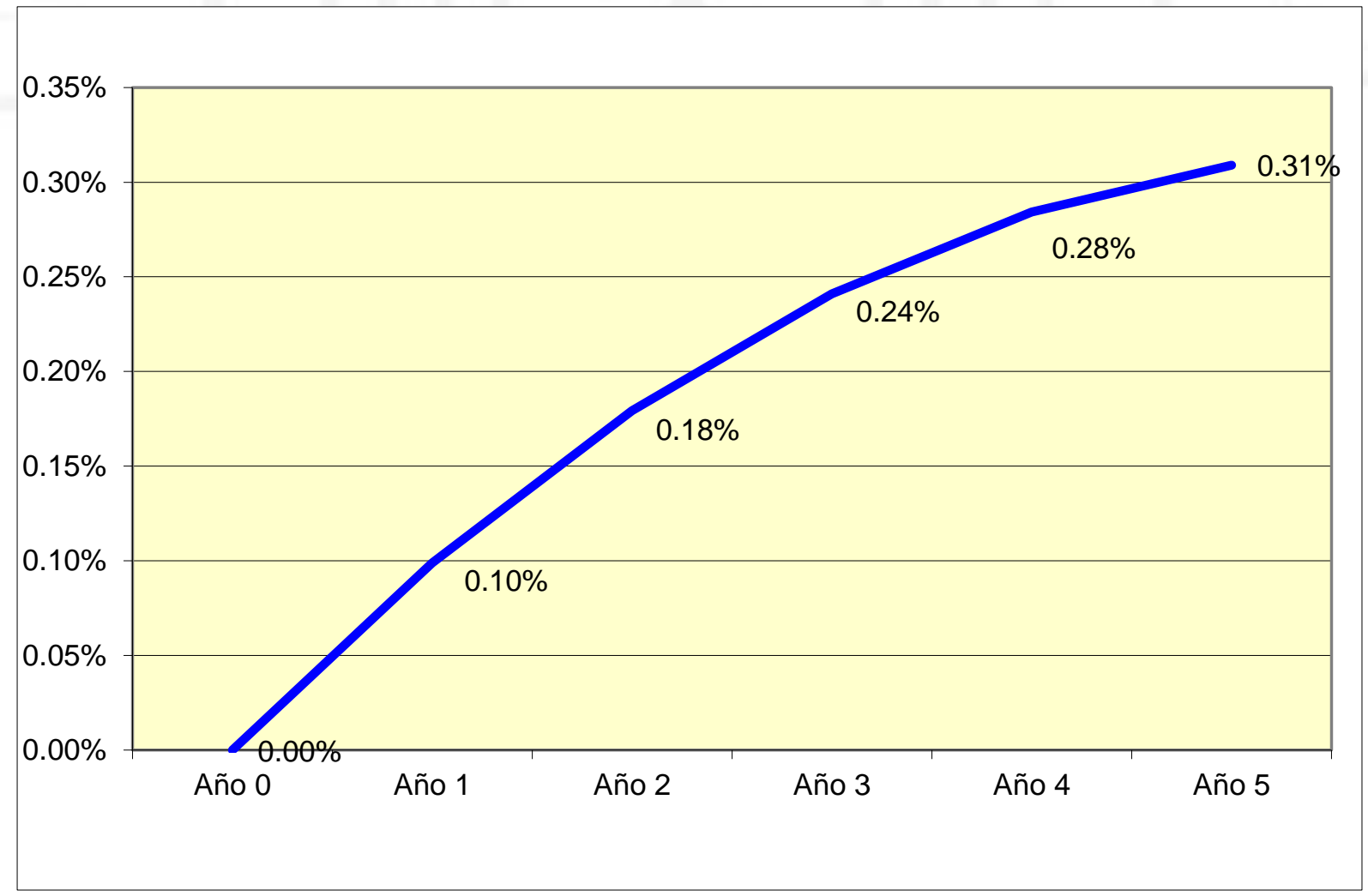

Elaboración propia 
Figura 1.18

Demanda por día

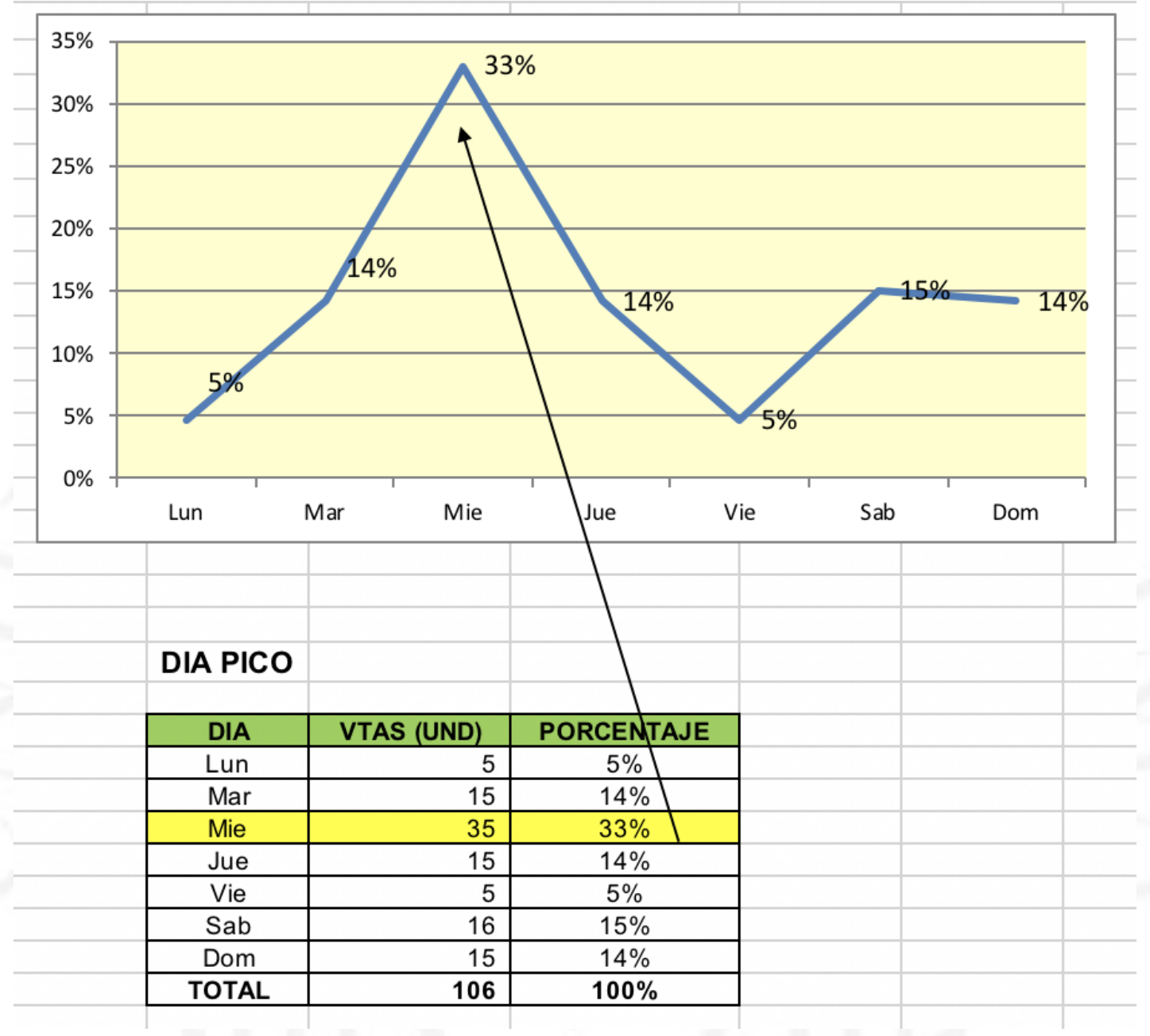

Elaboración propia

En Lima Metropolitana existe una población de 10`209,300 personas. La PEA, en ese ámbito geográfico es de 4`782,197. Por ello tenemos una proporcionalidad de 47\% que se toma en cuenta en nuestra demanda. 
Tabla 1.13

PEA por año

\begin{tabular}{|c|c|c|c|c|c|c|c|c|c|c|}
\hline \multicolumn{11}{|c|}{ POBLACIÓN ECONÓMICAMENTE ACTIVA, SEGÚN NIVELES DE EMPLEO, 2007-2016 } \\
\hline \multicolumn{11}{|c|}{\begin{tabular}{|l|l|l|l|} 
(Miles de personas) & & \\
\end{tabular}} \\
\hline Niveles de Empleo & 2007 & 2008 & 2009 & 2010 & 2011 & 2012 & 2013 & 2014 & 2015 & 2016 \\
\hline Total PEA & 4385.0 & 4410.4 & 4514.0 & 4703.7 & 4781.2 & 4812.2 & 4885.1 & 4916.5 & 5015.4 & 5128.4 \\
\hline PEA ocupada & 4016.7 & 4040.9 & 4135.4 & 4332.1 & 4414.8 & 4484.9 & 4594.2 & 4642.6 & 4689.9 & 4782.2 \\
\hline Adecuadamente empleada & 1748.7 & 1913.7 & 2122.1 & 2332.8 & 2542.0 & 2658.4 & 2840.2 & 3053.6 & 3043.6 & 3104.1 \\
\hline Subempleada & 2268.0 & 2127.1 & 2013.3 & 1999.3 & 1872.8 & 1826.5 & 1754.0 & 1589.0 & 1646.3 & 1678.1 \\
\hline Por horas (visible) & 665.0 & 631.3 & 636.4 & 627.9 & 547.1 & 541.5 & 536.8 & 486.5 & 487.3 & 541.7 \\
\hline Por ingresos (invisible) & 1603.0 & 1495.8 & 1376.9 & 1371.4 & 1325.7 & 1285.1 & 1217.1 & 1102.5 & 1159.1 & 1136.4 \\
\hline PEA desocupada & 368.3 & 369.5 & 378.5 & 371.6 & 366.5 & 327.3 & 290.9 & 273.9 & 325.5 & 346.2 \\
\hline Con experiencia laboral & 349.6 & 343.9 & 354.5 & 351.7 & 344.2 & 305.4 & 272.9 & 246.9 & 301.0 & 314.7 \\
\hline Sin experiencia laboral & 18.7 & 25.6 & 24.1 & 19.8 & 22.3 & 21.9 & 18.0 & 27.0 & 24.4 & 31.5 \\
\hline
\end{tabular}

Fuente: Instituto Nacional de Estadística e Informática - Encuesta Permanente de Empleo.

Fuente: INEI (año)

La estacionalidad existe por la baja de inversión en cursos/talleres en vacaciones de verano. Esto se debe a que las personas están más dispuestas a invertir en viajar y tener experiencias diferentes en esos meses. 
Tabla 1.14

Demanda valorizada en unidades y soles

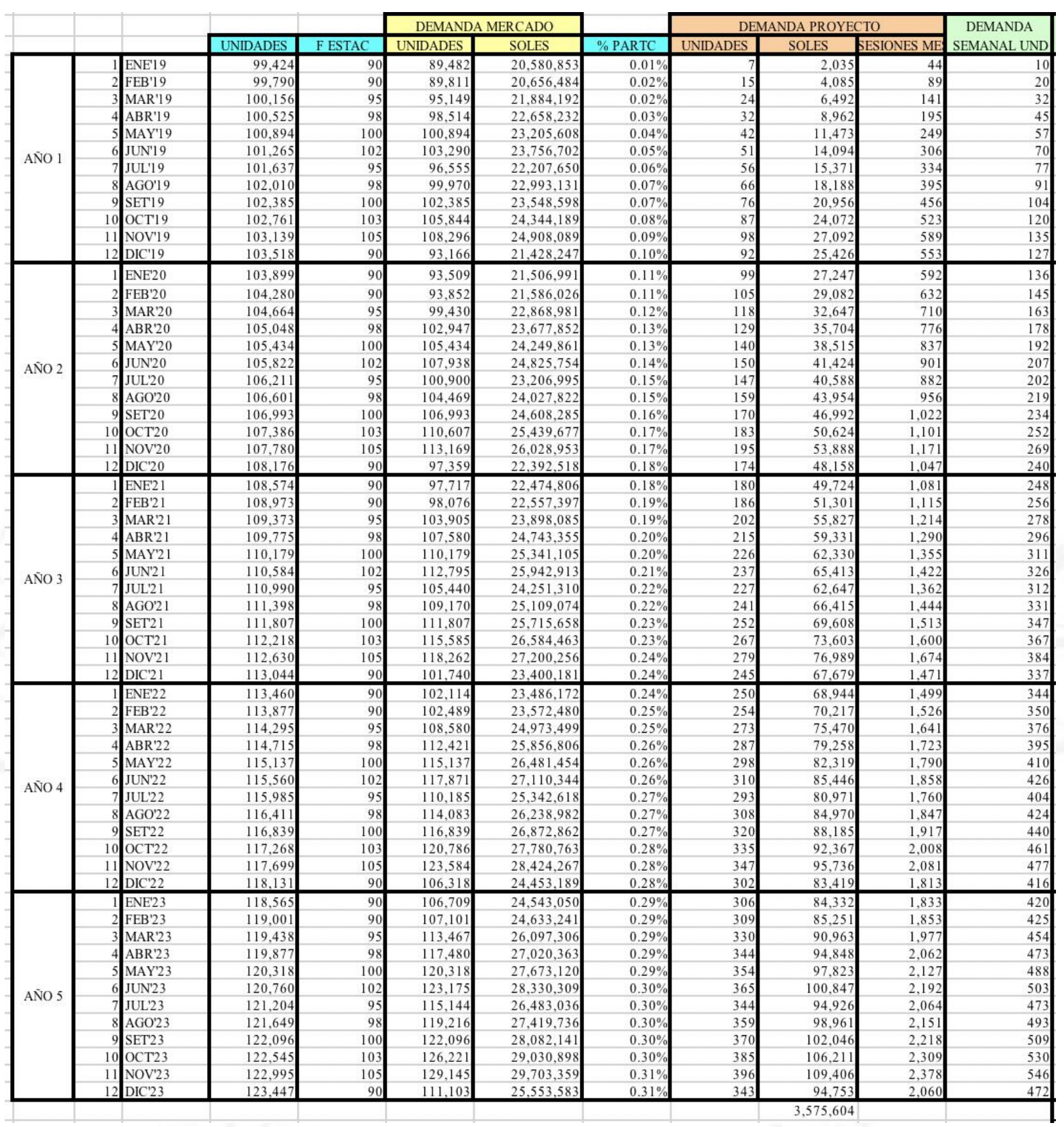

Elaboración propia

Para determinar la demanda de nuestro proyecto hemos proyectado unidades y soles a partir de 2019 al 2023. Con respecto a las ventas, el primer año venderemos S/ 178,246 y al término de quinto año S/ 3’575,604. 


\subsection{Sustento de atención de las ventas del mes 60}

En el quinto año, se tiene una demanda de 180 servicios en un día pico. Se buscará atender con un total de 3 turnos con 6 talleres por turno. Esto representa talleres de 10 personas en cada uno. Por ese motivo, se necesitarán 6 salones de clase para atender la demanda diaria.

Tabla 1.15

Determinación de servicios por turno

\begin{tabular}{|c|c|c|c|c|c|c|c|c|c|c|c|}
\hline & & & \multicolumn{3}{|c|}{ DEMANDA PROYECTO } & \multirow{2}{*}{$\begin{array}{c}\text { DEMANDA } \\
\text { SEMANAL UND }\end{array}$} & \multirow{2}{*}{$\begin{array}{l}\text { DIA } \\
\text { PICO }\end{array}$} & \multirow{2}{*}{$\begin{array}{l}\text { NRO DE } \\
\text { SALONES }\end{array}$} & & & \\
\hline & & & UNIDADES & SOLES & SESIONES MES & & & & & & \\
\hline \multirow{12}{*}{ AÑO 1} & & ENE'19 & 7 & 2,035 & 44 & 10 & 3 & 0.11 & & & \\
\hline & 2 & FEB'19 & 15 & 4,085 & 89 & 20 & 7 & 0.22 & & & \\
\hline & 3 & MAR'19 & 24 & 6,492 & 141 & 32 & 11 & 0.36 & & & \\
\hline & 4 & ABR'19 & 32 & 8,962 & 195 & 45 & 15 & 0.49 & & & \\
\hline & & MAY'19 & 42 & 11,473 & 249 & 57 & 19 & 0.63 & & & \\
\hline & 6 & JUN'19 & 51 & 14,094 & 306 & 70 & 23 & 0.77 & & & \\
\hline & 7 & JUL'19 & 56 & 15,371 & 334 & 77 & 25 & 0.84 & & & \\
\hline & 8 & AGO'19 & 66 & 18,188 & 395 & 91 & 30 & 1.00 & & & \\
\hline & 9 & SET19 & 76 & 20,956 & 456 & 104 & 35 & 1.15 & & & \\
\hline & 10 & OCT19 & 87 & 24,072 & 523 & 120 & 40 & 1.32 & & & \\
\hline & 11 & NOV'19 & 98 & 27,092 & 589 & 135 & 45 & 1.49 & & & \\
\hline & 12 & DIC'19 & 92 & 25,426 & 553 & 127 & 42 & 1.40 & & & \\
\hline \multirow{14}{*}{ ANNO 5} & 1 & ENE'23 & 306 & 84,332 & 1,833 & 420 & 139 & 4.63 & & & \\
\hline & 2 & FEB'23 & 309 & 85,251 & 1,853 & 425 & 140 & 4.68 & & & \\
\hline & 3 & MAR'23 & 330 & 90,963 & 1,977 & 454 & 150 & 4.99 & & & \\
\hline & 4 & ABR'23 & 344 & 94,848 & 2,062 & 473 & 156 & 5.21 & & & \\
\hline & 5 & MAY'23 & 354 & 97,823 & 2,127 & 488 & 161 & 5.37 & & & \\
\hline & 6 & JUN'23 & 365 & 100,847 & 2,192 & 503 & 166 & 5.53 & & & \\
\hline & 7 & JUL'23 & 344 & 94,926 & 2,064 & 473 & 156 & 5.21 & & & \\
\hline & 8 & AGO'23 & 359 & 98,961 & 2,151 & 493 & 163 & 5.43 & & & \\
\hline & 9 & SET23 & 370 & 102,046 & 2,218 & 509 & 168 & 5.60 & & & \\
\hline & 10 & OCT23 & 385 & 106,211 & 2,309 & 530 & 175 & 5.83 & & & \\
\hline & 11 & NOV23 & 396 & 109,406 & 2,378 & 546 & 180 & 6.00 & & & \\
\hline & 12 & DIC'23 & 343 & 94,753 & 2,060 & 472 & 156 & 5.20 & & & \\
\hline & & & \multirow{2}{*}{\multicolumn{2}{|c|}{$3,575,604$}} & & & 60.04 & \multirow{2}{*}{$\begin{array}{l}\text { Servicios por turno } \\
\text { Salones (=3) }\end{array}$} & 3 & TURNOS & \\
\hline & & & & & & & 6.00 & & 10 & \multicolumn{2}{|c|}{ CLIENTES X GRUPO } \\
\hline
\end{tabular}

Elaboración propia

\subsection{Análisis de la intensidad de y calidad de la publicidad y promoción}

\section{Estrategias de Penetración:}

Dentro de las principales estrategias de penetración que se ha considerado necesarias para lograr los objetivos de ingreso de un nuevo servicio en el rubro de bienestar personal, destacamos las siguientes a ser utilizadas en nuestro proyecto.

\section{$\checkmark \quad$ Internet (Redes Sociales)}

La presencia en redes sociales es fundamental para crear un posicionamiento de marca y hacerla conocida. La idea es que se transmita a través de Facebook e Instagram no solo los tipos de cursos que se dictarán, sino que también se interactúe y eduque al consumidor. Por esta razón, es que se plantea realizar lo siguiente en la etapa de lanzamiento:

- Tres publicaciones semanales. 
- Sorteo por lanzamiento del curso (regalar dos cursos) por compartir los post, darle like a las páginas y etiquetar a tres amigos.

- Publicaciones de conocimiento de marca (interactivas con imágenes, no mucho texto).

- Publicar los beneficios de Mindfulness.

- Interacción constante con sus seguidores (comentarios, likes, inbox, DM, mensajes internos).

- Utilizar hashtags en el caption de cada publicación como por ejemplo: \#BeMindfulPeru \#MeditacionConsciente \#ViveFeliz \#ViveAhora \#ViveElMomento \#Happiness \#Felicidad.

En internet actualmente hay una alta rotación de información y esto es muy beneficioso para muchas marcas. Se utiliza mucho y crece cada vez más la inversión de las empresas en este tipo de publicidad, que es directo a los consumidores.

Se utilizarán las redes sociales para publicar información de los diferentes cursos, talleres y retiros que irán saliendo, posts informativos, así como promociones y concursos donde también incentivaremos el contacto y la atención al cliente; respondiendo oportunamente las inquietudes que puedan tener los consumidores.

\section{$\checkmark \quad$ Mailing Directo:}

Armaremos una base de datos con nuestros clientes fieles y más importantes, a los cuales les iremos mandando mailings con las novedades que tenemos, descuentos y promociones, eventos, nuevos lanzamientos de cursos y descuentos por fechas importantes. Es muy importante, tener en cuenta que no se puede recargar de mailing a esta base de datos; ya que en vez de fidelizar al consumidor, podemos terminar ahuyentandolo. 


\section{$\checkmark$ Promoción de ventas:}

Se harán descuentos y ofertas por fechas festivas será a través de Mailing; o se podría hacer también en caso se tenga algún taller en el que falten llenar unos cuantos cupos.

\section{$\checkmark$ Charlas Informativas:}

El término "Mindfulness" es nuevo para la sociedad peruana. Es importante que se desarrollen charlas informativas para que el público conozca un poco más sobre lo que es el Mindfulness. Esto generará curiosidad y las personas van a demandar mayor información sobre esto. Por ello es importante repartir materiales con información sobre el tema y recopilar base de datos para posteriormente hacer Mailing. Al finalizar la charla los participantes que deseen van a poder matricularse o reservar su cupo en el próximo curso.

\section{$\checkmark$ Influencers:}

Tener un team de influencers o embajadores de la marca, será una acción de lanzamiento que beneficiará mucho a la marca para hacerla más conocida, puesto que hoy en día la mayoría de personas, y sobretodo, nuestro público objetivo, siguen a influencers todo el día, buscan hacer lo mismo que ellos y seguir su comportamiento. Por esta razón, invitar a influencers a los talleres y que ellos publiquen en sus redes sociales la experiencia que están teniendo en el curso y cómo cambió sus vidas, será muy relevante para impactar en el mercado.

\section{Influencers :}

- Nathalie Aspajo - Bhavana Blog

- Ana Paula Chávez - Plantbased

- Solange Martínez - Armónica Café

- Nicole Rasmussen - DelJardinVegan

- $\quad$ Alejandra Chavez - Lima Saludable

- Roxana Rodríguez

- Fiorella Fuentes

- $\quad$ Jessica Vega - Yoga o Clonzepam

Influencers (de moda que pueden servir para hacer la marca más conocida)

- Natalia Merino - Cinnamon Style

- Carolina Braedt - Fashadict

- Ximena Moral 
- Mafer Neyra

- $\quad$ Kiara Ventura

\section{Plan de marketing}

El objetivo es llegar a la mente de los consumidores como la empresa que se ocupa de la promoción de salud mental y bienestar integral aprovechando las técnicas de Mindfulness. Se quiere llegar a ser el Top of Mind de nuestro público objetivo cada vez que se hable de Bienestar Personal.

\section{Publicidad}

- Ingreso a las redes sociales: Abriremos una página de Facebook y otra en Instagram debido a la gran afluencia de gente en estas redes sociales. En estas mismas se colgará post informativos, promociones, se harán concursos y esto es un gran oportunidad para captar nuevos clientes.

- Página web oficial: Se contará con una página web oficial que abrirá las puertas, ya que el internet es una herramienta utilizada en todo el mundo. Aquí se tendrá publicada toda la información de los servicios así como los teléfonos y dirección de contacto.

- Repartición de folletos: Ingresar a empresas que se preocupen por el bienestar de su personal, tiendas de productos orgánicos, gimnasios y ferias relacionadas. De esta manera, se informará de los beneficios de los servicios que se ofrecen con el fin de que los clientes conozcan los servicios que ofrecemos y se interesen en los mismos.

- Charlas Informativas: Es importante realizar charlas informativas con el fin de que más personas conozcan el servicio que se ofrece, así como sus beneficios. La idea es realizar una charla al mes en empresas, universidades e institutos, con la finalidad de llegar a más personas.

- Alianzas estratégicas: Es importante las alianzas con instituciones, empresas, restaurantes, centros de yoga o deportivos para atraer al principio más tráfico de personas a los cursos y hacerse más conocidos, que estén relacionados con la marca y tengan la misma filosofía. Pueden dejar folletos o hacer descuentos especiales para sus alumnos. 
- Lima Yoga

- $\quad$ KO Urban Detox Center

- Ashtanga Yoga

- Raw Café

- Armónica

- La Sanahoria

- Flora y Fauna

- Mara BioMarket

- Quinoa Café

- Pickadeli

- La Nevera Fit

- Veggie Pizza

\section{Promoción}

- Como campaña de lanzamiento, se harán sorteos donde se regalaraá cursos gratis de bienestar personal por compartir los posts en Facebook e Instagram, darle "Me gusta" a las páginas y etiquetar a amigos para que de esa manera nuestra marca llegue a más personas.

- Se harán concursos en redes sociales de paquetes dobles para asistir gratis a talleres.

- Se ofrecerán descuentos esporádicos para días festivos (Semana Santa, Fiestas Patrias, Día de la madre, día del padre, etc).

\section{MARKETING MIX}

\section{Producto/Servicio}

El servicio a comercializar en Agora son cursos para aprender a vivir el presente, no tener pensamientos ni concentrarse en el futuro ni en lo que ya pasó. Este es un curso introductorio que consta de 6 sesiones (dos veces por semana) y dura 1 hora y media cada sesión.

Dentro de cada sesión, se tocan diversos temas que se relacionan con las diferentes áreas del bienestar personal: relaciones sociales, relaciones intrapersonales, relación con lo global con el cuerpo y con las emociones. Un experto de cada tema asistirá a la sesión y guiará la misma. Se dará en 3 turnos por día (6-7:30 a.m., 10-11:30 a.m. y de 7-8:30 p.m.) de lunes a domingo. 


\section{Precio}

\section{Política de fijación de precios}

La política de fijación de precios será por valor percibido, ya que el precio se fijará de acuerdo al valor que percibirán los potenciales clientes y el posicionamiento que obtendremos, tomando en cuenta además, el precio de la competencia directa e indirecta quienes ofrecen un servicio similar pero sin el valor agregado que nosotros ofrecemos en cada uno de nuestros talleres.

\section{Estrategia de precio de nuevo producto}

La estrategia de precio a utilizar será la estrategia de descreme, basándonos en los precios altos, puesto que buscamos ofrecer un servicio de excelente calidad que cuenta con el valor agregado de ser un taller experiencial para los participantes y todo el background de las coach, que lo hacen un curso muy rico en conocimiento. Nosotros, llegaremos a los clientes de NSE como el A y B, que son clientes potenciales dispuestos y con capacidad económica suficiente de pagar el precio que hemos establecido y adquirir nuestro servicio.

Tabla 1.16

Lista de precios

\begin{tabular}{l|l}
\hline Taller & S/ (Nuevos soles) \\
\hline 1 servicio x 6 clases (2hrs por sesión) & 260 \\
1 retiro (fin de semana) & 580 \\
\hline Elaboración propia &
\end{tabular}

Tabla 1.17

Determinación de precios

\begin{tabular}{|lc|l}
\hline PRECIO MERCADO & $\mathbf{2 3 0 . 0 0}$ & SOLES \\
\cline { 1 - 1 } PRECIO PROYECTO & $\mathbf{2 7 6 . 0 0}$ & SOLES \\
\cline { 1 - 2 } & $20.0 \%$ &
\end{tabular}

Elaboración propia

La encuesta arroja un precio de mercado de $\mathbf{S} / \mathbf{2 3 0 . 0 0}$. Se consideró que el $25 \%$ están dispuestos a invertir por mes "Entre S/201 y S/250" y el 49\% "Hasta S/200". Por el retiro, se 
considera un precio de $\mathbf{S}$ / 580.00. Se proyecta del total de ventas que el 95\% representan los paquetes de 6 sesiones y un 5\% de retiros. Por ello, se estableció que el precio promedio del proyecto debía ser S/ 276.00. Consideramos estar en un aumento de $20 \%$ por encima de los precios del mercado definidos hoy en día.

\section{Distribución}

\section{Tipo de distribución}

El tipo de distribución es directo, ya que es un servicio que se brinda en nuestras instalaciones a los clientes en cada sesión en el salón designado, según cada taller.

\section{Niveles de intermediarios}

En este caso, el tipo de canal a utilizar es el canal corto ya que es un servicio y se entrega directamente del instructor al participante en las sesiones. No pasa por ningún intermediario.

\subsection{Marca, logo y slogan}

Desarrollamos, luego de un proceso creativo la siguiente marca, logo y slogan:

Figura 1.19

Logo y Solgan

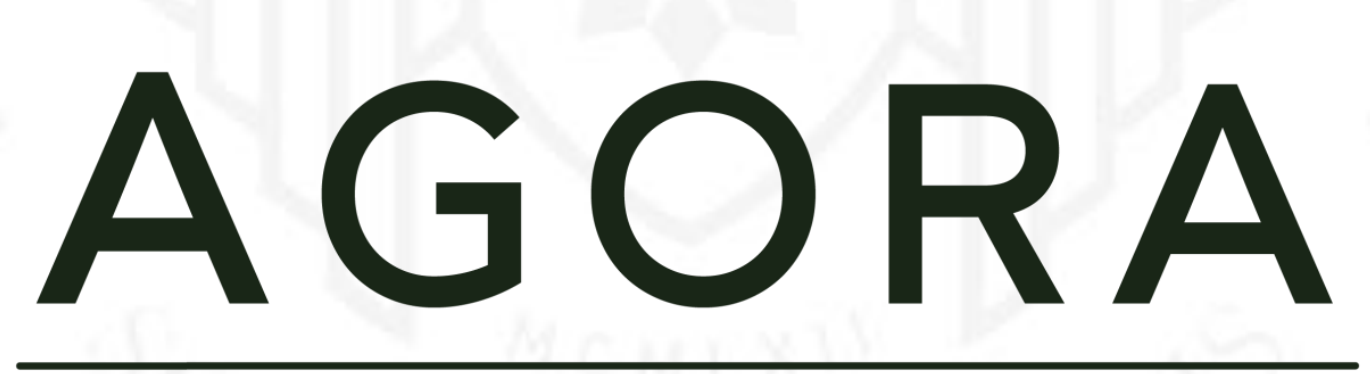

\section{Desarrolla la mente}

Elaboración propia 


\section{CAPÍTULO II: INGENIERIA DEL PROYECTO}

\subsection{Estudio tecnológico}

\subsubsection{El producto, Visión técnica y logística}

\section{a) El producto}

Agora, como servicio básico es un espacio donde se reúnen personas con el objetivo de mejorar ciertas habilidades a través de dinámicas personalizadas. El servicio les brinda herramientas y técnicas con las que se logra bienestar físico y mental. Por consiguiente, se busca mejorar el rendimiento de los clientes en diferentes aspectos de sus vidas. De esta forma, se busca que los participantes se centren en el presente, no en el pasado ni el futuro, a través de la meditación y la concentración o enfoque de lo que sucede en el presente.

Este espacio busca que cada persona desarrolle su concepto de felicidad, mecanismos para aprender a valorar cada momento por más insignificante que sea. Actualmente, la población peruana se preocupa más por su salud y bienestar, por esa razón buscan productos y servicios que permitan mejorar la calidad de vida y disminuir el nivel de estrés. Hoy en día, podemos identificar la creciente tendencia de la población por el yoga, la meditación y por buscar cursos innovadores que se vinculen a mejorar el rendimiento profesional, un consumidor más consciente de su salud que busca encontrar la felicidad, hacer las cosas con pasión para encontrar la plenitud en su vida.

Este hecho, representa una gran oportunidad para el negocio, ya que al tomar uno de los cursos de Agora se está ayudando a las personas a lograr un mejor estilo de vida, respondiendo a una necesidad actual del mercado.

Es importante proyectar profesionalismo y cercanía para que el público objetivo se interese en asistir a talleres/cursos que representen un beneficio en su estilo de vida. Además, la connotación de ser un servicio intangible, es un reto en la comunicación y descripción del servicio, por esa razón, la marca debe contar con el respaldo de profesionales de la salud que reflejen un estilo de vida aspiracional para los clientes.

El negocio depende de los siguientes tipos de especialistas: Psicólogo, Psiquiatra, Nutricionista, Sociólogo, Entrenador físico y Coach.

Con respecto al "servicio aumentado", se considera que en "Agora" la satisfacción de los clientes será $100 \%$ garantizada. Para esto, uno de los puntos más importantes será la 
capacitación de nuestro personal con el fin de que éstos puedan brindarles el mejor servicio a nuestros clientes. Haremos capacitaciones para cada uno de nuestros especialistas encargados de dictar los diferentes cursos, talleres y actividades.

Como se mencionó anteriormente, Agora busca hacer alianzas con diferentes empresas, institutos, restaurantes que tengan la misma filosofía y estén relacionados con la marca. Se ofrecerán descuentos en cursos y talleres así como también beneficios exclusivos para ese grupo de clientes.

\subsubsection{El proceso de producción y selección de la tecnología}

Al ser un servicio, Agora no cuenta con un proceso de producción. Sin embargo, existen determinados factores que serán claves en nuestras operaciones.

- Insumos (Input): Un punto clave en el negocio será el personal, ya que ellos son los que brindarán el servicio directamente a nuestros clientes. Como lo mencionamos anteriormente, se seleccionará a profesionales altamente capacitados y con previa experiencia en el rubro, y de esta manera ofrecer las mejores herramientas y técnicas a nuestros clientes, satisfaciendo así las necesidades de cada uno de ellos. Asimismo, la capacitación a nuestros colaboradores será constantemente.

- Otro aspecto muy importante a tomar en cuenta son las instalaciones. Este es un factor sumamente importante ya que será el lugar donde los participantes llevarán a cabo las diferentes actividades, cursos, talleres y lo que se busca con las instalaciones es que sea el lugar adecuado para que los participantes puedan realizar sus actividades de la mejor manera y se sientan cómodos en un lugar agradable. Se ha identificado el local para nuestra introducción en el mercado, es un lugar amplio, céntrico donde podrán disfrutar de áreas verdes, piscina y amplios espacios que permitirán a nuestros participantes desarrollarse en un ambiente seguro y agradable.

- Proceso de transformación: En Agora importa mucho la opinión de los clientes, es por ellos que al terminar cada actividad entregaremos encuestas de satisfacción a nuestros participantes con el fin de saber qué es lo que estamos haciendo bien y 
qué es lo que debemos mejorar, y de esta manera cumplir las expectativas de nuestros clientes brindándoles un excelente servicio.

- Producto (Output): Para Agora, el producto será un servicio de calidad que genere satisfacción en nuestros clientes, pero más allá de eso es poder contribuir al bienestar físico y mental de nuestros participantes, orientándolos a desarrollar habilidades y a superarse.

\subsubsection{Formulación del DOP}

A continuación, se presentará la secuencia que representa un día de talleres en Agora. Este es un modelo estándar que podría variar dependiendo el tipo de actividad que se realice. 
Figura 2.1

Formulación del DOP

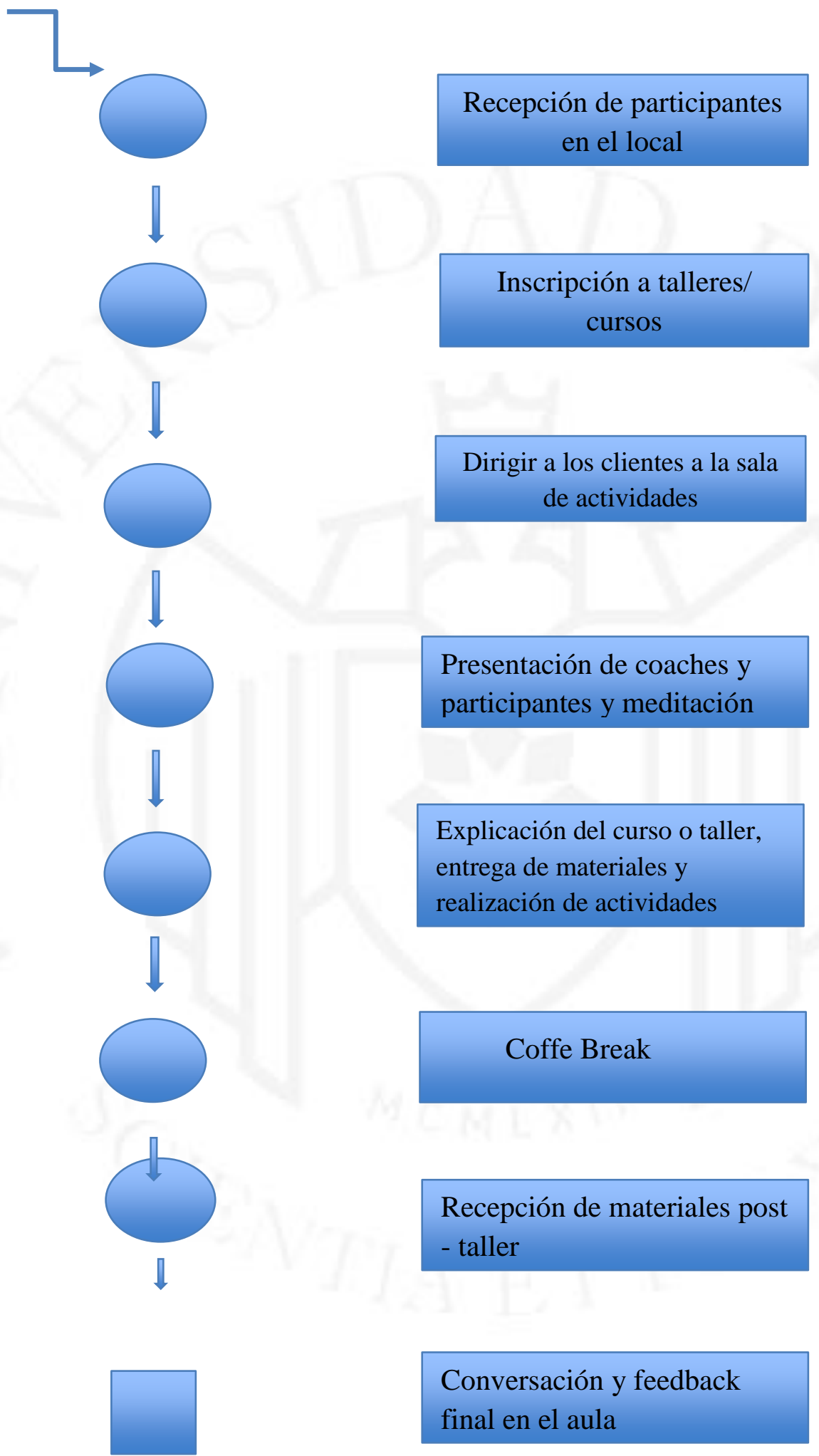

Elaboración propia 


\subsubsection{Formulación del programa de producción}

Tabla 2.1

Programa de producción

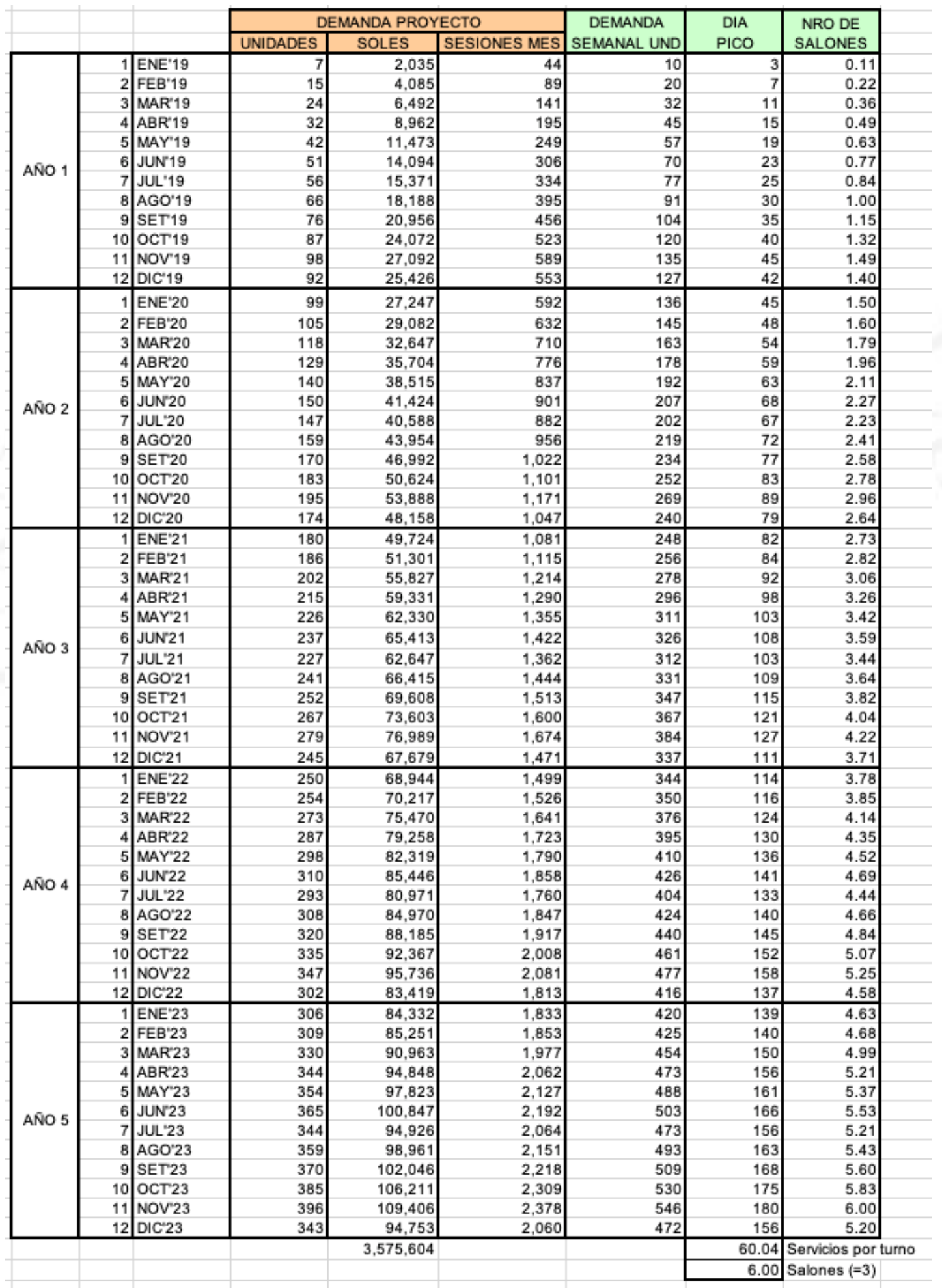

Elaboración propia 


\subsubsection{Requerimientos productivos: equipos, materia prima, insumos y otros recursos}

- Materiales para actividades: Para realizar las diversas actividades, se necesitarán hojas bond, plumones, hojas de colores, incienso, equipos de sonido, velas, banderines y cojines. Para el coffe break se necesitarán verduras, frutas y bebidas. Por otro lado, para empezar se deberán adquirir muebles, laptops, impresora, materiales de limpieza y equipos de sonido.

\subsection{Tamaño de planta}

\subsubsection{Determinación de la capacidad de planta necesaria}

La cantidad de salones que se necesitan es de 6 salones con un área de: $22 \mathrm{~m}^{2}, 23 \mathrm{~m}^{2}, 25 \mathrm{~m}^{2}$, $26 \mathrm{~m}^{2}, 28.5 \mathrm{~m}^{2}$ y $29 \mathrm{~m}^{2}$ cada uno

\subsubsection{Determinación del área de producción necesaria}

Con respecto a las áreas de producción tenemos a la sala de recepción y ventas con un área de: $33.30 \mathrm{~m}^{2}$, luego también tenemos a la oficina administrativa con un área de $61 \mathrm{~m}^{2} \mathrm{y}$ a los 6 salones donde se realizarán los talleres, cursos y diversas actividades dando un tota de $300 \mathrm{~m}^{2}$.

\subsection{Evaluación del impacto ambiental}

\subsubsection{Normas técnicas a ser aplicadas}

El SEIA (Sistema Nacional de Evaluación de Impacto Ambiental), es un sistema único y coordinado, de carácter preventivo, cuya función principal es la identificación, evaluación, mitigación y corrección anticipada de los impactos ambientales negativos derivados de acciones humanas, expresadas como políticas, planes, programas y proyectos de inversión, potenciando asimismo, la generación de impactos ambientales positivos derivados de dichas acciones. Este sistema opera mediante procesos participativos y de vigilancia, control, supervisión, fiscalización y sanciones e incentivos.

Según el reglamento del SEIA, es obligatorio contar con la certificacion ambiental. No se puede iniciar un proyecto sin contar con ésta y tampoco puede ser de manera parcial. La autoridad competente para dar la certificación es MINAM.

En primer lugar se debe definir la categoría a la cual pertenece la empresa: 
- Categoría I: Declaración de Impacto Ambiental (DIA): Estudio ambiental mediante el cual se evalúan los proyectos de inversión respecto de los cuales se prevé la generación de impactos ambientales negativos leves.

- Categoría II: Estudio de Impacto Ambiental Semidetallado (EIA-sd): Estudio ambiental mediante el cual se evalúan los proyectos de inversión respecto de los cuales se prevé la generación de impactos ambientales negativos moderados.

- Categoría III: Estudio de Impacto Ambiental Detallado (EIA-d): Estudio ambiental mediante el cual se evalúan los proyectos de inversión respecto de los cuales se prevé la generación de impactos ambientales negativos significativos.

En este caso, Agora se encuentra en la Categoría I ya que el local está construido, por lo tanto no producirá un impacto significativo al medio ambiente.

El procedimiento para la certificación ambiental es el siguiente:

- Presentación de la solicitud: Se debe detallar características de la acción a ejecutar, antecedentes ambientales, posibles impactos que podrían producirse y las medidas de prevención o corrección pertinentes.

- Clasificación de la acción.

$>$ Evaluación del instrumento de gestión ambiental.

$>$ Resolución dada por la autoridad competente.

$>$ Seguimiento y control.

\subsubsection{Evaluación del proyecto dentro del impacto ambiental}

En nuestro caso no tenemos ningún tipo de impacto negativo grave que afecte al medio ambiente ni al entorno. Por el contrario, nosotros buscaremos fomentar un ambiente sostenible y poder inculcar esto a nuestros clientes. 


\subsection{Localización de planta}

Debido a que nuestro proyecto se trata de un servicio y no se requiere de una planta por tratar de estar cerca al mercado objetivo y por tratar de tener junto los talleres y cursos y la parte administrativa. Se hizo el análisis detallado en los siguientes puntos.

\subsubsection{Factores y análisis de éstos}

Los factores a tomar en cuenta en la búsqueda del local fueron los siguientes:

- Ubicación: Se buscó que el local seleccionado se encuentre en uno de los siguientes distritos: Miraflores, San Isidro, San Borja, Santiago de Surco y La Molina. Esto fue decidido tras la elección de los clientes potenciales mediante el estudio de mercado hecho anteriormente (encuestas, entrevistas y Focus Group).

- Tamaño del terreno: El proyecto "Agora" requiere de un local grande donde podamos contar con varios espacios en donde podamos realizar las diversas actividades, por eso consideramos que el local elegido de 3 pisos es el adecuado para este tipo de negocio.

- Grado de idoneidad de la construcción: Se evaluó la infraestructura de varias opciones. Lo óptimo es una construcción con espacios amplios para poder realizar las diversas actividades.

- Nivel de ruido: Con respecto a esto se tomó en cuenta la cantidad de ruido que había a los alrededores; es por ello que decidimos situarnos en una zona residencial, tranquila y donde no transiten muchos vehículos.

- Nivel de tránsito: Por la misma razón que el punto anterior, la elección se inclinaría por una propiedad que no se encuentre en una avenida principal pues eso significaría aparte de ruido, mucho tránsito de gente, transporte público, movimiento, monóxido y peligro de accidentes.

- Clima: El clima es un factor súper importante. Mucha gente disfruta caminar por jardines, admirar la naturaleza, etc. Además un buen clima influencia de manera positiva en el estado de ánimo de las personas.

- Áreas verdes: En el local contamos con un amplio jardín en donde se realizarán varias actividades.

- Disponibilidad de mano de obra: El personal que conformará nuestra empresa son psicólogos, coaches, entrenador físico y personal administrativo Este no es un 
tema muy preocupante pues disponibilidad de estos tipos de mano de obra hay en Lima.

- Estacionamiento: Esto también es un favor muy importante para los clientes que vayan con sus vehículos, lo que más busca uno es dejarlos en un lugar seguro.

\subsubsection{Búsqueda y Evaluación de las ubicaciones candidatas}

Al buscar locales que satisfagan las necesidades del negocio en los distritos de San Isidro, Miraflores, San Borja, Santiago de Surco y La Molina, hubo dos locales que nos interesaron. El primero una casa en La Molina y otra casa en Miraflores. Una vez determinada nuestras dos opciones realizamos un análisis mediante el método de factores ponderados con una escala de calificación del 1 al 5. Este análisis lo presentamos a continuación y podemos observar que la alternativa ganadora es el local en Miraflores.

Tabla 2.2

Evaluación del local

\begin{tabular}{|c|c|c|c|c|c|}
\hline \multirow{2}{*}{ FACTORES } & \multirow{2}{*}{ PESO } & \multicolumn{2}{|c|}{ MIRAFLORES } & \multicolumn{2}{|c|}{ LA MOLINA } \\
\hline & & CALIFICACIÓN & PUNTAJE & CALIFICACIÓN & PUNTAJE \\
\hline Ubicación & $15 \%$ & 4 & 0.6 & 5 & 0.6 \\
\hline Precio de alquiler & $19 \%$ & 3 & 0.57 & 4 & 0.76 \\
\hline Tamaño & $15 \%$ & 5 & 0.75 & 3 & 0.45 \\
\hline Infraestructura & $14 \%$ & 5 & 0.7 & 2 & 0.28 \\
\hline Ruido & $4 \%$ & 5 & 0.2 & 5 & 0.2 \\
\hline Tránsito & $7 \%$ & 5 & 0.35 & 4 & 0.28 \\
\hline Clima & $6 \%$ & 5 & 0.3 & 4 & 0.24 \\
\hline Áreas verdes & $11 \%$ & 5 & 0.55 & 3 & 0.33 \\
\hline Mano de obra & $5 \%$ & 4 & 0.2 & 5 & 0.25 \\
\hline Estacionamiento & $4 \%$ & 4 & 0.16 & 4 & 0.16 \\
\hline Total & $100 \%$ & 45 & 4.38 & 39 & 3.55 \\
\hline
\end{tabular}

Elaboración propia 


\subsubsection{Determinación de la localización de planta}

Debido al análisis anterior decidimos que nuestro local será la opción de La Aurora en Miraflores. Mediante nuestro método de ranking de factores, el local mencionado tuvo el mayor puntaje con un 4.38 .

La localización del local se ha definido en la propiedad con dirección de calle: Victor Maldonado 345. Urbanización La Aurora, Miraflores. Esta propiedad cuenta con 1,000 metros cuadrados y cuenta con una infraestructura que se alinea a las necesidades de la compañía. Este local será alquilado por \$600 ó S/ 20,135.00 al mes.

Figura 2.2

Ubicación geográfica del local

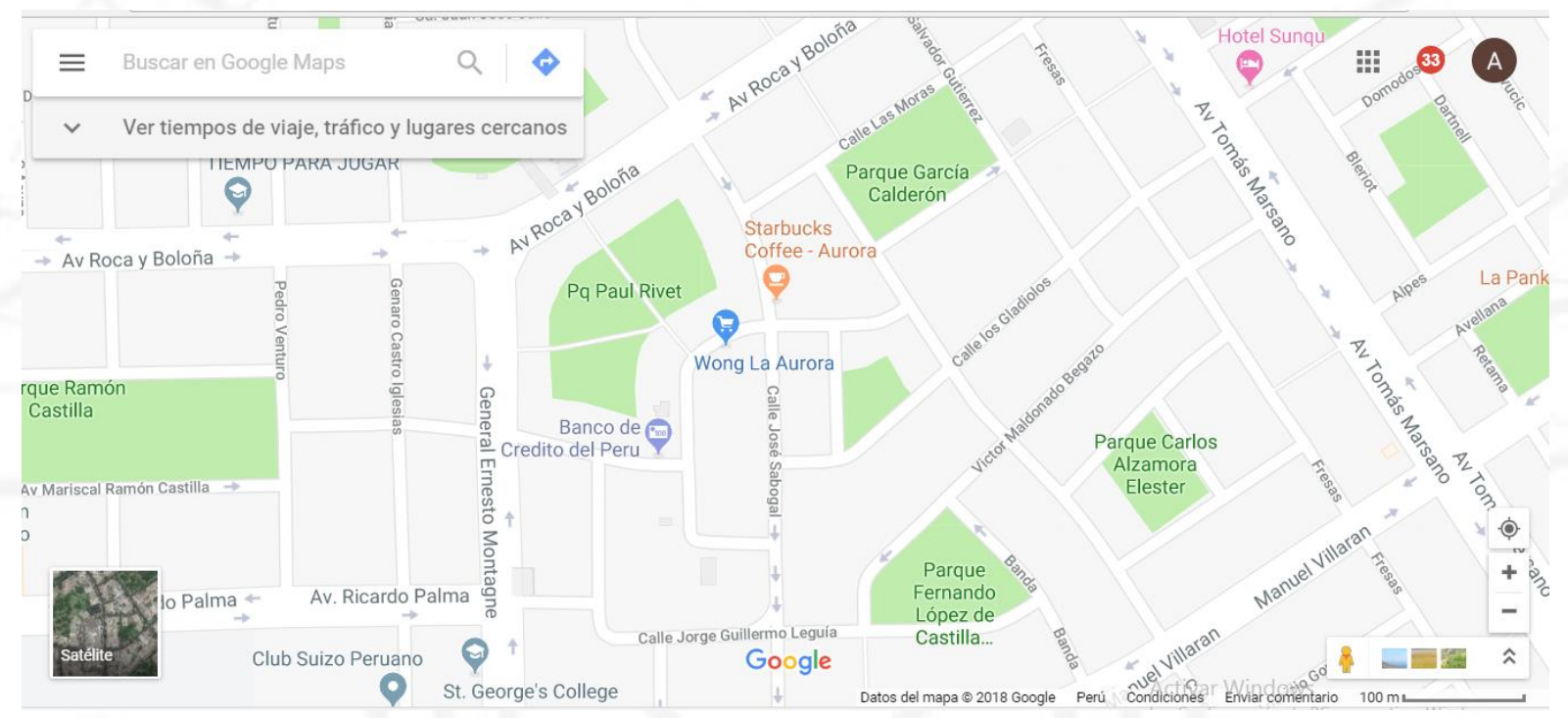

Fuente: Google Maps )día y año de consulta)

\subsection{Diseño y distribución de planta}

\subsubsection{Criterios de diseño}

Los principales criterios para el diseño y distribución de la planta son los siguientes: tamaño, es decir el local que cuenta con amplios espacios e instalaciones en donde se llevarán a cabo los talleres, la comodidad, iluminación de los ambientes, un local que cuenta con áreas verdes para que se tenga una sensación de tranquilidad y los participantes puedan concentrase y llevar a cabo las actividades de la mejor manera. El local debe llevar una decoración que vaya acorde al público al que nos dirigimos y por último, el diseño debe ser básico para poder captar la atención y el interés de mayor número de clientes. 


\subsubsection{Diseño y distribución de la planta}

En la entrada se contará con una recepción muy agradable, este es un espacio muy importante ya que será la primera impresión del cliente al entrar al local. Por otro lado, contamos con un amplio jardín en donde se realizarán varias actividades. El local también cuenta con una oficina administrativa, una cafetería súper acogedora con muebles y sillones donde los participantes podrán tomar un break y amplios salones en los tres pisos, en los cuales se llevarán a cabo los diversos talleres. 


\subsubsection{Planos de distribución de la planta}

Figura 2.3

Croquis del local (Piso 1)

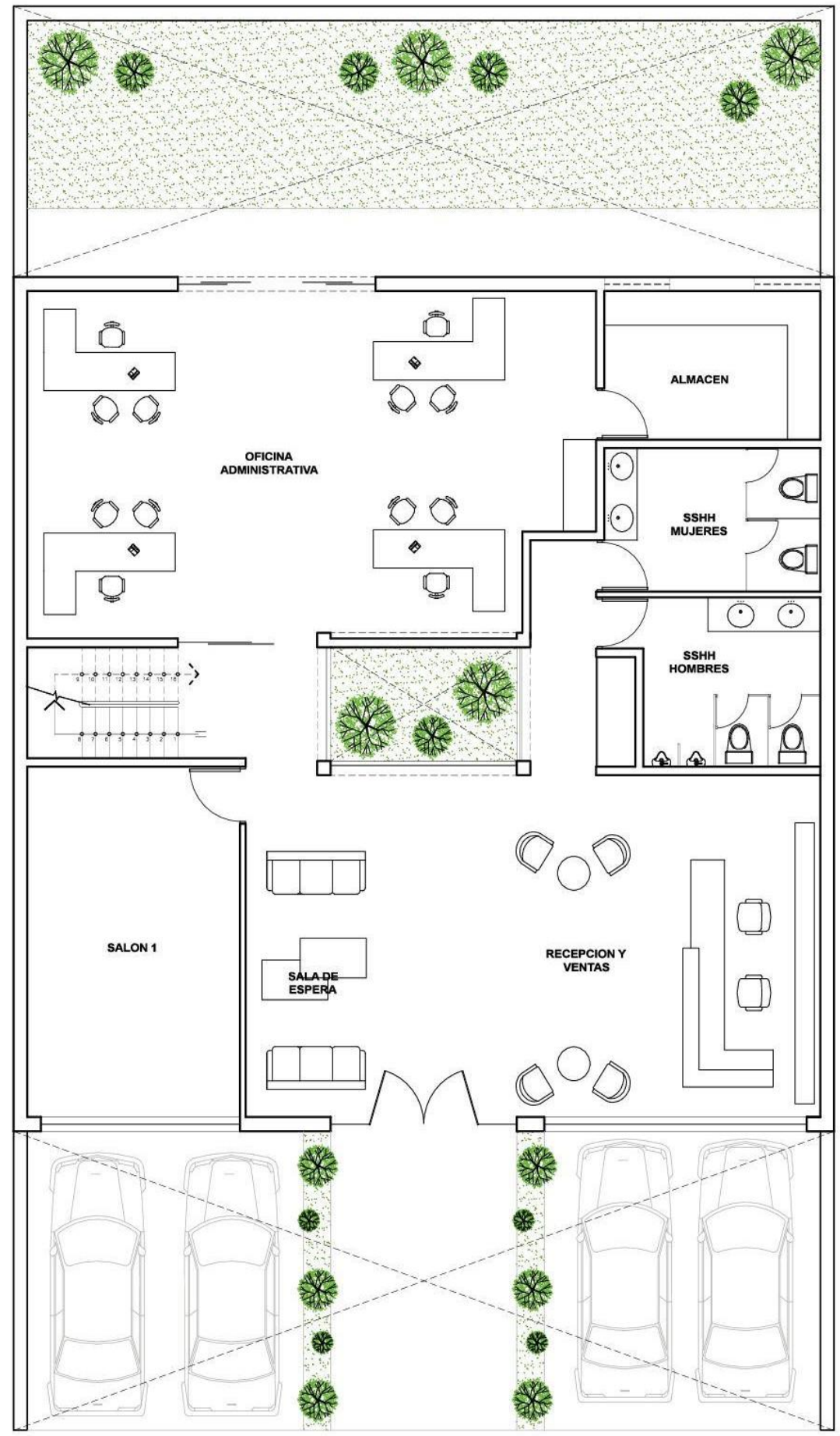

Elaboración propia 
Figura 2.4

Croquis del local (Piso 2)

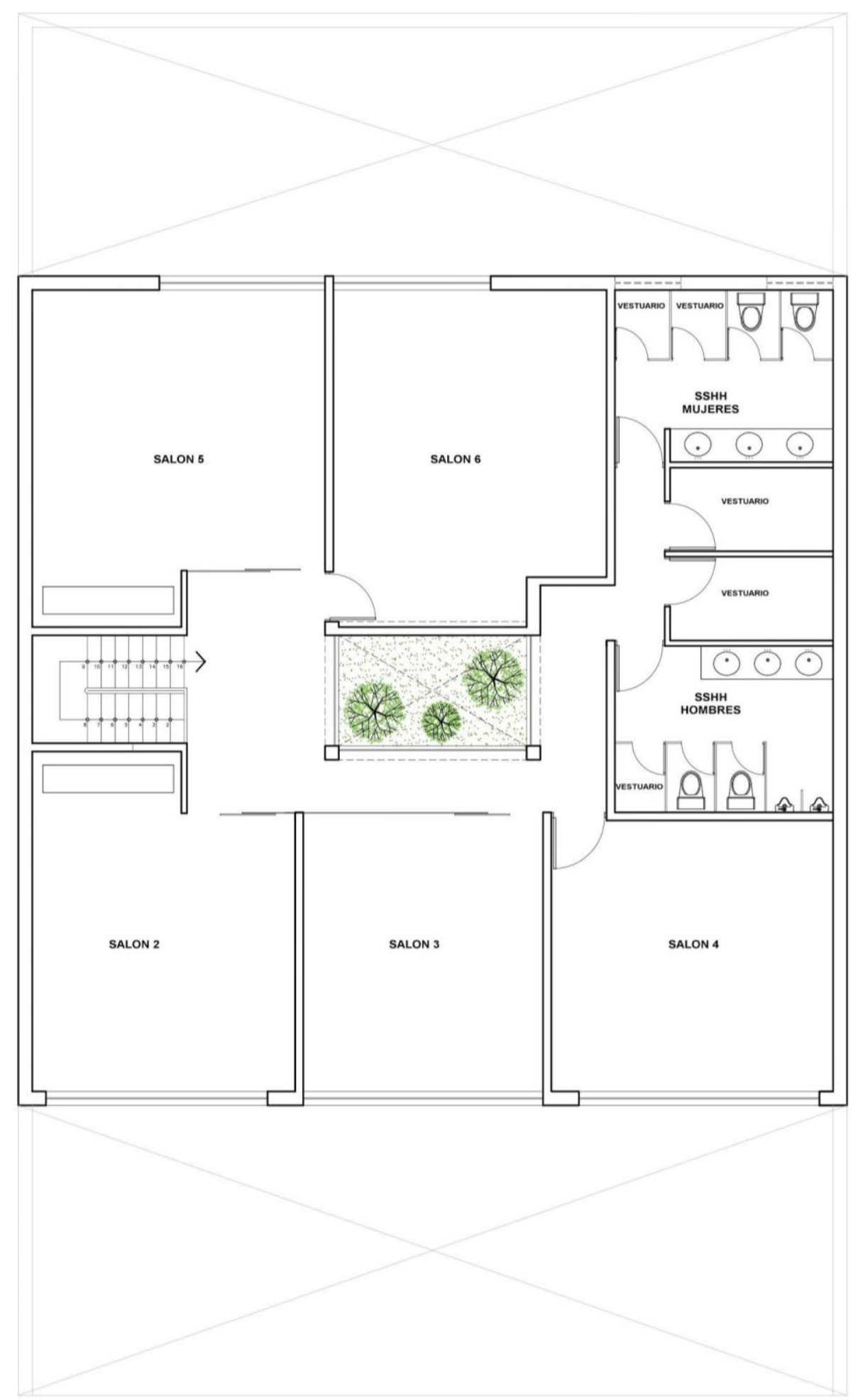

Elaboración propia 


\section{CAPÍTULO III: ASPECTOS ADMINISTRATIVOS, ORGANIZATIVOS Y LEGALES}

\subsection{Determinación del recurso humano necesario}

Hemos considerado los recursos necesarios tomando en cuenta la demanda que tendríamos al inicio de nuestras operaciones, a los 30 meses y 60 meses. Debido a que Agora ofrece servicios innovadores para el mercado, debemos tener especial cuidado con los recursos que se contraten. Buscamos estabilidad, evitando la rotación que podría poner en riesgo la oferta de la empresa.

En el primer mes de funcionamiento se realizarán 03 servicios (sesiones) en un día pico. Los servicios son por persona. Cada sesión puede tener hasta 10 personas. Si a estas 3 personas las metemos en un mismo turno, tendremos 1 salón. Esto significa contar en el mes 0 con:

- Psicólogo (1)

- Nutricionista (1)

- $\quad \operatorname{Coach}(1)$

- $\quad$ Educador físico (1)

- Sociólogo (1)

- Recepcionista (1)

- $\quad$ Gerente General (1)

En el mes 30 de funcionamiento se realizarán 108 servicios en un día pico. Los servicios son por persona. Si a estas 108 personas las dividimos en grupos de máximo 10 personas en 3 turnos, tendremos 4 salones por turno. No se necesitan especialistas en cada salón ya que se dividen según temática como se detallo en descripción de producto. Esto significa contar en el mes 30 con:

- Psicólogo (2)

- Nutricionista (2)

- $\quad$ Coach (2)

- $\quad$ Educador físico (2)

- Sociólogo (2) 
- Recepcionista (1)

- $\quad$ Gerente General (1)

En el mes 60 de funcionamiento se realizarán 180 servicios en un día pico. Los servicios son por persona. Si a estas 180 personas las dividimos en grupos de máximo 10 personas en 3 turnos, tendremos 6 salón por turno. Esto significa contar en el mes 60 con:

- Psicólogo (4)

- Nutricionista (4)

- $\quad$ Coach (4)

- $\quad$ Educador físico (4)

- Sociólogo (4)

- Recepcionista (1)

- $\quad$ Gerente General (1)

- Jefe de Marketing (1)

- Coordinador de especialistas (1)

3.2. Diseño organizacional (organigrama meses 0,30 y 60 )

\section{Al inicio:}

Figura 3.1

Diseño Organizacional (Mes 0)

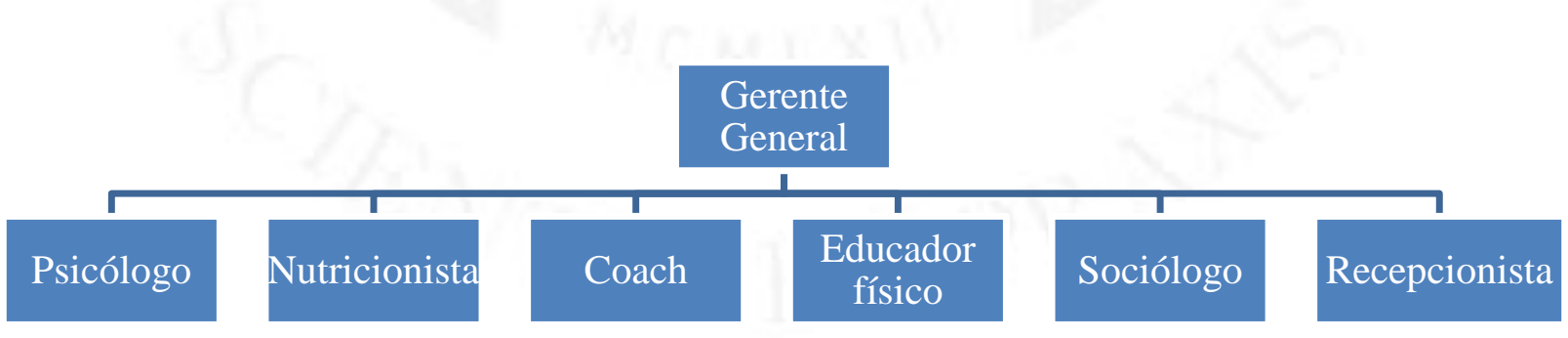

Elaboración propia 


\section{En el mes 30:}

Figura 3.2

Diseño Organizacional (Mes 30)

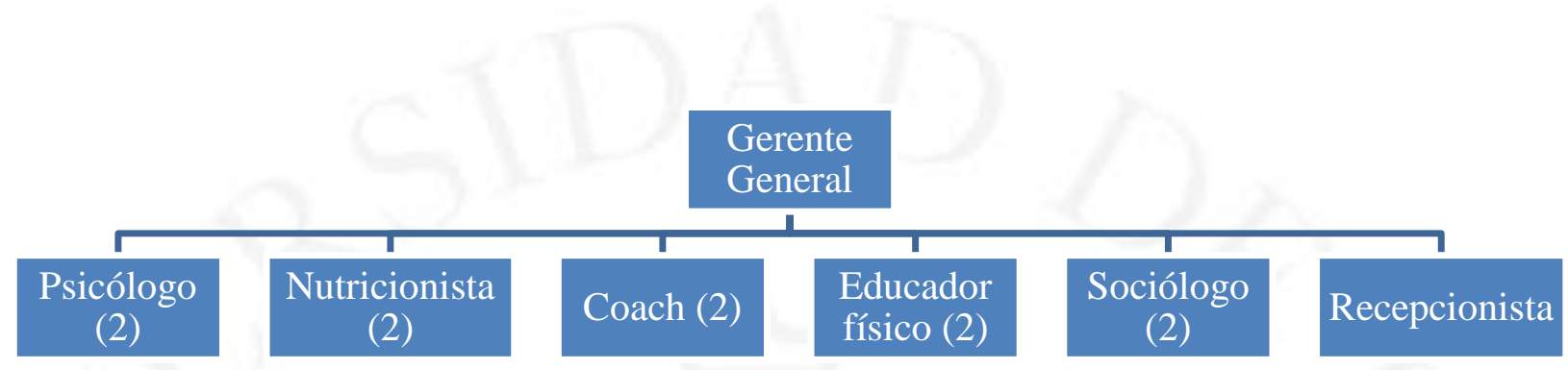

Elaboración propia

\section{En el mes 60:}

Figura 3.3

Diseño Organizacional (Mes 60)

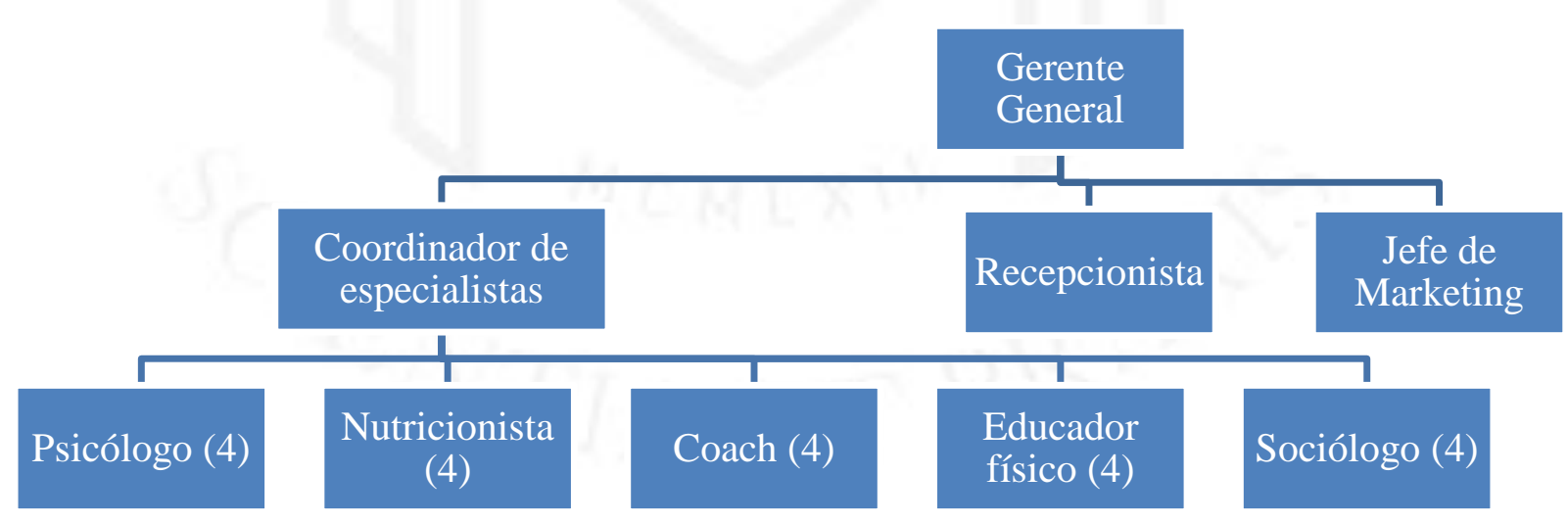

Elaboración propia 


\subsection{Funciones y perfiles de los puestos de trabajo}

\section{Funciones}

Psicólogo:

1. Realizar charlas con materiales didácticos sobre la importancia del comportamiento en lo social y el individuo.

2. Generar diagnósticos de los clientes antes de iniciar el servicio o acompañamiento.

3. Contar con el respaldo de investigaciones científicas actualizadas que tangibilicen los beneficios.

4. Generar propuestas para desarrollar nuevas investigaciones con el equipo de Agora.

5. Planificar, gestionar y ejecutar los talleres personalizados de "Relaciones intrapersonales" junto al Coach para determinar qué herramientas son necesarias para llevar a cabo un proyecto de alto valor para el cliente.

6. Cumplir con los objetivos del taller que dictará.

7. Garantizar que el proyecto cumple los estándares de calidad esperados.

Coach:

1. Realizar charlas con materiales didácticos sobre liderazgo.

2. Encargado del taller de habilidades blandas y Relaciones Intrapersonales.

3. Seguimiento motivacional de los participantes.

4. Reunión con los demás especialistas para determinar cómo apoyar a los clientes.

5. Generar propuestas para desarrollar nuevas investigaciones con el equipo de Agora.

6. Planificar, gestionar y ejecutar los talleres personalizados de "Relaciones intrapersonales" junto al Psicólogo para determinar qué herramientas son necesarias para llevar a cabo un proyecto de alto valor para el cliente.

7. Garantizar que el proyecto cumple los estándares de calidad esperados.

Sociólogo:

1. Realizar charlas con materiales didácticos sobre cultura y sociedad.

2. Planificar, gestionar y ejecutar los talleres de "Interpretación de causas, significados e influencias culturales en el Perú y Latinoamérica”.

3. Reunión con los demás especialistas para determinar cómo apoyar a los clientes. 
4. Generar propuestas para desarrollar nuevas investigaciones con el equipo de Agora.

5. Garantizar que el proyecto cumple los estándares de calidad esperados.

Nutricionista:

1. Realizar charlas con materiales didácticos sobre nutrición en las diferentes etapas de desarrollo humano.

2. Planificar, gestionar y ejecutar los talleres de "Comida Saludable".

3. Reunión con los demás especialistas para determinar cómo apoyar a los clientes.

4. Generar propuestas para desarrollar nuevas investigaciones con el equipo de Agora.

5. Garantizar que el proyecto cumple los estándares de calidad esperados.

\section{Educador físico:}

1. Realizar charlas con materiales didácticos sobre prevención de lesiones y anatomía.

2. Planificar, gestionar y ejecutar los talleres personalizados de "La rutina de ejercicios ideal".

3. Reunión con los demás especialistas para determinar cómo apoyar a los clientes.

4. Generar propuestas para desarrollar nuevas investigaciones con el equipo de Agora.

5. Garantizar que el proyecto cumple los estándares de calidad esperados.

Recepcionista:

1. Recibir y atender a los clientes.

2. Agendar las citas de los clientes.

3. Enviar el horario de actividades a cada cliente.

4. Gestionar recordatorios para los clientes.

5. Dar informes a los potenciales clientes.

6. Cotización, compra y recepción de material requerido en las actividades de la empresa. 


\section{Gerente General:}

Llevar a cabo funciones de Marketing como publicidad, promoción, presencia en los puntos de venta, entre otros.

Cumplir con objetivos relaciones a funciones de Recursos Humanos como: reclutamiento, selección, capacitación, entre otros.

Incrementar la rentabilidad del negocio.

Buscar satisfacer las necesidades de cada Stakeholder involucrado.

Ejecutar de manera eficiente cada taller (recursos y tareas necesarias para llevar a cabo un proyecto de alto valor para el cliente).

Cumplir con los objetivos del proyecto.

Garantizar que el proyecto cumple los estándares de calidad esperados.

Jefe de Marketing:

1. Desarrollar la marca de la empresa e idear la constante mejora del producto o servicio.

2. Generar una estrategia de posicionamiento con las investigaciones de los especialistas.

3. Generar campañas comunicacionales.

4. Analizar la competencia.

5. Desarrollar campañas para fidelizar a los clientes.

6. Desarrollar campañas para encontrar potenciales clientes.

Coordinador de Especialistas:

1. Gestión y organización de los talleres de cada especialista.

2. Gestión y organización de las charlas de cada especialista.

3. Unificación de material recopilado por los especialistas sobre cada cliente para el Gerente General.

4. Organización de reuniones con los especialistas y Gerente General sobre el desarrollo de cada cliente.

5. Informe mensual del estado de las investigaciones de cada especialista. 


\section{$\underline{\text { Perfiles }}$}

Psicólogo:

- Experiencia en dinámicas grupales y desarrollo de habilidades cognitivas.

- Disponibilidad de 30 horas semanales con horario flexible.

- Formación en terapia gestáltica o cognitivo conductual.

- Experiencia de 3 años con pacientes como mínimo.

- Psicólogo licenciado con especialidad organizacional, clínica o educacional.

- Manejo de reportes estadísticos en Excel.

Coach:

- Coach certificado por la Association of Coaching Institutes (ICI).

- 2 años de experiencia.

- Experiencia en liderezgo y gestión de organizaciones.

- Formación en liderazgo adaptativo, coaching ontológico y programación neurolingüística.

- Disponibilidad de 30 horas semanales con horario flexible.

- Afiliado a la Asociación Peruana de Coaching (APCO).

Sociólogo:

- Sociólogo licenciado.

- Estudios y publicaciones sobre cultura o perfiles de la cultura peruana.

- Disponibilidad de 30 horas semanales con horario flexible.

- Experiencia en investigaciones con poblaciones indígenas.

- Manejo de office a nivel avanzado.

Nutricionista:

- Nutricionista, colegiado y habilitado.

- Experiencia mínima de 1 año en Clínica y/o Hospitales.

- Diplomado o curso de especialización en nutrición clínica 
- Manejo de office a nivel avanzado.

- Disponibilidad de 30 horas semanales con horario flexible

Educador físico:

- Bachiller o Titulado en educación.

- Contar con especialidad en la materia que desempeña

- Manejo de office a nivel intermedio.

- Experiencia mínima de 2 años como profesor de su especialidad.

- Disponibilidad de 30 horas semanales con horario flexible

Recepcionista:

- Secundaria completo, estudios técnicos o universitarios en curso o inconclusos de cualquier carrera

- Experiencia como asesor en call center.

- Conocimiento de Ingles a nivel Intermedio-avanzado.

- Orientación al cliente, trabajo en equipo.

Gerente General:

- Bachiller o Titulado en carreras de negocios.

- Manejo de office a nivel avanzado.

- Experiencia mínima de 2 años como administrador.

- Experiencia mínima de 2 años en el área de ventas.

Coordinador especialistas:

- Secundaria completo, estudios técnicos o universitarios en curso o inconclusos de cualquier carrera.

- Experiencia como coordinador o asistente.

- Conocimiento de inglés a nivel Intermedio-avanzado.

- Orientación al cliente, trabajo en equipo. 
Jefe de marketing:

- Bachiller o Titulado en carreras de negocios.

- Manejo de office a nivel avanzado.

- Experiencia mínima de 1 año en el área de marketing.

- Experiencia mínima de 1 años en rubro de bienestar.

- Orientación al cliente, trabajo en equipo.

\subsection{Determinación de la estructura salarial}

La estructura salarial propuesta es en base a una investigación del mercado laboral y se desarrolla de la siguiente manera:

Tabla 3.1

Sueldos de personal

\begin{tabular}{|l|c|cc|}
\hline \multicolumn{1}{|c|}{ Puestos } & \# Personas & \multicolumn{2}{c|}{ Sueldo } \\
\hline Gerente General & 1 & S/. & 4,000 \\
\hline Recepcionista & 1 & S/. & 1,500 \\
\hline Coordinador de especialistas & 1 & S/. & 2,500 \\
\hline Jefe de marketing & 1 & S/. & 2,500 \\
\hline Psicólogo(s) & 4 & S/. & 2,000 \\
\hline Nutricionista(s) & 4 & S/. & 1,200 \\
\hline Coach(es) & 4 & S/. & 1,200 \\
\hline Educador(es) Físico(s) & 4 & S/. & 1,200 \\
\hline Sociólogo(s) & 4 & S/. & 2,000 \\
\hline
\end{tabular}

Elaboración propia 


\subsection{Determinación del costo salarial mensual y anual}

A continuación, el detalle del costo salarial mensual y anual:

Tabla 3.2

Costo salarial por año

\begin{tabular}{|c|c|c|c|c|c|}
\hline Detalle & AÑNO 1 & AÑO 2 & AÑO 3 & AÑO 4 & AÑO 5 \\
\hline Gerente General & $48,000.00$ & $50,400.00$ & $52,920.00$ & $55,566.00$ & $58,344.30$ \\
\hline Recepcionista & $18,000.00$ & $18,900.00$ & $19,845.00$ & $20,837.25$ & $21,879.11$ \\
\hline $\begin{array}{c}\text { Coordinador de } \\
\text { especialistas }\end{array}$ & 0.00 & 0.00 & 0.00 & $30,000.00$ & $31,500.00$ \\
\hline Jefe de marketing & 0.00 & 0.00 & 0.00 & $30,000.00$ & $31,500.00$ \\
\hline & $66,000.00$ & $69,300.00$ & $72,765.00$ & $136,403.25$ & $143,223.41$ \\
\hline Gratificaciones & $11,000.00$ & $11,550.00$ & $12,127.50$ & $22,733.88$ & $23,870.57$ \\
\hline & $77,000.00$ & $80,850.00$ & $84,892.50$ & $159,137.13$ & $167,093.98$ \\
\hline CTS & $6,416.67$ & $6,737.50$ & $7,074.38$ & $13,261.43$ & $13,924.50$ \\
\hline ESSALUD & $6,930.00$ & $7,276.50$ & $7,640.33$ & $14,322.34$ & $15,038.46$ \\
\hline Costo salarial planilla & $90,346.67$ & $94,864.00$ & $99,607.20$ & $186,720.89$ & $196,056.94$ \\
\hline Contador & $9,600.00$ & $10,080.00$ & $10,584.00$ & $11,113.20$ & $11,668.86$ \\
\hline Psicólogo(s) & $24,000.00$ & $50,400.00$ & $52,920.00$ & $111,132.00$ & $116,688.60$ \\
\hline Nutricionista(s) & $14,400.00$ & $30,240.00$ & $31,752.00$ & $66,679.20$ & $70,013.16$ \\
\hline Coach(es) & $14,400.00$ & $30,240.00$ & $31,752.00$ & $66,679.20$ & $70,013.16$ \\
\hline Educador(es) Físico(s) & $14,400.00$ & $30,240.00$ & $31,752.00$ & $66,679.20$ & $70,013.16$ \\
\hline Sociólogo(s) & $24,000.00$ & $50,400.00$ & $52,920.00$ & $111,132.00$ & $116,688.60$ \\
\hline Costo salarial anual & $191,146.67$ & $296,464.00$ & $311,287.20$ & $620,135.69$ & $651,142.48$ \\
\hline
\end{tabular}

\begin{tabular}{|c|r|r|r|r|r|}
\hline $\begin{array}{c}\text { Beneficios } \\
\text { provisionados }\end{array}$ & $1,069.44$ & $1,122.92$ & $1,179.06$ & $2,210.24$ & $2,320.75$ \\
\hline
\end{tabular}

\begin{tabular}{|c|r|r|r|r|r|}
\hline Desembolso & $190,077.22$ & $296,410.53$ & $311,231.05$ & $619,104.52$ & $651,031.97$ \\
\hline
\end{tabular}

Elaboración propia 


\subsection{Políticas administrativas}

\section{CAPÍTULO I}

ART. $1^{\circ}$.- Sobre estructura orgánica: se diseñará con un enfoque hacia el cliente, buscando satisfacer sus necesidades y la mejora de los servicios. Cualquier modificación de la estructura se deberá aprobar por la Gerencia General.

ART. $2^{\circ}$.- Sobre reclutamiento de personal: se priorizará la selección de personal interno mediante un proceso de selección definido. Este proceso se utilizará para relcumatmiento externo, solo si no se cumple con el perfil requerido. No se aceptará niguna contratación de personal si no se cumplió con el proceso de selección definido.

ART. 3 .- Sobre la administración de recursos humanos: los planes de reclutamiento, selección, inducción y capacitación de personal se deberán aprobar por la Gerencia General. Cualquier modificación de la recién mencionado se deberá aprobar por la Gerencia General.

ART. 3 .- Sobre la orientación al cliente: se brindará atención diferenciada y preferencial a los clientes que generen mayor ingresos a la compañía. Estos planes se definirán con Marketing pero se aprobarán con la Gerencia General. Cualquier modificación de la forma de gestionar la orientación al cliente se deberá aprobar por la Gerencia General.

ART. 4 .- Sobre la recaudación de facturación de los servicios: se adecuarán sistemas digitales y procesos para optimizar la experiencia del cliente. Estos sistemas y procesos deberán ser aprobados con la Gerencia General. Cualquier modificación de la forma de gestionar la recaudación de facturación de nuestros servicios se deberá aprobar por la Gerencia General.

ART. 5 .- Sobre la oferta diferenciada: se desarrollarán convenios y alianzas con empresas o negocios afines con el fin de agregar valor a los servicios ofrecidos al cliente. Cualquier convenio y alianza nueva o modificada deberá ser aprobadas con la Gerencia General.

ART. 6 .- Sobre la cultura e identidad de la compañía: se gestionará un código de comportamiento según la personalidad de marca que deberán seguir todos los clientes internos de la compañía. Este código lo definirá Marketing pero se aprobará con la Gerencia General.

ART. 7 .- Sobre administraciones salariales: se gestionará una política de sueldos definida basada en formas de pago, beneficios y tiempos definidos; y se incluirán los aumentos tomando en cuenta el tiempo de permanencia, cumplimiento de objetivos y necesidades del colaborador. Estas políticas salariales deberán ser aprobadas con la Gerencia General. 
Cualquier modificación de la forma de gestionar la administración de sueldos se deberá aprobar por la Gerencia General.

\section{CAPÍTULO II}

ART. 1 .- Sobre la administración de inventarios: cotización, compras y recepción de materiales requeridos en las diferentes actividades de la empresa. Esta administración la aprobará la Gerencia General y la implementará la recepcionista. Cualquier modificación de la recién mencionado se deberá aprobar por la Gerencia General.

ART. 2 .- Sobre el uso de materiales proporcionados al cliente: se deberá poner a disponibilidad del cliente materiales necesarios en estado adecuado, tomando en cuenta la funcionalidad y limpieza de los mismos. Los materiales que se proporcionan al cliente se propondrá con los especialistas y la aprobará la Gerencia General. El coordinador de especialistas velará por que se cumpla lo solicitado. Cualquier modificación de lo recién mencionado deberá ser aprobado por la Gerencia General.

ART. 3 .- Sobre la limpieza de nuestro local: se deberá cumplir con estándares adecuados para que la experiencia del cliente se complemente con el local al que ingresa. Esta gestión la aprobará la Gerencia General y la implementará la recepcionista. Cualquier modificación de lo recién mencionado deberá ser aprobado por la Gerencia General.

ART. 4 .- Sobre la administración de elementos para el correcto funcionamiento del servicio: se deberá cumplir con estándares adecuados para que la experiencia del cliente se complemente con los elementos adicionales (música, aroma, iluminación e inmuebles) a los del local. Esta gestión la aprobará la Gerencia General y la implementará la recepcionista. Cualquier modificación de lo recién mencionado deberá ser aprobado por la Gerencia General.

ART. 5 .- Sobre el horario de atención del servicio en el local: se definirá un horario de atención que satisface el correcto desarrollo y preparación de las actividades. Esta gestión la aprobará la Gerencia General. Cualquier modificación de lo recién mencionado deberá ser aprobado por la Gerencia General.

ART. 6 .- Sobre la entrega de información al cliente: se buscará entregar información veraz y necesaria con el fin de evitar confusiones al cliente. Esta gestión lo aprobará la Gerencia General con el apoyo de Marketing. 


\section{CAPÍTULO III}

ART. 1 .- Sobre la mejora continua de los talleres: se realizarán Comités semanales con cada especialista y el Gerente General. Esta administración la aprobará y liderará la Gerencia General.

ART. 2 .- Sobre la propuesta de nuevos servicios: se realizarán reuniones semanales, mensuales y trimestrales en donde se deberá contar con un equipo multidisciplinario de la compañía para la toma de decisiones. Se deberá contar con un invitado especialista en el rubro a criterio del Gerente General. Esta administración la aprobará y liderará la Gerencia General.

ART. 3 .- Sobre reportes de cumplimiento de nuestros servicios: se realizarán reuniones quincenales, mensuales y trimestrales en donde se deberá contar con los reportes de los diferentes especialistas, coordinador de especialistas y jefe de marketing para la toma de decisiones. Estos reportes deben incluir indicadores de talleres básicos, indicadores de satisfacción del cliente y comparaciones con la competencia. Esta administración la aprobará y liderará la Gerencia General.

\subsection{Minuta de Constitución de la empresa y marco legal}

El siguiente modelo de minuta y marco legal fue obtenido de la SUNARP (si es una cita literal indicarlo; asimismo, citar fecha y año):

\section{MODELO DE CONSTITUCIÓN DE SOCIEDAD ANÓNIMA CERRADA CON DIRECTORIO -} (CON APORTES EN BIENES DINERARIOS)

\section{SEÑOR NOTARIO}

SÍRVASE USTED EXTENDER EN SU REGISTRO DE ESCRITURAS PÚBLICAS UNA DE CONSTITUCIÓN DE SOCIEDAD ANÓNIMA CERRADA, QUE OTORGAN:

A. CONSUELO CHAUNY SCHIRMER, DE NACIONALIDAD PERUANA, OCUPACIÓN ADMINISTRADORA, CON DOCUMENTO DE IDENTIDAD 47635983, ESTADO CIVIL SOLTERO. 
B. MARCIE VIGIL PALOMA GASCO, DE NACIONALIDAD PERUANA, OCUPACIÓN ADMINISTRADORA, CON DOCUMENTO DE IDENTIDAD 73214253, ESTADO CIVIL SOLTERO.

SEÑALANDO COMO DOMICILIO COMÚN PARA EFECTOS DE ESTE INSTRUMENTO EN CALLE VICTOR MALDONADO BEGAZO 345, MIRAFLORES, EN LOS TÉRMINOS SIGUIENTES:

PRIMERO.- POR EL PRESENTE PACTO SOCIAL, LOS OTORGANTES MANIFIESTAN SU LIBRE VOLUNTAD DE CONSTITUIR UNA SOCIEDAD ANÓNIMA CERRADA, BAJO LA DENOMINACIÓN DE AGORA S.A.C.

LOS SOCIOS SE OBLIGAN A EFECTUAR LOS APORTES PARA LA FORMACIÓN DEL CAPITAL SOCIAL Y A FORMULAR EL CORRESPONDIENTE ESTATUTO.

SEGUNDO.- EL MONTO DEL CAPITAL DE LA SOCIEDAD ES DE S/ 107,160.00 [CIENTO SIETE MIL Y CIENTO SESENTA CON 00/100 NUEVOS SOLES] DIVIDIDO EN 107,160 ACCIONES NOMINATIVAS DE UN VALOR NOMINAL DE S/1.00 CADA UNA, SUSCRITAS Y PAGADAS DE LA SIGUIENTE MANERA:

1 CONSUELO CHAUNY SCHIRMER, SUSCRIBE 70,000 ACCIONES NOMINATIVAS Y PAGA S/ 70,000.00 MEDIANTE APORTES EN BIENES DINERARIOS.

2 MARCIE PALOMA VIGIL GASCO, SUSCRIBE 37,160 ACCIONES NOMINATIVAS $\quad \mathrm{Y}$ PAGA $\mathrm{S} / 37,160.00$ MEDIANTE APORTES EN BIENES DINERARIOS.

EL CAPITAL SOCIAL SE ENCUENTRA TOTALMENTE SUSCRITO Y PAGADO

TERCERO.- LA SOCIEDAD SE REGIRÁ POR EL ESTATUTO SIGUIENTE Y EN TODO LO NO PREVISTO POR ESTE, SE ESTARÁ A LO DISPUESTO POR LA LEY GENERAL DE SOCIEDADES - LEY 26887 - QUE EN ADELANTE SE LE DENOMINARA LA "LEY".

ESTATUTO

ARTICULO 1.- DENOMINACIÓN-DURACIÓN-DOMICILIO: LA SOCIEDAD SE DENOMINA “AGORA SOCIEDAD ANÓNIMA CERRADA”. 
LA SOCIEDAD TIENE UNA DURACIÓN INDETERMINADA, INICIA SUS OPERACIONES EN LA FECHA DE ESTE PACTO Y ADQUIERE PERSONALIDAD JURÍDICA DESDE SU INSCRIPCIÓN EN EL REGISTRO DE PERSONAS JURÍDICAS. SU DOMICILIO ES EN CALLE VICTOR MALDONADO BEGAZO 345, MIRAFLORES, PROVINCIA DE LIMA Y DEPARTAMENTO DE LIMA, PUDIENDO ESTABLECER SUCURSALES U OFICINAS EN CUALQUIER LUGAR DEL PAÍS O EN EL EXTRANJERO.

ARTICULO 2.- OBJETO SOCIAL: LA SOCIEDAD TIENE POR OBJETO DEDICARSE A SERCIVICIOS DE BIENESTAR SE ENTIENDEN INCLUIDOS EN EL OBJETO SOCIAL LOS ACTOS RELACIONADOS CON EL MISMO QUE COADYUVEN A LA REALIZACIÓN DE SUS FINES. PARA CUMPLIR DICHO OBJETO, PODRÁ REALIZAR TODOS AQUELLOS ACTOS Y CONTRATOS QUE SEAN LÍCITOS, SIN RESTRICCIÓN ALGUNA.

ARTÍCULO 3.- CAPITAL SOCIAL: EL MONTO DEL CAPITAL DE LA SOCIEDAD ES DE S/ 107,160.00 (CIENTO SIETE MIL Y CIENTO SESENTA CON 00/100 NUEVOS SOLES) REPRESENTADO POR 60,000 ACCIONES NOMINATIVAS DE UN VALOR NOMINAL DE S/ 1.00 CADA UNA.

EL CAPITAL SOCIAL SE ENCUENTRA TOTALMENTE SUSCRITO Y PAGADO.

ARTICULO 4.- TRANSFERENCIA Y ADQUISICIÓN DE ACCIONES: LOS OTORGANTES ACUERDAN SUPRIMIR EL DERECHO DE PREFERENCIA PARA LA ADQUISICIÓN DE ACCIONES, CONFORME A LO PREVISTO EN EL ULTIMO PÁRRAFO DEL ARTICULO $237^{\circ}$ DE LA "LEY".

ARTICULO 5.- ÓRGANOS DE LA SOCIEDAD: LA SOCIEDAD QUE SE CONSTITUYE TIENE LOS SIGUIENTES ÓRGANOS:

A) LA JUNTA GENERAL DE ACCIONISTAS;

B) EL DIRECTORIO Y

C) LA GERENCIA.

ARTICULO 6.- JUNTA GENERAL DE ACCIONISTAS: LA JUNTA GENERAL DE ACCIONISTAS ES EL ÓRGANO SUPREMO DE LA SOCIEDAD. LOS ACCIONISTAS CONSTITUIDOS EN JUNTA GENERAL DEBIDAMENTE 
CONVOCADA, Y CON EL QUÓRUM CORRESPONDIENTE, DECIDEN POR LA MAYORÍA QUE ESTABLECE LA "LEY" LOS ASUNTOS PROPIOS DE SU COMPETENCIA. TODOS LOS ACCIONISTAS INCLUSO LOS DISIDENTES Y LOS QUE NO HUBIERAN PARTICIPADO EN LA REUNIÓN, ESTÁN SOMETIDOS A LOS ACUERDOS ADOPTADOS POR LA JUNTA GENERAL.

LA CONVOCATORIA A JUNTA DE ACCIONISTAS SE SUJETA A LO DISPUESTO EN EL ART. 245 DE LA "LEY".

EL ACCIONISTA PODRÁ HACERSE REPRESENTAR EN LAS REUNIONES DE JUNTA GENERAL POR MEDIO DE OTRO ACCIONISTA, SU CÓNYUGE, O ASCENDIENTE O DESCENDIENTE EN PRIMER GRADO, PUDIENDO EXTENDERSE LA REPRESENTACIÓN A OTRAS PERSONAS.

ARTICUlO 7.- JUNTAS NO PRESENCIALES: LA CELEBRACIÓN DE JUNTAS NO PRESENCIALES SE SUJETA A LO DISPUESTO POR EL ARTICULO 246 DE LA "LEY".

ARTÍCULO 8.- EL DIRECTORIO: LA SOCIEDAD TENDRÁ UN DIRECTORIO INTEGRADO POR 2 (DOS) MIEMBROS QUE PUEDEN O NO, SER ACCIONISTAS, CUYO PERÍODO DE DURACIÓN SERÁ DE 5 (CINCO) AÑOS, PUDIENDO SUS MIEMBROS SER REELEGIDOS.

EL CARGO DE DIRECTOR SÓLO RECAE EN PERSONAS NATURALES. LOS DIRECTORES PUEDEN SER REMOVIDOS EN CUALQUIER MOMENTO POR LA JUNTA GENERAL. EL CARGO DE DIRECTOR ES RETRIBUIDO. LOS DIRECTORES SERÁN ELEGIDOS CON REPRESENTACIÓN DE LA MINORÍA, DE ACUERDO A LA "LEY".

ARTíCUlO 9.- VACANCIA: VACA EL CARGO DE DIRECTOR POR FALLECIMIENTO, RENUNCIA, REMOCIÓN O POR INCURRIR EL DIRECTOR EN ALGUNA DE LAS CAUSALES DE IMPEDIMENTO SEÑALADAS POR LA "LEY". EN CASO DE VACANCIA, EL MISMO DIRECTORIO PODRÁ ELEGIR A LOS REEMPLAZANTES PARA COMPLETAR SU NÚMERO POR EL PERÍODO QUE AÚN RESTA AL DIRECTORIO. EN CASO DE QUE SE PRODUZCA VACANCIA DE DIRECTORES EN NÚMERO TAL QUE NO PUEDA REUNIRSE VÁLIDAMENTE EL DIRECTORIO, LOS DIRECTORES HÁBILES ASUMIRÁN PROVISIONALMENTE LA ADMINISTRACIÓN Y CONVOCARÁN DE INMEDIATO A LA JUNTA DE 
ACCIONISTAS QUE CORRESPONDA PARA QUE ELIJAN NUEVO DIRECTORIO. DE NO HACERSE ESTA CONVOCATORIA O DE HABER VACADO EL CARGO DE TODOS LOS DIRECTORES, CORRESPONDERÁ AL GERENTE REALIZAR DE INMEDIATO DICHA CONVOCATORIA. SI LAS REFERIDAS CONVOCATORIAS NO SE PRODUJESEN DENTRO DE LOS DIEZ SIGUIENTES, CUALQUIER ACCIONISTA PUEDE SOLICITAR AL JUEZ QUE LA ORDENE, POR EL PROCESO SUMARÍSIMO.

ARTÍCULO 10.- CONVOCATORIA, QUÓRUM Y ACUERDOS: EL DIRECTORIO SERÁ CONVOCADO POR EL PRESIDENTE, O QUIEN HAGA SUS VECES, CONFORME A LO ESTABLECIDO EN EL ARTÍCULO $167^{\circ}$ DE LA "LEY". EL QUÓRUM PARA LA REUNIONES DEL DIRECTORIO SERÁ DE LA MITAD MÁS UNO DE SUS MIEMBROS. SI EL NÚMERO DE DIRECTORES ES IMPAR, EL QUÓRUM ES EL NÚMERO ENTERO INMEDIATO SUPERIOR AL DE LA MITAD DE AQUÉL. CADA DIRECTOR TIENE DERECHO A UN VOTO. LOS ACUERDOS DE DIRECTORIO SE ADOPTAN POR MAYORÍA ABSOLUTA DE VOTOS DE LOS DIRECTORES PARTICIPANTES; EN CASO DE EMPATE, DECIDE QUIEN PRESIDE LA SESIÓN.

ARTÍCULO 11.- GESTIÓN Y REPRESENTACIÓN: EL DIRECTORIO TIENE LAS FACULTADES DE GESTIÓN Y DE REPRESENTACIÓN LEGAL NECESARIAS PARA LA ADMINISTRACIÓN DE LA SOCIEDAD, DENTRO DE SU OBJETO, CON EXCEPCIÓN DE LOS ASUNTOS QUE LA “LEY” O EL ESTATUTO ATRIBUYAN A LA JUNTA GENERAL.

ARTÍCULO 12.- DELEGACIÓN: EL DIRECTORIO PUEDE DELEGAR SUS FACULTADES CONFORME A LO ESTABLECIDO EN EL ARTÍCULO $174^{\circ}$ DE LA "LEY".

ARTÍCULO 13.- RESPONSABILIDAD: LA RESPONSABILIDAD DE LOS DIRECTORES SE RIGE POR LO ESTABLECIDO EN LOS ARTÍCULO $177^{\circ} \mathrm{Y}$ SIGUIENTES DE LA "LEY".

ARTÍCULO 14.- GERENTE GENERAL: LA SOCIEDAD TENDRÁ UN GERENTE GENERAL. LA DURACIÓN DEL CARGO ES POR TIEMPO INDEFINIDO. EL GERENTE PUEDE SER REMOVIDO EN CUALQUIER MOMENTO POR EL DIRECTORIO O POR LA JUNTA GENERAL, CUALQUIERA QUE SEA EL ÓRGANO DEL QUE HAYA EMANADO SU NOMBRAMIENTO. 
ARTÍCULO 15.- ATRIBUCIONES: EL GERENTE GENERAL ESTA FACULTADO PARA LA EJECUCIÓN DE TODO ACTO Y/O CONTRATO CORRESPONDIENTES AL OBJETO DE LA SOCIEDAD, PUDIENDO ASIMISMO REALIZAR LOS SIGUIENTES ACTOS:

A) DIRIGIR LAS OPERACIONES COMERCIALES Y ADMINISTRATIVAS.

B) REPRESENTAR A LA SOCIEDAD ANTE TODA CLASE DE AUTORIDADES. EN LO JUDICIAL GOZARA DE LAS FACULTADES GENERALES Y ESPECIALES, SEÑALADAS EN LOS ARTÍCULOS $74^{\circ}, 75^{\circ}, 77^{\circ}$ Y $436^{\circ}$ DEL CÓDIGO PROCESAL CIVIL. EN LO ADMINISTRATIVO GOZARÁ DE LA FACULTAD DE REPRESENTACIÓN PREVISTA EN EL ARTICULO 115² DE LA LEY No 27444 Y DEMÁS NORMAS CONEXAS Y COMPLEMENTARIAS. TENIENDO EN TODOS LOS CASOS FACULTAD DE DELEGACIÓN O SUSTITUCIÓN. ADEMÁS PODRÁ CONSTITUIR PERSONAS JURÍDICAS EN NOMBRE DE LA SOCIEDAD Y REPRESENTAR A LA SOCIEDAD ANTE LAS PERSONAS JURÍDICAS QUE CREA CONVENIENTE. ADEMÁS PODRÁ SOMETER LAS CONTROVERSIAS A ARBITRAJE, CONCILIACIONES EXTRAJUDICIALES Y DEMÁS MEDIOS ADECUADOS DE SOLUCIÓN DE CONFLICTO, PUDIENDO SUSCRIBIR LOS DOCUMENTOS QUE SEAN PERTINENTES.

C) ABRIR, TRANSFERIR, CERRAR Y ENCARGARSE DEL MOVIMIENTO DE TODO TIPO DE CUENTA BANCARIA; GIRAR, COBRAR, RENOVAR, ENDOSAR, DESCONTAR Y PROTESTAR, ACEPTAR Y RE-ACEPTAR CHEQUES, LETRAS DE CAMBIO, VALES, PAGARES, GIROS, CERTIFICADOS, CONOCIMIENTOS, PÓLIZAS, CARTAS FIANZAS Y CUALQUIER CLASE DE TÍTULOS VALORES, DOCUMENTOS MERCANTILES Y CIVILES, OTORGAR RECIBOS Y CANCELACIONES, SOBREGIRARSE EN CUENTA CORRIENTE CON GARANTÍA O SIN ELLA, SOLICITAR TODA CLASE DE PRESTAMOS CON GARANTÍA HIPOTECARIA, PRENDARIA Y DE CUALQUIER FORMA.

D) ADQUIRIR Y TRANSFERIR BAJO CUALQUIER TITULO; COMPRAR, VENDER, ARRENDAR, DONAR, DAR EN COMODATO, ADJUDICAR Y GRAVAR LOS BIENES DE LA SOCIEDAD SEAN MUEBLES O INMUEBLES, SUSCRIBIENDO LOS RESPECTIVOS DOCUMENTOS YA SEAN PRIVADOS O PÚBLICOS. EN GENERAL PODRÁ CELEBRAR TODA CLASE DE CONTRATOS NOMINADOS E INNOMINADOS, 
INCLUSIVE LOS DE: LEASING O ARRENDAMIENTO FINANCIERO, LEASE BACK, FACTORING Y/O UNDERWRITING, CONSORCIO, ASOCIACIÓN EN PARTICIPACIÓN Y CUALQUIER OTRO CONTRATO DE COLABORACIÓN EMPRESARIAL VINCULADOS CON EL OBJETO SOCIAL.

E) SOLICITAR, ADQUIRIR, DISPONER, TRANSFERIR REGISTROS DE PATENTES, MARCAS, NOMBRES COMERCIALES, CONFORME A LEY SUSCRIBIENDO CUALQUIER CLASE DE DOCUMENTOS VINCULADOS A LA PROPIEDAD INDUSTRIAL O INTELECTUAL.

F) PARTICIPAR EN LICITACIONES, CONCURSOS PÚBLICOS Y/O ADJUDICACIONES, SUSCRIBIENDO LOS RESPECTIVOS DOCUMENTOS, QUE CONLLEVE A LA REALIZACIÓN DEL, OBJETO SOCIAL.

EL GERENTE GENERAL PODRÁ REALIZAR TODOS LOS ACTOS NECESARIOS PARA LA ADMINISTRACIÓN DE LA SOCIEDAD, SALVO LAS FACULTADES RESERVADAS A LA JUNTA GENERAL DE ACCIONISTAS.

EL GERENTE GENERAL PODRÁ REALIZAR TODOS LOS ACTOS NECESARIOS PARA LA ADMINISTRACIÓN DE LA SOCIEDAD, SALVO LAS FACULTADES RESERVADAS A LA JUNTA GENERAL DE ACCIONISTAS.

ARTÍCULO 16.- RESPONSABILIDAD: EL GERENTE RESPONDE ANTE LA SOCIEDAD, LOS ACCIONISTAS Y TERCEROS, CONFORME A LO QUE SE ESTABLECE EN EL ARTÍCULO 190 DE LA “LEY”.

EL GERENTE ES RESPONSABLE, SOLIDARIAMENTE CON LOS MIEMBROS DEL DIRECTORIO CUANDO PARTICIPE EN ACTOS QUE DEN LUGAR A RESPONSABILIDAD DE ÉSTOS O CUANDO, CONOCIENDO LA EXISTENCIA DE ESOS ACTOS, NO INFORME SOBRE ELLOS AL DIRECTORIO O A LA JUNTA GENERAL.

ARTICULO 17.- MODIFICACIÓN DEL ESTATUTO, AUMENTO Y REDUCCIÓN DEL CAPITAL: LA MODIFICACIÓN DEL ESTATUTO, SE RIGE POR LOS ARTÍCULOS 198 Y 199 DE LA "LEY", ASÍ COMO EL AUMENTO Y REDUCCIÓN 
DEL CAPITAL SOCIAL, SE SUJETA A LO DISPUESTO POR LOS ARTÍCULOS 201 AL 206 Y 215 AL 220, RESPECTIVAMENTE, DE LA "LEY".

ARTICULO 18.- ESTADOS FINANCIEROS Y APLICACIÓN DE UTILIDADES: SE RIGE POR LO DISPUESTO EN LOS ARTÍCULOS 40, 221 AL 233 DE LA "LEY".

ARTICULO 19.- DISOLUCIÓN, LIQUIDACIÓN Y EXTINCIÓN: EN CUANTO A LA DISOLUCIÓN, LIQUIDACIÓN Y EXTINCIÓN DE LA SOCIEDAD, SE SUJETA A LO DISPUESTO POR LOS ARTÍCULOS 407, 409, 410, 412, 413 A 422 DE LA "LEY".

CUARTO.- EL PRIMER DIRECTORIO DE LA SOCIEDAD ESTARÁ INTEGRADO POR:

PRESIDENTE DEL DIRECTORIO: CONSUELO CHAUNY SCHIRMER 47635983

DIRECTOR 1: MARCIE PALOMA GASCO VIGIL 73214253.

QUINTO. - QUEDA DESIGNADO COMO GERENTE GENERAL CONSUELO CHAUNY SCHIRMER CON 4763983, CON DOMICILIO VICTOR MALDONADO BEGAZO 345, LA AURORA, MIRAFLORES, LIMA.

ASI MISMO, SE DESIGNA COMO SUB GERENTE DE LA SOCIEDAD A MARCIE PALOMA VIGIL GASCO IDENTIFICADA CON DOCUMENTO DE IDENTIDAD DNI, CON NUMERO 73214253 QUIEN TENDRA LAS SIGUIENTES FACULTADES:

- $\quad$ REEMPLAZAR AL GERENTE EN CASO DE AUSENCIA.

- INTERVENIR EN FORMA CONJUNTA CON EL GERENTE GENERAL, EN LOS CASOS PREVISTOS EN LOS INCISOS C, D, E Y F DEL ARTÍCULO 15 DEL ESTATUTO.

LIMA, 14, JULIO DE DOS MIL DIECIOCHO. 


\section{CAPÍTULO IV: PLANEAMIENTO}

\subsection{Inversión en gastos pre operativos}

Tabla 4.1

Gastos pre operativos

\begin{tabular}{|c|c|c|c|}
\hline & Valor Venta & IGV & Total \\
\hline Constitución de la empresa & 500.59 & 90.11 & 590.70 \\
\hline INDECOPI & 593.22 & 106.78 & 700.00 \\
\hline Licencia de Funcionamiento & 423.73 & 76.27 & 500.00 \\
\hline Permiso Publicidad Externa & $1,144.07$ & 205.93 & $1,350.00$ \\
\hline Boletas y facturas & $2,288.14$ & 411.86 & $2,700.00$ \\
\hline Defensa Civil & 61.02 & 10.98 & 72.00 \\
\hline Legalizacion de libros contables & 381.36 & 68.64 & 450.00 \\
\hline Remodelacion local & $8,898.31$ & $1,601.69$ & $10,500.00$ \\
\hline Garantía local alquilado & $2,796.61$ & 503.39 & $3,300.00$ \\
\hline Materiales Operativos & 336.44 & 60.56 & 397.00 \\
\hline Materiales de oficina & 712.51 & 122.49 & 835.00 \\
\hline Materiales de seguridad & 165.25 & 29.75 & 195.00 \\
\hline Materiales de limpieza & 196.19 & 35.31 & 231.50 \\
\hline TOTAL & $18,497.42$ & $3,323.78$ & $21,821.20$ \\
\hline
\end{tabular}

Elaboración propia 
Tabla 4.2

Detalle de gastos en materiales

\begin{tabular}{|c|c|c|c|c|c|}
\hline $\mathbf{Q}$ & Materiales Operativos & Precio unitario & Valor & IGV & Total \\
\hline 10 & Colchoneta de Yoga & 10.00 & 84.75 & 15.25 & 100.00 \\
\hline 1 & Portaincienso & 9.00 & 7.63 & 1.37 & 9.00 \\
\hline 10 & Inciensos & 0.20 & 1.69 & 0.31 & 2.00 \\
\hline 10 & Tijeras & 5.00 & 42.37 & 7.63 & 50.00 \\
\hline 10 & Velas & 5.00 & 42.37 & 7.63 & 50.00 \\
\hline 10 & Banderines & 5.00 & 42.37 & 7.63 & 50.00 \\
\hline 10 & Cojines & 10.00 & 84.75 & 15.25 & 100.00 \\
\hline 10 & Frutas & 1.00 & 8.47 & 1.53 & 10.00 \\
\hline 1 & Agua (bidón de 21 litros) & 26.00 & 22.03 & 3.97 & 26.00 \\
\hline & TOTAL & & 336.44 & 60.56 & 397.00 \\
\hline $\mathbf{Q}$ & Materiales de oficina & Precio unitario & Valor & IGV & Total \\
\hline 10 & Paquete de 5,000 Hojas Bond & 13.00 & 110.17 & 19.83 & 130.00 \\
\hline 1 & $\begin{array}{l}\text { Toner HP LaserJet Ent MFP } \\
\text { M527dn }\end{array}$ & 627.00 & 531.36 & 95.64 & 627.00 \\
\hline 2 & Engrapador & 10.00 & 16.95 & 3.05 & 20.00 \\
\hline 10 & Caja con 5,000 grapas & 3.20 & 32.00 & 0.00 & 32.00 \\
\hline 20 & Lapiceros & 0.50 & 8.47 & 1.53 & 10.00 \\
\hline 20 & Plumones & 0.80 & 13.56 & 2.44 & 16.00 \\
\hline & TOTAL & & 712.51 & 122.49 & 835.00 \\
\hline $\mathbf{Q}$ & Materiales de seguridad & Precio unitario & Valor & IGV & Total \\
\hline 1 & Extintor de $6 \mathrm{Kg}$ & 115.00 & 97.46 & 17.54 & 115.00 \\
\hline 1 & Botiquín laboral & 80.00 & 67.80 & 12.20 & 80.00 \\
\hline & TOTAL & & 165.25 & 29.75 & 195.00 \\
\hline $\mathbf{Q}$ & Materiales de limpieza & Precio unitario & Valor & IGV & Total \\
\hline 2 & Escoba & 5.00 & 8.47 & 1.53 & 10.00 \\
\hline 2 & Trapeador & 6.00 & 10.17 & 1.83 & 12.00 \\
\hline 1 & Lavavajilla (2 potes de 360 grs.) & 4.00 & 3.39 & 0.61 & 4.00 \\
\hline 2 & Limpia pisos (pomo 1,960 ml.) & 4.00 & 6.78 & 1.22 & 8.00 \\
\hline
\end{tabular}




\subsection{Inversión en capital de trabajo (4 meses)}

Tabla 4.3

Inversión en capital de trabajo

\begin{tabular}{|l|r|r|}
\hline \multicolumn{1}{|c|}{ Capital de trabajo } & ANO1 & \multicolumn{1}{c|}{ Total 4 meses } \\
\hline CAJA & & $100,000.00$ \\
\hline CAJA & $100,000.00$ & $16,000.00$ \\
\hline Sueldos & & $6,000.00$ \\
\hline Gerente General & $48,000.00$ & $3,200.00$ \\
\hline Recepcionista & $18,000.00$ & $\mathbf{1 2 5 , 2 0 0 . 0 0}$ \\
\hline Contador & $9,600.00$ & $\mathbf{1 7 5 , 6 0 0 . 0 0}$ \\
\hline
\end{tabular}

Elaboración propia

Podemos deducir en esta Tabla que el recupero de inversión en capital de trabajo es de 4 meses a través de nuestras ventas. 


\subsection{Inversión en activos fijos e intangibles en el periodo pre operativo}

Tabla 4.4

Inversión en equipos de producción

\begin{tabular}{|c|c|c|c|}
\hline EQUIPOS DE PRODUCCION & $\begin{array}{c}\text { COSTO } \\
\text { UNITARIO }\end{array}$ & CANTIDAD & $\begin{array}{l}\text { COSTO } \\
\text { TOTAL }\end{array}$ \\
\hline Equipo de sonido & 300.00 & 1 & 300.00 \\
\hline Aromatizador REFISA 81ts & 320.00 & 1 & 320.00 \\
\hline MUEBLES DE OFICINA & $\begin{array}{c}\text { COSTO } \\
\text { UNITARIO }\end{array}$ & CANTIDAD & $\begin{array}{l}\text { COSTO } \\
\text { TOTAL }\end{array}$ \\
\hline Silla giratoria Modelo Rta-905 & 229.00 & 8 & $1,832.00$ \\
\hline Sillones De Espera & 340.00 & 4 & $1,360.00$ \\
\hline Counter de recepcion & 400.00 & 1 & 400.00 \\
\hline Archivador metálico & 179.00 & 2 & 358.00 \\
\hline Mueble escritorio para oficina & 350.00 & 5 & $1,750.00$ \\
\hline EQUIPOS DE COMPUTACÍON Y & COSTO & & COSTO \\
\hline ELECTRODOMESTICO & UNITARIO & CANTIDAD & TOTAL \\
\hline Laptop Hp Core I7, Empresarial Elitebook & $1,190.00$ & 8 & $9,520.00$ \\
\hline HP LaserJet Ent MFP M527dn Printer (F2A76A) & $1,206.00$ & 1 & $1,206.00$ \\
\hline Microondas Miray & 250.00 & 1 & 250.00 \\
\hline POS & 23.00 & 1 & 23.00 \\
\hline Instalacion POS & 60.00 & 1 & 60.00 \\
\hline 2 play Empresas 4Mbps CLARO- Telefonia fija + internet & 139.00 & 1 & 139.00 \\
\hline
\end{tabular}

Elaboración propia 
Tabla 4.5

Inversión en activos fijos e intangibles

\begin{tabular}{|c|c|c|c|c|}
\hline Activos fijos & Valor de venta & IGV & Precio & Vida útil (años) \\
\hline \multicolumn{5}{|l|}{$\begin{array}{l}\text { EQUIPOS DE } \\
\text { PRODUCCION }\end{array}$} \\
\hline Equipo de sonido & 254.24 & 45.76 & 300.00 & 5 \\
\hline Aromatizador REFISA 81ts & 271.19 & 48.81 & 320.00 & 3 \\
\hline \multicolumn{5}{|l|}{ MUEBLES DE OFICINA } \\
\hline Silla giratoria Modelo Rta-905 & $1,552.54$ & 279.46 & $1,832.00$ & 3 \\
\hline Sillones De Espera & $1,152.54$ & 207.46 & $1,360.00$ & 3 \\
\hline Counter de recepcion & 338.98 & 61.02 & 400.00 & 5 \\
\hline Archivador metálico & 303.39 & 54.61 & 358.00 & 5 \\
\hline Mueble escritorio para oficina & $1,483.05$ & 266.95 & $1,750.00$ & 5 \\
\hline \multicolumn{5}{|l|}{$\begin{array}{l}\text { EQUIPOS DE } \\
\text { COMPUTACÍON Y } \\
\text { ELECTRODOMESTICO }\end{array}$} \\
\hline $\begin{array}{c}\text { Laptop Hp Core I7, } \\
\text { Empresarial Elitebook }\end{array}$ & $8,067.80$ & $1,452.20$ & $9,520.00$ & 3 \\
\hline $\begin{array}{l}\text { HP LaserJet Ent MFP M527dn } \\
\text { Printer (F2A76A) }\end{array}$ & $1,022.03$ & 183.97 & $1,206.00$ & 3 \\
\hline Microondas Miray & 211.86 & 38.14 & 250.00 & 3 \\
\hline POS & 19.49 & 3.51 & 23.00 & 3 \\
\hline Instalacion POS & 50.85 & 9.15 & 60.00 & 3 \\
\hline $\begin{array}{c}2 \text { play Empresas } 4 \mathrm{Mbps} \\
\text { CLARO- Telefonia fija }+ \\
\text { internet }\end{array}$ & 117.80 & 21.20 & 139.00 & 3 \\
\hline TOTAL & $14,845.76$ & $2,672.24$ & 17,518.00 & \\
\hline
\end{tabular}

\begin{tabular}{|c|c|c|c|c|}
\hline Activos intangibles & Valor & IGV & Precio & Amortización (años) \\
\hline Gastos pre operativos & $18,497.42$ & $3,323.78$ & $21,821.20$ & 5 \\
\hline Software & 847.46 & 152.54 & $1,000.00$ & 3 \\
\hline TOTAL & $19,344.88$ & $3,476.32$ & $22,821.20$ & \\
\hline
\end{tabular}

Elaboración propia 


\subsection{Resumen de las inversiones totales iniciales}

Tabla 4.6

Resumen de inversiones totales

\begin{tabular}{|c|c|c|c|}
\hline & Valor de venta & IGV & TOTAL \\
\hline Activo Intangible & $19,344.88$ & $3,476.32$ & $22,821.20$ \\
\hline Activo Tangible & $14,845.76$ & $2,672.24$ & $17,518.00$ \\
\hline Capital de trabajo & $125,200.00$ & 0.00 & $125,200.00$ \\
\hline TOTAL & $159,390.64$ & $6,148.56$ & $165,539.20$ \\
\hline
\end{tabular}

Elaboración propia

\subsection{Fuente y Estructura de Financiamiento}

Tabla 4.7

Estructura de financiamiento

\begin{tabular}{|l|r|r|}
\hline Préstamo banco & $55,179.73$ & $33.3 \%$ \\
\hline Socios & $110,359.47$ & $66.7 \%$ \\
\hline & $165,539.20$ & $100.0 \%$ \\
\hline
\end{tabular}

Aporte cada Socio

$27,589.87$

Elaboración propia 


\subsection{Cronograma de nuevas inversiones en activos fijos e intangibles (3er año)}

Tabla 4.8

Nuevas inversiones de activos fijos

\begin{tabular}{|c|c|c|c|c|}
\hline Activos fijos & $\begin{array}{c}\text { Valor de } \\
\text { venta }\end{array}$ & IGV & Precio & $\begin{array}{l}\text { Vida útil } \\
\text { (años) }\end{array}$ \\
\hline \multicolumn{5}{|l|}{ EQUIPOS DE PRODUCCION } \\
\hline Aromatizador REFISA 81ts & 271.19 & 48.81 & 320.00 & 3 \\
\hline \multicolumn{5}{|l|}{ MUEBLES DE OFICINA } \\
\hline Silla giratoria Modelo Rta-905 & $1,552.54$ & 279.46 & $1,832.00$ & 3 \\
\hline Sillones De Espera & $1,152.54$ & 207.46 & $1,360.00$ & 3 \\
\hline \multicolumn{5}{|l|}{$\begin{array}{c}\text { EQUIPOS DE COMPUTACÍON Y } \\
\text { ELECTRODOMESTICO }\end{array}$} \\
\hline Laptop Hp Core I7, Empresarial Elitebook & $8,067.80$ & $1,452.20$ & $9,520.00$ & 3 \\
\hline HP LaserJet Ent MFP M527dn Printer (F2A76A) & $1,022.03$ & 183.97 & $1,206.00$ & 3 \\
\hline Microondas Miray & 211.86 & 38.14 & 250.00 & 3 \\
\hline POS & 19.49 & 3.51 & 23.00 & 3 \\
\hline Instalacion POS & 50.85 & 9.15 & 60.00 & 3 \\
\hline 2 play Empresas 4Mbps CLARO- Telefonia fija + internet & 117.80 & 21.20 & 139.00 & 3 \\
\hline Activos Intangibles & $\begin{array}{c}\text { Valor de } \\
\text { venta }\end{array}$ & IGV & Precio & $\begin{array}{l}\text { Vida útil } \\
\text { (años) }\end{array}$ \\
\hline Software & 847.46 & 152.54 & $1,000.00$ & 3 \\
\hline
\end{tabular}

Elaboración propia 
Tabla 4.9

Renovación de activos fijos tangibles (3er año)

\begin{tabular}{|c|c|c|c|c|c|}
\hline Activos fijos & Año 1 & Año 2 & Año 3 & Año 4 & Año 5 \\
\hline \multicolumn{6}{|l|}{$\begin{array}{c}\text { EQUIPOS DE } \\
\text { PRODUCCION }\end{array}$} \\
\hline Aromatizador REFISA 81ts & & & 271.19 & 271.19 & 271.19 \\
\hline \multicolumn{6}{|l|}{ MUEBLES DE OFICINA } \\
\hline Silla giratoria Modelo Rta-905 & & & $1,552.54$ & & \\
\hline Sillones De Espera & & & $1,152.54$ & & \\
\hline \multicolumn{6}{|l|}{$\begin{array}{c}\text { EQUIPOS DE } \\
\text { COMPUTACÍON Y } \\
\text { ELECTRODOMESTICO }\end{array}$} \\
\hline $\begin{array}{c}\text { Laptop Hp Core I7, } \\
\text { Empresarial Elitebook }\end{array}$ & & & $8,067.80$ & & \\
\hline $\begin{array}{l}\text { HP LaserJet Ent MFP M527dn } \\
\text { Printer (F2A76A) }\end{array}$ & & & $1,022.03$ & & \\
\hline Microondas Miray & & & 211.86 & & \\
\hline POS & & & 19.49 & & \\
\hline Instalacion POS & & & 50.85 & & \\
\hline $\begin{array}{c}2 \text { play Empresas } 4 \mathrm{Mbps} \\
\text { CLARO- Telefonia fija + } \\
\text { internet }\end{array}$ & & & 117.80 & & \\
\hline Total inversión excluído IGV & & & $12,466.10$ & 271.19 & 271.19 \\
\hline & & & $14,710.00$ & 320.00 & 320.00 \\
\hline & & & $2,243.90$ & 48.81 & 48.81 \\
\hline
\end{tabular}

Elaboración propia 
Tabla 4.10

Renovación de activos fijos intangibles (3er año)

\begin{tabular}{|c|r|r|r|r|r|}
\hline Activos Intangibles & Año 1 & Año 2 & Año 3 & Año 4 & Año 5 \\
\hline Software & & & 847.46 & & \\
\hline Total inversión excluído IGV & & & $\mathbf{8 4 7 . 4 6}$ & & \\
\hline
\end{tabular}

Elaboración propia

Inversión en activos fijos e intangibles durante la vida del proyecto (3er año)

Tabla 4.11

Ampliación de capacidad de producción y venta

\begin{tabular}{|c|r|r|r|c|}
\hline Activos fijos & Valor de venta & IGV & Precio & $\begin{array}{c}\text { Vida útil } \\
\text { (años) }\end{array}$ \\
\hline EQUIPOS DE PRODUCCION & & & & \\
\hline Equipo de sonido & 254.24 & 45.76 & 300.00 & 5 \\
\hline Aromatizador REFISA 8lts & 271.19 & 48.81 & 320.00 & 3 \\
\hline MUEBLES DE OFICINA & & & $1,832.00$ & 3 \\
\hline Silla giratoria Modelo Rta-905 & $1,552.54$ & 279.46 & $1,360.00$ & 3 \\
\hline Sillones De Espera & $1,152.54$ & 207.46 & 358.00 & 5 \\
\hline Archivador metálico & 303.39 & 54.61 & $1,750.00$ & 5 \\
\hline Mueble escritorio para oficina & $1,483.05$ & 266.95 & & 3 \\
\hline EQUIPOS DE COMPUTACÍ⿴囗十 Y \\
ELECTRODOMESTICO
\end{tabular}

Elaboración propia 
Tabla 4.12

Total inversión de activos fijos tangibles

\begin{tabular}{|c|c|c|c|c|c|}
\hline Activos fijos & Año 1 & Año 2 & Año 3 & Año 4 & Año 5 \\
\hline \multicolumn{6}{|l|}{ EQUIPOS DE PRODUCCION } \\
\hline Equipo de sonido & 254.24 & 254.24 & 508.47 & 254.24 & 0 \\
\hline Aromatizador REFISA 81ts & 271.19 & 271.19 & 542.37 & 271.19 & 0 \\
\hline \multicolumn{6}{|l|}{ MUEBLES DE OFICINA } \\
\hline Silla giratoria Modelo Rta-905 & & & $1,552.54$ & & \\
\hline Sillones De Espera & & & $1,152.54$ & & \\
\hline Archivador metálico & & & 303.39 & & \\
\hline Mueble escritorio para oficina & & & $1,483.05$ & & \\
\hline \multicolumn{6}{|l|}{$\begin{array}{l}\text { EQUIPOS DE } \\
\text { COMPUTACÍON Y } \\
\text { ELECTRODOMESTICO }\end{array}$} \\
\hline $\begin{array}{l}\text { Laptop Hp Core I7, Empresarial } \\
\text { Elitebook }\end{array}$ & & & $8,067.80$ & & \\
\hline Microondas Miray & & & 211.86 & & \\
\hline \multirow[t]{3}{*}{ Total inversión excluído IGV } & 525.42 & 525.42 & $13,822.03$ & 525.42 & $\mathbf{0 . 0 0}$ \\
\hline & 620.00 & 620.00 & $16,310.00$ & 620.00 & 0.00 \\
\hline & 94.58 & 94.58 & $2,487.97$ & 94.58 & 0.00 \\
\hline
\end{tabular}

Elaboración propia 


\subsubsection{Criterios y ppto. anual de depreciación de activos fijos e intangibles}

Tabla 4.13

Criterios y ppto anual de depreciación de activos fijos

\begin{tabular}{|c|c|c|c|c|c|c|c|}
\hline Activos fijos & $\begin{array}{l}\text { Valor de } \\
\text { venta }\end{array}$ & $\begin{array}{l}\text { Vida útil } \\
\text { (años) }\end{array}$ & $\begin{array}{c}\text { Dep. } \\
\text { AÑO } 1\end{array}$ & $\begin{array}{l}\text { Dep. } \\
\text { AÑO } 2\end{array}$ & $\begin{array}{c}\text { Dep. } \\
\text { AÑ̃ } 3\end{array}$ & $\begin{array}{c}\text { Dep. } \\
\text { AÑNO } 4\end{array}$ & $\begin{array}{c}\text { Dep. } \\
\text { AÑ̃ } 5\end{array}$ \\
\hline \multicolumn{8}{|c|}{ EQUIPOS DE PRODUCCION } \\
\hline Equipo de sonido & 254.24 & 5 & 101.69 & 152.54 & 254.24 & 305.08 & 305.08 \\
\hline $\begin{array}{l}\text { Aromatizador REFISA } \\
\text { 81ts }\end{array}$ & 271.19 & 3 & 180.79 & 271.19 & 451.98 & 542.37 & 542.37 \\
\hline \multicolumn{8}{|c|}{ MUEBLES DE OFICINA } \\
\hline $\begin{array}{l}\text { Silla giratoria Modelo } \\
\text { Rta-905 }\end{array}$ & $1,552.54$ & 3 & 517.51 & 517.51 & $1,035.03$ & $1,035.03$ & $1,035.03$ \\
\hline Sillones De Espera & $1,152.54$ & 3 & 384.18 & 384.18 & 768.36 & 768.36 & 768.36 \\
\hline Counter de recepción & 338.98 & 5 & 67.80 & 67.80 & 67.80 & 67.80 & 67.80 \\
\hline Archivador metálico & 303.39 & 5 & 60.68 & 60.68 & 121.36 & 121.36 & 121.36 \\
\hline $\begin{array}{l}\text { Mueble escritorio para } \\
\text { oficina }\end{array}$ & $1,483.05$ & 5 & 296.61 & 296.61 & 593.22 & 593.22 & 593.22 \\
\hline \multicolumn{8}{|c|}{ EQUIPOS DE COMPUTACÍON Y ELECTRODOMESTICO } \\
\hline $\begin{array}{l}\text { Laptop Hp Core I7, } \\
\text { Empresarial Elitebook }\end{array}$ & $8,067.80$ & 3 & $2,689.27$ & $2,689.27$ & $5,378.53$ & $5,378.53$ & $5,378.53$ \\
\hline $\begin{array}{l}\text { HP LaserJet Ent MFP } \\
\text { M527dn Printer } \\
\text { (F2A76A) }\end{array}$ & $1,022.03$ & 3 & 340.68 & 340.68 & 340.68 & 340.68 & 340.68 \\
\hline Microondas Miray & 211.86 & 3 & 70.62 & 70.62 & 141.24 & 141.24 & 141.24 \\
\hline POS & 19.49 & 3 & 6.50 & 6.50 & 6.50 & 6.50 & 6.50 \\
\hline Instalacion POS & 50.85 & 3 & 16.95 & 16.95 & 16.95 & 16.95 & 16.95 \\
\hline $\begin{array}{l}2 \text { play Empresas } 4 \mathrm{Mbps} \\
\text { CLARO- Telefonia fija } \\
+ \text { internet }\end{array}$ & 117.80 & 3 & 39.27 & 39.27 & 39.27 & 39.27 & 39.27 \\
\hline & & TOTAL & $4,772.54$ & 4,913.79 & $9,215.14$ & 9,356.38 & 9,356.38 \\
\hline
\end{tabular}

Elaboración propia 
Tabla 4.14

Criterios y ppto. anual de activos intangibles

\begin{tabular}{|c|c|c|c|c|c|c|c|}
\hline $\begin{array}{l}\text { Activos } \\
\text { intangibles }\end{array}$ & $\begin{array}{c}\text { Valor de } \\
\text { venta }\end{array}$ & $\begin{array}{l}\text { Vida útil } \\
\text { (años) }\end{array}$ & $\begin{array}{c}\text { Amortizació } \\
\text { n AÑO } 1\end{array}$ & Am.AÑO 2 & $\begin{array}{c}\text { Am. AÑNO } \\
\mathbf{3}\end{array}$ & $\begin{array}{c}\text { Am. AÑ } \\
4\end{array}$ & $\begin{array}{c}\text { Am. AÑ } \\
5\end{array}$ \\
\hline $\begin{array}{l}\text { Gastos pre } \\
\text { operativos }\end{array}$ & $18,497.42$ & 5 & $3,699.48$ & $3,699.48$ & $3,699.48$ & $3,699.48$ & $3,699.48$ \\
\hline Software & 847.46 & 3 & 282.49 & 282.49 & 282.49 & 282.49 & 282.49 \\
\hline \multicolumn{3}{|c|}{ TOTAL } & $3,981.97$ & $3,981.97$ & $3,981.97$ & $3,981.97$ & $3,981.97$ \\
\hline
\end{tabular}

\begin{tabular}{|l|r|r|r|r|r|}
\hline CIF & 282.49 & 423.73 & 706.21 & 847.46 & 847.46 \\
\hline ADM & $4,264.07$ & $4,264.07$ & $8,090.85$ & $8,090.85$ & $8,090.85$ \\
\hline VTAS & 225.99 & 225.99 & 418.08 & 418.08 & 418.08 \\
\hline & $4,772.54$ & $4,913.79$ & $9,215.14$ & $9,356.38$ & $9,356.38$ \\
\cline { 2 - 6 }
\end{tabular}

Elaboración propia 


\subsection{Presupuesto Anual}

\subsubsection{Pptos. de ventas en unidades y en soles}

Tabla 4.15

Proporción de ventas y precio del servicio

\begin{tabular}{|l|c|}
\hline \multicolumn{1}{|c|}{ Servicio } & \% de consumo \\
\hline PAQUETE 6 SESIONES & \multicolumn{1}{|c|}{$105.0 \%$} \\
\hline RETIROS & \multicolumn{1}{|c|}{$100.0 \%$} \\
\hline & Precio (S/.) \\
\hline Servicio & 260.00 \\
\hline PAQUETE 6 SESIONES & \multicolumn{2}{|c|}{580.00} \\
\hline RETIROS & \multicolumn{2}{|c|}{} \\
\hline
\end{tabular}

Elaboración propia

Tabla 4.16

Cantidad de servicios vendidos por año

\begin{tabular}{|c|c|c|c|c|c|}
\hline Cantidad de servicios & AÑO1 & AÑO2 & AÑO3 & AÑO4 & AÑN5 \\
\hline$\%$ CRECIMIENTO & & $174 \%$ & $56 \%$ & $30 \%$ & $18 \%$ \\
\hline PAQUETE 6 SESIONES & 614 & 1,683 & 2,619 & 3,398 & 3,994 \\
\hline RETIROS & 32 & 89 & 138 & 179 & 210 \\
\hline Ventas & 646 & 1,771 & 2,757 & 3,577 & 4,204 \\
\hline
\end{tabular}

Elaboración propia 
Tabla 4.17

Cantidad de servicios valorizado en soles

\begin{tabular}{|c|c|c|c|c|c|}
\hline Soles & AÑO1 & AÑO2 & AÑO3 & AÑO4 & AÑ O5 \\
\hline PAQUETE 6 SESIONES & $159,517.58$ & $437,461.49$ & $680,920.06$ & $883,563.82$ & $1,038,443.60$ \\
\hline RETIROS & $18,728.78$ & $51,361.87$ & $79,946.08$ & $103,738.26$ & $121,922.53$ \\
\hline Ventas & $178,246.37$ & $488,823.36$ & $760,866.14$ & $987,302.08$ & $1,160,366.13$ \\
\hline IGV & $27,190.12$ & $74,566.28$ & $116,064.33$ & $150,605.40$ & $177,005.00$ \\
\hline Valor de venta & $151,056.24$ & $414,257.09$ & $644,801.82$ & $836,696.68$ & $983,361.13$ \\
\hline
\end{tabular}

Elaboración propia

\subsubsection{Ppto. de producción en unidades}

Tabla 4.18

Proporción de servicios y costo de materiales

\begin{tabular}{|l|c|}
\hline Servicio & \% de consumo \\
\hline PAQUETE 6 SESIONES & $95.0 \%$ \\
\hline RETIROS & $5.0 \%$ \\
\hline & $100.0 \%$ \\
\hline Servicio & Costo materiales(S/.) \\
\hline PAQUETE 6 SESIONES & 7.94 \\
\hline RETIROS & 167.94 \\
\hline
\end{tabular}

Elaboración propia 
Tabla 4.19

Cantidad de servicios producidos por año

\begin{tabular}{|c|c|c|c|c|c|}
\hline Cantidad de servicios & AÑNO1 & AÑO2 & AÑO3 & AÑO4 & AÑ̃5 \\
\hline PAQUETE 6 SESIONES & 614 & 1,683 & 2,619 & 3,398 & 3,994 \\
\hline RETIROS & 32 & 89 & 138 & 179 & 210 \\
\hline PRODUCCION & 646 & 1,771 & 2,757 & 3,577 & 4,204 \\
\hline
\end{tabular}

Elaboración propia

Tabla 4.20

Presupuesto de materiales utilizados por año

\begin{tabular}{|c|c|c|c|c|c|}
\hline Insumos & AÑN1 & AÑN2 & AÑO3 & AÑN4 & AÑO5 \\
\hline PAQUETE 6 SESIONES & $4,871.42$ & $13,359.40$ & $20,794.25$ & $26,982.68$ & $31,712.47$ \\
\hline RETIROS & $5,422.95$ & $14,871.92$ & $23,148.53$ & $30,037.59$ & $35,302.88$ \\
\hline TOTAL INCLUIDO IGV & $10,294.37$ & $28,231.32$ & $43,942.78$ & $57,020.27$ & $67,015.35$ \\
\hline IGV & $1,570.33$ & $4,306.47$ & $6,703.14$ & $8,698.01$ & $10,222.68$ \\
\hline VALOR & $8,724.05$ & $23,924.85$ & $37,239.64$ & $48,322.26$ & $56,792.67$ \\
\hline
\end{tabular}

Elaboración propia 


\subsubsection{Pptos. de consumo de materiales, insumos, etc. en unidades y soles}

Tabla 4.21

Presupuesto de materiales operativos

\begin{tabular}{|c|c|c|c|c|c|}
\hline $\mathbf{Q}$ & Materiales Operativos & Precio unitario & Valor & IGV & Total \\
\hline 10 & Colchoneta de Yoga & 10.00 & 84.75 & 15.25 & 100.00 \\
\hline 1 & Portaincienso & 9.00 & 7.63 & 1.37 & 9.00 \\
\hline 10 & Inciensos & 0.20 & 1.69 & 0.31 & 2.00 \\
\hline 10 & Tijeras & 5.00 & 42.37 & 7.63 & 50.00 \\
\hline 10 & Velas & 5.00 & 42.37 & 7.63 & 50.00 \\
\hline 10 & Banderines & 5.00 & 42.37 & 7.63 & 50.00 \\
\hline 10 & Cojines & 10.00 & 84.75 & 15.25 & 100.00 \\
\hline 10 & Frutas & 1.00 & 8.47 & 1.53 & 10.00 \\
\hline 1 & Agua (bidón de 21 litros) & 26.00 & 22.03 & 3.97 & 26.00 \\
\hline
\end{tabular}

Elaboración propia 


\subsubsection{Costo Salarial}

Tabla 4.22

Detalle de costos de planilla total

\begin{tabular}{|c|c|c|c|c|c|}
\hline Detalle & AÑO 1 & AÑO 2 & AÑO 3 & AÑO 4 & AÑO 5 \\
\hline Gerente General & $48,000.00$ & $50,400.00$ & $52,920.00$ & $55,566.00$ & $58,344.30$ \\
\hline Recepcionista & $18,000.00$ & $18,900.00$ & $19,845.00$ & $20,837.25$ & $21,879.11$ \\
\hline $\begin{array}{c}\text { Coordinador de } \\
\text { especialistas }\end{array}$ & 0.00 & 0.00 & 0.00 & $30,000.00$ & $31,500.00$ \\
\hline Jefe de marketing & 0.00 & 0.00 & 0.00 & $30,000.00$ & $31,500.00$ \\
\hline & $66,000.00$ & 69,300.00 & $72,765.00$ & $136,403.25$ & $143,223.41$ \\
\hline Gratificaciones & $11,000.00$ & $11,550.00$ & $12,127.50$ & $22,733.88$ & $23,870.57$ \\
\hline & $77,000.00$ & $80,850.00$ & $84,892.50$ & $159,137.13$ & $167,093.98$ \\
\hline CTS & $6,416.67$ & $6,737.50$ & $7,074.38$ & $13,261.43$ & $13,924.50$ \\
\hline ESSALUD & $6,930.00$ & $7,276.50$ & $7,640.33$ & $14,322.34$ & $15,038.46$ \\
\hline Costo salarial planilla & $90,346.67$ & $94,864.00$ & $99,607.20$ & $186,720.89$ & $196,056.94$ \\
\hline Contador & $9,600.00$ & $10,080.00$ & $10,584.00$ & $11,113.20$ & $11,668.86$ \\
\hline Psicólogo(s) & $24,000.00$ & $50,400.00$ & $52,920.00$ & $111,132.00$ & $116,688.60$ \\
\hline Nutricionista(s) & $14,400.00$ & $30,240.00$ & $31,752.00$ & $66,679.20$ & $70,013.16$ \\
\hline Coach(es) & $14,400.00$ & $30,240.00$ & $31,752.00$ & $66,679.20$ & $70,013.16$ \\
\hline Educador(es) Físico(s) & $14,400.00$ & $30,240.00$ & $31,752.00$ & $66,679.20$ & $70,013.16$ \\
\hline Sociólogo(s) & $24,000.00$ & $50,400.00$ & $52,920.00$ & $111,132.00$ & $116,688.60$ \\
\hline Costo salarial anual & $191,146.67$ & $296,464.00$ & $311,287.20$ & $620,135.69$ & $651,142.48$ \\
\hline
\end{tabular}

\begin{tabular}{|c|r|r|r|r|r|}
\hline $\begin{array}{c}\text { Beneficios } \\
\text { provisionados }\end{array}$ & $1,069.44$ & $1,122.92$ & $1,179.06$ & $2,210.24$ & $2,320.75$ \\
\hline
\end{tabular}

\begin{tabular}{|c|r|r|r|r|r|}
\hline Desembolso & $190,077.22$ & $296,410.53$ & $311,231.05$ & $619,104.52$ & $651,031.97$ \\
\hline
\end{tabular}

Elaboración propia 
Tabla 4.23

Cantidad de especialistas por año

\begin{tabular}{|c|c|c|c|c|c|}
\cline { 2 - 6 } \multicolumn{1}{c|}{} & AÑO 1 & AÑ 2 & AÑ 3 & AÑ 4 & ANO 5 \\
\hline Psicólogo(s) & 1 & 2 & 2 & 4 & 4 \\
\hline Nutricionista(s) & 1 & 2 & 2 & 4 & 4 \\
\hline Coach(es) & 1 & 2 & 2 & 4 & 4 \\
\hline Educador(es) Físico(s) & 1 & 2 & 2 & 4 & 4 \\
\hline Sociólogo(s) & 1 & 2 & & 1 & 1 \\
\hline Coordinador de & & & & 1 & 1 \\
\hline
\end{tabular}

Elaboración propia

Tal como se explicó anteriormente, en nuestro programa habrán 3 turnos, 10 clientes por cada grupo. Con estos datos podemos identificar la cantidad de especialistas que se necesitan en los próximos años. 
4.7.5 Pptos. de gastos de luz, agua, teléfono, limpieza, seguridad, impuesto predial, etc

Tabla 4.24

Presupuesto de gastos en servicios públicos

\begin{tabular}{|c|c|c|c|c|c|}
\hline Detalle & AÑNO 1 & AÑNO 2 & AÑNO 3 & AÑO 4 & AÑNO 5 \\
\hline Luz para producción & $3,600.00$ & $9,872.65$ & $15,367.03$ & $19,940.31$ & $23,435.64$ \\
\hline Luz de oficinas & $1,200.00$ & $1,260.00$ & $1,323.00$ & $1,389.15$ & $1,458.61$ \\
\hline Agua & 600.00 & 630.00 & 661.50 & 694.58 & 729.30 \\
\hline Teléfono & $3,600.00$ & $3,780.00$ & $3,969.00$ & $4,167.45$ & $4,375.82$ \\
\hline Seguridad & $1,200.00$ & $1,260.00$ & $1,323.00$ & $1,389.15$ & $1,458.61$ \\
\hline Limpieza & $2,400.00$ & $2,520.00$ & $2,646.00$ & $2,778.30$ & $2,917.22$ \\
\hline Impuesto Predial & $1,500.00$ & $1,575.00$ & $1,653.75$ & $1,736.44$ & $1,823.26$ \\
\hline TOTAL S/IGV & $14,100.00$ & $20,897.65$ & $26,943.28$ & $32,095.37$ & $36,198.46$ \\
\hline IGV & $2,538.00$ & $3,761.58$ & $4,849.79$ & $5,777.17$ & $6,515.72$ \\
\hline TOTAL C/IGV & $16,638.00$ & $24,659.23$ & $31,793.08$ & $37,872.54$ & 42,714.18 \\
\hline
\end{tabular}

Elaboración propia

Tabla 4.25

Proporción de gastos en servicios públicos

\begin{tabular}{|l|c|c|c|c|}
\hline \multicolumn{1}{|c|}{ Detalle } & Produc & Admin & Vtas & Total \\
\hline Luz para producción & $100.0 \%$ & $0.0 \%$ & $0.0 \%$ & $100.0 \%$ \\
\hline Luz de oficinas & $20.0 \%$ & $50.0 \%$ & $30.0 \%$ & $100.0 \%$ \\
\hline Agua & $30.0 \%$ & $40.0 \%$ & $30.0 \%$ & $100.0 \%$ \\
\hline Teléfono & $10.0 \%$ & $30.0 \%$ & $60.0 \%$ & $100.0 \%$ \\
\hline Seguridad & $40.0 \%$ & $40.0 \%$ & $20.0 \%$ & $100.0 \%$ \\
\hline Limpieza & $60.0 \%$ & $30.0 \%$ & $10.0 \%$ & $100.0 \%$ \\
\hline Impuesto Predial & $50.0 \%$ & $30.0 \%$ & $20.0 \%$ & $100.0 \%$ \\
\hline
\end{tabular}

Elaboración propia

Consideramos estas tasas en función al número de personas que laboran en cada área. 


\subsubsection{Pptos. de costo de mano de obra indirecta}

Tabla 4.26

Sueldos de mano de obra indirecta

\begin{tabular}{|c|c|c|c|c|c|}
\hline Detalle & AÑNO 1 & AÑO 2 & AÑO 3 & AÑO 4 & AÑNO 5 \\
\hline $\begin{array}{l}\text { Coordinador de } \\
\text { especialistas }\end{array}$ & 0.00 & 0.00 & 0.00 & $30,000.00$ & $31,500.00$ \\
\hline & 0.00 & $\mathbf{0 . 0 0}$ & 0.00 & $30,000.00$ & $31,500.00$ \\
\hline Gratificaciones & 0.00 & 0.00 & 0.00 & $5,000.00$ & $5,250.00$ \\
\hline & 0.00 & 0.00 & 0.00 & $35,000.00$ & $36,750.00$ \\
\hline CTS & 0.00 & 0.00 & 0.00 & $2,916.67$ & $3,062.50$ \\
\hline ESSALUD & 0.00 & 0.00 & 0.00 & $3,150.00$ & $3,307.50$ \\
\hline Costo salarial anual & 0.00 & 0.00 & 0.00 & $41,066.67$ & $43,120.00$ \\
\hline $\begin{array}{l}\text { Beneficios } \\
\text { provisionados }\end{array}$ & 0.00 & 0.00 & 0.00 & 486.11 & 510.42 \\
\hline Desembolso & 0.00 & 0.00 & 0.00 & $40,580.56$ & $43,095.69$ \\
\hline
\end{tabular}

Elaboración propia

\subsubsection{Pptos. de gastos indirectos de producción}

Tabla 4.27

Gastos indirectos de producción

\begin{tabular}{|c|c|c|c|c|c|}
\hline & AÑO 1 & AÑO 2 & Ã̃̃ 3 & Ã̃O 4 & AÑO 5 \\
\hline \multicolumn{6}{|c|}{ DEPRECIACION DE EQUIPOS DE PRODUCCION } \\
\hline Equipo de sonido & 101.69 & 152.54 & 254.24 & 305.08 & 305.08 \\
\hline $\begin{array}{l}\text { Aromatizador } \\
\text { REFISA 81ts }\end{array}$ & 180.79 & 271.19 & 451.98 & 542.37 & 542.37 \\
\hline SUB TOTAL & 282.49 & 423.73 & 706.21 & 847.46 & 847.46 \\
\hline \multicolumn{6}{|c|}{ MATERIALES DE LIMPIEZA } \\
\hline Escoba & 5.08 & 13.94 & 21.70 & 28.16 & 33.10 \\
\hline
\end{tabular}




\begin{tabular}{|c|c|c|c|c|c|}
\hline Trapeador & 6.10 & 16.73 & 26.05 & 33.80 & 39.72 \\
\hline $\begin{array}{l}\text { Lavavajilla ( } 2 \text { potes } \\
\text { de } 360 \text { grs.) }\end{array}$ & 2.03 & 5.58 & 8.68 & 11.27 & 13.24 \\
\hline $\begin{array}{l}\text { Limpia pisos (pomo } \\
1,960 \mathrm{ml} . \text { ) }\end{array}$ & 4.07 & 11.16 & 17.36 & 22.53 & 26.48 \\
\hline Recogedor & 6.10 & 16.73 & 26.05 & 33.80 & 39.72 \\
\hline Guantes de hule & 4.07 & 11.16 & 17.36 & 22.53 & 26.48 \\
\hline Jabon liquido manos & 13.98 & 38.35 & 59.69 & 77.45 & 91.03 \\
\hline $\begin{array}{l}\text { Dispensador de } \\
\text { papel higienico }\end{array}$ & 76.27 & 209.17 & 325.57 & 422.46 & 496.52 \\
\hline SUB TOTAL & 117.71 & 322.81 & 502.47 & 652.00 & 766.29 \\
\hline \multicolumn{6}{|c|}{ GASTOS EN SERVICIOS PUBLICOS } \\
\hline Luz para producción & $3,600.00$ & $9,872.65$ & $15,367.03$ & $19,940.31$ & $23,435.64$ \\
\hline Luz de oficinas & 240.00 & 252.00 & 264.60 & 277.83 & 291.72 \\
\hline Agua & 180.00 & 189.00 & 198.45 & 208.37 & 218.79 \\
\hline Teléfono & 360.00 & 378.00 & 396.90 & 416.75 & 437.58 \\
\hline Seguridad & 480.00 & 504.00 & 529.20 & 555.66 & 583.44 \\
\hline Limpieza & $1,440.00$ & $1,512.00$ & $1,587.60$ & $1,666.98$ & $1,750.33$ \\
\hline Impuesto Predial & 750.00 & 787.50 & 826.88 & 868.22 & 911.63 \\
\hline SUB TOTAL & $7,050.00$ & $13,495.15$ & $19,170.66$ & $23,934.11$ & $27,629.14$ \\
\hline \multicolumn{6}{|c|}{ GASTOS EN SERVICIOS PUBLICOS } \\
\hline Psicólogo(s) & $24,000.00$ & $50,400.00$ & $52,920.00$ & $111,132.00$ & $116,688.60$ \\
\hline Nutricionista(s) & $14,400.00$ & $30,240.00$ & $31,752.00$ & $66,679.20$ & $70,013.16$ \\
\hline Coach(es) & $14,400.00$ & $30,240.00$ & $31,752.00$ & $66,679.20$ & $70,013.16$ \\
\hline $\begin{array}{l}\text { Educador(es) } \\
\text { Físico(s) }\end{array}$ & $14,400.00$ & $30,240.00$ & $31,752.00$ & $66,679.20$ & $70,013.16$ \\
\hline Sociólogo(s) & $24,000.00$ & $50,400.00$ & $52,920.00$ & $111,132.00$ & $116,688.60$ \\
\hline SUB TOTAL & $91,200.00$ & $191,520.00$ & $201,096.00$ & $422,301.60$ & $443,416.68$ \\
\hline TOTAL & $98,650.20$ & $205,761.69$ & $221,475.34$ & $447,735.18$ & $472,659.57$ \\
\hline
\end{tabular}

Elaboración propia

\subsubsection{Pptos. de costos indirectos de producción}


Tabla 4.28

Costos indirectos de producción

\begin{tabular}{|c|c|c|c|c|c|}
\hline CIF & AÑO 1 & AÑO 2 & AÑO 3 & AÑO 4 & AÑO 5 \\
\hline GIF & $98,650.20$ & $205,761.69$ & $221,475.34$ & $447,735.18$ & $472,659.57$ \\
\hline MOI & 0.00 & 0.00 & 0.00 & $41,066.67$ & $43,120.00$ \\
\hline TOTAL & $98,650.20$ & $205,761.69$ & $221,475.34$ & $488,801.84$ & $515,779.57$ \\
\hline
\end{tabular}

Elaboración propia

\subsubsection{Pptos. de costo de mano de obra directa}

Tabla 4.29

Sueldos de mano de obra directa

\begin{tabular}{|c|c|c|c|c|c|}
\hline Detalle & AÑNO 1 & AÑNO 2 & AÑ̃ 3 & AÑO 4 & AÑNO 5 \\
\hline NN & 0.00 & 0.00 & 0.00 & 0.00 & 0.00 \\
\hline NN & 0.00 & 0.00 & 0.00 & 0.00 & 0.00 \\
\hline & 0.00 & 0.00 & 0.00 & $\mathbf{0 . 0 0}$ & 0.00 \\
\hline Gratificaciones & 0.00 & 0.00 & 0.00 & 0.00 & 0.00 \\
\hline & 0.00 & 0.00 & 0.00 & 0.00 & 0.00 \\
\hline CTS & 0.00 & 0.00 & 0.00 & 0.00 & 0.00 \\
\hline ESSALUD & 0.00 & 0.00 & 0.00 & 0.00 & 0.00 \\
\hline Costo salarial anual & 0.00 & 0.00 & 0.00 & 0.00 & 0.00 \\
\hline Beneficios provisionados & 0.00 & 0.00 & 0.00 & 0.00 & 0.00 \\
\hline Desembolso & 0.00 & 0.00 & 0.00 & 0.00 & 0.00 \\
\hline
\end{tabular}

Elaboración propia

No fabricamos, somo una empresa que brinda servicios; por lo tanto, no contamos con mano de obra directa. 


\subsubsection{Pptos. de costo de venta}

Tabla 4.30

Costo de producción valorizado en soles

\begin{tabular}{|c|c|c|c|c|c|}
\hline SOLES & AÑO 1 & AÑNO 2 & AÑNO 3 & AÑO 4 & AÑNO 5 \\
\hline $\begin{array}{l}\text { Costo de } \\
\text { Insumos }\end{array}$ & $8,724.05$ & $23,924.85$ & $37,239.64$ & $48,322.26$ & $56,792.67$ \\
\hline MOD & 0.00 & 0.00 & 0.00 & 0.00 & 0.00 \\
\hline CIF & $98,650.20$ & $205,761.69$ & $221,475.34$ & $488,801.84$ & $515,779.57$ \\
\hline $\begin{array}{c}\text { TOTAL } \\
\text { COSTO } \\
\text { PRODUCCION }\end{array}$ & $107,374.24$ & 229,686.54 & 258,714.98 & $537,124.11$ & $572,572.24$ \\
\hline
\end{tabular}

Elaboración propia

Tabla 4.31

Servicios producidos y vendidos

\begin{tabular}{|c|c|c|c|c|c|}
\hline $\begin{array}{c}\text { Servicios } \\
\text { Producidas }\end{array}$ & 646 & 1,771 & 2,757 & 3,577 & 4,204 \\
\hline $\begin{array}{c}\text { Servicios } \\
\text { Vendidas }\end{array}$ & 646 & 1,771 & 2,757 & 3,577 & 4,204 \\
\hline
\end{tabular}

Elaboración propia

No fabricamos; por lo tanto se entiende que forma parte de los materiales que se utilizarán para los servicios que brindaremos. 
Tabla 4.32

Costo de venta

\begin{tabular}{|l|r|r|r|r|r|}
\hline $\begin{array}{l}\text { Costo de } \\
\text { Producción }\end{array}$ & $107,374.24$ & $229,686.54$ & $258,714.98$ & $537,124.11$ & $572,572.24$ \\
\hline Costo de Venta & $107,374.24$ & $229,686.54$ & $258,714.98$ & $537,124.11$ & $572,572.24$ \\
\hline
\end{tabular}

Elaboración propia

\subsubsection{Pptos. de gastos administrativos directos}

Tabla 4.33

Gastos administrativos directos

\begin{tabular}{|c|c|c|c|c|c|}
\hline & A ̃̃NO 1 & AÑ̃ 2 & AÑ̃ 3 & AÑ̃ 4 & AÑO 5 \\
\hline Contador & $9,600.00$ & $10,080.00$ & $10,584.00$ & $11,113.20$ & $11,668.86$ \\
\hline Alquiler local & $20,135.59$ & $20,135.59$ & $40,271.19$ & $40,271.19$ & $40,271.19$ \\
\hline TOTAL & $29,735.59$ & $30,215.59$ & $\mathbf{5 0 , 8 5 5 . 1 9}$ & $51,384.39$ & $51,940.05$ \\
\hline
\end{tabular}

Elaboración propia 
4.7.12 Pptos. de gastos de mano de obra administrativa

Tabla 4.34

Gastos de mano de obra administrativa

\begin{tabular}{|c|c|c|c|c|c|}
\hline DETALLE & AÑO 1 & AÑO 2 & AÑO 3 & AÑO 4 & AÑN 5 \\
\hline Gerente & & & & & \\
\hline General(Administrador) & $48,000.00$ & $50,400.00$ & $52,920.00$ & $55,566.00$ & $58,344.30$ \\
\hline \multirow[t]{2}{*}{ Recepcionista } & $18,000.00$ & $18,900.00$ & $19,845.00$ & $20,837.25$ & $21,879.11$ \\
\hline & $66,000.00$ & $69,300.00$ & $72,765.00$ & $76,403.25$ & $80,223.41$ \\
\hline \multirow[t]{2}{*}{ Gratificaciones } & $11,000.00$ & $11,550.00$ & $12,127.50$ & $12,733.88$ & $13,370.57$ \\
\hline & $77,000.00$ & $80,850.00$ & $84,892.50$ & $89,137.13$ & 93,593.98 \\
\hline CTS & $6,416.67$ & $6,737.50$ & $7,074.38$ & $7,428.09$ & $7,799.50$ \\
\hline ESSALUD & $6,930.00$ & $7,276.50$ & $7,640.33$ & $8,022.34$ & $8,423.46$ \\
\hline Costo salarial anual & $90,346.67$ & $94,864.00$ & $99,607.20$ & $104,587.56$ & $109,816.94$ \\
\hline
\end{tabular}

\begin{tabular}{|l|r|r|r|r|r|}
\hline Beneficios provisionados & $1,069.44$ & $1,122.92$ & $1,179.06$ & $1,238.02$ & $1,299.92$ \\
\hline
\end{tabular}

\begin{tabular}{|l|r|r|r|r|r|}
\hline Desembolso & $89,277.22$ & $94,810.53$ & $99,551.05$ & $104,528.61$ & $109,755.04$ \\
\hline
\end{tabular}

Elaboración propia

\subsubsection{Pptos. de gastos administrativos indirectos}

Tabla 4.35

Gastos administrativos indirectos

\begin{tabular}{|c|c|c|c|c|c|}
\hline & AÑO 1 & AÑO 2 & AÑO 3 & AÑ̃ 4 & AÑNO 5 \\
\hline \multicolumn{6}{|c|}{ DEPRECIACION DE MUEBLES DE OFICINA } \\
\hline Silla giratoria Modelo Rta-905 & 517.51 & 517.51 & $1,035.03$ & $1,035.03$ & $1,035.03$ \\
\hline Sillones De Espera & 192.09 & 192.09 & 384.18 & 384.18 & 384.18 \\
\hline Counter de recepcion & 33.90 & 33.90 & 33.90 & 33.90 & 33.90 \\
\hline Archivador metálico & 60.68 & 60.68 & 121.36 & 121.36 & 121.36 \\
\hline Mueble escritorio para oficina & 296.61 & 296.61 & 593.22 & 593.22 & 593.22 \\
\hline
\end{tabular}




\begin{tabular}{|c|c|c|c|c|c|}
\hline & Ã̃O 1 & Ã̃̃ 2 & AÑO 3 & AÑO 4 & AÑO 5 \\
\hline \multicolumn{6}{|c|}{ DEPRECIACION DE EQUIPOS DE COMPUTACÍON Y ELECTRODOMESTICO } \\
\hline $\begin{array}{l}\text { Laptop Hp Core I7, Empresarial } \\
\text { Elitebook }\end{array}$ & $2,689.27$ & $2,689.27$ & $5,378.53$ & $5,378.53$ & $5,378.53$ \\
\hline $\begin{array}{l}\text { HP LaserJet Ent MFP M527dn } \\
\text { Printer (F2A76A) }\end{array}$ & 340.68 & 340.68 & 340.68 & 340.68 & 340.68 \\
\hline Microondas Miray & 70.62 & 70.62 & 141.24 & 141.24 & 141.24 \\
\hline POS & 6.50 & 6.50 & 6.50 & 6.50 & 6.50 \\
\hline Instalacion POS & 16.95 & 16.95 & 16.95 & 16.95 & 16.95 \\
\hline $\begin{array}{l}2 \text { play Empresas } 4 \mathrm{Mbps} \\
\text { CLARO- Telefonia fija + } \\
\text { internet }\end{array}$ & 39.27 & 39.27 & 39.27 & 39.27 & 39.27 \\
\hline \multicolumn{6}{|c|}{ AMORTIZACION DE INTANGIBLES } \\
\hline Gastos pre operativos & $3,699.48$ & $3,699.48$ & $3,699.48$ & $3,699.48$ & $3,699.48$ \\
\hline Software & 282.49 & 282.49 & 282.49 & 282.49 & 282.49 \\
\hline \multicolumn{6}{|l|}{ OTROS GASTOS } \\
\hline Paquete de 5,000 Hojas Bond & 110.17 & 121.19 & 266.61 & 293.27 & 322.60 \\
\hline $\begin{array}{l}\text { Toner HP LaserJet Ent MFP } \\
\text { M527dn }\end{array}$ & 531.36 & 584.49 & $1,285.88$ & $1,414.47$ & $1,555.92$ \\
\hline Engrapador & 16.95 & 18.64 & 41.02 & 45.12 & 49.63 \\
\hline Caja con 5,000 grapas & 8.47 & 9.32 & 20.51 & 22.56 & 24.82 \\
\hline Lapiceros & 13.56 & 14.92 & 32.81 & 36.09 & 39.70 \\
\hline Extintor & 97.46 & 107.20 & 235.85 & 259.43 & 285.38 \\
\hline Botiquín laboral & 67.80 & 74.58 & 164.07 & 180.47 & 198.52 \\
\hline \multicolumn{6}{|c|}{ GASTOS EN SERVICIOS PUBLICOS } \\
\hline Luz de oficinas & 600.00 & 630.00 & 661.50 & 694.58 & 729.30 \\
\hline Agua & 240.00 & 252.00 & 264.60 & 277.83 & 291.72 \\
\hline Teléfono & $1,080.00$ & $1,134.00$ & $1,190.70$ & $1,250.24$ & $1,312.75$ \\
\hline Seguridad & 480.00 & 504.00 & 529.20 & 555.66 & 583.44 \\
\hline Limpieza & 720.00 & 756.00 & 793.80 & 833.49 & 875.16 \\
\hline Impuesto Predial & 450.00 & 472.50 & 496.13 & 520.93 & 546.98 \\
\hline TOTAL & $12,661.80$ & $12,924.88$ & $18,055.49$ & $18,456.96$ & $18,888.74$ \\
\hline
\end{tabular}

Elaboración propia 


\subsubsection{Pptos. de gastos administrativos totales}

Tabla 4.36

Gastos administrativos totales

\begin{tabular}{|c|c|c|c|c|c|}
\hline & AÑO 1 & AÑO 2 & AÑ̃ 3 & AÑ̃ 4 & AÑO 5 \\
\hline $\begin{array}{c}\text { Gastos administrativos } \\
\text { directos }\end{array}$ & $29,735.59$ & $30,215.59$ & $50,855.19$ & $51,384.39$ & $51,940.05$ \\
\hline Mano de obra administrativa & $90,346.67$ & $94,864.00$ & $99,607.20$ & $104,587.56$ & $109,816.94$ \\
\hline $\begin{array}{c}\text { Gastos administrativos } \\
\text { indirectos }\end{array}$ & $12,661.80$ & $12,924.88$ & $18,055.49$ & $18,456.96$ & $18,888.74$ \\
\hline TOTAL & $132,744.06$ & $138,004.47$ & $168,517.88$ & $174,428.91$ & $180,645.72$ \\
\hline
\end{tabular}

Elaboración propia

\subsubsection{Pptos. de gastos de venta directos}

Tabla 4.37

Gastos de venta directos

\begin{tabular}{|c|c|c|c|c|c|}
\hline Medios digitales & AÑO 1 & AÑO 2 & AÑNO 3 & AÑO 4 & AÑNO 5 \\
\hline $\begin{array}{l}\text { Redes sociales (15 } \\
\text { soles dia) }\end{array}$ & $5,400.00$ & $5,670.00$ & $5,953.50$ & $6,251.18$ & $6,563.73$ \\
\hline Total & $5,400.00$ & $5,670.00$ & $5,953.50$ & $6,251.18$ & $6,563.73$ \\
\hline
\end{tabular}

\begin{tabular}{|c|c|c|c|c|c|}
\hline & AÑNO 1 & AÑO 2 & AÑ̃ 3 & AÑ̃ 4 & AÑNO 5 \\
\hline Medios digitales & $5,400.00$ & $5,670.00$ & $5,953.50$ & $6,251.18$ & $6,563.73$ \\
\hline PRECIO & $5,400.00$ & $5,670.00$ & $5,953.50$ & $6,251.18$ & $6,563.73$ \\
\hline IGV & 823.73 & 864.92 & 908.16 & 953.57 & $1,001.25$ \\
\hline VALOR & $4,576.27$ & $4,805.08$ & $5,045.34$ & $5,297.61$ & $5,562.49$ \\
\hline$\%$ INC VTAS & $0.0 \%$ & $174.2 \%$ & $55.7 \%$ & $29.8 \%$ & $17.5 \%$ \\
\hline
\end{tabular}

Elaboración propia 


\subsubsection{Pptos. de gastos para personal de ventas}

Tabla 4.38

Gastos para personal de ventas

\begin{tabular}{|c|c|c|c|c|c|}
\hline DETALLE & AÑNO 1 & AÑO 2 & AÑO 3 & AÑO 4 & AÑO 5 \\
\hline Jefe de marketing & 0.00 & 0.00 & 0.00 & $30,000.00$ & $31,500.00$ \\
\hline & $\mathbf{0 . 0 0}$ & $\mathbf{0 . 0 0}$ & 0.00 & $30,000.00$ & $31,500.00$ \\
\hline Gratificaciones & 0.00 & 0.00 & 0.00 & $5,000.00$ & $5,250.00$ \\
\hline & $\mathbf{0 . 0 0}$ & $\mathbf{0 . 0 0}$ & 0.00 & $35,000.00$ & $36,750.00$ \\
\hline CTS & 0.00 & 0.00 & 0.00 & $2,916.67$ & $3,062.50$ \\
\hline ESSALUD & 0.00 & 0.00 & 0.00 & $3,150.00$ & $3,307.50$ \\
\hline Costo salarial anual & $\mathbf{0 . 0 0}$ & $\mathbf{0 . 0 0}$ & 0.00 & $41,066.67$ & $43,120.00$ \\
\hline Beneficios provisionados & 0.00 & 0.00 & 0.00 & 486.11 & 510.42 \\
\hline Desembolso & 0.00 & 0.00 & 0.00 & $40,580.56$ & $43,095.69$ \\
\hline
\end{tabular}

Elaboración propia 


\subsubsection{Pptos. de gastos de venta indirectos}

Tabla 4.39

Gastos de venta indirectos

\begin{tabular}{|c|c|c|c|c|c|}
\hline & AÑO 1 & AÑO 2 & AÑO 3 & AÑO 4 & AÑ̃ 5 \\
\hline \multicolumn{6}{|c|}{ DEPRECIACION DE MUEBLES DE OFICINA } \\
\hline Sillones De Espera & 192.09 & 192.09 & 384.18 & 384.18 & 384.18 \\
\hline $\begin{array}{l}\text { Counter de } \\
\text { recepcion }\end{array}$ & 33.90 & 33.90 & 33.90 & 33.90 & 33.90 \\
\hline \multicolumn{6}{|c|}{ GASTOS EN SERVICIOS PUBLICOS } \\
\hline Luz de oficinas & 360.00 & 378.00 & 396.90 & 416.75 & 437.58 \\
\hline Agua & 180.00 & 189.00 & 198.45 & 208.37 & 218.79 \\
\hline Teléfono & $2,160.00$ & $2,268.00$ & $2,381.40$ & $2,500.47$ & $2,625.49$ \\
\hline Seguridad & 240.00 & 252.00 & 264.60 & 277.83 & 291.72 \\
\hline Limpieza & 240.00 & 252.00 & 264.60 & 277.83 & 291.72 \\
\hline Impuesto Predial & 300.00 & 315.00 & 330.75 & 347.29 & 364.65 \\
\hline TOTAL & $3,705.99$ & $3,879.99$ & $4,254.78$ & $4,446.61$ & $4,648.04$ \\
\hline
\end{tabular}

Elaboración propia

\subsubsection{Pptos. de gastos de venta totales}

Tabla 4.40

Gastos de venta totales

\begin{tabular}{|c|c|c|c|c|c|}
\hline & AÑO 1 & AÑO 2 & AÑO 3 & AÑO 4 & AÑO 5 \\
\hline Gastos de ventas directos & $4,576.27$ & $4,805.08$ & $5,045.34$ & $5,297.61$ & $5,562.49$ \\
\hline Mano de obra de venta & 0.00 & 0.00 & 0.00 & $41,066.67$ & $43,120.00$ \\
\hline $\begin{array}{c}\text { Gastos de ventas } \\
\text { indirectos }\end{array}$ & $3,705.99$ & $3,879.99$ & $4,254.78$ & $4,446.61$ & $4,648.04$ \\
\hline TOTAL & $8,282.26$ & $8,685.07$ & $9,300.12$ & $50,810.89$ & $53,330.53$ \\
\hline
\end{tabular}

Elaboración propia 


\subsection{Financiamiento}

\subsubsection{Fuentes de financiamiento}

Tabla 4.41

Cronograma de financiamiento

\begin{tabular}{|l|r|}
\hline $\begin{array}{l}\text { Tasa de Costo Efectivo } \\
\text { Anual: }\end{array}$ & $14.00 \%$ \\
\hline $\begin{array}{l}\text { Tasa de Costo Efectivo } \\
\text { Ajustada Anual: }\end{array}$ & $14.00 \%$ \\
\hline
\end{tabular}

\begin{tabular}{|c|c|r|r|r|r|r|}
\hline Cuota & F.Vencimiento & Saldo Inicial & \multicolumn{1}{|c|}{ Amortización } & \multicolumn{1}{l|}{ Intereses } & Importe Cuota & Saldo final \\
\hline 1 & AÑO 1 & $55,179.73$ & $8,347.79$ & $7,725.16$ & $16,072.95$ & $46,831.95$ \\
\hline 2 & AÑO 2 & $46,831.95$ & $9,516.48$ & $6,556.47$ & $16,072.95$ & $37,315.47$ \\
\hline 3 & AÑO 3 & $37,315.47$ & $10,848.78$ & $5,224.17$ & $16,072.95$ & $26,466.69$ \\
\hline 4 & AÑO 4 & $26,466.69$ & $12,367.61$ & $3,705.34$ & $16,072.95$ & $14,099.08$ \\
\hline 5 & AÑO 5 & $14,099.08$ & $14,099.08$ & $1,973.87$ & $16,072.95$ & 0.00 \\
\hline
\end{tabular}

\begin{tabular}{|c|r|r|r|r|r|r|}
\hline & AÑO CERO & \multicolumn{1}{c|}{ AÑO 1 } & AÑO 2 & AÑO 3 & AÑO 4 & AÑO 5 \\
\hline $\begin{array}{c}\text { Deuda } \\
\text { CP }\end{array}$ & $8,347.79$ & $9,516.48$ & $10,848.78$ & $12,367.61$ & $14,099.08$ & 0.00 \\
\hline $\begin{array}{c}\text { Deuda } \\
\text { LP }\end{array}$ & $46,831.95$ & $37,315.47$ & $26,466.69$ & $14,099.08$ & 0.00 & 0.00 \\
\hline $\begin{array}{c}\text { Intereses } \\
(\text { GF })\end{array}$ & 0.00 & $7,725.16$ & $6,556.47$ & $5,224.17$ & $3,705.34$ & $1,973.87$ \\
\hline
\end{tabular}




\begin{tabular}{|c|c|c|}
\hline AÑO & Deuda CP & Deuda LP \\
\hline 1 & $8,347.79$ & $46,831.95$ \\
\hline 2 & $9,516.48$ & $37,315.47$ \\
\hline 3 & $10,848.78$ & $26,466.69$ \\
\hline 4 & $12,367.61$ & $14,099.08$ \\
\hline 5 & $14,099.08$ & 0.00 \\
\hline
\end{tabular}

Elaboración propia 


\subsection{Ppto. de pagos del IGV}

Tabla 4.42

Presupuesto de pagos del IGV

\begin{tabular}{|c|c|c|c|c|c|c|}
\hline & $\begin{array}{c}\text { MES } \\
\text { CERO }\end{array}$ & AÑNO 1 & AÑO 2 & AÑ̃ 3 & AÑO 4 & AÑO 5 \\
\hline Gastos pre operativos & $-3,476.32$ & 0.00 & 0.00 & 0.00 & 0.00 & 0.00 \\
\hline Activos fijos & $-2,672.24$ & 0.00 & 0.00 & 0.00 & 0.00 & 0.00 \\
\hline Recompra Activo Fijo & 0.00 & -94.58 & -94.58 & $-4,884.41$ & -143.39 & -48.81 \\
\hline Ventas & 0.00 & $27,190.12$ & $74,566.28$ & $116,064.33$ & $150,605.40$ & $177,005.00$ \\
\hline Compra de insumos & 0.00 & $-1,570.33$ & $-4,306.47$ & $-6,703.14$ & $-8,698.01$ & $-10,222.68$ \\
\hline $\begin{array}{c}\text { Materiales Operativos y } \\
\text { de Limpieza }\end{array}$ & 0.00 & -21.19 & -58.11 & -90.44 & -117.36 & -137.93 \\
\hline $\begin{array}{c}\text { Gastos en Servicios } \\
\text { Públicos }\end{array}$ & 0.00 & $-2,538.00$ & $-3,761.58$ & $-4,849.79$ & $-5,777.17$ & $-6,515.72$ \\
\hline Alquiler Local & 0.00 & $-3,624.41$ & $-3,624.41$ & $-7,248.81$ & $-7,248.81$ & $-7,248.81$ \\
\hline $\begin{array}{c}\text { Materiales Seguridad y } \\
\text { de Oficina }\end{array}$ & 0.00 & -152.24 & -167.46 & -368.41 & -405.26 & -445.78 \\
\hline Gastos de venta directos & 0.00 & -823.73 & -864.92 & -908.16 & -953.57 & $-1,001.25$ \\
\hline TOTAL & $-6,148.56$ & $18,365.66$ & $61,688.76$ & $91,011.16$ & $127,261.84$ & $151,384.01$ \\
\hline
\end{tabular}

\begin{tabular}{|c|r|r|r|r|r|r|}
\hline IGV ACUMULADO & $-6,148.56$ & $12,217.10$ & $61,688.76$ & $91,011.16$ & $127,261.84$ & $151,384.01$ \\
\hline PAGO DEL IGV & 0.00 & $12,217.10$ & $61,688.76$ & $91,011.16$ & $127,261.84$ & $151,384.01$ \\
\hline
\end{tabular}

Elaboración propia 


\section{CAPÍTULO V: ESTADOS FINANCIEROS}

\subsection{Ppto. de Estado de Resultados o Ganancias y Pérdidas}

Tabla 5.1

Estado de resultados

\begin{tabular}{|c|c|c|c|c|c|}
\hline & AÑO 1 & AÑO 2 & AÑNO 3 & AÑNO 4 & AÑO 5 \\
\hline Ventas netas & $151,056.24$ & $414,257.09$ & $644,801.82$ & $836,696.68$ & $983,361.13$ \\
\hline (Costo de ventas) & $107,374.24$ & $229,686.54$ & $258,714.98$ & $537,124.11$ & $572,572.24$ \\
\hline Utilidad Bruta & $43,682.00$ & $184,570.55$ & $386,086.83$ & 299,572.57 & $410,788.89$ \\
\hline $\begin{array}{l}\text { (Gastos } \\
\text { Administrativos) }\end{array}$ & $132,744.06$ & $138,004.47$ & $168,517.88$ & $174,428.91$ & $180,645.72$ \\
\hline (Gasto de Ventas) & $8,282.26$ & $8,685.07$ & $9,300.12$ & $50,810.89$ & $53,330.53$ \\
\hline $\begin{array}{l}\text { Utilidad } \\
\text { Operativa }\end{array}$ & $-97,344.32$ & 37,881.00 & $208,268.84$ & $74,332.78$ & $176,812.64$ \\
\hline $\begin{array}{l}\text { (Gastos } \\
\text { Financieros) }\end{array}$ & $7,725.16$ & $6,556.47$ & $5,224.17$ & $3,705.34$ & $1,973.87$ \\
\hline Ingreso Financiero & $4,382.00$ & $1,027.11$ & $1,903.69$ & $7,829.87$ & $7,788.70$ \\
\hline $\begin{array}{l}\text { Utilidad antes } \\
\text { impuestos }\end{array}$ & $-100,687.48$ & $32,351.64$ & $204,948.36$ & $78,457.31$ & $182,627.46$ \\
\hline $\begin{array}{l}\text { (Impuestos a la } \\
\text { Renta) }\end{array}$ & 0.00 & $9,705.49$ & $61,484.51$ & $23,537.19$ & $54,788.24$ \\
\hline Utilidad Neta & $-100,687.48$ & $22,646.15$ & $143,463.85$ & $54,920.12$ & $127,839.23$ \\
\hline
\end{tabular}

Elaboración propia 
5.2 Ppto. anual de las utilidades retenidas, capitalizadas, pasadas a reserva técnica y pagadas en dividendos

Tabla 5.2

Distribución de utilidades

\begin{tabular}{|c|c|c|c|c|c|}
\hline & AÑO 1 & AÑNO 2 & AÑO 3 & AÑ̃ 4 & A ÑO 5 \\
\hline Pago de & & & & & \\
\hline Dividendos & 0.00 & 0.00 & 0.00 & $16,476.03$ & $38,351.77$ \\
\hline Capitalización & 0.00 & 0.00 & 0.00 & $10,984.02$ & $25,567.85$ \\
\hline Reserva Legal & 0.00 & 0.00 & 0.00 & $5,492.01$ & $12,783.92$ \\
\hline Utilidades del & & & & & \\
\hline Ejercicio & $-100,687.48$ & $22,646.15$ & $143,463.85$ & $21,968.05$ & $51,135.69$ \\
\hline Utilidad Neta & $-100,687.48$ & $22,646.15$ & $143,463.85$ & $54,920.12$ & $127,839.23$ \\
\hline
\end{tabular}

Elaboración propia

En la Tabla anterior se puede observar que no se reparten dividendos hasta el cuarto año. Decidimos repartir dividendos ese año, debido a que recién en el tercer año generamos utilidades positivas. La utilidad se calcula restándole al resultado acumulado el resultado del ejercicio. 
Figura 5.1

Distribución de utilidades por año

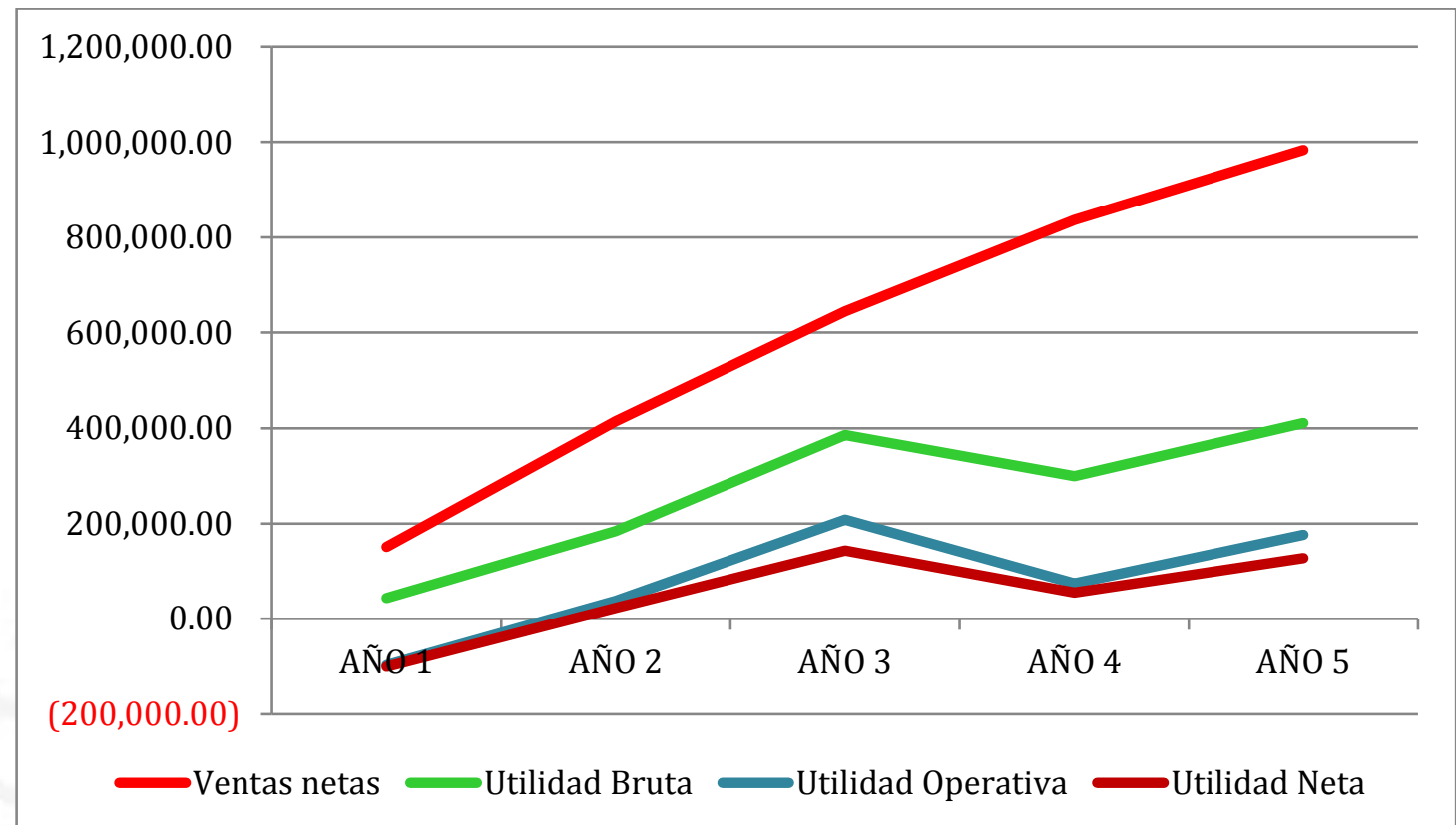

Elaboración propia

\subsection{Ppto. de pagos del impuesto a la renta}

Tabla 5.3

Pagos de impuesto a la renta

\begin{tabular}{|c|c|c|c|c|c|}
\hline & AÑNO 1 & AÑNO 2 & AÑO 3 & AÑ̃ 4 & AÑNO 5 \\
\hline Ventas netas & $151,056.24$ & $414,257.09$ & $644,801.82$ & $836,696.68$ & $983,361.13$ \\
\hline IR pago a cuenta & $-2,265.84$ & $-6,213.86$ & $-9,672.03$ & $-12,550.45$ & $-14,750.42$ \\
\hline IR EGYP & 0.00 & $9,705.49$ & $61,484.51$ & $23,537.19$ & $54,788.24$ \\
\hline IR BG & $-2,265.84$ & $1,225.79$ & $51,812.48$ & $10,986.74$ & $40,037.82$ \\
\hline IR regularización & 0.00 & $1,225.79$ & $51,812.48$ & $10,986.74$ & $40,037.82$ \\
\hline
\end{tabular}

Elaboración propia 


\subsection{Flujo de caja}

Tabla 5.4

Flujo de caja

\begin{tabular}{|c|c|c|c|c|c|c|}
\hline & $\begin{array}{c}\text { AÑO } \\
\text { CERO }\end{array}$ & AÑN 1 & AÑN 2 & AÑ̃ 3 & AÑNO 4 & AÑO 5 \\
\hline \multicolumn{7}{|l|}{$\begin{array}{c}\text { INGRESOS } \\
\text { OPERATIVOS }\end{array}$} \\
\hline $\begin{array}{l}\text { Ingreso por ventas } \\
\text { contado }\end{array}$ & 0.00 & $178,246.37$ & $488,823.36$ & $760,866.14$ & $987,302.08$ & $1,160,366.13$ \\
\hline Aporte de Capital & $110,359.47$ & & & & & \\
\hline Préstamo Bancario & $55,179.73$ & & & & & \\
\hline $\begin{array}{c}\text { INGRESOS } \\
\text { FINANCIEROS }\end{array}$ & 0.00 & $4,382.00$ & $1,027.11$ & $1,903.69$ & $7,829.87$ & $7,788.70$ \\
\hline & & & & & & \\
\hline $\begin{array}{l}\text { TOTAL DE } \\
\text { INGRESOS }\end{array}$ & $165,539.20$ & $182,628.37$ & $489,850.47$ & $762,769.83$ & 995,131.95 & $1,168,154.82$ \\
\hline $\begin{array}{c}\text { ACTIVO } \\
\text { INTANGIBLE }\end{array}$ & $22,821.20$ & & & & & \\
\hline ACTIVO FIJO & $17,518.00$ & & & & & \\
\hline $\begin{array}{c}\text { COMPRA DE } \\
\text { ACTIVOS FIJOS }\end{array}$ & & 620.00 & 620.00 & $32,020.00$ & 940.00 & 320.00 \\
\hline \multicolumn{7}{|l|}{$\begin{array}{c}\text { EGRESOS } \\
\text { OPERATIVOS }\end{array}$} \\
\hline Compra de Insumos & & $10,294.37$ & $28,231.32$ & $43,942.78$ & $57,020.27$ & $67,015.35$ \\
\hline $\begin{array}{c}\text { Materiales Operativos y } \\
\text { de Limpieza }\end{array}$ & & 138.90 & 380.92 & 592.91 & 769.36 & 904.23 \\
\hline $\begin{array}{c}\text { Gastos en Servicios } \\
\text { Públicos }\end{array}$ & & $16,638.00$ & $24,659.23$ & $31,793.08$ & $37,872.54$ & $42,714.18$ \\
\hline Alquiler local & & $23,760.00$ & $23,760.00$ & $47,520.00$ & $47,520.00$ & $47,520.00$ \\
\hline Materiales de Oficina & & 998.00 & $1,097.80$ & $2,415.16$ & $2,656.68$ & $2,922.34$ \\
\hline $\begin{array}{l}\text { Gastos de ventas } \\
\text { directos }\end{array}$ & & $5,400.00$ & $5,670.00$ & $5,953.50$ & $6,251.18$ & $6,563.73$ \\
\hline Mano de Obra Indirecta & & 0.00 & 0.00 & 0.00 & $40,580.56$ & $43,095.69$ \\
\hline Mano de Obra Directa & & 0.00 & 0.00 & 0.00 & 0.00 & 0.00 \\
\hline $\begin{array}{l}\text { Mano de Obra } \\
\text { Administrativa }\end{array}$ & & $89,277.22$ & $94,810.53$ & $99,551.05$ & $104,528.61$ & $109,755.04$ \\
\hline Mano de Obra Venta & & 0.00 & 0.00 & 0.00 & $40,580.56$ & $43,095.69$ \\
\hline $\begin{array}{l}\text { Mano de obra } \\
\text { subcontratada }\end{array}$ & & $100,800.00$ & $201,600.00$ & $211,680.00$ & $433,414.80$ & $455,085.54$ \\
\hline
\end{tabular}




\begin{tabular}{|c|c|c|c|c|c|c|}
\hline & $\begin{array}{l}\text { AÑO } \\
\text { CERO }\end{array}$ & AÑO 1 & AÑNO 2 & AÑ̃ 3 & AÑO 4 & AÑO 5 \\
\hline Pago de IGV & & $12,217.10$ & $61,688.76$ & $91,011.16$ & $127,261.84$ & $151,384.01$ \\
\hline $\begin{array}{l}\text { Impuesto a la Renta } \\
\text { (pago a cuenta) }\end{array}$ & & $2,265.84$ & $6,213.86$ & $9,672.03$ & $12,550.45$ & $14,750.42$ \\
\hline $\begin{array}{l}\text { Impuesto a la Renta } \\
\text { (regularización) }\end{array}$ & & 0.00 & 0.00 & $1,225.79$ & $51,812.48$ & $10,986.74$ \\
\hline Pago de Dividendos & & 0.00 & 0.00 & 0.00 & $16,476.03$ & $38,351.77$ \\
\hline $\begin{array}{c}\text { EGRESOS } \\
\text { FINANCIEROS }\end{array}$ & & & & & & \\
\hline Cuota Préstamo & & $16,072.95$ & $16,072.95$ & $16,072.95$ & $16,072.95$ & $16,072.95$ \\
\hline TOTAL EGRESOS & $40,339.20$ & $278,482.39$ & $464,805.36$ & $593,450.41$ & $996,308.30$ & $1,050,537.68$ \\
\hline Caja Inicial & 0.00 & $125,200.00$ & $29,345.98$ & $54,391.09$ & $223,710.51$ & $222,534.16$ \\
\hline Ingresos menos Egresos & $125,200.00$ & $-95,854.02$ & $25,045.11$ & $169,319.42$ & $-1,176.35$ & $117,617.14$ \\
\hline CAJA FINAL & $125,200.00$ & $29,345.98$ & $54,391.09$ & $223,710.51$ & $222,534.16$ & $340,151.30$ \\
\hline
\end{tabular}

Elaboración propia

Figura 5.2

Evolución de flujo de caja

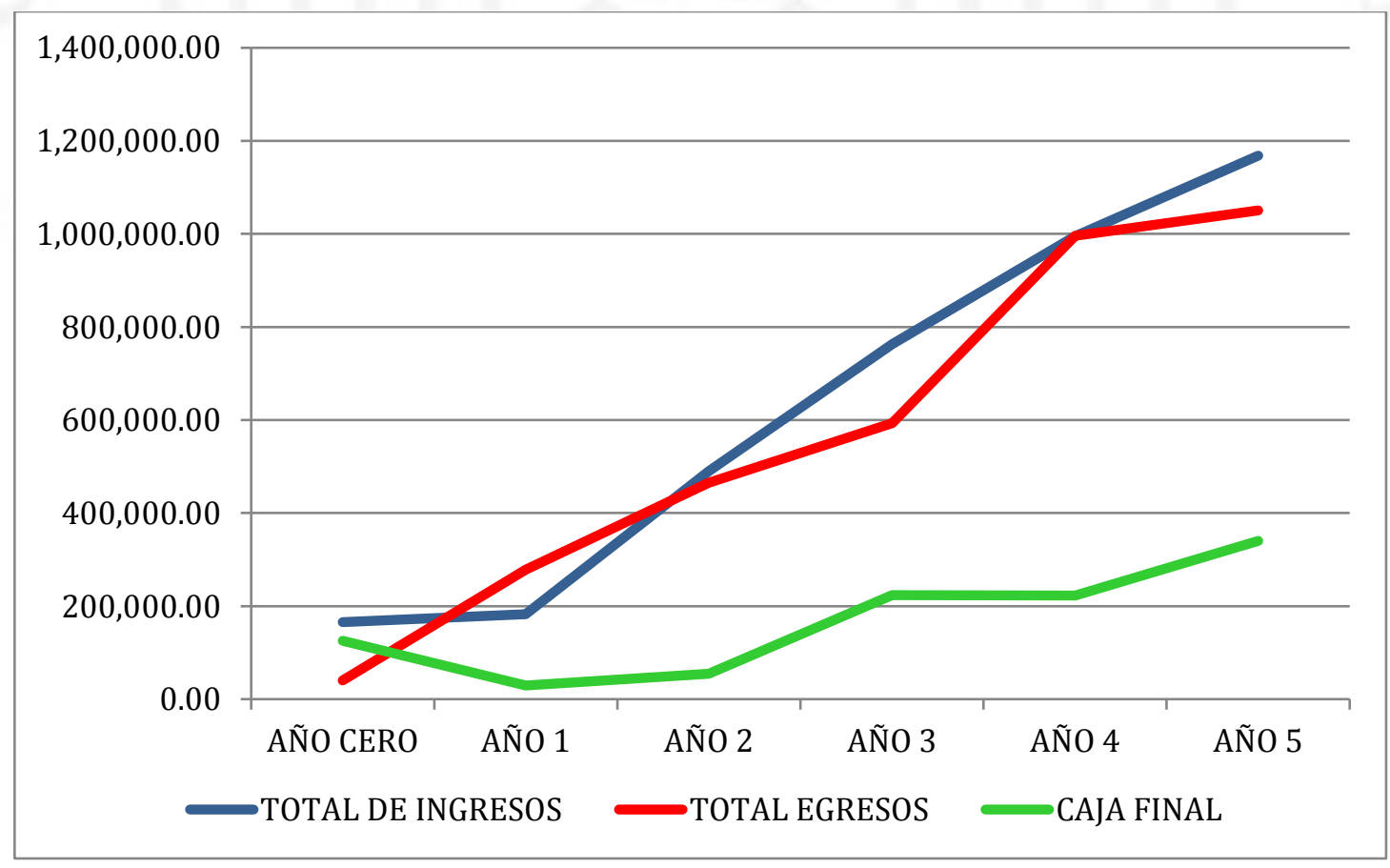

Elaboración propia 


\subsection{Ppto. de Situación Financiera o Balance General}

Tabla 5.5

Balance general

\begin{tabular}{|c|c|c|c|c|c|c|}
\hline & AÑO 0 & AÑ̃ 1 & AÑO 2 & AÑO 3 & AÑO 4 & AÑO 5 \\
\hline \multicolumn{7}{|l|}{$\underline{\text { ACTIVO }}$} \\
\hline \multicolumn{7}{|l|}{ Activo Corriente } \\
\hline Caja Bancos & $125,200.00$ & $29,345.98$ & $54,391.09$ & $223,710.51$ & $222,534.16$ & $340,151.30$ \\
\hline Existencias & 0.00 & 0.00 & 0.00 & 0.00 & 0.00 & 0.00 \\
\hline Total Activo Corriente & $125,200.00$ & 29,345.98 & $54,391.09$ & $223,710.51$ & $222,534.16$ & $340,151.30$ \\
\hline \multicolumn{7}{|l|}{ Activo No Corriente } \\
\hline Activo Fijo & $14,845.76$ & $15,371.19$ & $15,896.61$ & $42,184.75$ & $42,981.36$ & $43,252.54$ \\
\hline Depreciación Acumulada & 0.00 & $4,772.54$ & $9,686.33$ & $18,901.47$ & $28,257.85$ & $37,614.24$ \\
\hline Intangibles & $19,344.88$ & $19,344.88$ & $19,344.88$ & $20,192.34$ & $20,192.34$ & $20,192.34$ \\
\hline Amortización Acumulada & 0.00 & $3,981.97$ & $7,963.94$ & $11,945.91$ & $15,927.88$ & $19,909.85$ \\
\hline Total Activo No Corriente & $34,190.64$ & $25,961.55$ & $17,591.22$ & 31,529.70 & $18,987.96$ & $5,920.79$ \\
\hline TOTAL ACTIVOS & $159,390.64$ & $55,307.53$ & $71,982.31$ & $255,240.22$ & $241,522.12$ & $346,072.09$ \\
\hline \multicolumn{7}{|l|}{ PASIVO } \\
\hline \multicolumn{7}{|l|}{ Pasivo Corriente } \\
\hline IGV por pagar & $-6,148.56$ & 0.00 & 0.00 & 0.00 & 0.00 & 0.00 \\
\hline Imp a la Renta & 0.00 & $-2,265.84$ & $1,225.79$ & $51,812.48$ & $10,986.74$ & $40,037.82$ \\
\hline Beneficios por pagar & 0.00 & $1,069.44$ & $1,122.92$ & $1,179.06$ & $2,210.24$ & $2,320.75$ \\
\hline Deuda a Corto Plazo & $8,347.79$ & $9,516.48$ & $10,848.78$ & $12,367.61$ & $14,099.08$ & 0.00 \\
\hline Total Pasivo Corriente & $2,199.23$ & $8,320.08$ & $13,197.49$ & $65,359.16$ & $27,296.06$ & $42,358.57$ \\
\hline \multicolumn{7}{|l|}{ Pasivo No Corriente } \\
\hline Deuda a Largo Plazo & $46,831.95$ & $37,315.47$ & $26,466.69$ & $14,099.08$ & 0.00 & 0.00 \\
\hline Total Pasivo No Corriente & $46,831.95$ & $37,315.47$ & $26,466.69$ & $14,099.08$ & 0.00 & 0.00 \\
\hline TOTAL PASIVOS & $49,031.18$ & $45,635.55$ & $39,664.18$ & $79,458.23$ & $27,296.06$ & $42,358.57$ \\
\hline
\end{tabular}




\begin{tabular}{|c|c|c|c|c|c|c|}
\hline & AÑ̃O 0 & AÑ̃ 1 & AÑO 2 & AÑ̃ 3 & AÑO 4 & AÑO 5 \\
\hline \multicolumn{7}{|l|}{ PATRIMONIO } \\
\hline Capital Social & $110,359.47$ & $110,359.47$ & $110,359.47$ & $110,359.47$ & $121,343.49$ & $146,911.33$ \\
\hline Reserva Legal & 0.00 & 0.00 & 0.00 & 0.00 & $5,492.01$ & $18,275.93$ \\
\hline Resultados acumulados & 0.00 & 0.00 & $-100,687.48$ & $-78,041.34$ & $65,422.52$ & $87,390.56$ \\
\hline Resultado del ejercicio & 0.00 & $-100,687.48$ & $22,646.15$ & $143,463.85$ & $21,968.05$ & $51,135.69$ \\
\hline TOTAL PATRIMONIO & $110,359.47$ & $9,671.98$ & $32,318.13$ & $175,781.98$ & $214,226.06$ & $303,713.52$ \\
\hline TOTAL PASIVO Y PATRIMONIO & $159,390.64$ & $55,307.53$ & $71,982.31$ & $255,240.22$ & $241,522.12$ & 346,072.09 \\
\hline & 0.00 & 0.00 & 0.00 & 0.00 & 0.00 & 0.00 \\
\hline & & 0.00 & 0.00 & 0.00 & 0.00 & 0.00 \\
\hline
\end{tabular}

\begin{tabular}{|l|r|r|r|r|r|r|}
\hline CAPITAL DE TRABAJO & $123,000.77$ & $21,025.90$ & $41,193.60$ & $158,351.36$ & $195,238.10$ & $297,792.73$ \\
\hline
\end{tabular}

Elaboración propia 
Figura 5.3

Evolución Activo Corriente y No Corriente

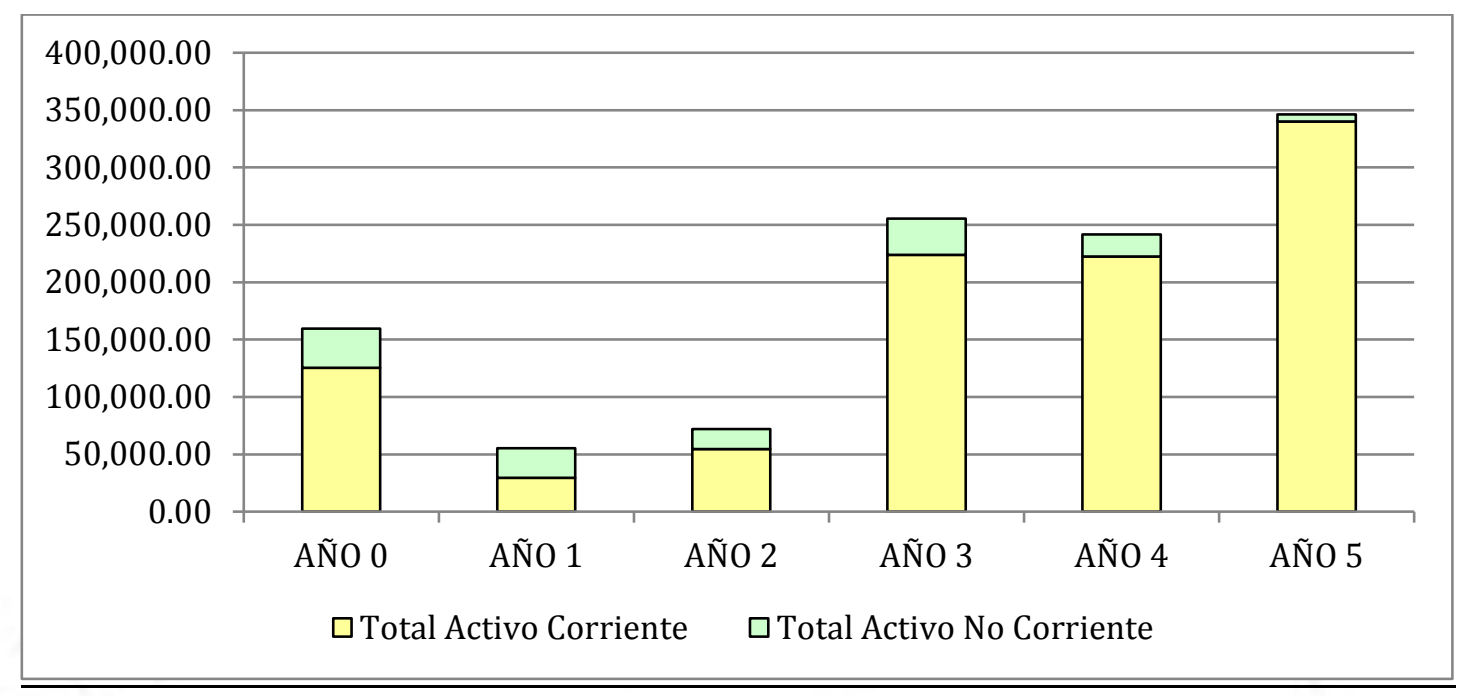

Elaboración propia

Figura 5.4

Evolución de Patrimonio y Pasivos

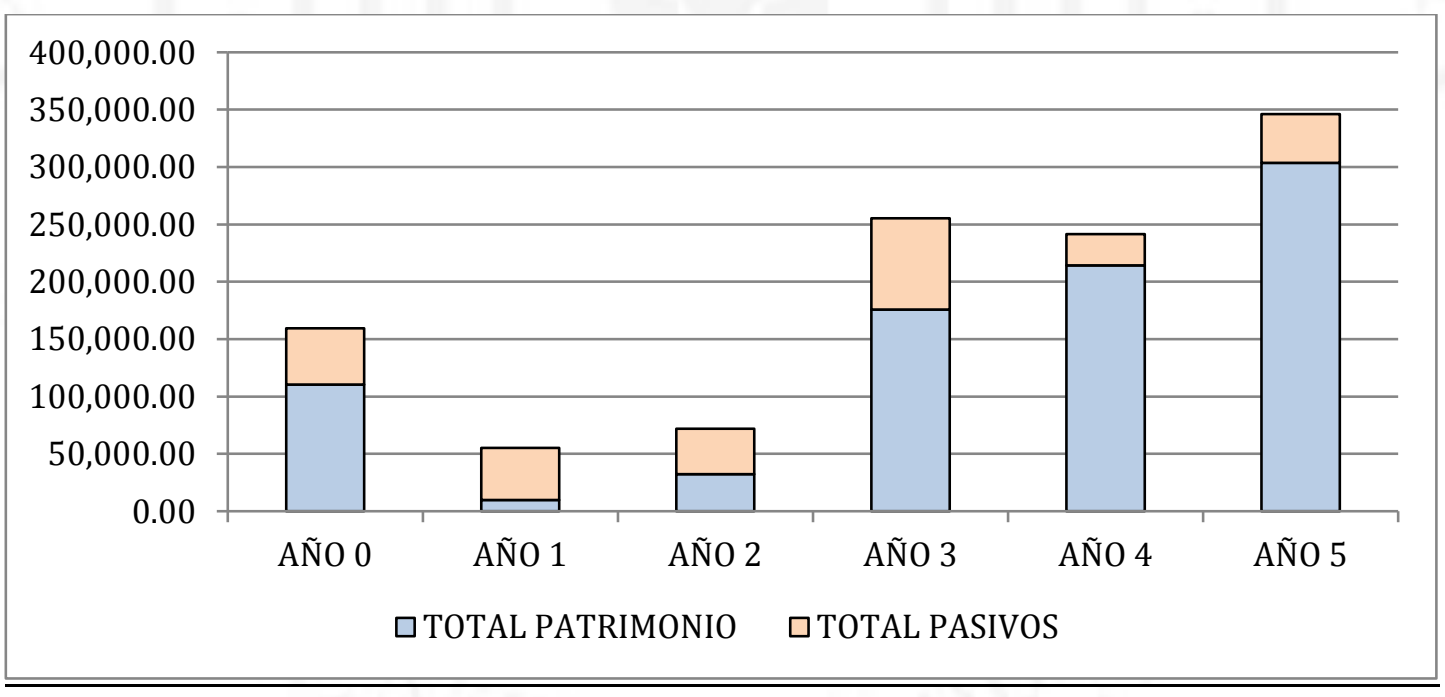

Elaboración propia 


\section{CAPÍTULO VI: ANALISIS Y EVALUACION DEL PROYECTO}

\subsection{Cálculo de las tasas para evaluación del proyecto}

Se calculó el Beta desapalancado obteniendo un resultado de 0.76. La prima de riesgo por formar una nueva empresa en el rubro de "Healthcare Support Services" o "Servicios de apoyo de salud" es de $10 \%$. Esta tasa es riesgosa y se explica por encontrarnos en un rubro que recién está en crecimiento.

En la tabla se detalla el cálculo de las tasas utilizadas para el proyecto.

\section{Tabla 6.1}

Cálculo de tasas para evaluación de proyecto

\begin{tabular}{|l|r|}
\hline Año & $24.00 \%$ \\
\hline Tasa de impuesto a la renta USA & $30.00 \%$ \\
\hline Tasa de impuesto a la renta PERU & 0.76 \\
\hline Beta desapalancado (1) & 0.76 \\
\hline Beta desapalancado cálculo manual & 0.9 \\
\hline Beta apalancado (2) & $24.83 \%$ \\
\hline D/E (3) & \\
\hline
\end{tabular}

\begin{tabular}{|l|r|}
\hline \multicolumn{2}{|c|}{ Estructura de capital } \\
\hline Deuda & $54,734.89$ \\
\hline Patrimonio & $109,469.78$ \\
\hline
\end{tabular}




\begin{tabular}{|l|r|}
\hline D+E & $\mathbf{1 6 4 , 2 0 4 . 6 7}$ \\
\hline D/E & $50 \%$ \\
\hline Beta apalancado (BL) & 1.03 \\
\hline Rf (tasa libre de riesgo) (4) & $2.88 \%$ \\
\hline Prima de riesgo de mercado (Rm - Rf) (5) & $5.08 \%$ \\
\hline Riesgo país & $1.74 \%$ \\
\hline Re (COK - tasa mínima del accionista) & $10 \%$ \\
\hline Prima de riesgo de nueva empresa & $10 \%$ \\
\hline KL (costo del accionista) & $20 \%$ \\
\hline Rd (costo de la deuda) & $14 \%$ \\
\hline D / (D+E) & $33.3 \%$ \\
\hline E / (D+E) & $66.7 \%$ \\
\hline
\end{tabular}

WACC (costo de la empresa)

$16.49 \%$

$\mathrm{Ku}$

(1), (2), (3) Fuente Damodaran

(4) Bloomberg

(5) Fuente Damodaran (citar año)

\subsection{EBITDA}

Tabla 6.2

EBITDA

\begin{tabular}{|c|c|c|c|c|c|}
\hline & AÑNO 1 & AÑ 2 & AÑO 3 & AÑO 4 & Ã̃O 5 \\
\hline Utilidad Operativa & $-97,344.32$ & $37,881.00$ & $208,268.84$ & $74,332.78$ & $176,812.64$ \\
\hline Depreciación Activos & $4,772.54$ & $4,913.79$ & $9,215.14$ & $9,356.38$ & $9,356.38$ \\
\hline $\begin{array}{c}\text { Amortización de } \\
\text { Intangibles }\end{array}$ & $3,981.97$ & $3,981.97$ & $3,981.97$ & $3,981.97$ & $3,981.97$ \\
\hline EBITDA & $-88,589.81$ & $46,776.76$ & $221,465.95$ & $87,671.13$ & $190,150.99$ \\
\hline
\end{tabular}

Elaboración propia 


\subsection{Rentabilidad EVA}

Tabla 6.3

Rentabilidad EVA

\begin{tabular}{|c|c|c|c|c|c|}
\hline & AÑO 1 & AÑO 2 & AÑO 3 & AÑO 4 & AÑO 5 \\
\hline Utilidad Operativa & $-97,344.32$ & $37,881.00$ & $208,268.84$ & $74,332.78$ & $176,812.64$ \\
\hline Activo Total & $55,307.53$ & $71,982.31$ & $255,240.22$ & $241,522.12$ & $346,072.09$ \\
\hline ROA & $-176.01 \%$ & $52.63 \%$ & $81.60 \%$ & $30.78 \%$ & $51.09 \%$ \\
\hline Deuda Bancaria & $46,831.95$ & $37,315.47$ & $26,466.69$ & $14,099.08$ & 0.00 \\
\hline Tasa Bancaria & $14 \%$ & $14 \%$ & $14 \%$ & $14 \%$ & $14 \%$ \\
\hline Patrimonio & $9,671.98$ & $32,318.13$ & $175,781.98$ & $214,226.06$ & $303,713.52$ \\
\hline $\begin{array}{l}\text { Tasa de los } \\
\text { accionistas }\end{array}$ & $23.6 \%$ & $23.6 \%$ & $23.6 \%$ & $23.6 \%$ & $23.6 \%$ \\
\hline WACC & $12.16 \%$ & $16.20 \%$ & $21.79 \%$ & $22.75 \%$ & $23.60 \%$ \\
\hline VENTAS NETAS & $151,056.24$ & $414,257.09$ & $644,801.82$ & $836,696.68$ & $983,361.13$ \\
\hline$\%$ RENTAB EVA & $-188.2 \%$ & $36.4 \%$ & $59.8 \%$ & $8.0 \%$ & $27.5 \%$ \\
\hline $\begin{array}{c}\text { RENTABILIDA } \\
\text { D EVA }\end{array}$ & $-284,239.12$ & $150,875.00$ & $385,611.38$ & $67,177.95$ & $270,338.50$ \\
\hline
\end{tabular}

Elaboración propia 


\subsection{Análisis de los ratios financieros}

Tabla 6.4

Ratios Financieros

\begin{tabular}{|c|c|c|c|c|c|}
\hline PUNTO DE EQUILIBRIO & AÑNO 1 & AÑNO 2 & AÑ̃ 3 & AÑO 4 & AÑNO 5 \\
\hline VENTAS NETAS S/. & 151,056 & 414,257 & 644,802 & 836,697 & 983,361 \\
\hline VENTAS NETAS UND & 646 & 1,771 & 2,757 & 3,577 & 4,204 \\
\hline
\end{tabular}

\begin{tabular}{|l|r|r|r|r|r|}
\hline COSTO INSUMOS & 8,724 & 23,925 & 37,240 & 48,322 & 56,793 \\
MANO DE OBRA DIRECTA & 0 & 0 & 0 & 0 & 0 \\
CIF & 98,650 & 205,762 & 221,475 & 488,802 & 515,780 \\
\hline $\begin{array}{l}\text { PTO DE EQUIL PRODUCC } \\
\text { UND }\end{array}$ & 448 & 934 & 1,005 & 2,218 & 2,340 \\
\hline
\end{tabular}

\begin{tabular}{|l|r|r|r|r|r|}
\hline GTOS ADM DIRECTOS & 29,736 & 30,216 & 50,855 & 51,384 & 51,940 \\
MANO DE OBRA ADM & 90,347 & 94,864 & 99,607 & 104,588 & 109,817 \\
GTOS ADM INDIRECTOS & 12,662 & 12,925 & 18,055 & 18,457 & 18,889 \\
\hline GTOS DE VTA DIRECTOS & 4,576 & 4,805 & 5,045 & 5,298 & 5,562 \\
MANO DE OBRA VTA & 0 & 0 & 0 & 41,067 & 43,120 \\
GTOS DE VTA INDIRECTOS & 3,706 & 3,880 & 4,255 & 4,447 & 4,648 \\
\hline $\begin{array}{l}\text { PTO DE EQUIL OPERATIVO } \\
\text { UND }\end{array}$ & 1,088 & 1,599 & 1,812 & 3,240 & 3,402 \\
\hline
\end{tabular}

\begin{tabular}{|l|r|r|r|r|r|}
\hline GASTOS FINANCIEROS & 7,725 & 6,556 & 5,224 & 3,705 & 1,974 \\
INGRESOS FINANCIEROS & 4,382 & 1,027 & 1,904 & 7,830 & 7,789 \\
\hline $\begin{array}{l}\text { PTO DE EQUIL FINANCIERO } \\
\text { UND }\end{array}$ & 1,103 & 1,624 & 1,827 & 3,221 & 3,376 \\
\hline
\end{tabular}

\begin{tabular}{|l|r|r|r|r|r|}
\hline IMPUESTO A LA RENTA & 0 & 9,705 & 61,485 & 23,537 & 54,788 \\
\hline PTO DE EQUIL NETO UND & 1,103 & 1,668 & 2,106 & 3,328 & 3,624 \\
\hline
\end{tabular}

Elaboración propia 


\subsection{Análisis del punto muerto}

Tabla 6.5

Análisis del punto muerto

\begin{tabular}{|l|r|}
\hline VAN VTAS (CON EL WACC) & $1,760,634$ \\
\hline VAN ECON & 72,762 \\
\hline PUNTO MUERTO ECON & $4.1 \%$ \\
\hline & $1,592,995$ \\
\hline VAN VTAS (CON EL KCOC) & 51,857 \\
\hline VAN FIN & $3.3 \%$ \\
\hline PUNTO MUERTO FINAN & $1,592,995$ \\
\hline & 57,325 \\
\hline VAN VTAS (CON EL KCOC) & $3.6 \%$ \\
\hline VAN FIN ACID & \\
\hline PUNTO MUERTO FINAN ACID & \\
\hline
\end{tabular}

Elaboración propia 


\subsection{Flujo de la caja económica (desde la UN, UO y Vtas)}

Tabla 6.6

Flujo de caja económica

\begin{tabular}{|c|c|c|c|c|c|c|}
\hline & AÑO 0 & AÑO 1 & AÑ̃ 2 & AÑNO 3 & AÑNO 4 & AÑNO 5 \\
\hline Utilidad Neta & & $-100,687.48$ & $22,646.15$ & $143,463.85$ & $54,920.12$ & $127,839.23$ \\
\hline Depreciación & & & & & & \\
\hline Activos & & $4,772.54$ & $4,913.79$ & $9,215.14$ & $9,356.38$ & $9,356.38$ \\
\hline Amortización & & & & & & \\
\hline Intangible & & $3,981.97$ & $3,981.97$ & $3,981.97$ & $3,981.97$ & $3,981.97$ \\
\hline Costo de & & & & & & \\
\hline Venta & & $107,374.24$ & $229,686.54$ & $258,714.98$ & $537,124.11$ & $572,572.24$ \\
\hline - Costo de & & & & & - & \\
\hline Producción & & $-107,374.24$ & $-229,686.54$ & $-258,714.98$ & $537,124.11$ & $-572,572.24$ \\
\hline Gast Finan & & & & & & \\
\hline $\mathrm{x} \quad(1-\mathrm{T})$ & & $5,407.61$ & $4,589.53$ & $3,656.92$ & $2,593.74$ & $1,381.71$ \\
\hline - Activo & & & & & & \\
\hline nuevo & & -525.42 & -525.42 & $-27,135.59$ & -796.61 & -271.19 \\
\hline \multirow[t]{2}{*}{$\begin{array}{c}\text { Valor de } \\
\text { recup. (1-T) }\end{array}$} & & 0.00 & 0.00 & 0.00 & 0.00 & $208,454.91$ \\
\hline & $-165,539.20$ & $-87,050.78$ & $35,606.01$ & $133,182.29$ & $70,055.60$ & $350,743.01$ \\
\hline
\end{tabular}

\begin{tabular}{|l|r|r|}
\cline { 2 - 3 } \multicolumn{1}{c|}{} & INVERSION & \multicolumn{1}{c|}{$\%$ TASA } \\
\hline $\begin{array}{l}\text { Préstamo } \\
\text { banco }\end{array}$ & $55,179.73$ & $13.60 \%$ \\
\hline Socios & $110,359.47$ & $19.83 \%$ \\
\hline TOTAL & $165,539.20$ & $16.39 \%$ \\
WACC
\end{tabular}

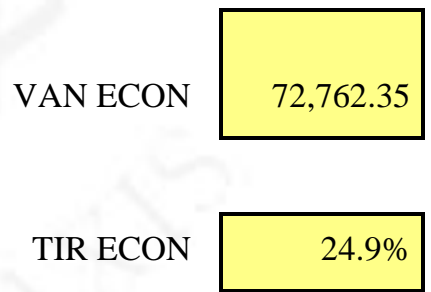

Elaboración propia

\subsection{Evaluación del VAN y TIR Económico}

El proyecto es rentable al tener un VAN económico mayor a $0(\mathrm{VAN}>0)$.

\subsection{Flujo de la caja financiera}


Tabla 6.7

Flujo de caja financiera

\begin{tabular}{|c|c|c|c|c|c|c|}
\hline & & AÑNO 1 & AÑ̃ 2 & AÑ̃ 3 & AÑNO 4 & AÑNO 5 \\
\hline FCE & $-165,539.20$ & $-87,050.78$ & $35,606.01$ & $133,182.29$ & $70,055.60$ & $350,743.01$ \\
\hline $\begin{array}{c}\text { Amortización de } \\
\text { Deuda }\end{array}$ & $-55,179.73$ & $8,347.79$ & $9,516.48$ & $10,848.78$ & $12,367.61$ & $14,099.08$ \\
\hline Gast Finan $*(1-\mathrm{T})$ & & $5,407.61$ & $4,589.53$ & $3,656.92$ & $2,593.74$ & $1,381.71$ \\
\hline & $-110,359.47$ & $-100,806.18$ & $21,500.00$ & $118,676.59$ & $55,094.25$ & $335,262.23$ \\
\hline
\end{tabular}

\begin{tabular}{|l|r|r|}
\cline { 2 - 3 } \multicolumn{1}{c|}{} & INVERSION & \multicolumn{1}{c|}{$\%$ TASA } \\
\hline Socios & $110,359.47$ & $19.83 \%$ \\
\hline
\end{tabular}

VAN FIN

$51,857.44$

Elaboración propia

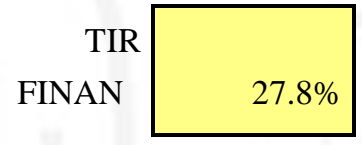

\subsection{Evaluación del VAN y TIR Financiero}

El proyecto es rentable para los accionistas al tener un VAN financiero mayor a $0(\mathrm{VAN}>0)$.

\subsection{Flujo de la caja libre (Sin deuda)}

Tabla6.8

Flujo de caja libre (Sin deuda)

\begin{tabular}{|c|c|c|c|c|c|c|}
\hline & & AÑO 1 & AÑO 2 & AÑNO 3 & AÑNO 4 & AÑNO 5 \\
\hline FCE & $-165,539.20$ & $-87,050.78$ & $35,606.01$ & $133,182.29$ & $70,055.60$ & $350,743.01$ \\
\hline $\begin{array}{l}\text { Gast Finan } \\
* \mathrm{~T}\end{array}$ & & $2,317.55$ & $1,966.94$ & $1,567.25$ & $1,111.60$ & 592.16 \\
\hline & $-165,539.20$ & $-84,733.23$ & $37,572.95$ & $134,749.54$ & $71,167.20$ & $351,335.18$ \\
\hline
\end{tabular}




\begin{tabular}{|l|r|r|}
\cline { 2 - 3 } \multicolumn{1}{c|}{} & INVERSION & $\%$ TASA \\
\hline Socios & $165,539.20$ & $18.48 \%$ \\
\hline
\end{tabular}

RENTAB ADICI POR FINANCIARSE CON EL BANCO (VAN ECON - VAN

LIBRE)

Elaboración propia

\subsection{Evaluación del VAN y TIR Libre}

El proyecto es rentable para los accionistas al tener un VAN mayor a $0(\mathrm{VAN}>0)$. 


\subsection{Análisis del punto de equilibrio anual}

Tabla 6.9

Análisis del punto de equilibrio

\begin{tabular}{|c|c|c|c|c|c|}
\hline PUNTO DE EQUILIBRIO & AÑO 1 & Ã̃NO 2 & AÑ̃ 3 & AÑO 4 & AÑO 5 \\
\hline VENTAS NETAS S/. & 151,056 & 414,257 & 644,802 & 836,697 & 983,361 \\
\hline VENTAS NETAS UND & 646 & 1,771 & 2,757 & 3,577 & 4,204 \\
\hline
\end{tabular}

\begin{tabular}{|l|r|r|r|r|r|}
\hline COSTO INSUMOS & 8,724 & 23,925 & 37,240 & 48,322 & 56,793 \\
MANO DE OBRA DIRECTA & 0 & 0 & 0 & 0 & 0 \\
CIF & 98,650 & 205,762 & 221,475 & 488,802 & 515,780 \\
\hline $\begin{array}{l}\text { PTO DE EQUIL PRODUCC } \\
\text { UND }\end{array}$ & 448 & 934 & 1,005 & 2,218 & 2,340 \\
\hline
\end{tabular}

\begin{tabular}{|l|r|r|r|r|r|}
\hline GTOS ADM DIRECTOS & 29,736 & 30,216 & 50,855 & 51,384 & 51,940 \\
MANO DE OBRA ADM & 90,347 & 94,864 & 99,607 & 104,588 & 109,817 \\
GTOS ADM INDIRECTOS & 12,662 & 12,925 & 18,055 & 18,457 & 18,889 \\
\hline GTOS DE VTA DIRECTOS & 4,576 & 4,805 & 5,045 & 5,298 & 5,562 \\
MANO DE OBRA VTA & 0 & 0 & 0 & 41,067 & 43,120 \\
GTOS DE VTA INDIRECTOS & 3,706 & 3,880 & 4,255 & 4,447 & 4,648 \\
\hline PTO DE EQUIL OPERATIVO & 1,088 & 1,599 & 1,812 & 3,240 & 3,402 \\
UND & & & & & \\
\hline
\end{tabular}

\begin{tabular}{|l|r|r|r|r|r|}
\hline GASTOS FINANCIEROS & 7,725 & 6,556 & 5,224 & 3,705 & 1,974 \\
INGRESOS FINANCIEROS & 4,382 & 1,027 & 1,904 & 7,830 & 7,789 \\
\hline $\begin{array}{l}\text { PTO DE EQUIL FINANCIERO } \\
\text { UND }\end{array}$ & 1,103 & 1,624 & 1,827 & 3,221 & 3,376 \\
\hline
\end{tabular}

\begin{tabular}{|l|r|r|r|r|r|}
\hline IMPUESTO A LA RENTA & 0 & 9,705 & 61,485 & 23,537 & 54,788 \\
\hline
\end{tabular}

Elaboración propia 


\section{CAPÍTULO VII: SIMULACION Y SENSIBILIDAD}

\subsection{Identificación de las variables importantes}

Las variables que se identificaron son: precio, sueldos, insumos, insumos industriales, servicios, marketing, tasa bancaria, ingresos financieros, IGV, impuesto a la renta, \% participación y tasa de riesgo.

\subsection{Análisis Tornado y Araña}

Tabla 7.1

Escenarios financieros

\begin{tabular}{|l|r|}
\hline \multicolumn{1}{|c|}{ VARIABLES } & ACTUAL \\
\hline PRECIO & $100.0 \%$ \\
\hline SUELDOS & $100.0 \%$ \\
\hline INSUMOS & $100.0 \%$ \\
\hline INSUMOS IND & $100.0 \%$ \\
\hline SERV. EXTIN, BOTIQ Y \\
UNIF & $100.0 \%$ \\
\hline MARKETING & $100.0 \%$ \\
\hline TASA BANCARIA & $100.0 \%$ \\
\hline ING FINANCIEROS & $100.0 \%$ \\
\hline IGV & $100.0 \%$ \\
\hline IMP RENTA & $100.0 \%$ \\
\hline$\%$ PARTIC & $100.0 \%$ \\
\hline TASA DE RIESGO & $100.0 \%$ \\
\hline
\end{tabular}

\begin{tabular}{|r|r|r|}
\hline PESIMISTA & ESPERADO & OPTIMISTA \\
\hline $94.0 \%$ & $100.0 \%$ & $104.5 \%$ \\
\hline $107.0 \%$ & $100.0 \%$ & $94.8 \%$ \\
\hline $108.0 \%$ & $100.0 \%$ & $94.0 \%$ \\
\hline $108.0 \%$ & $100.0 \%$ & $94.0 \%$ \\
\hline $106.0 \%$ & $100.0 \%$ & $95.5 \%$ \\
\hline $107.0 \%$ & $100.0 \%$ & $94.8 \%$ \\
\hline $104.0 \%$ & $100.0 \%$ & $97.0 \%$ \\
\hline $104.0 \%$ & $100.0 \%$ & $97.0 \%$ \\
\hline $100.5 \%$ & $100.0 \%$ & $99.6 \%$ \\
\hline $100.5 \%$ & $100.0 \%$ & $99.6 \%$ \\
\hline $94.0 \%$ & $100.0 \%$ & $104.5 \%$ \\
\hline $106.0 \%$ & $100.0 \%$ & $95.5 \%$ \\
\hline
\end{tabular}

\begin{tabular}{|l|l|}
\hline PRESTAMO BANCARIO & $100.0 \%$ \\
\hline ACTIVOS FIJOS & $100.0 \%$ \\
\hline ACTIVOS INTAG & $100.0 \%$ \\
\hline
\end{tabular}

\begin{tabular}{|l|l|l|}
\hline $100.0 \%$ & $100.0 \%$ & $100.0 \%$ \\
\hline $100.0 \%$ & $100.0 \%$ & $100.0 \%$ \\
\hline $100.0 \%$ & $100.0 \%$ & $100.0 \%$ \\
\hline
\end{tabular}


VAN ECON

VAN FINAN

$$
51,857.44
$$

\begin{tabular}{|l|r|}
\hline$-148,898.32$ & $51,857.44$ \\
\hline
\end{tabular}

$196,881.73$

VAN LIBRE

$57,324.52$

\begin{tabular}{|l|r|}
\hline$-151,326.59$ & $57,324.52$ \\
\hline
\end{tabular}

$208,085.77$

Elaboración propia

7.3 Determinación de las variaciones porcentuales de las variables importantes en cada uno de los escenarios

Tabla 7.2

Variaciones porcentuales en cada escenario

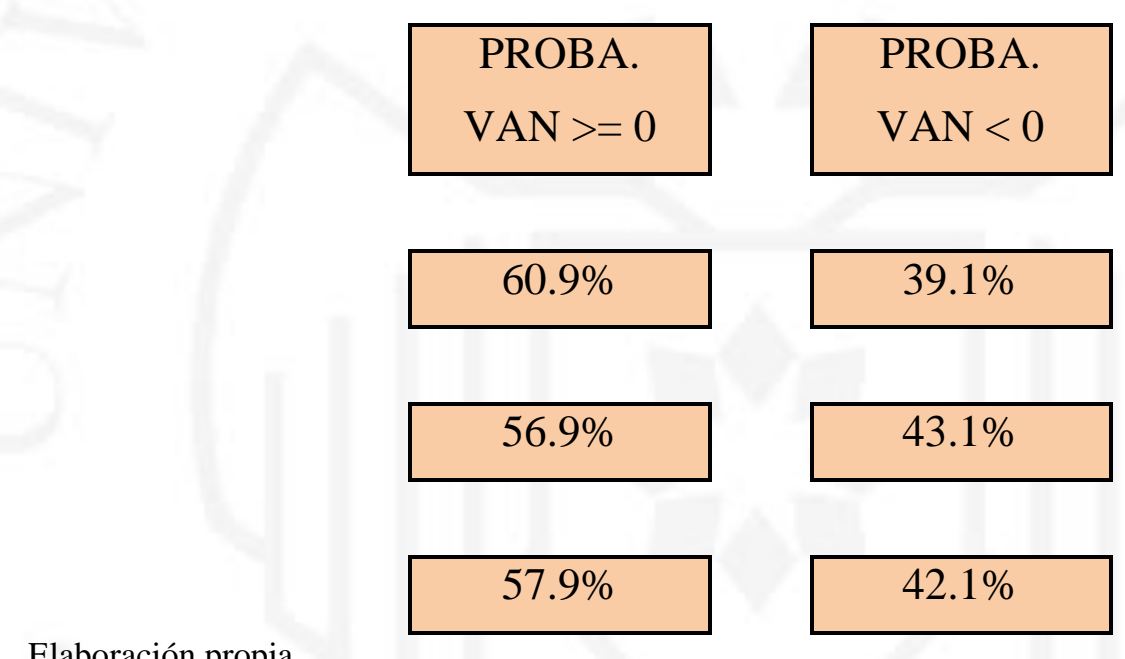




\subsection{Evaluación económica y financiera de cada escenario}

Figura 7.1

VAN ECONOMICO

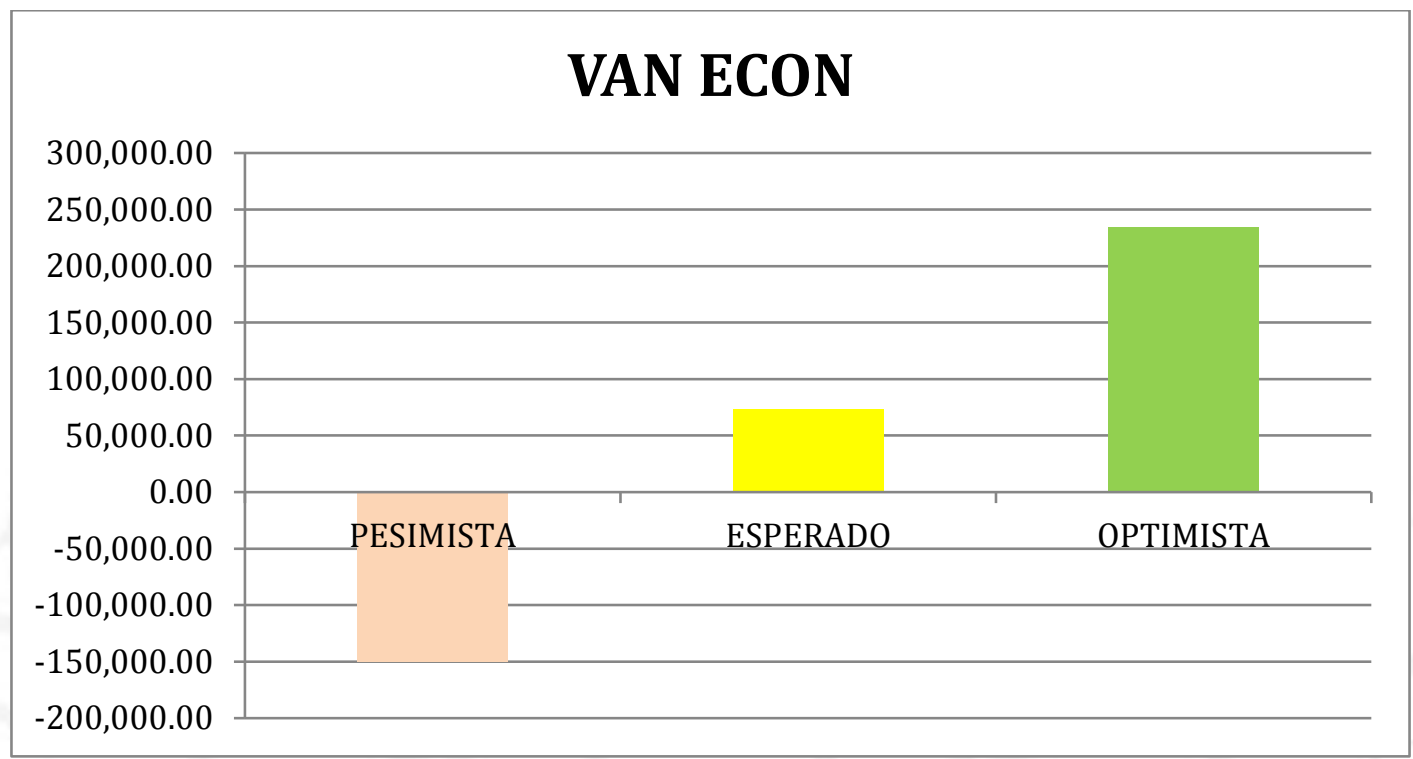

Elaboración propia

Figura 7.2

VAN FINANCIERO

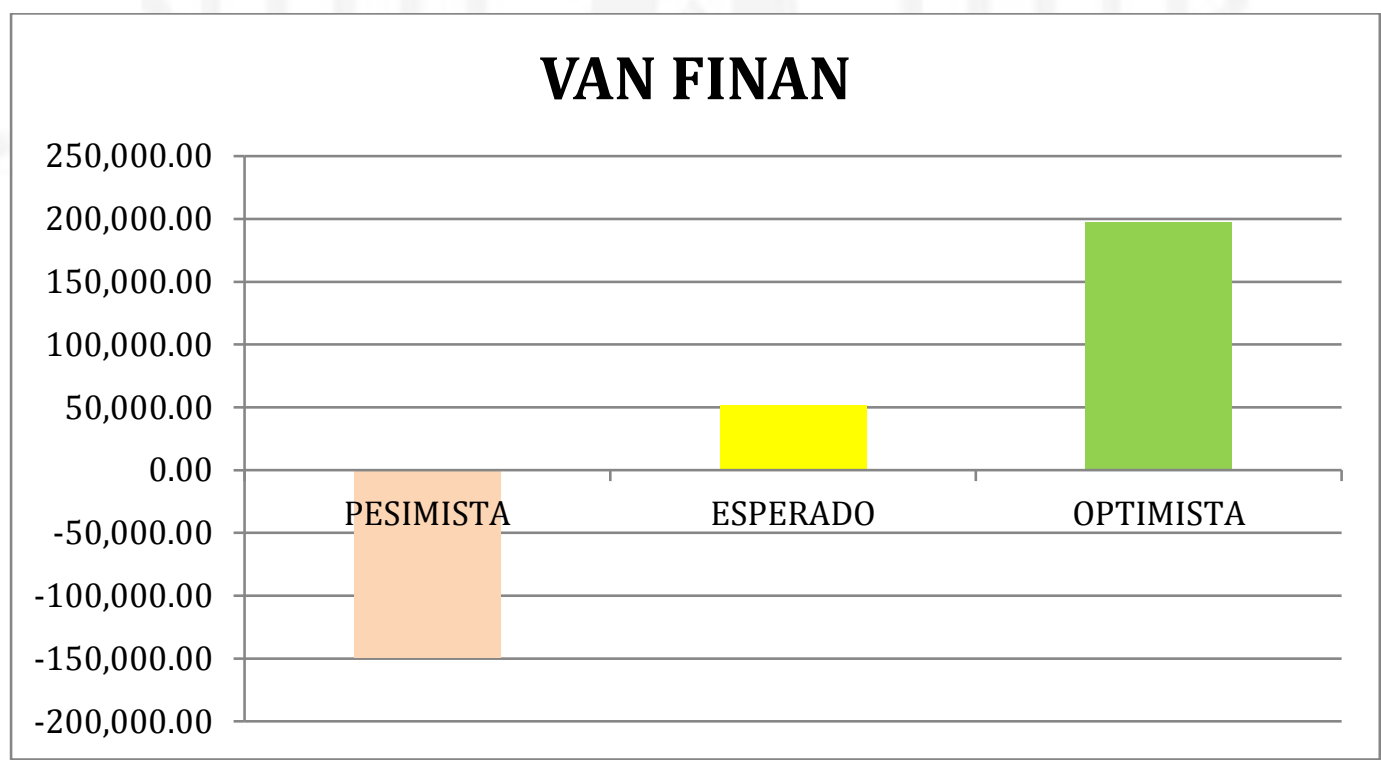

Elaboración propia 
Figura 7.3

VAN LIBRE

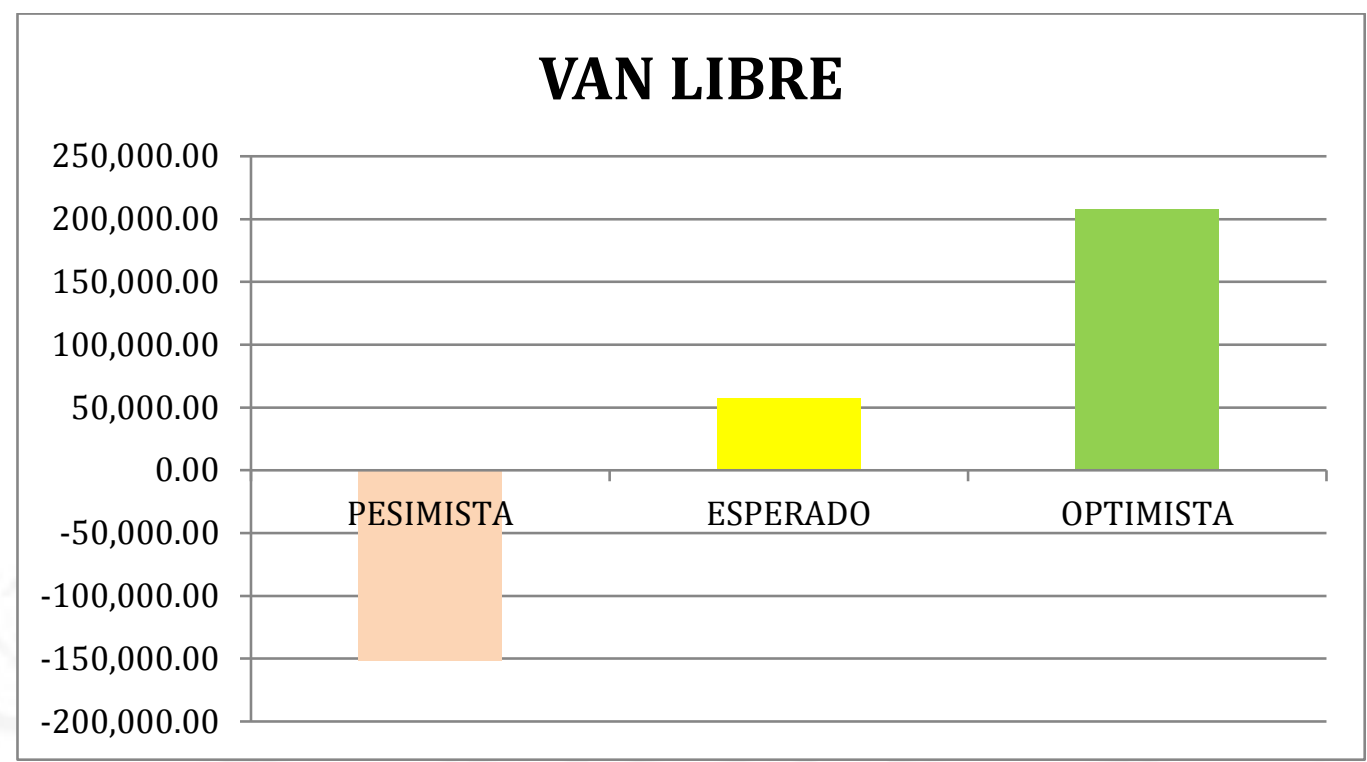

Elaboración propia

\subsection{Planes de contingencia}

Dentro de los planes de contingencia, hemos visto necesario contratar seguros: contra robos, contra incendios, seguros médicos de primeros auxilios para los clientes con el fin de protegerlos ante cualquier problema que se pueda presentar y al mismo tiempo proteger nuestro negocio en caso sucediera algún robo, incendio, entre otros, y podamos seguir trabajando con normalidad sin perjudicar a nuestros clientes. 


\section{CONCLUSIONES}

- Existe una demanda insatisfecha real por atender.

- El proyecto es viable y rentable.

- Después de haber realizado el proyecto de negocios "Agora" se puede concluir que hay una gran demanda insatisfecha del mercado y se encuentra en crecimiento debido a que cada vez hay mayor interés por el bienestar personal, por la salud física y mental así; y por otro lado, al haber tanta competencia hoy en día, las personas buscan desarrollar habilidades, superarse y es ahí donde nosotros seremos sus aliados para que puedan lograr esto.

- El local con el que se contará es una gran oportunidad ya que cuenta con espacios amplios y muy bien acondicionados para que los participantes puedan desarrollar sus actividades sin ningún problema.

- "Agora" tiene una propuesta de valor diferente ya que más que un servicio es un espacio que busca que cada persona desarrolle su concepto de felicidad, mecanismos para aprender a valorar cada momento por más insignificante que sea, un espacio donde les brindaremos las herramientas y técnicas necesarias para desarrollar habilidades. 


\section{RECOMENDACIONES}

- Se debe desarrollar capacitaciones constantemente a nuestro personal y de esta manera puedan ofrecer un mejor servicio a nuestros participantes. Asimismo, se debe realizar un buen plan de selección y retención, ya que nuestro personal es nuestro activo más importante y valioso en la compañía.

- Implementar benchmarking a lo largo de la vida del proyecto para estar pendientes de los precios de la competencia y del mercado en sí, así como también saber qué productos/ servicios están ofreciendo a sus clientes. Con esta información podemos mejorar nuestro servicio teniendo en cuenta siempre nuestra ventaja competitiva y a la vez adaptarnos a los estándares de la industria.

- Trabajar bastante con el tema de las alianzas estratégicas con empresas claves con el fin de hacernos más conocidos y atraer mayor clientela.

- Realizar servicio post-venta con el fin de saber qué tan satisfechos quedaron nuestros clientes con el servicio ofrecido. Asimismo no dejar de comunicarnos con nuestros participantes, así hayan culminado con el taller o curso, ya que ellos serán nuestra referencia para futuros clientes. La idea es mantenernos en contacto y así poder ofrecerles también promociones o descuentos para un siguiente taller. 


\section{REFERENCIAS BIBLIOGRAFICAS}

Aguirre, F. (23, diciembre, 2015) Lista de 250 emociones y sentimientos. Recuperado de http://psicologos.mx/lista-de-emociones-que-podemos-sentir.php

Alvear Morón, D. (2015). Mindfulness, autocompasión y estrés docente en el profesorado de Educación Secundaria (tesis doctoral, Universidad del País Vasco). Recuperado de https://addi.ehu.es/bitstream/handle/10810/18424/TESIS_ALVEAR_MORON_DAVI D.pdf;jsessionid=3DE77DDB84311BD57FFA8A5588DE3ADD? sequence $=1$

Calvo, José Manuel. Getabstract. (1 de Julio de 2017). Mindfulness: el arte de controlar tu mente. Recuperado de https://www.getabstract.com/es/resumen/desarrolloprofesional/mindfulness-el-arte-de-controlar-tumente/30434?drt=73KObFsEFlW56NrWsxWcH_TZugWVxbofElQvvxPkKD8=\&l=3 \&u=lapositiva\&esid=351598556\&l=3\&u=lapositiva

Consulta Baekland. (20 de Julio de 2017). ¿Qué es la Salud Mental? Recuperado de https://www.consultabaekeland.com/p/es/psicologo-madrid-faqs/que-es-la-saludmental.php

Contemplative science: where Buddhism and 4. neuroscience converge. New York: Colombia. UniversityPress; 2007.

Harmonía.la. (30 de Marzo de 2017). Tres características de un estilo de vida saludable.

Recuperado de

https://www.harmonia.la/entorno/tres_caracteristicas_de_un_estilo_de_vida_saludabl $\underline{\mathrm{e}}$

Henigin, H., y Wildgruber, J. (2015). From Business to being [Documental]. Alemania.

Hrund Gunnsteinsdottir \& Kristín Ólafsdóttir. (2016). InnSaei [Documental]. Islandia: Coproducción Islandia-GB-Dinamarca-India-EEUU

Germer CK. 1. Mindfulness. What is it? What does It matter? En C. K. Germer, R.D. Siegel \&amp; P.R. Fulton. Mindfulness psychotherapy. New York: GuilfordPress; 2005. P.327. Baer, R. 2.

Guerrero, Carmen. (23 de Diciembre de 2015). La rueda de la conciencia [archivo de video]. Recuperado de https://vimeo.com/159272783

Imagine Family Ministries. (7 de diciembre de 2015). Dollar Store Game Ideas For Your Children’s Ministry. Recuperado de http://www.imaginefamilyministries.com/kidminthemes--object-talks/dollar-store-game-ideas 
Instituto Mexicano de Mindfulness. Recuperado de https://www.mindfulness.org.mx/quienes$\underline{\text { somos/ }}$

Martinez Escoda, Nacho. (23 de Diciembre de 2017). Simon Sinek - Millenials in the Workplace español HD [archivo de video]. Recuperado de https://www.google.com.pe/search?q=ted+simon+sinek+millennials\&oq=ted+simon+ $\underline{\text { sinek } \& a q s=\text { chrome } 1.69 i 57 j 015.13837 j 0 j 8 \& \text { sourceid }=\text { chrome } \& i e=U T F-8}$

Mindfulness in plain English. Somerville, MA: Wisdom Publications; 2002. Wallace A.

Mindfulness Practice and the Brain. Recuperado de

https://www.bing.com/videos/search?q=mindfulness+brain+\&\&view=detail \&mid=7E 13FEBB5BBC11599A057E13FEBB5BBC11599A05\&rvsmid=6CF709A2F339EBD 267B46CF709A2F339EBD267B4\&FORM=VDQVAP

Mindfulness training as a clinical intervention: A conceptual and empirical review. ClinPsychySciandPrac. 2003;10:125-42. Gunaratana, H. 3.

Moñivas, A., García-Diex, G., \& García-De-Silva, R. (2012). Mindfulness (Atención Plena): Concepto Y Teoría. Portularia, XII , 83-89. Recuperado de http://www.redalyc.org/pdf/1610/161024437009.pdf

Ortega, C. (17 de julio de 2014). Mindfulness qué es y para qué sirve [archivo de video]. Recuperado de https://www.youtube.com/watch?v=qqR7QmjxiWE

Palouse Mindfulness. MBSR en línea ("Mindfulness-Based Stress Reduction"). Recuperado de https://palousemindfulness.com/es/

Phie Ambo. (2012). Free the mind [Documental]. Dinamarca.

Regader, B. (4 de Julio de 2017). ¿Qué es el Mindfulness? Las 7 respuestas a tus preguntas. Recuperado de https://psicologiaymente.net/meditacion/que-es-Mindfulness\#

Roko Belic. (2011). Happy [Documental]. Bélgica.

TEDSummit. Cómo los árboles se comunican entre sí [archivo de video]. Recuperado de https://www.ted.com/talks/suzanne_simard_how_trees_talk_to_each_other?language= $\underline{\text { es }}$

TEDx Talks (13 de noviembre de 2012). Mindfulness and Parenting: Mary Ann Christie Burnside at TEDxWaldenPond [archivo de video]. Recuperado de https://www.youtube.com/watch?v=5KfD9pElmA8

TEDx Talks (16 de noviembre de 2012). Conscious Parenting: Shefali Tsabary at TEDxSF (7 Billion Well) [archivo de video]. Recuperado de https://www.youtube.com/watch?v=QM_PQ2WUD2k 
Wikipedia. (20 de Julio de 2016). Bien ser. Recuperado de https://es.wikipedia.org/wiki/Bien_ser 
ANEXOS 


\section{Anexo 1: Entrevistas}

PunkieHermoza (Blogger de yoga, comida saludable, thai massage, organizadora de retiros/ www.punkiehermoza.com. Organiza talleres como "Herramientas para potenciar tu vida cotidiana"

$\rightarrow$ PERSONAL

1. ¿Qué estudiaste?

2. ¿A qué te dedicas actualmente?

3. ¿Cuál es tu experiencia profesional?

4. ¿Cómo empezaste tu negocio?

5. ¿Sabes qué es Mindfulness?

6. ¿Dónde lo escuchaste?

7. ¿Sabes qué beneficios tiene?

8. ¿Cuáles son los talleres que reemplazarían a uno de Mindfulness?

9. ¿Para ti qué es el yoga y cómo contribuye al bienestar personal?

10. ¿Qué es para ti la felicidad?

11. ¿Qué personas necesitan la meditación?

12. ¿Qué aspectos mides en una persona para saber si está estresada?

13. ¿Cuánto está dispuesta la gente a pagar por un taller de bienestar personal?

14. ¿Cómo crees que es el perfil de una persona que busca un taller de este tipo?

15. ¿Sientes que este rubro está creciendo?

$\rightarrow$ IDEA DE NEGOCIO

1. Contar idea de negocio

2. ¿Qué recomendaciones podrías darnos para nuestro taller?

3. En base a tu experiencia, ¿Qué opinas de la idea de elaborar talleres de Mindfulness? ¿Qué precio crees que deberíamos ponerle a nuestro taller? ¿En qué horarios de preferencia?

\section{$\underline{\text { Ana Loret de Mola }}$}

Entrevista - Ana Loret de Mola "Dos de los centros más importantes donde se dictan talleres, seminarios y cursos de Mindfulness se llaman "Conciencia Plena Perú" y "Mindfulness 
Perú". Brisa Deneumostier, chef holística y coach, y Ana Loret de Mola, psicóloga especialista en mindfulness, son las directoras de este último.

$\rightarrow$ PERSONAL

1. ¿Qué estudiaste?

2. ¿A qué te dedicas actualmente?

3. ¿Cuál es tu experiencia profesional?

4. ¿Cómo empezaste tu negocio?

5. ¿Dónde escuchaste por primera vez Mindfulness?

6. ¿Qué beneficios tiene?

7. ¿Cuáles son los talleres que reemplazarían a uno de Mindfulness?

8. ¿Para ti qué es el Mindfulness y cómo contribuye al bienestar personal?

9. ¿Qué es para ti la felicidad?

10. ¿Qué personas necesitan Mindfulness?

11. ¿Qué aspectos mides en una persona para saber si está estresada?

12. ¿Cuánto crees que esté dispuesta a pagar la gente por un taller de bienestar personal?

13. ¿Cómo crees que es el perfil de una persona que busca un taller de este tipo?

14. ¿Sientes que este rubro está creciendo?

$\rightarrow$ IDEA DE NEGOCIO

4. Contar idea de negocio

5. ¿Qué recomendaciones podrías darnos para nuestro taller?

6. En base a tu experiencia, ¿Qué opinas de la idea de elaborar talleres de Mindfulnesss? ¿Qué precio crees que deberíamos ponerle a nuestro taller? ¿En qué horarios de preferencia?

\section{$\underline{\text { Alex Canales - Hari Purana }}$}

Gerente General de LimaYoga, academia de yoga promueve un armonioso equilibrio mental, físico y emocional de las personas a través del Yoga y el Ayurveda.

\section{$\rightarrow$ PERSONAL}

1. ¿Qué estudiaste?

2. ¿A qué te dedicas actualmente?

3. ¿Cuál es tu experiencia profesional? 
4. ¿Cómo empezaste tu negocio?

5. ¿Sabes qué es Mindfulnesss?

6. ¿Dónde lo escuchaste?

7. ¿Sabes qué beneficios tiene?

8. ¿Cuáles son los talleres que reemplazarían a uno de Mindfulness?

9. ¿Para ti qué es el yoga y cómo contribuye al bienestar personal?

10. ¿Qué es para ti la felicidad?

11. ¿Qué personas necesitan la meditación?

12. ¿Qué aspectos mides en una persona para saber si está estresada?

13. ¿Cuánto está dispuesta la gente a pagar por un taller de bienestar personal?

14. ¿Cómo crees que es el perfil de una persona que busca un taller de este tipo?

15. ¿Sientes que este rubro está creciendo?

$\rightarrow$ IDEA DE NEGOCIO

7. Contar idea de negocio

8. ¿Qué recomendaciones podrías darnos para nuestro taller?

9. En base a tu experiencia, ¿Qué opinas de la idea de elaborar talleres de Mindfulnesss? ¿Qué precio crees que deberíamos ponerle a nuestro taller? ¿En qué horarios de preferencia?

\section{Maite Schirmer}

Psicóloga clínica con formación en terapia Gestalt y Mindfulness con 30 años de experiencia en meditación.Su experiencia profesional se dio en parte en la Universidad Católica del Perú en Familia Saludable con las intervenciones que tenían mucho que ver con dejar un espacio antes de la reacción (propio de Mindfulness). Ha trabajado con niños en Aldeas Infantiles y en el Puericultorio Pérez Araníbar y el Mindfulness ayudó a generar un espacio antes de las acciones impulsivas de los niños con pausas de respiraciones.

1. Experiencia profesional

2. ¿Qué es el Mindfulness?

3. ¿En qué aspectos de la vida puede ayudar el Mindfulness?

4. ¿Qué otras tecnicas hay para el autoconocimiento?

5. ¿Cómo el autoconocimiento mejora la salud física y mental?

6. ¿Qué necesitamos para lograr el autoconocimiento?

7. ¿Cómo creamos un espacio que permita a las personas el autoconocimiento? 
8. ¿Cómo logramos tangibilizar los beneficios del autoconocimiento? Cientifica experiencia practica

9. ¿Hasta qué punto tenemos injerencia en las hormonas que producimos?

10. ¿Qué características debe tener un espacio para aportar a la salud mental de una persona? 


\section{Anexo 2: Encuestas}

255 respuestas

¿Estarías dispuesto a pagar por participar en un taller Mindfulness? Puede consistir en un día o varios días.

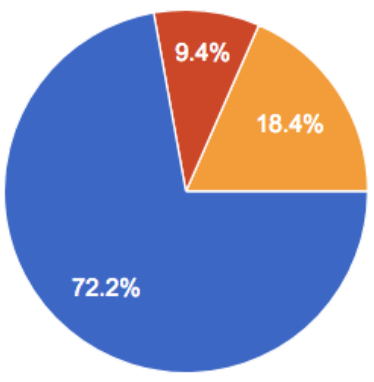




\section{Interés en el bienestar personal}

¡Hola! Nos encontramos investigando para un proyecto de la universidad. Ayúdanos con esta simple encuesta. Tu opinión nos importa. ¡Gracias!

\section{SIGUIENTE}

Nunca envies contraseñas a través de Formularios de Google. 


\section{Anexo 3: Plan de Marketing Digital}

\section{Marketing Digital \\ Presentación Final \\ Consuelo Chauny \\ Diciembre 2017}

\section{INDEX}

1. Brief

2. Análisis de competencia

3. Plan de medios

4. Prácticas de inversión 
1. | Misión y visión

isión Ser la primera empresa que se ocupa de la promoción de salud mental y bienestar integral aprovechando las técnicas del Mindfulness.

Transformar las vidas de las familias y de la comunidad. Lograr que los niños y jóvenes puedan manejar el estrés al que están expuestos y esto les traiga bienestar en su salud, sus estudios, su vida. Como efecto colateral este bienestar será llevado a sus hogares y finalmente a la comunidad, logrando seres humanos más bondadosos y compasivos.

1. | Reto

Como pioneros en el mercado deseamos asumir los siguientes retos:

- Introducir el concepto mindfulness en el nicho de mercado a través de nuevos medios vinculados a BeMindful.

- Al ser un producto intangible, la marca debe posicionarse por en el lenguaje y estética de la marca.

- Generar una comunidad que comparta la propuesta mindful y difunda los contenidos de la marca.

- Finalmente, al contar con una comunidad que comprende la propuesta mindful, se buscará posicionar el servicio de talleres y charlas sobre mindfulness.

El reto que se presenta es la forma de comunicación con el cliente objetivo y el cómo nos vamos a dar a conocer en el medio, ya que somos nuevos en el mercado. 
1. Insights del consumidor

\begin{tabular}{ll}
\hline$\#$ & \multicolumn{1}{c}{ Insight } \\
1 & $\begin{array}{l}\text { El consumidor necesita herramientas que le aseguren su bienestar y felicidad para rendir } \\
\text { mejor. }\end{array}$ \\
2 & El peruano es corto placista. \\
3 & El futuro no es tangible. El futuro es incierto. \\
4 & No puedo poner mi mente en blanco, no tengo tiempo \\
& \\
5 & Así es la vida
\end{tabular}

$20 \%$ de personas de 9 y 21 años tienen algún tipo de desorden mental que afecta su rendimiento y aprendizaje (déficit atencional, hiperactividad y ansiedad).

1. | Objetivos del negocio

\begin{tabular}{|c|c|}
\hline $\begin{array}{c}\text { Generar rentabilidad al } \\
\text { negocio teniendo en cuenta }\end{array}$ & $>\begin{array}{l}\text { Categoría y Público al que se dirigen } \\
\text { Credibilidad y valor de influencia }\end{array}$ \\
\hline
\end{tabular}

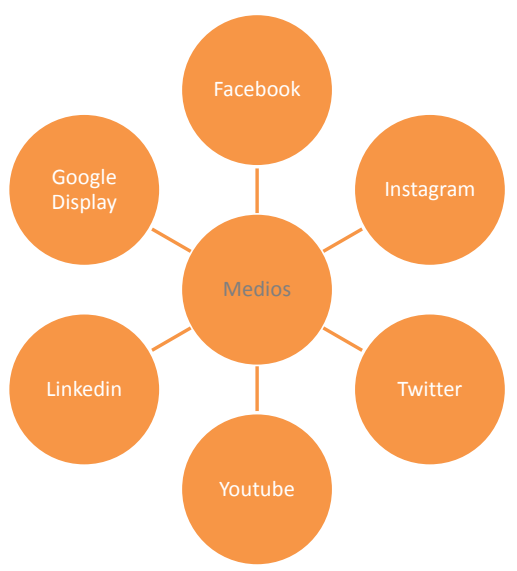


1. | Objetivos del negocio

\begin{tabular}{|c|c|}
\hline $\begin{array}{c}\text { Generar rentabilidad al } \\
\text { negocio teniendo en cuenta }\end{array}$ & $>\begin{array}{l}\text { Categoría y Público al que se dirigen } \\
\text { Credibilidad y valor de influencia }\end{array}$ \\
\hline
\end{tabular}

\section{Objetivo}

- Incrementar en un $50 \%$ el nivel de ventas en el 2018.

Posicionar la marca en el mercado.

Promocionar conductas saludables y generar bienestar mental integral en un $10 \%$ en el rubro.

Poder ocupar $10 \%$ del mercado en los primeros 5 años.

Realizar retiros.

- Tráfico hacia algún sitio como página web o redes sociales.

1. | Objetivos de comunicación

\begin{tabular}{|c|c|}
\hline $\begin{array}{l}\text { Generar rentabilidad al } \\
\text { negocio teniendo en cuenta }\end{array}$ & $\begin{array}{l}\text { Categoría y Público al que se dirigen } \\
\text { Credibilidad y valor de influencia }\end{array}$ \\
\hline
\end{tabular}

Objetivo

Recordación de marca

Ser conocidos como únicos en el mercado

Posicionamiento entre los top 5 como centro dedicado al servicio de

bienestar personal y meditación en Lima en el 2018.

- Pioneros en integrar psicología y meditación para brindar

herramientas de una filosofía de vida con mayor bienestar.

- Realizar 4 concursos de paquetes dobles para poder asistir gratis a los

talleres con la temática de estaciones (verano, otoño, invierno y primavera) en Facebook durante el 2018.

- Realizar 5 descuentos esporádicos relacionados a fiestas (Semana Santa, Fiestas Patrias, Día de la madre, Día del padre y Navidad) en Facebook durante el 2018.

- Todas las publicaciones deberán tener el nombre de la marca: BeMindful. 
1. | Objetivos de comunicación - Facebook

\begin{tabular}{|c|c|c|}
\hline \multicolumn{2}{|c|}{$\begin{array}{l}\text { Generar rentabilidad al } \\
\text { negocio teniendo en cuenta }\end{array}$} & $\begin{array}{l}\text { Categoría y Público al que se dirigen } \\
\text { Credibilidad y valor de influencia }\end{array}$ \\
\hline Medio & \multicolumn{2}{|r|}{ Objetivo } \\
\hline Facebook & $\begin{array}{l}\text { - Conseguir } 1 \\
\text { - Incrementa } \\
\text { Facebook. } \\
\text { - Dar a conoc } \\
\text { - Compartir r } \\
\text { Facebook p } \\
\text { durante toc } \\
\text { - Fans: } 10,00 \\
\text { - Interacción } \\
\text { cada post. } \\
\text { - Real } \\
\text { Minc } \\
\text { - Gen } \\
\text { - el pr } \\
\text { - Imprear respu }\end{array}$ & $\begin{array}{l}\text { dores orgánicos en el primer trimestre del año. } \\
\text { as ventas en el primer trimestre del año por } \\
\text { ca y sus servicios durante todo el } 2018 \text {. } \\
\text { ublicaciones de Twitter y de Instagram en } \\
\text { ar conocimiento de nuestras redes sociales } \\
\text { el } 2018 \text {. } \\
\text { un promedio de } 25 \text { comentarios y } 100 \text { likes por } \\
\text { nes por } 10 \text { meses) } \\
\text { smisiones en vivo realizando meditaciones } \\
\text { ara crear prospectos. } \\
\text { evistas con influenciadores de nuestro rubro en } \\
\text { stre del año por Facebook. } \\
\text { náticas (poner saludo y teléfono de contacto) }\end{array}$ \\
\hline
\end{tabular}

*Las campañas de conversiones tienen como objetivo Leads Registration.

1. Objetivos de comunicación - Instagram

\begin{tabular}{|c|c|c|}
\hline \multicolumn{2}{|c|}{$\begin{array}{l}\text { Generar rentabilidad al } \\
\text { negocio teniendo en cuenta }\end{array}$} & $\begin{array}{l}\text { Categoría y Público al que se dirigen } \\
\text { Credibilidad y valor de influencia }\end{array}$ \\
\hline \multicolumn{2}{|l|}{ Medio } & Objetivo \\
\hline Instagram & \multicolumn{2}{|c|}{$\begin{array}{l}\text { - Conseguir } 1000 \text { seguidores orgánicos en el primer trimestre del año. } \\
\text { - } \quad \text { Gar a conocer la marca y sus servicios durante todo el } 2018 . \\
\text { Instagram. } \\
\text { - Fans: } 6,000 \text { fans en el } 2018 \text {. } \\
\text { - Interacción: generar un promedio de } 25 \text { likes por cada post. } \\
\text { - Impresiones: } 8,000 . \\
\text { - Ventas: } 10\end{array}$} \\
\hline
\end{tabular}

**Las campañas de conversiones tienen como objetivo Leads Registration.

*Instagram resulta poco rentable, por lo que las campañas no tendrán mucha duración 
1. Objetivos de comunicación - Twitter

\begin{tabular}{|c|c|c|}
\hline \multicolumn{2}{|c|}{$\begin{array}{l}\text { Generar rentabilidad al } \\
\text { negocio teniendo en cuenta }\end{array}$} & $\begin{array}{l}\text { Categoría y Público al que se dirigen } \\
\text { Credibilidad y valor de influencia }\end{array}$ \\
\hline Medio & & Objetivo \\
\hline Twitter & $\begin{array}{l}\text { - Generar ur } \\
\text { - } \text { yar a conono } \\
\text { - Generar ur } \\
\text { en el prime } \\
\text { - Alcance } \\
\text { - Fans: } 4,00 \\
\text { - Interacciór } \\
\text { - Ima post. } \\
\text { - Impresione }\end{array}$ & $\begin{array}{l}\text { de } 15 \text { retweets por cada post en Twitter. } \\
\text { s psicólogos y coaches en cuanto a sus intereses } \\
\text { do el } 2018 \text {. } \\
\text { de } 15 \text { post por cada experto de nuestra empresa } \\
\text { del año en Twitter. } \\
2017 \text {. } \\
\text { n promedio de } 25 \text { comentarios y } 40 \text { likes por }\end{array}$ \\
\hline
\end{tabular}

1. Objetivos de comunicación - Youtube

\begin{tabular}{|c|c|c|}
\hline \multicolumn{2}{|c|}{$\begin{array}{l}\text { Generar rentabilidad al } \\
\text { negocio teniendo en cuenta }\end{array}$} & $\begin{array}{l}\text { Categoría y Público al que se dirigen } \\
\text { Credibilidad y valor de influencia }\end{array}$ \\
\hline Medio & & Objetivo \\
\hline Youtube & $\begin{array}{l}\text { - Generar un } \\
\text { - } \text { Dar a conoc } \\
\text { - } \text { gexpertise } \\
\text { - } \text { enerar un } \\
\text { - } \text { Alcance } \\
\text { - Fans: } 4,000 \\
\text { - Interacción } \\
\text { - } \text { Impresione }\end{array}$ & $\begin{array}{l}\text { de } 15 \text { retweets por cada post en Twitter. } \\
\text { s psicólogos y coaches en cuanto a sus intereses } \\
\text { do el } 2018 \text {. } \\
\text { de } 15 \text { post por cada experto de nuestra empresa } \\
\text { del año en Twitter. } \\
2017 \text {. } \\
\text { n promedio de } 25 \text { comentarios y } 40 \text { likes por }\end{array}$ \\
\hline
\end{tabular}


1. | Objetivos del negocio - Linkedin

Generar rentabilidad al negocio teniendo en cuenta
Categoría y Público al que se dirigen

Credibilidad y valor de influencia

\begin{tabular}{ll}
\hline Medio & \multicolumn{1}{c}{ Objetivo } \\
\hline & Llegada a empresas, gerentes generales, gente con mayor nivel educativo \\
& - Conocimiento de marca \\
Linkedin & Venerar interacciones \\
& - Usos de plataforma virtual \\
& - Conversiones: lograr objetivo en específico. \\
& Realizar entrevistas \\
& Mostrar los talleres que se ofrecen \\
\hline
\end{tabular}


1. | Objetivos del negocio - Google Display

Generar rentabilidad al negocio teniendo en cuenta

Categoría y Público al que se dirigen

Credibilidad y valor de influencia

\begin{tabular}{cll}
\hline Medio & & Objetivo \\
\hline & & \\
Google Display & $\bullet$ & Remarketing \\
& & Ventas: 10
\end{tabular}

1. | Personalidad de marca

- Mujer 33 años

- Independiente, visionaria, aspiracional

- Medita, hace yoga

- Se preocupa por la sociedad y el medioambiente

- Hace dieta

- Viaja, le gusta la naturaleza

- Difunde, comparte

conocimiento de bienestar

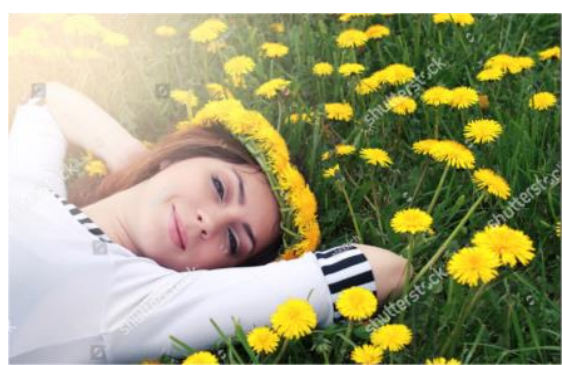


1. | Público Objetivo

\begin{tabular}{ll}
\multicolumn{1}{c}{ Demográficas } & \multicolumn{1}{c}{ Psicográficas } \\
Sexo: Hombres y mujeres & Les gusta meditar \\
Edad: $25-50$ años & Son familiares \\
NSE: A y B+ & Desarrollo personal \\
\hline $\begin{array}{l}\text { Distrito: San Isidro, Miraflores, La } \\
\text { Molina, Barranco y Surco. }\end{array}$ & Bienestar físico y mental \\
\hline Estado civil: casados y solteros & *Descritas en personalidad de marca \\
\cline { 2 - 2 }
\end{tabular}

Se definirá más adelante con una encuesta que se realizará 200 personas.

\section{1. | Campaña}

Pensamos que debe ser constante en el tiempo

\section{Monitoreo de campaña:}

Se debe determinar los KPI's que se van a considerar en la campaña para determinar su eficiencia.

$\square$ Interacción o Engagement

Alcance $=$ alcance $x$ frecuencia (1 persona 3 veces $=3$ impresiones)

Frecuencia

Vista

Conversión [Formulario, Visita a una página, Venta de un producto, entre otros]

Otros [Los KPI's pueden variar dependiendo del objetivo que se desea lograr

Evaluacion de resultados:

La Planificación de los Medios Digitales requiere de un constante monitoreo de los resultados para medir la eficiencia del medio, es por ello que una vez determinados los KPI's que se van a considerar para medir la rentabilidad, se debe tener un Plan de Contingencia para ponerlo en acción en caso no se logren los resultados.

Aprendizajes para una siguiente campaña: cambios de campaña, de productos, servicios, etc 
1. | Período de campaña

Pensamos que debe ser constante en el tiempo

Limitado.

En caso no se tenga un estimado de los costos, es recomendable realizar una campaña de prueba durante 7 días para tener un costo promedio y así poder realizar una proyección del presupuesto. *Es deber de un planificador de medios digitales tener conocimiento de la plataforma de Google, lo que le permitirá ser objetivo en la selección de los medios

Antes de tomar una decisión para invertir en los medios de comunicación o influencers que te han presupuestado, es necesario evaluar la rentabilidad de cada uno de ellos en base a las siguientes factores:

Categoría y Público al que se dirigen

Credibilidad y valor de influencia

Costo por mil personas alcanzadas

Costo por conversión

1. | Presupuesto de campaña

Pensamos que debe ser constante en el tiempo

La vigencia de campaña deberá ser la necesaria para poder cumplir con los objetivos

\begin{tabular}{|l|c|c|}
\hline & Unidades & Ingresos \\
\hline Ventas & 25 & 9,500
\end{tabular}


1. Mandatorios - Los NO de la marca

Como pioneros en el mercado deseamos asumir los siguientes retos:

- No queremos que se vea como un adoctrinamiento ni como una religión, tampoco queremos ser vistos como moralizadores.

- Bloquear lisuras y comentarios negativos.

- Derechos de autor en imágenes y canciones.

- Pedir permiso para mostrar fotos de los alumnos en el taller.

- Seguir lineamientos de la línea gráfica y del manual de marca.

- No memes, ni comentarios absurdos.

- Responder sin remordimientos, rencores, frustraciones. Las marcas no pueden odiar.

- No ocupar más del $20 \%$ en texto de cada publicación.

- En cada publicación se deberá seguir con las políticas de privacidad de anuncios.

1. Manual de crisis

1. Analizar la situación del comentario.

2. Evaluar si la respuesta se debe hacer pública o privada.

3. Responde sin remordimientos, rencores, frustraciones. 
2. | Análisis de competencia

Limayoga

Frecuencia de publicación: 2-3 al día

Seguidores: 96,200

Página Web

Sí hay lineamientos de marca

Ubicación

Redireccionamiento a página web

Correo para información

Contenido: afín al público y de servicios

2. Análisis de competencia

Mindfulness Perú

- Frecuencia de publicación: 4 posts al mes

- Seguidores: 10,500

- Página Web: en construcción

- Sí hay lineamientos de marca

- Ubicación

- Redireccionamiento a página web

- Correo para información

- Contenido: hacia servicios básicamente 
2. | Análisis de competencia

Conciencia Plena

- Frecuencia de publicación: cada 3 días

- Seguidores: 3120

- Página Web

- No hay lineamientos de marca

- Ubicación

- Redireccionamiento a página web

- Correo para información

- Contenido: hacia servicios básicamente

3. I Plan de Medios

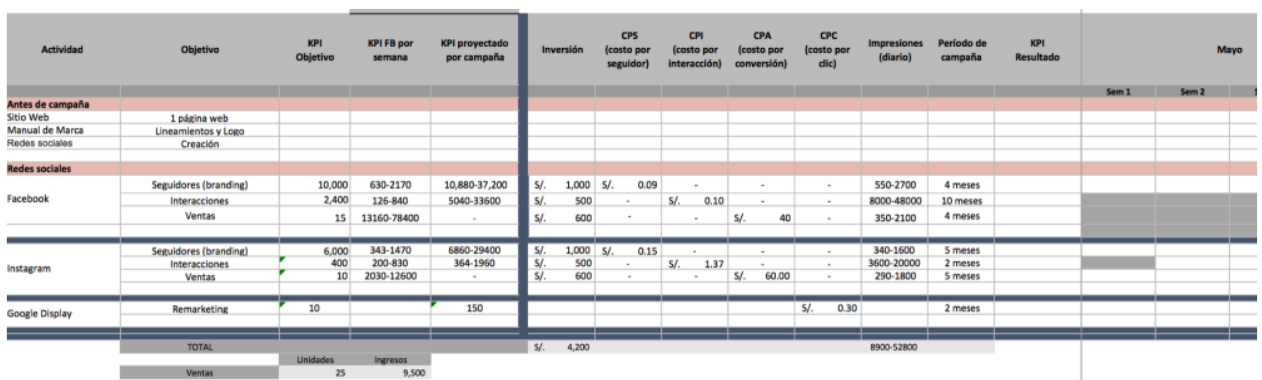




\section{Anexo 4: Análisis de demanda}

\begin{tabular}{|c|c|c|c|c|c|}
\hline & CENSO DE JULIO DEL 2007 & & & & \\
\hline $\mathbf{N}^{0}$ & Distrito & $\begin{array}{c}\text { Población } \\
\text { (hab.) }\end{array}$ & Código Postal & Zona & \\
\hline 1 & Ancón & 33,367 & LIMA 02 & 2 & \\
\hline 2 & Santa Rosa & 10,903 & LIMA 38 & 11 & \\
\hline 3 & Ventanilla & 277,895 & CALLAO 06 & 1 & \\
\hline 4 & Callao & 415,888 & CALLAO 01 & 10 & \\
\hline 5 & La Punta & 4,370 & CALLAO 05 & 10 & \\
\hline 6 & Carmen de La Lequa-Reynoso & 41,863 & CALLAO 03 & 10 & \\
\hline 7 & Bellavista & 75,163 & CALLAO 02 & 10 & \\
\hline 8 & La Perla & 61,698 & CALLAO 04 & 10 & \\
\hline 9 & Carabayllo & 213,386 & LIMA 06 & 1 & \\
\hline 10 & Puente Piedra & 233,602 & LIMA 22 & 1 & \\
\hline 11 & San Martín de Porres & 579,561 & LIMA 31 & 2 & \\
\hline 12 & Los Olivos & 318,140 & LIMA 39 & 2 & \\
\hline 13 & Comas & 486,977 & LIMA 07 & 1 & \\
\hline 14 & Independencia & 207,647 & LIMA 28 & 2 & \\
\hline 15 & San Juan de Lurigancho & 898,443 & LIMA 36 & 3 & \\
\hline 16 & Cercado de Lima & 299,493 & LIMA 01 & 4 & \\
\hline 17 & Breña & 81,909 & LIMA 05 & 4 & \\
\hline 18 & Rímac & 176,169 & LIMA 26 & 4 & \\
\hline 19 & El Agustino & 180,262 & LIMA 10 & 5 & \\
\hline 20 & San Miguel & 129,107 & LIMA 32 & 6 & \\
\hline 21 & Pueblo Libre & 74,164 & LIMA 21 & 6 & \\
\hline 22 & Jesús María & 66,171 & LIMA 11 & 6 & \\
\hline 23 & Magdalena del Mar & 50,764 & LIMA 17 & 6 & \\
\hline 24 & Lince & 55,242 & LIMA 14 & 6 & \\
\hline 25 & La Victoria & 192,724 & LIMA 13 & 4 & \\
\hline 26 & San Luis & 54,634 & LIMA 30 & 5 & \\
\hline 27 & San Isidro & 58,056 & LIMA 27 & 7 & \\
\hline 28 & Miraflores & 85,065 & LIMA 18 & 7 & \\
\hline 29 & Surquillo & 89,283 & LIMA 34 & 8 & \\
\hline 30 & Barranco & 33,903 & LIMA 04 & 8 & \\
\hline 31 & San Borja & 105,076 & LIMA 41 & 7 & \\
\hline 32 & Santiago de Surco & 289,597 & LIMA 33 & 7 & \\
\hline 33 & Chorrillos & 286,977 & LIMA 09 & 8 & \\
\hline 34 & Santa Anita & 184,614 & LIMA 43 & 5 & \\
\hline 35 & Ate & 478,278 & LIMA 03 & 5 & \\
\hline 36 & La Molina & 132,498 & LIMA 12 & 7 & \\
\hline 37 & Lurigancho-Chosica & 169,359 & LIMA 15 & 5 & \\
\hline 38 & Chaclacayo & 41,110 & LIMA 08 & 5 & \\
\hline 39 & Cienequilla & 26,725 & LIMA 40 & 9 & \\
\hline 40 & Pachacámac & 68,441 & LIMA 19 & 9 & \\
\hline 41 & San Juan de Miraflores & 362,643 & LIMA 29 & 8 & \\
\hline 42 & Villa María del Triunfo & 381,790 & LIMA 35 & 9 & \\
\hline 43 & Villa El Salvador & 378,470 & LIMA 42 & 9 & \\
\hline 44 & Lurín & 62,940 & LIMA 16 & 9 & \\
\hline 45 & Punta Hermosa & 5,762 & LIMA 24 & 11 & \\
\hline 46 & Punta Negra & 5,284 & LIMA 23 & 11 & \\
\hline 47 & San Bartolo & 6,412 & LIMA 26 & 11 & \\
\hline 48 & Santa María del Mar & 161 & LIMA 37 & 11 & \\
\hline \multirow[t]{2}{*}{49} & Pucusana & 10,633 & LIMA 20 & 11 & \\
\hline & TOTAL & $8,482,619$ & & & \\
\hline
\end{tabular}




\section{Datos de nivel socioeconómico}

\begin{tabular}{|c|c|c|c|c|c|c|c|}
\hline ZONA & NSE A & NSE B & NSE C & NSE D & NSE E & TOT & Población \\
\hline ZONA 1 (Ventanilla, Puente Piedra, Comas, Carabayllo) & 0.5 & 8.6 & 27.3 & 33.5 & 30.1 & 100.0 & $1,211,860$ \\
\hline ZONA 2 (Independencia, Los Olivos, San Martín de Porras, Ancón) & 4.5 & 18.3 & 34.3 & 32.3 & 10.6 & 100.0 & $1,138,715$ \\
\hline ZONA 3 (San Juan de Lurigancho) & 0.0 & 9.2 & 25.1 & 42.6 & 23.1 & 100.0 & 898,443 \\
\hline ZONA 4 (Cercado de Lima, Rímac, Breña, La Victoria) & 1.9 & 18.1 & 34.8 & 36.1 & 9.1 & 100.0 & 750,295 \\
\hline ZONA 5 (Ate, Chaclacayo, Lurigancho, Santa Anita, San Luis, El Agustino) & 1.0 & 9.6 & 22.5 & 40.4 & 26.5 & 100.0 & $1,108,257$ \\
\hline ZONA 6 (Jesus Maria, Lince, Pueblo Libre, Magdalena del Mar, San Miguel) & 26.5 & 41.2 & 23.1 & 9.2 & 0.0 & 100.0 & 375,448 \\
\hline ZONA 7 (Miraflores, San Isidro, San Borja, Santiago de Surco, La Molina) & 34.1 & 39.7 & 21.5 & 4.3 & 0.4 & 100.0 & 670,292 \\
\hline ZONA 8 (Surquillo, Barranco, Chorrillos, San Juan de Miraflores) & 3.0 & 15.3 & 37.9 & 35.9 & 7.9 & 100.0 & 772,806 \\
\hline ZONA 9 (Villa el Salvador, Villa María del Triunfo, Lurin, Pachacamac, Cinieguilla) & 0.0 & 7.6 & 22.1 & 47.8 & 22.5 & 100.0 & 918,366 \\
\hline ZONA 10 (Callao, Bellavista, La Perla, La Punta, Carmen de la Legua) & 1.2 & 12.2 & 40.4 & 35.8 & 10.4 & 100.0 & 598,982 \\
\hline ZONA 11 (Pucusana, Punta Hermosa, Punta Negra, San Bartolo, Santa María, Santa Rosa) & 23.5 & 32.2 & 20.5 & 15.7 & 8.1 & 100.0 & 39,155 \\
\hline 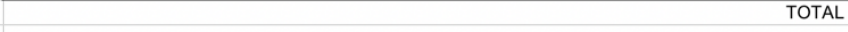 & 5.3 & 15.7 & 28.7 & 33.9 & 16.4 & 100.0 & $8,482,619$ \\
\hline & & & & & & & \\
\hline
\end{tabular}

Datos por edad

\begin{tabular}{l|r|r|r|}
\hline \multicolumn{1}{|c|}{ Grupo de edad } & Hombre & Mujer & Total \\
\hline De 0 a 4 años & 361,825 & 346,276 & 708,101 \\
De 5 a 9 años & 347,375 & 331,616 & 678,991 \\
De 10 a 14 años & 371,786 & 363,632 & 735,418 \\
De 15 a 19 años & 393,860 & 407,428 & 801,288 \\
De 20 a 24 años & 416,761 & 433,423 & 850,184 \\
\hline De 25 a 29 años & 386,658 & 408,077 & 794,735 \\
\hline De 30 a 34 años & 355,414 & 377,340 & 732,754 \\
\hline De 35 a 39 años & 302,923 & 330,995 & 633,918 \\
De 40 a 44 años & 265,046 & 287,367 & 552,413 \\
De 45 a 49 años & 218,034 & 242,134 & 460,168 \\
De 50 a 54 años & 189,075 & 214,996 & 404,071 \\
\hline De 55 a 59 años & 148,716 & 162,477 & 311,193 \\
\hline De 60 a 64 años & 118,480 & 127,287 & 245,767 \\
\hline De 65 a 69 años & 90,832 & 98,117 & 188,949 \\
\hline De 70 a 74 años & 69,074 & 77,048 & 146,122 \\
\hline De 75 a 79 años & 51,964 & 59,344 & 111,308 \\
De 80 a 84 años & 30,580 & 38,262 & 68,842 \\
De 85 a 89 años & 15,835 & 22,184 & 38,019 \\
\hline De 90 a 94 años & 5,235 & 8,869 & 14,104 \\
De 95 a 99 años & 2,130 & 4,144 & 6,274 \\
\hline Total & $4,141,603$ & $4,341,016$ & $8,482,619$ \\
\hline
\end{tabular}




\section{Definición de precio}

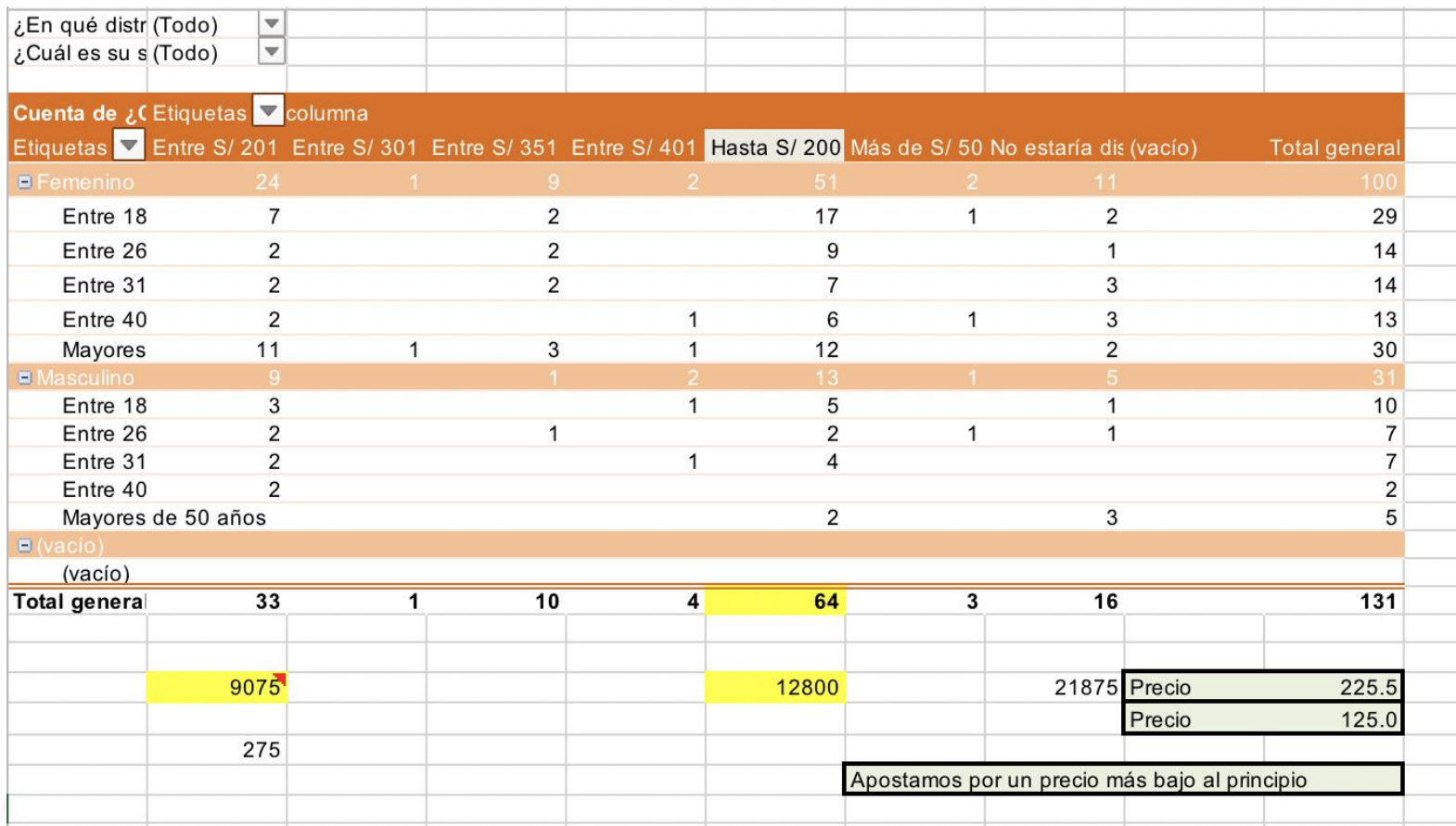

\section{Cálculo de \% de personas trabajadoras independientes}

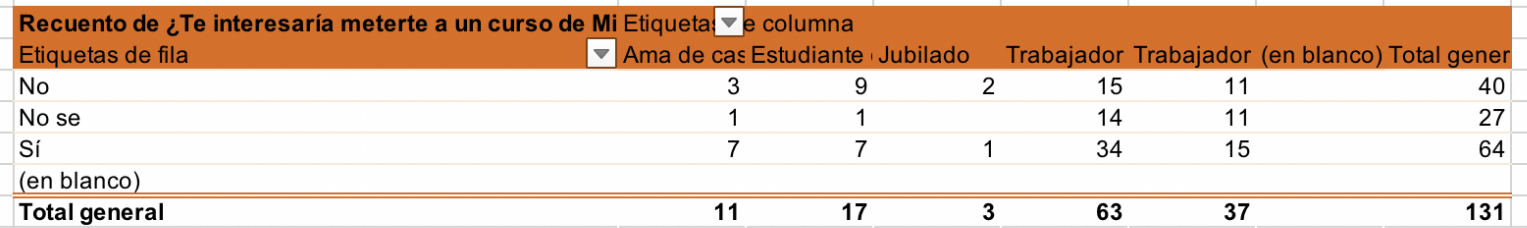

\begin{tabular}{|c|c|c|c|c|c|c|}
\hline Total general & 11 & 17 & 3 & 63 & 37 & 131 \\
\hline & & & & & & \\
\hline & & & & & & \\
\hline & & & & & & \\
\hline & & & & & | & \\
\hline 64 & & & 34 & & & \\
\hline 131 & & & 63 & & & \\
\hline $49 \%$ & Interés en gra & & $54 \%$ & Interés de trab & ependiente & \\
\hline & & & & & & \\
\hline & & & & & & \\
\hline & & & & & & \\
\hline Poblacion neruana & 31237385 & & & & & \\
\hline Trabajadores dependientes & $\begin{array}{r}31231300 \\
2110000\end{array}$ & & & & 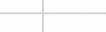 & \\
\hline 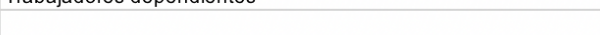 & $6.8 \%$ & & & & & \\
\hline & & & & & & \\
\hline & & & & & & \\
\hline
\end{tabular}

